TE WHARE WĀNANGA O TE ŪPOKO O TE IKA A MĀUI

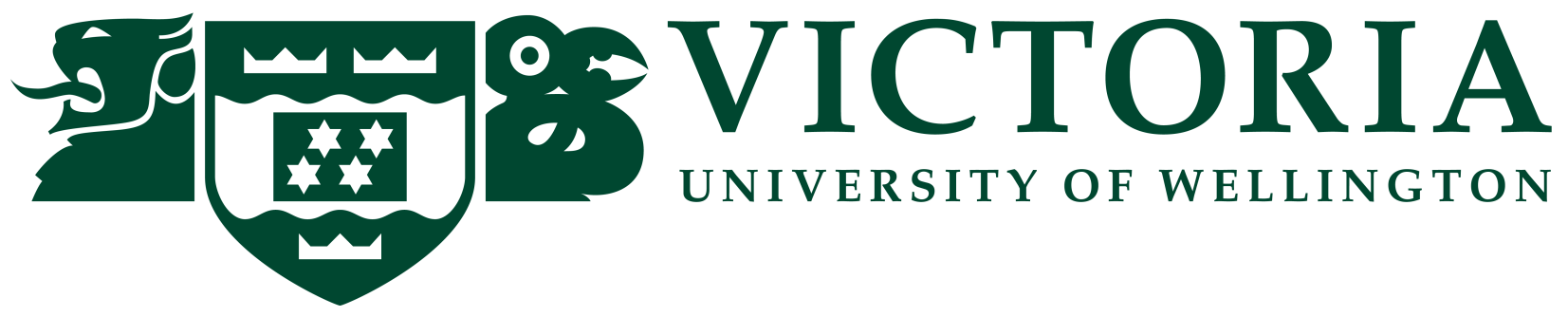

\title{
A seismic stratigraphic model for understanding the sedimentary and tectonic evolution of Solander Trough, offshore Fiordland, New Zealand
}

By

Jiten H. Patel

A thesis

submitted to Victoria University of Wellington in fulfilment of the requirements for the degree of Master of Science in Geology

Victoria University of Wellington

2019 


\section{Abstract}

Solander Trough is located offshore and south of Fiordland, New Zealand, adjacent to the geologically young Pacific-Australian plate boundary. Petroleum industry exploration was restricted to the near-shore. This thesis presents the first stratigraphic analysis of Solander Trough south of $\sim 46.5^{\circ} \mathrm{S}$, using $2 \mathrm{D}$ seismic reflection data acquired and processed onboard the R/V Marcus G. Langseth in 2018 (voyage MGL1803). The only pre-existing high-quality line, which was acquired onboard the R/V Maurice Ewing during voyage EW9601a in 1996, was reprocessed.

The study area is divided into northern and southern sub-basins by Tauru High. Four megasequences and eight sequences are identified in the northern sub-basin (SLN). In the southern sub-basin (SLS), three megasequences and seven sequences are mapped. Biostratigraphy from the Parara-1 exploration well enabled age determination in the northern sub-basin. High resolution $(\sim 10 \mathrm{~m})$ swath bathymetry data collected along seismic reflection lines provide insight into modern sedimentary processes.

Solander Trough formed in the Eocene, but most sediment is young (< 15 Ma). Puysegur Ridge formed in the Miocene during subduction initiation and now shelters Solander Trough from the Antarctic Circumpolar Current, which affects depositional architecture. The oldest megasequences, SLN1 and SLS1, relate to normal-faulted basement with irregular relief. An increase in sediment supply from the north created megasquence SLN2, but it is thin and not recognised in the southern sub-basin. Megasequence SLN3 signals reverse reactivation on the Parara Anticline and Tauru High; its equivalent (SLS2) marks the first sediments rapidly deposited in southern Solander Trough, and is also linked in the south to initial growth of Puysegur Ridge. SLN4 is a product of Pliocene-Quaternary reverse reactivation of Solander Anticline, and its correlative, SLS3 in the southern sub-basin, is related to folding and widening 
of the eastern margin of Puysegur Ridge. 


\section{Acknowledgements}

This thesis has been a fruit of the beauty of international scientific collaboration. Therefore, the mahi leading to its completion has been influenced by many people, some of whom remain behind the scenes, so I will do my best to cover as many people as I can!

First and foremost, near-unparalleled thanks goes out to my supervisor/"dad" Dr. Rupert Sutherland. You first introduced me to this project a couple of years ago and I have not looked back since, even with a churning stomach in the middle of the Southern Ocean. Thank you for answering endless questions, being patient with my overzealous nitpicking and for the number of red pens you would have gone through over the year.

Special thanks goes out to the scientific party during voyage MGL1803. In particular, thank you to Brandon and Justin, who were super helpful with onboard seismic processing. Brandon was integral to the completion of the processing chapters, thank you. Dan and Marcy, thank you for the long chats about anything and everything, and for your help with swath bathymetry data. Unreserved gratitude goes out to the crew of the $\mathrm{R} / \mathrm{V}$ Langseth, the efforts of whom allowed me to actually have data to work on.

Back onland, Wanda Stratford provided EW9601a data and assisted with pre-voyage processing of these data. She also showed great patience when trying to (unsucessfully, my fault, not yours) explain terminal commands to me. Thanks for your time Wanda! Adrian Benson and Aleks Beliaev provided technical support at VUW, thanks for always helping out whenever SeisWare decided to spit the dummy. Patricia Stein has been the voice of reassurance when it comes to deadlines, thank you for being super flexible with when this piece of work ends up crossing your desk. 
Damo, Clarrie, Dani, Benji and Callum provided one of the best office environments I could have asked for. Thank you for the endless banter, laughs and shared struggles, I would never have been able to figure out this MSc without you. You are all aspirational scientists and I hope I get to work with you in the future, where we can continue to discuss but not actually action on buying a beer fridge for the office.

My lengthy stay at VUW has produced some of the best memories of my life because of the numerous friends that I have had the privilege of making. In recent months, I have neglected ice cream journeys, laser tag, games nights and countless other antics and I assure you all that I will give you back all that time and so much more in the future! Special thanks goes to Alec, Jesse, Joanna and Morgan (thanks especially to Morgan for taking longer than the part-timer to finish your thesis). This group of individuals are the best life coaches around and I cherish our friendship more than words can express.

The Mega crew deserves a pint for providing me gainful employment for nearly a decade. Thanks for providing an avenue for forgetting the pressures of a thesis.

Last and definitely not least, I extend thanks to my family to the ends of the Milky Way and back. Despite often trying reminders that "You have a thesis to write!", your encouragement and support has been the biggest driver for me getting to where I am today and completing this thesis, though I suspect some of that is related to a desire for me to leave home! Thank you for late night rides home, thank you for topping up my university stash constantly, thank you for proofreading my work, thank you for much needed laughs. Thank you for everything. I love you all. 


\section{Contents}

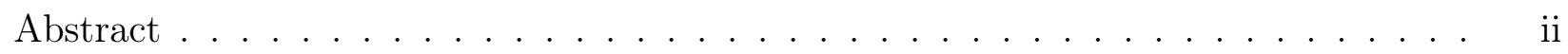

Acknowledgements ...................... iv

1 Introduction 1

1.1 Motivation . . . . . . . . . . . . . . . . . . 1

$1.2 \quad$ SISIE Objectives . . . . . . . . . . . . . . . . . . . 3

1.3 Geologic and Geographic Setting . . . . . . . . . . . . . . . . . 4

1.3 .1 Geologic setting . . . . . . . . . . . . . . . . . . . . 4

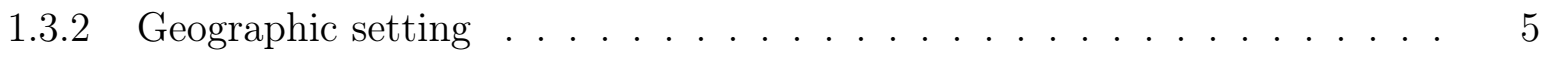

1.4 Oceanographic Setting . . . . . . . . . . . . . . . . . . 9

1.5 Petroleum Exploration . . . . . . . . . . . . . . . . . . . . . . 10

1.5.1 Vintage seismic data: 1960s-1970s . . . . . . . . . . . . . . . 10

1.5.2 Post-vintage data: $1980 \mathrm{~s}-2000 \mathrm{~s} \ldots \ldots \ldots \ldots \ldots$

1.5.3 Petroleum exploration data summary . . . . . . . . . . . . . . . 12

1.5.4 Data quality control . . . . . . . . . . . . . . . . . . 14

1.6 Methods . . . . . . . . . . . . . . . . . . . . . . . 14

1.6.1 Seismic reflection: data acquisition . . . . . . . . . . . 14

1.6.2 Seismic reflection: data processing . . . . . . . . . . . . . . 17

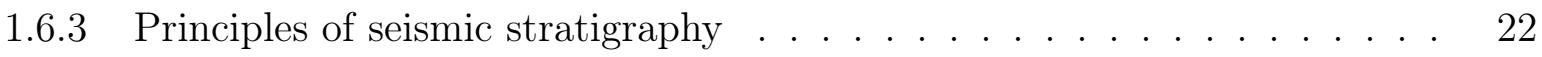

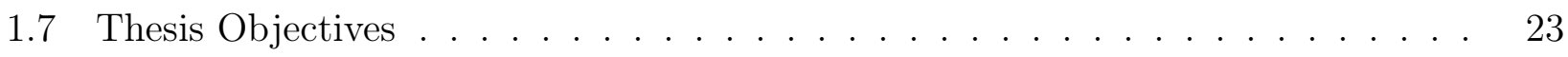

2 Petroleum Industry Well Data 25

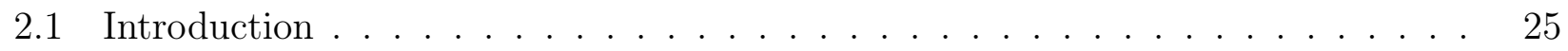

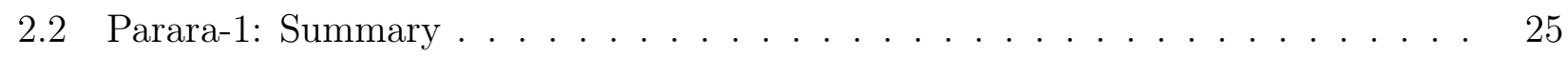

2.2 .1 Parara-1 stratigraphy . . . . . . . . . . . . . . . . . . . 26 
2.2.2 Parara-1 downhole observations . . . . . . . . . . . . . . . 29

2.3 Solander-1: Summary . . . . . . . . . . . . . . . . . . 33

2.3.1 Solander-1 stratigraphy . . . . . . . . . . . . . . . 33

2.3.2 Solander-1 downhole observations . . . . . . . . . . . . . . . . 34

2.4 Chapter Conclusion . . . . . . . . . . . . . . . . . . 38

3 Voyage EW9601a $\quad 39$

3.1 Chapter Purpose . . . . . . . . . . . . . . . . . . . . . . . . 39

3.2 Introduction to EW9601a . . . . . . . . . . . . . . . . . . . 39

3.3 Pre-MGL1803: EW9601a Data Processing . . . . . . . . . . . . . . . . . . 41

3.3.1 Seismic job EW9601_prevoyage.job . . . . . . . . . . . . . . 42

3.4 Line P1: MGL1803 Processing Sequence . . . . . . . . . . . . . . . . . . . . 44

3.4.1 Geometry and GIN . . . . . . . . . . . . . . . . . 44

3.4.2 Trace editing, deconvolution, sorting . . . . . . . . . . . . 44

3.4.3 Velocity picking . . . . . . . . . . . . . . . . . 49

3.4.4 Radon demultiple . . . . . . . . . . . . . . . . 50

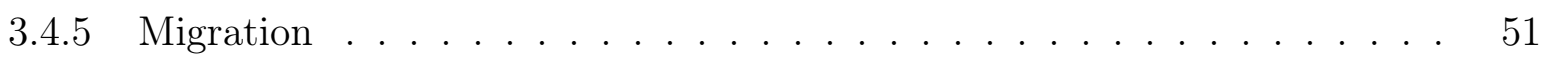

3.5 Comparison of Processing Results . . . . . . . . . . . . . . . . . . . 52

3.6 Chapter Conclusion . . . . . . . . . . . . . . . . . . 55

4 Voyage MGL1803 $\quad 57$

4.1 Background Information . . . . . . . . . . . . . . . . . . 57

4.1.1 Summary of MCS data . . . . . . . . . . . . . . 57

4.2 Seismic Data Acquisition Parameters . . . . . . . . . . . . . . . . . . . 59

4.2.1 Seismic source . . . . . . . . . . . . . . . . 59

4.2 .2 Seismic streamer . . . . . . . . . . . . . . . . . . 61

4.2.3 Summary acquisition parameters ............... 61

4.3 MGL1803 Shipboard Processing Sequence . . . . . . . . . . . . . . . . 63

4.3.1 Pre-processing of M18-03a and M18-23a ............ 63

4.3.2 SEGD: data read and resample . . . . . . . . . . . . . 68 
4.3 .3 Marine geometry . . . . . . . . . . . . . . . . 69

4.3.4 Brute stack . . . . . . . . . . . . . . . . . . . . . . . 69

4.3.5 Deconvolution and CDP sorting . . . . . . . . . . . 71

4.3 .6 Velocity picking . . . . . . . . . . . . . . . . 72

4.3.7 Radon demultiple . . . . . . . . . . . . . . . . . . . . . . . . . . 73

4.3.8 Stacking, migration and scaling . . . . . . . . . . . . . 74

4.4 Chapter Conclusion . . . . . . . . . . . . . . . . . . 75

$\begin{array}{lll}5 & \text { Seismic Stratigraphy } & 77\end{array}$

5.1 Introduction . . . . . . . . . . . . . . . . . . . 77

5.2 Northern Sub-basin . . . . . . . . . . . . . . . . . . . 78

5.2 .1 SLN1-1 . . . . . . . . . . . . . . . . . . 78

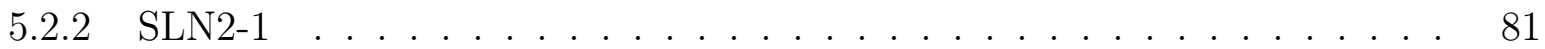

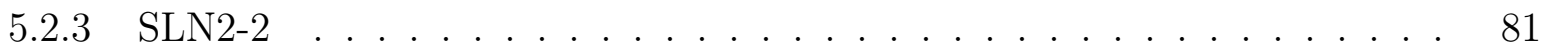

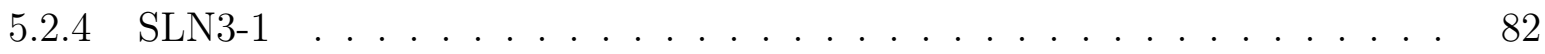

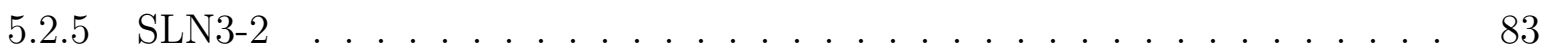

5.2 .6 SLN4-1 . . . . . . . . . . . . . . . . . . 83

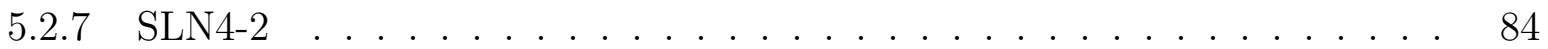

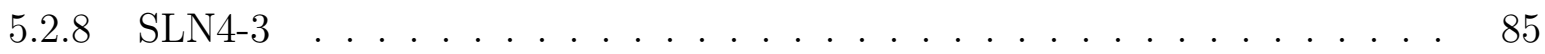

5.3 Southern Sub-basin . . . . . . . . . . . . . . . 86

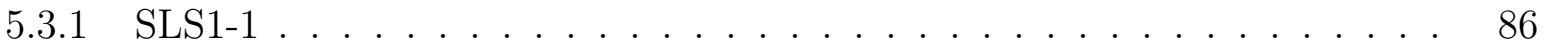

5.3 .2 SLS2-1 . . . . . . . . . . . . . . . . . . . . 92

5.3 .3 SLS2-2 . . . . . . . . . . . . . . . . . . . . . . 93

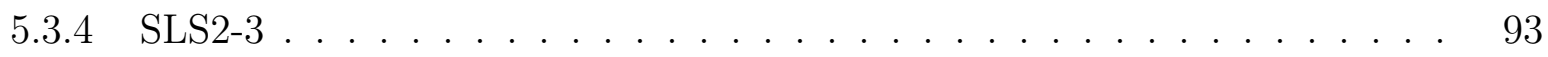

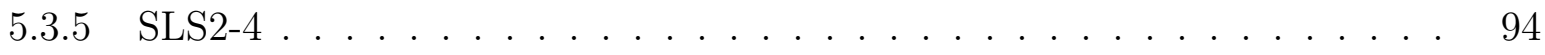

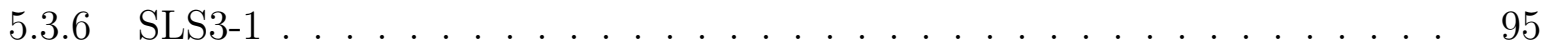

5.3 .7 SLS3-2 . . . . . . . . . . . . . . . . . . 96

5.4 Chapter Conclusion . . . . . . . . . . . . . . . . . . . 97

$\begin{array}{llr}6 & \text { Discussion } & 99\end{array}$

6.1 Introduction . . . . . . . . . . . . . . . . . . . . . 99 
6.2 Present Day Depositional Mechanisms _. . . . . . . . . . . . . . . . . 99

6.2.1 Tasman Sea . . . . . . . . . . . . . . . . . . . . 99

6.2.2 Solander Trough . . . . . . . . . . . . . . . . . 102

6.2.3 Modern shelf and slope . . . . . . . . . . . . . . . . . 112

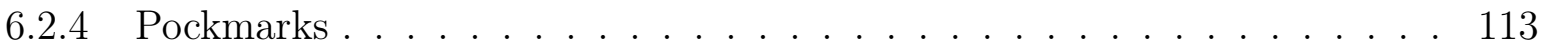

6.3 Parara Anticline: Age Control of SLN Stratigraphy . . . . . . . . . . . . . . . 115

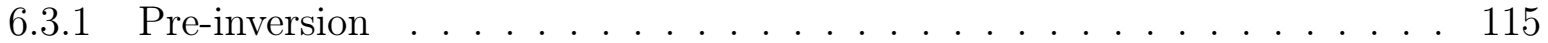

6.3.2 Inversion and post-tectonic phase . . . . . . . . . . . . 115

6.4 Tauru High: SLN-SLS Correlation . . . . . . . . . . . . . . . . . . . 118

6.4.1 Before inversion . . . . . . . . . . . . . . . 118

6.4 .2 End inversion . . . . . . . . . . . . . . . . 121

6.4 .3 Post-inversion . . . . . . . . . . . . . . . . . . . . 122

6.4.4 Age correlation model . . . . . . . . . . . . . . . . 122

6.5 Basin Analysis . . . . . . . . . . . . . . . . . . . . . . 124

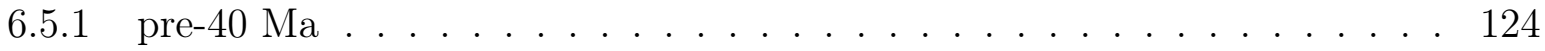

$6.5 .2 \quad 23-11 \mathrm{Ma} \ldots \ldots \ldots \ldots \ldots \ldots \ldots$

6.5.3 11-5 $\mathrm{Ma} \ldots \ldots \ldots \ldots \ldots \ldots \ldots \ldots$

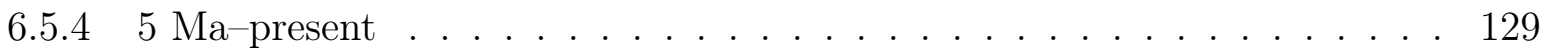

$\begin{array}{llr}7 & \text { Conclusions } & 131\end{array}$

7.1 Thesis Objectives ............................ 131

7.2 Recommendations for Future Work . . . . . . . . . . . . . . . . . . . 132

$\begin{array}{ll}\text { Appendices } & \text { A-1 }\end{array}$

1 Appendix: Introduction ...................... A-1

2 Appendix: Voyage EW9601a . . . . . . . . . . . . . . . . A-4

2.1 Line P1 processing, employed by Melhuish et al. (1999) . . . . . . . . A-4

2.2 Processing sequence employed in this thesis . . . . . . . . . . A

3 Appendix: Voyage MGL1803 . . . . . . . . . . . . . . . . A-13

4 Appendix: Discussion . . . . . . . . . . . . . . . . A-22 
Contents 


\section{List of Figures}

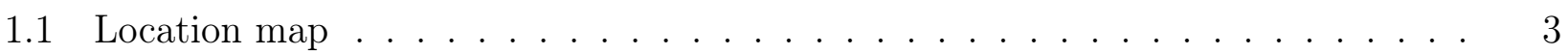

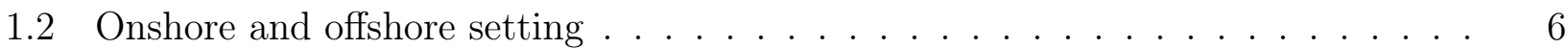

1.3 Solander Islands, Macquarie Ridge Complex, Snares Zone and DSDP sites . . . 8

1.4 Modern oceanographic setting . . . . . . . . . . . . . . . . . 9

1.5 Pre-existing petroleum industry seismic data . . . . . . . . . . . . . . . . . 13

1.6 Illustration of the common mid-point method f . . . . . . . . . . . . 16

1.7 Noise within a shot $\ldots \ldots \ldots \ldots \ldots \ldots \ldots$

1.8 Velocity model picking . . . . . . . . . . . . . . . . . . . . . . . . . 21

1.9 Seismic stratigraphic relationships . . . . . . . . . . . . . . . 22

2.1 Petroleum well locations . . . . . . . . . . . . . . . . . . . . 26

2.2 Parara-1 wireline $\log$ data $\ldots \ldots \ldots \ldots$

2.3 Parara-1 checkshot residual plot . . . . . . . . . . . . . . . . . 32

2.4 Solander-1 wireline $\log$ data $\ldots \ldots \ldots \ldots \ldots$

2.5 Solander-1 checkshot residual plot . . . . . . . . . . . . . . . . . 38

3.1 EW9601a survey location . . . . . . . . . . . . . . . . . . . 40

3.2 Data quality control for Line P1 . . . . . . . . . . . . . . . . . 42

3.3 Noisy channels within Line $\mathrm{P} 1 \ldots \ldots$. . . . . . . . . . . . . . . 47

3.4 Migrated section of Line P1 without noisy channels removed . . . . . . . . . . 48

3.5 Velocity model picked for Line $\mathrm{P} 1 \ldots \ldots$. . . . . . . . . . . . . . 50

3.6 Line P1 processed by Melhuish et al. (1999) _ . . . . . . . . . . . . . 53

3.7 Line $\mathrm{P} 1$ processed during MGL1803 . . . . . . . . . . . . . . . 54

4.1 Actual vs. proposed seismic coverage during MGL1803 f . . . . . . . . . . 58 
4.2 Seismic acquisition equipment used during MGL1803 . . . . . . . . . . . . . . 60

4.3 Source-streamer configuration during MGL1803 . . . . . . . . . . . . . . . . . . 61

4.4 "Double shot" information recorded during seismic acquisition . . . . . . . . . . 64

4.5 Migration swings from removing "double shots" from the dataset . . . . . . . 65

4.6 Removed "double shot" from a duplicate shot record . . . . . . . . . . . . . 66

4.7 Removing vs. retaining "double shots" from the dataset, Line M18-03a . . . . . 67

4.8 Line M18-17b brute stack . . . . . . . . . . . . . . . . . . . . . . . 70

4.9 Velocity model picked for line M18-17b . . . . . . . . . . . . . . . . . 73

5.1 Seismic stratigraphy, line M18-17c . . . . . . . . . . . . . . . . . . 79

5.2 Seismic stratigraphy, line $\mathrm{S} 86-34 \ldots \ldots \ldots$. . . . . . . . . . . 80

5.3 Seismic stratigraphy, line M18-17b . . . . . . . . . . . . . . . 87

5.4 Seismic stratigraphy, line M18-01 f . . . . . . . . . . . . . . . . . 88

5.5 Seismic stratigraphy, line M18-23ab . . . . . . . . . . . . . . . . 89

5.6 Seismic stratigraphy, line M18-14 . . . . . . . . . . . . . . . . . . . 90

5.7 Seismic stratigraphy, Puysegur Ridge, line M18-14 . . . . . . . . . . . . . . . . 91

6.1 Tasman Sea deposition, line M18-01 . . . . . . . . . . . . . . . . 100

6.2 Tasman Sea deposition, line M18-14 . . . . . . . . . . . . . . . . . . . . . 101

6.3 Canyon system, line M18-01 . . . . . . . . . . . . . . . . . . . . . . 102

6.4 Canyon system, line M18-03a . . . . . . . . . . . . . . . . . . . 103

6.5 Solander Channel and tributary channel, line M18-17c . . . . . . . . . . . 105

6.6 Solander Channel and tributary channel, line M18-17b . . . . . . . . . . . 106

6.7 Solander Channel, line M18-01 . . . . . . . . . . . . . . . . . . . . . . 107

6.8 Solander Channel and more developed channel, line M18-23ab . . . . . . . . . 108

6.9 Solander Channel, line M18-14 . . . . . . . . . . . . . . . . . . . . . . . . 109

6.10 Sediment drifts, line M18-01 . . . . . . . . . . . . . . . . . . 110

6.11 Sediment drifts, line M18-03a . . . . . . . . . . . . . . . . . 111

6.12 Prograding shelf deposits, line M18-17c . . . . . . . . . . . . . . . . . . 112 
6.13 Prograding shelf deposits, line S86-34 . . . . . . . . . . . . . . . 112

6.14 Pockmarks, line M18-17c . . . . . . . . . . . . . . . . . . . . . . 114

6.15 Change in tectonic regime at Parara Anticline . . . . . . . . . . . . . 117

6.16 Evolution of Tauru High . . . . . . . . . . . . . . . . . . . . 120

6.17 Tauru High modern setting and age correlation model . . . . . . . . . . . . 123

6.18 Paleogeographic constructions . . . . . . . . . . . . . . . . . 127

1A-1 New Zealand Geological Time Scale (v.2015/1) . . . . . . . . . . . . . . . . A-1

4A-1 Locations of swath and seismic images . . . . . . . . . . . . . . . . A-22

4A-2 Bathymetric features not observed in seismic . . . . . . . . . . . . . . A-23 


\section{List of Tables}

2.1 Parara-1 chronostratigraphic divisions . . . . . . . . . . . . . . . 27

2.2 Parara-1 OWTs from checkshot survey . . . . . . . . . . . . . . 31

2.3 Interval velocities from Parara-1 checkshot data . . . . . . . . . . . . . . 32

2.4 Solander-1 chronostratigraphic divisions . . . . . . . . . . . . . . . . 33

2.5 Solander-1 OWTs from checkshot survey . . . . . . . . . . . . . . 36

2.6 Interval velocities from Solander-1 checkshot data . . . . . . . . . . . . . . 37

3.1 EW9601a acquisition parameters . . . . . . . . . . . . . . 41

3.2 Line P1 GLOBE Claritas trace removal . . . . . . . . . . . . . . . . . . . 43

3.3 Line P1 GLOBE Claritas segy combination . . . . . . . . . . . . . . . . . 44

3.4 Line $\mathrm{P} 1$ geometry job (Echos) . . . . . . . . . . . . . . . . 45

3.5 Line $\mathrm{P} 1$ Echos GIN job . . . . . . . . . . . . . . . . . . . 45

3.6 Line $\mathrm{P} 1$ deconvolution and sort job (Echos) . . . . . . . . . . . . . 46

3.7 Line $\mathrm{P} 1$ velocity model job (Echos) . . . . . . . . . . . . . . . . . 49

3.8 Line $\mathrm{P} 1$ radon demultiple job (Echos) . . . . . . . . . . . . . . . . 51

3.9 Line P1 FK migration job (Echos) . . . . . . . . . . . . . . . . 52

4.1 MGL1803 acquisition parameters . . . . . . . . . . . . . . . . 62

4.2 MGL1803 Echos segd job . . . . . . . . . . . . . . . . . . 68

4.3 MGL1803 Echos geometry job . . . . . . . . . . . . . . . . 69

4.4 MGL1803 Echos brute stack job . . . . . . . . . . . . . . . . . 70

4.5 MGL1803 Echos deconvolution and sort job . . . . . . . . . . . . . 71

4.6 MGL1803 Echos velocity job . . . . . . . . . . . . . . . . . 72

4.7 MGL1803 Echos radon demultiple job . . . . . . . . . . . . . . . . . . 74 
4.8 MGL1803 Echos F-K migration job . . . . . . . . . . . . . . . . . . . . . 74

1A-1 Summary acquisition parameters for the "vintage surveys" . . . . . . . . . . . A-2

1A-2 Summary acquisition parameters for 1980s seismic reflection data . . . . . . . A-3

2A-1 Line P1 processing steps by Melhuish et al. (1999) . . . . . . . . . . . . . . . A-4

2A-2 Line P1 GLOBE Claritas trace editing parameters . . . . . . . . . . . . . . . A-5

2A-3 Line P1 GLOBE Claritas segy output parameters . . . . . . . . . . . . . . . A-6

2A-4 Line P1 Echos geometry job parameters . . . . . . . . . . . . . . . . A-7

2A-5 Line P1 Echos GIN job parameters . . . . . . . . . . . . . . . . . . A-7

2A-6 Line P1 Echos sort job parameters . . . . . . . . . . . . . . . . . . A-8

2A-7 Line P1 Echos velocity model job parameters . . . . . . . . . . . . . . . . A-9

2A-8 Line P1 Echos radon demultiple job parameters . . . . . . . . . . . . . . . . A-9

2A-9 Line P1 Echos FK migration job parameters . . . . . . . . . . . . . . . A-10

3A-1 MGL1803 Echos segd job parameters . . . . . . . . . . . . . . . . . A-13

3A-2 MGL1803 Echos velocity model job parameters . . . . . . . . . . . . . . . . . A-14

3A-3 MGL1803 Echos brute stack job parameters . . . . . . . . . . . . . . A-15

3A-4 MGL1803 Echos sort job parameters . . . . . . . . . . . . . . . A-16

3A-5 MGL1803 Echos velocity model parameters . . . . . . . . . . . . . . . . A-17

3A-6 MGL1803 Echos radon demultiple parameters . . . . . . . . . . . . . . . . . A-18

3A-7 MGL1803 Echos FK migration parameters . . . . . . . . . . . . . . . . . . A-19 


\section{Chapter 1}

\section{Introduction}

\subsection{Motivation}

New Zealand is located on the boundary between the Pacific and Australian plates, where changing plate boundary dynamics have affected the distribution, sedimentation and tectonic histories of New Zealand's onshore and offshore sedimentary basins. Basin stratigraphy provides a wealth of information about the overarching plate dynamics, with implications for natural resource distribution.

Sedimentary patterns reflect the interplay of plate dynamics with local deposition effects such as current flow, sediment supply and accommodation space. Solander Trough is strategically located toward the southern end of the plate boundary through New Zealand (Sutherland, 1995), and at the northern edge of the Antarctic Circumpolar Current (ACC), the largest ocean current on Earth (Barker et al., 2007).

This thesis presents the first stratigraphic analysis of Solander Trough, offshore southwest Fiordland, New Zealand (Fig. 1.1). This is achieved using newly acquired 2D seismic reflection data onboard the $\mathrm{R} / \mathrm{V}$ Marcus G. Langseth (voyage MGL1803), in accompaniment with previously acquired petroleum industry data. 


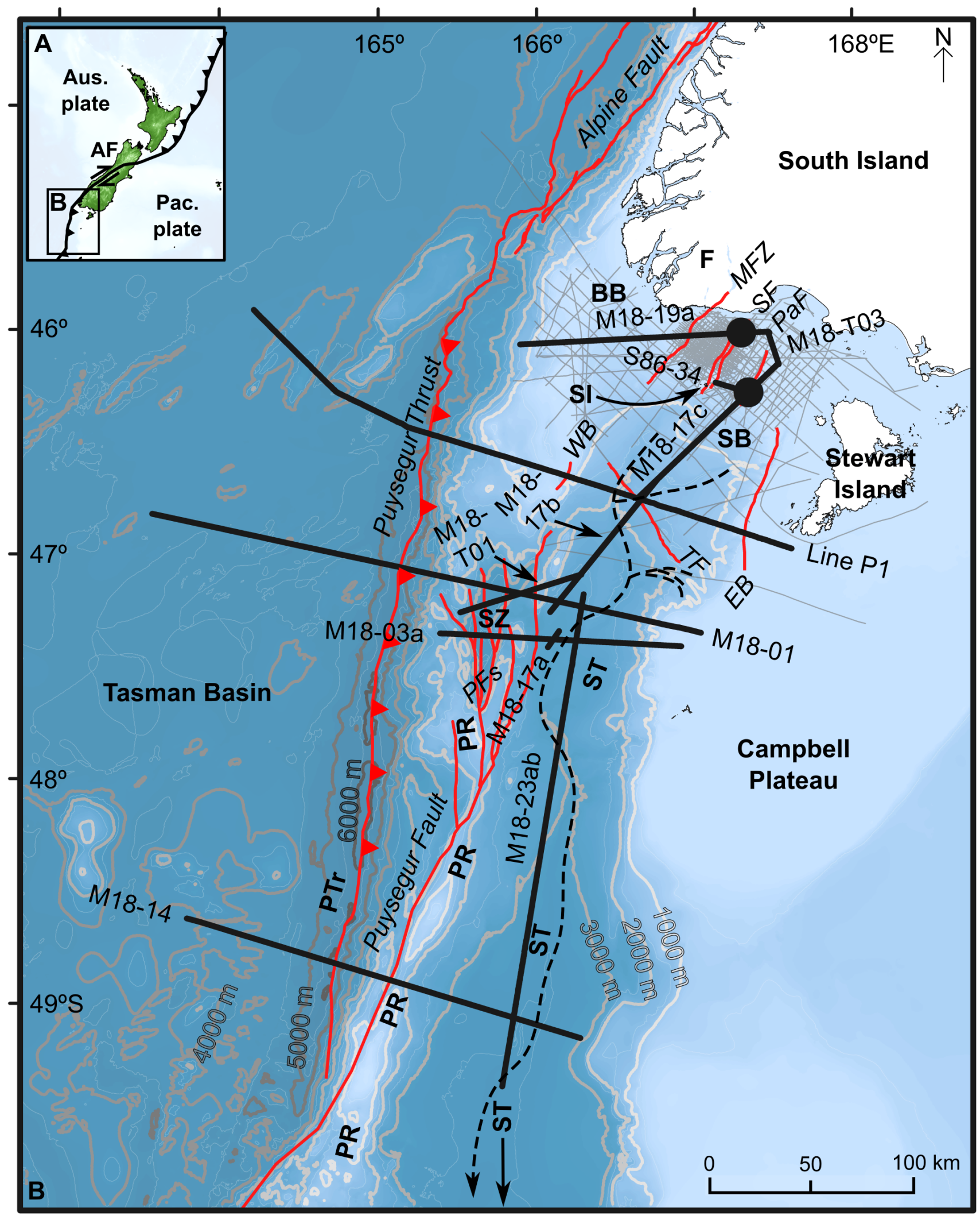

Fig. 1.1: (Caption on next page) 
Fig. 1.1: Location of New Zealand (Panel A), outlining the study area (Panel B). Panel B shows the location of $2 D$ seismic reflection data in the area. Dark-grey lines show the seismic data used in this paper, with MGL1803, Line P1 from EW9601a and S86-34 lines labelled; light grey lines show locations of pre-existing seismic data. Black circles show offshore petroleum wells (see Chapter 2). F=Fiordland, BB=Balleny Basin, SB=Solander Basin, SI=Solander Island, $S T=$ Solander Trough, $S Z=$ Snares Zone, $P T r=$ Puysegur Trench and PR=Puysegur Ridge. Faults are outlined in red, where (italicised): PaF=Parara Fault, $S F=$ Solander Fault, $M F Z=$ Moonlight Fault Zone, $W B=$ Western Boundary Fault, EB=Eastern Boundary Fault, TF=Tauru Fault and $P F s=$ Puysegur Fault splays, where thrust direction is showed by the red teeth. The dashed arrow shows the location of Solander Channel. Bold lines are $1000 \mathrm{~m}$ bathymetric contours (1000-6000 $m$ contours labelled); thin lines are $500 \mathrm{~m}$ intervals

\subsection{SISIE Objectives}

SISIE (South Island Subduction Initiation Experiment) is a multi-national collaboration aimed at constraining the geophysical nature and reconstructing the geological history of the Pacific-Australian subduction thrust (Gurnis and Stock, 2017). This was an active source experiment involving acquisition of $2 \mathrm{D}$ seismic reflection and seismic refraction data during voyage MGL1803 from $19^{\text {th }}$ February 2018 to $19^{\text {th }}$ March 2018. The main research axis involves determining whether the Puysegur-Fiordland subduction (an example of incipient subduction zone initiation) is transitioning from a forced to a self-sustaining state (e.g. Stern, 2004). The study area is one of the few locations in the world where subduction is young and associated sedimentary and tectonic patterns are not overprinted by later stage activity, as is the case with older examples like the Izu-Bonin-Mariana and Tonga-Kermadec subduction zones (Stern, 2004). I participated in voyage MGL1803, and my contribution to the broader project is to analyse the stratigraphy of Solander Trough. 


\subsection{Geologic and Geographic Setting}

\subsubsection{Geologic setting}

New Zealand was once part of the supercontinent Gondwana. At around $100 \mathrm{Ma}$, the continent of Zealandia started to rift from Gondwana (King, 2000). Separation from Gondwana was manifested as Tasman seafloor spreading, which lasted from 85-52 Ma (Laird and Bradshaw, 2004; Gaina et al., 1998). Post-rift, New Zealand's basins were subject to marine transgression as a result of post-rift thermal subsidence (e.g. McKenzie, 1978). To the southeast in Emerald Basin, an emergent plate boundary began to develop as a spreading centre at around $45 \mathrm{Ma}$ (Sutherland, 1995; Wood et al., 1996; Sutherland et al., 2000), probably initially as a pre-existing fracture zone (Collot et al., 1995; Barker et al., 2008).

Ongoing subsidence occurred through the Oligocene, when maximum transgression was reached in New Zealand (King, 2000). In the Oligocene, global cooling led to the establishment of permanent Antarctic Ice Sheets and development of the ACC (Carter et al., 1996b). Subduction northeast of New Zealand began in the late Oligocene (Ballance, 1976). By the early Miocene, this northeastern subduction zone had linked to the south-eastern spreading centre, where the Alpine Fault became the dominant accommodating fault for plate boundary movement (Sutherland et al., 2000). Plate motions became more convergent during the Neogene (Walcott, 1978), due to Australian-Pacific plate pole migration Sutherland (1995); Cande and Stock (2004). Changing plate motions facilitated development of an incipient subduction zone during the Miocene (Collot et al., 1995; Gurnis et al., 2004; Sutherland et al., 2006), which saw rapid uplift of the New Zealand continent and a corresponding increase in clastic sediment supply (e.g. Turnbull et al., 1993; Sutherland, 1996).

Today, New Zealand is located on the boundary between the Pacific and Australian plates (Panel A, Fig. 1.1). The Pacific plate overrides the Australian plate south of New Zealand at the Puysegur Trench, and the opposite occurs north of New Zealand at the Hikurangi Margin. In between these subduction zones, plate boundary motion is accommodated by the oblique dextral-reverse slip Alpine Fault. 


\subsubsection{Geographic setting}

Solander Trough is a bathymetric low and sedimentary depocentre, south of Fiordland, southwest New Zealand. It is bound to the west by the Puysegur Ridge and to the east by the Campbell Plateau. Solander Trough gently slopes to the south and merges with the relatively flat floor of Emerald Basin (Carter and McCave, 1997), beyond the extent of the study area.

The main sedimentary basins in the offshore region are the Solander and Balleny Basins (Fig. 1.1). Solander Basin is bound to the west and east by the Western Boundary (WB) fault and Eastern Boundary (EB) fault, and is bifurcated into the upper and lower Solander sub-basins to the south by Tauru High at the Tauru Fault (TF, see Fig. 1.1 for locations and Sutherland and Melhuish, 2000, for fault nomenclature). Balleny Basin is located to the west of Solander Basin between the Puysegur Thrust and Moonlight Fault Zone, and has onshore outcrops limited to the southern edge of Fiordland. The Waitutu, Hautere and Parara sub-basins are smaller depocentres constrained by the Moonlight Fault Zone, Solander High and Parara Fault (Turnbull et al., 1993, Fig. 1.2).

Onshore sediments are deposited in the Te Anau and Waiau Basins, both comprising mostly Eocene-Recent strata with Cretaceous coal measures in the Waiau Basin (Uruski and Turnbull, 1990). Te Anau Basin is constrained to the north by the Hollyford Fault System, and to the west and south by the Moonlight Fault Zone. The Waiau Basin is similarly constrained by the Moonlight Fault Zone to the west, and in the north, a splay off the Hauroko Fault separates the Monowai and Blackmount sub-basins. It is bound to the east by the Longwood Range (Turnbull et al., 1993, Fig. 1.2).

Along the axis of Solander Trough is Solander Channel (Fig. 1.1). It extends from the Stewart Island continental shelf to beyond the study area, where it merges into the relatively flat floor of the Emerald Basin. Bathymetry data acquired during MGL1803 reveals the channel incises up to $220 \mathrm{~m}$. 


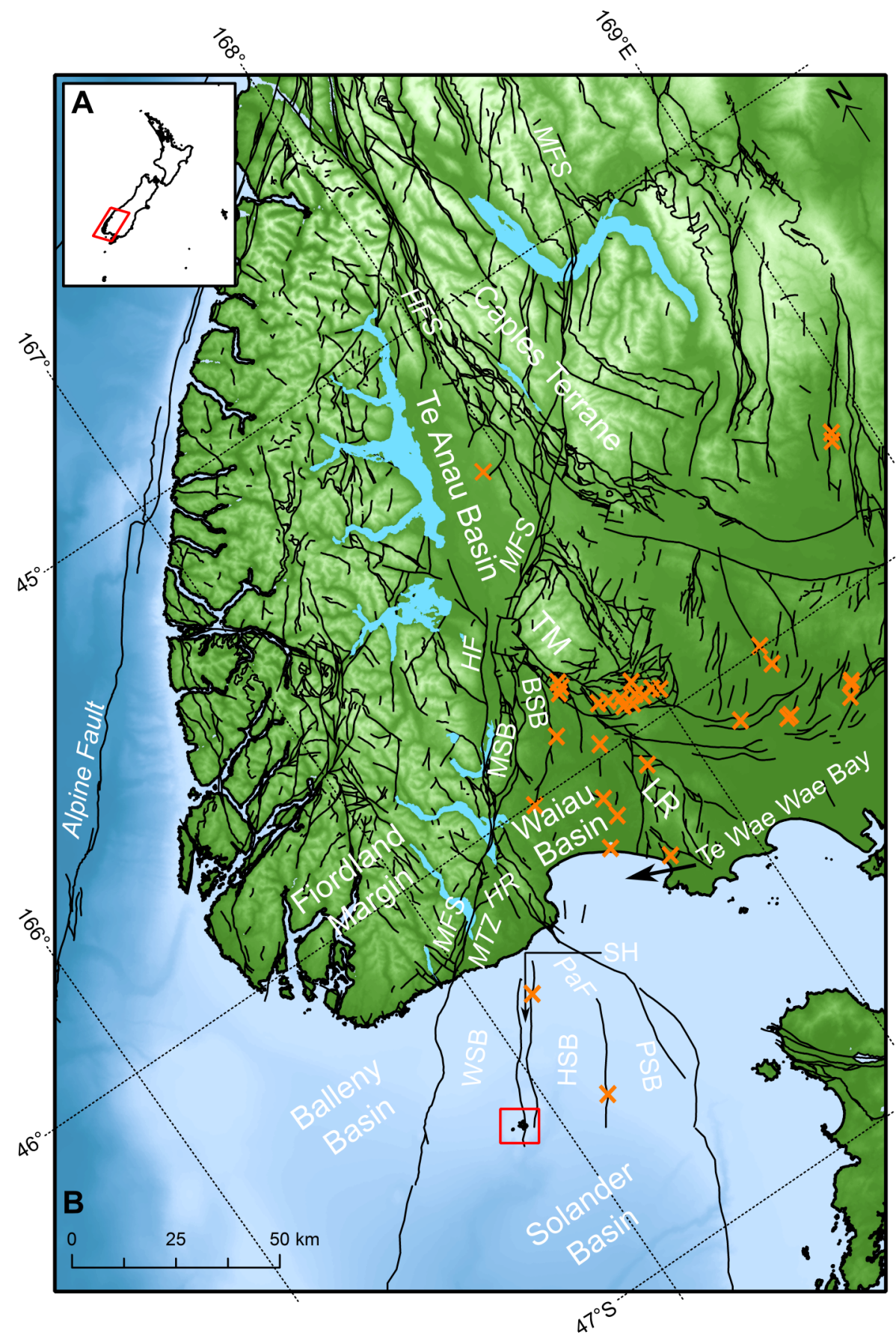

Fig. 1.2: Onshore and offshore locations of sedimentary basins and faults (adapted from Turnbull et al., 1993). Faults are shown in black (faults mentioned in text are italicised), and petroleum wells are shown by orange crosses. MFS=Moonlight Fault System, $M T Z=$ Moonlight Tectonic Zone, HFS=Hollyford Fault System, HF=Hauroko Fault, $H R=H u m p$ Ridge, BSB=Blackmount sub-basin, $M S B=$ Monowai sub-basin TM=Takitimu Mountains, $L R=$ Longwood Range, WSB=Waitutu sub-basin, HSB=Hautere sub-basin, PaF=Parara Fault, $S H=$ Solander High and $P S B=$ Parara sub-basin. The red box shows Solander Islands (Fig. 1.3) 
The only subduction related volcanism on the Puysegur Margin is represented by Solander Island and Little Solander Island (Fig. 1.3, Panel A). Located $40 \mathrm{~km}$ south of the Fiordland coast and $60 \mathrm{~km}$ WNW of Stewart Island, they are extinct adakitic (Reay and Parkinson, 1997) volcanic remnants of a larger edifice (Mortimer et al., 2013). Solander Island is important for understanding the relationship between incipient subduction and arc volcanism (Mortimer et al., 2013). Radiometric dating from Mortimer et al. (2013) determined the age of volcanism at Solander Island to be 350-100 ka, and at Little Solander Island to be 50-20 ka.

Further to the south lies the Macquarie Ridge Complex, which extends from western offshore Fiordland to just south of $60^{\circ} \mathrm{S}$ (Frohlich et al., 1997; Conway et al., 2012, Fig. 1.3, Panel B). It is a $1400 \mathrm{~km}$ long (Carter and McCave, 1997) arc shaped system of ridges and troughs that has a major influence on Southern Ocean circulation and deposition patterns (Schuur et al., 1998). The northernmost section of Macquarie Ridge, between $51^{\circ} \mathrm{S}$ and $47^{\circ} \mathrm{S}$, is Puysegur Ridge (Fig. 1.3). This structure is $3-5 \mathrm{~km}$ high, and is flanked to the west by the Puysegur Trench, and to the east by Solander Trough. Collot et al. (1995) divide Puysegur Ridge into a deeper, more complex, asymmetrical northern segment and a shallower more linear southern segment, which widens to the south. The contrast in depths is related to differential uplift and subsidence along an incipient plate boundary (Collot et al., 1995; Lebrun et al., 1998; Mao et al., 2017). Subsidence along Puysegur Ridge is manifested in the Snares Zone, a complex deformation zone from $47^{\circ} \mathrm{S}$ to $48^{\circ} \mathrm{S}$ (Delteil et al., 1996, Fig. 1.3, Panel C).

Beyond 50 S, Deep Sea Drilling Project (DSDP) holes 277, 278 and 279 were drilled in 1973 on the Campbell Plateau, in the south Emerald Basin and southern Puysegur Ridge, respectively (Fig. 1.3, Panel D). Site 277 drilled to mid Paleocene, Site 278 to mid Oligocene, and Site 279 drilled to early Miocene (Kennett et al., 1975a,b,c). There are no seismic ties to any of these sites. 


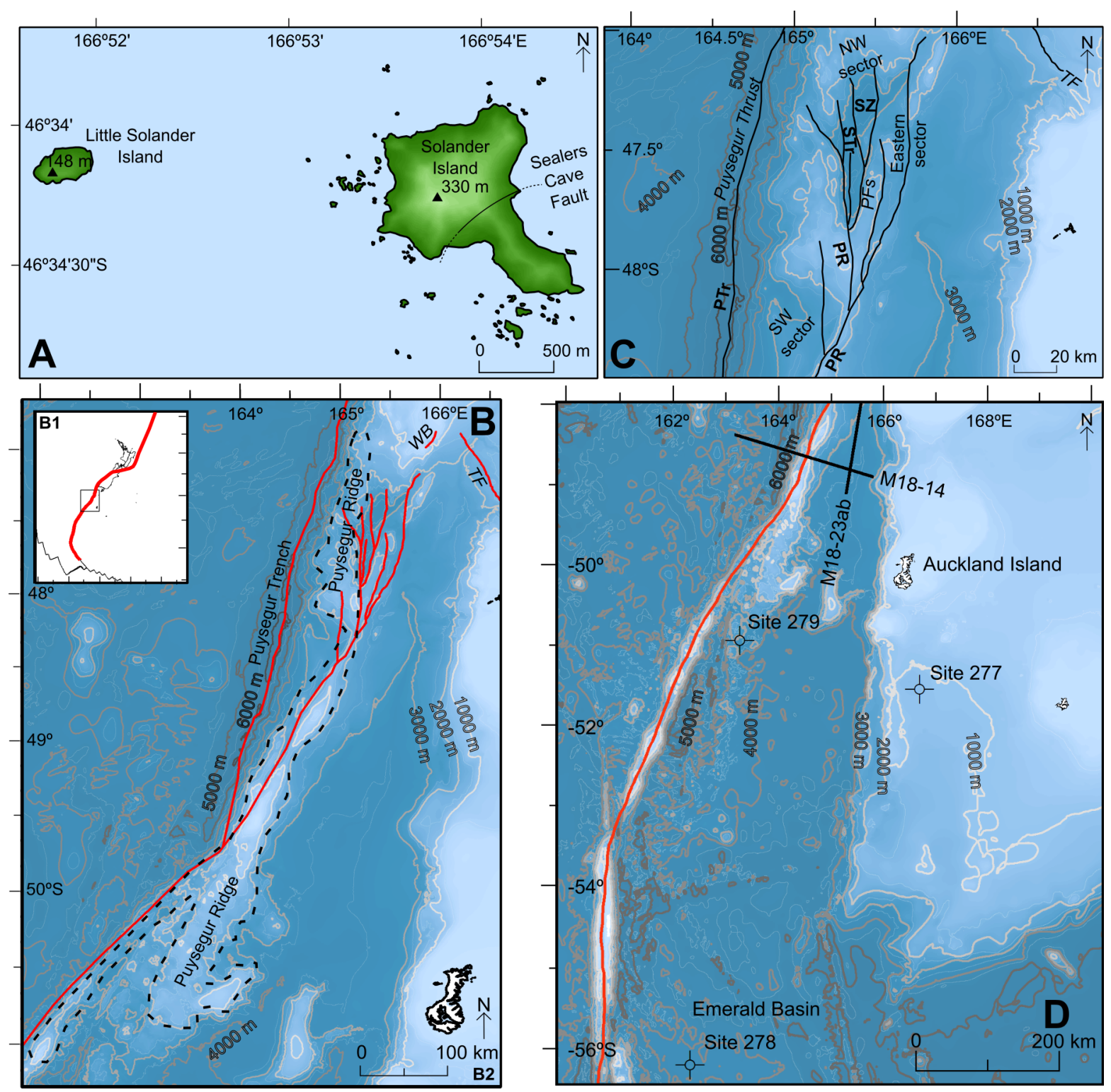

Fig. 1.3: Location of Solander Islands (Panel A, see red square in Fig. 1.2, and Mortimer et al., 2013), Macquarie Ridge Complex (Panel B1) and Puysegur Ridge (Panel B2), Snares Zone (Panel C, see Lamarche et al., 1997, for sector division), and DSDP sites 277-279 (Panel $D$, with MGL1803 lines M18-23ab and M18-14 for context). Panel C: STr=Snares Trough; other abbreviations as per Fig. 1.1. $1000 \mathrm{~m}$ bathymetric contours are labelled; thin lines are $500 \mathrm{~m}$ intervals 


\subsection{Oceanographic Setting}

New Zealand's modern oceanographic setting is shown in Fig. 1.4. Southern Ocean waters in the study area include sub-tropical waters (STW), and sub-antarctic waters (SAW). These waters affect the productivity and pelagic sedimentation of the study area, and currents are a major control on sedimentary deposition patterns in Solander Trough. The sub-antarctic front (SAF) represents the northern front of the ACC, and it is deflected by Macquarie Ridge and the Campbell Plateau (Schuur et al., 1998; Carter and McCave, 1997).

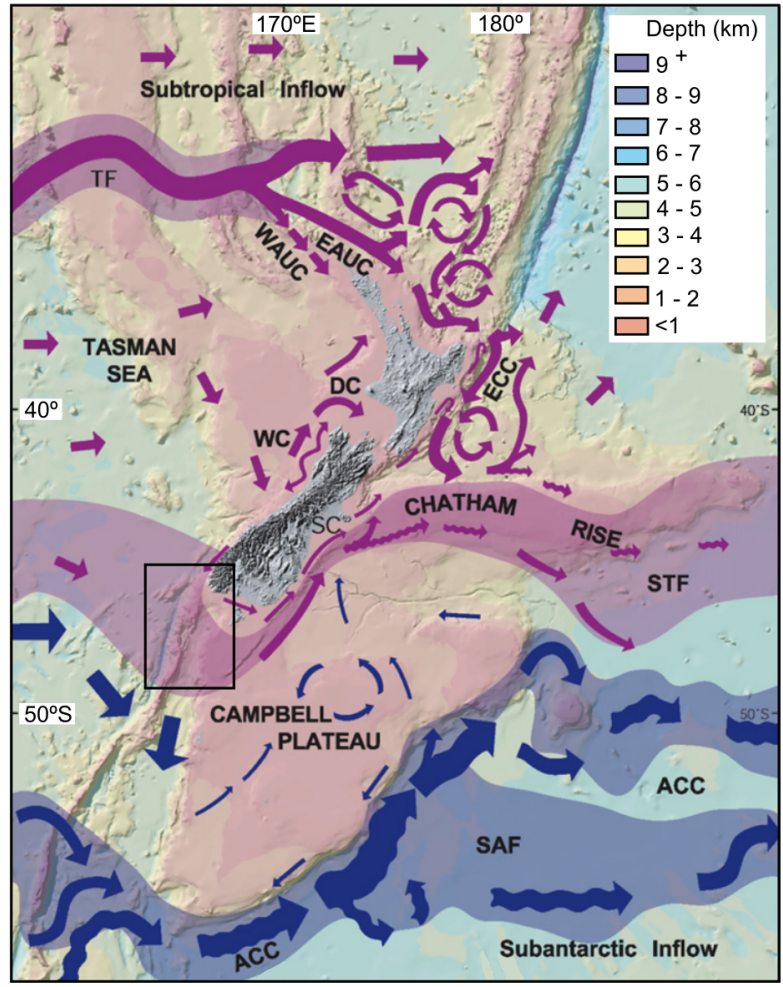

Fig. 1.4: Modern circulation patterns around New Zealand (modified fromx Carter et al., 1998). TF=Tasman Front; EAUC=East Auckland Current; WAUC=West Auckland Current, $E C C=$ East Cape Current; DC=Durville Current, $W C=$ West coast current, STF=sub-tropical front, $A C C=$ Antarctic Circumpolar Current, SAF=sub-antarctic front. Warm currents are shown in purple, cool currents are shown in blue. Current strength is indicated by arrow size. The extent of Fig. 1.1 is shown by the black box 
Elevated chlorophyll-a (enabling photosynthesis in phytoplankton) concentrations exist along the sub-tropical front (STF), which occurs due to mixing of warm, saline, macronutrient-deficient and micronutrient-rich STW, with cool, less saline, macronutrient-rich yet micronutrient-poor sub-antarctic water (SAW; Deacon, 1982; Smith et al., 2013). This combination of waters leads to high Southern Ocean biologic productivity. Tasman Sea to the west (Fig. 1.4) is also highly productive (Jitts, 1965; Hassler et al., 2014), though sedimentation patterns differ either side of the plate boundary due to current flow (see Chapter 6).

\subsection{Petroleum Exploration}

Discoveries of economically viable oil and gas fields in the Taranaki region, such as the Maui gas field in 1969, led to exploration of New Zealand's frontier basins, including Solander Basin. Several hundreds of thousands of kilometres of 2D seismic reflection data are publicly available under New Zealand's open-file system. In the offshore Fiordland area, two petroleum wells were drilled (Parara-1 in 1974/1975 and Solander-1 in 1985, see Chapter 2 for further discussion). This section summarises previously acquired seismic reflection data in the study area. In the appendices, Tables 1A-1 and 1A-2 summarise acquisition parameters for these data.

\subsubsection{Vintage seismic data: $1960 \mathrm{~s}-1970 \mathrm{~s}$}

"Vintage" seismic data were shot in five separate surveys from 1969 to 1973.

\section{Hunt PR556}

The Hunt PR556 survey was shot in 1969 by Hunt International Petroleum Company, and provided the first insight into offshore stratigraphy of the region. Documentation of this survey is poor: any information presented is sourced from Petroleum Report 556 and associated enclosures (Hunt International Petroleum Company, 1970).

\section{NZPET70}

The NZPET70 survey was acquired in 1970 by New Zealand Petroleum Co. Ltd in Te Wae 
Wae Bay (Fig. 1.2). Further information can be found in Petroleum Report 538 (New Zealand Petroleum Exploration Co. Ltd., 1970).

\section{Mobil72}

The Mobil72 seismic survey covered western and eastern offshore North Island, offshore eastern South Island, Great South Basin and Solander region. Like the Hunt PR556 survey, acquisition data are sparse and have been sourced from Petroleum Report 738 (Mobil International Oil Company, 1979).

\section{Hunt A, B and D}

These Hunt data were part of a survey covering the Solander and Great South Basins. Data were acquired by Western Geophysical Company of America: Hunt A was acquired from 19701971 (Hunt International Petroleum Company, 1971; Seahawk Oil International Inc., 1982), Hunt B in 1972 (Hunt International Petroleum Company, 1974) and Hunt D from 1972 - 1973 (Hunt International Petroleum Company, 1974; Seahawk Oil International Inc., 1982).

\subsubsection{Post-vintage data: 1980s-2000s}

These data were shot in five further surveys from 1982 to 2006.

\section{S82}

The S82 survey was shot from $10^{\text {th }}-30^{\text {th }}$ December 1982 by The Geophysical Company of Norway for Seahawk Oil Australia Ltd in PPL38206. Weather conditions were poor and lapses in rough conditions were not long enough to allow the sea state to calm to an acceptable level. Thus, the S82 survey remained incomplete. Further information regarding the acquisition of S82 can be found in Petroleum Report 912 (Geophysical Company of Norway, 1982).

\section{S84}

The S84 survey was shot from $23^{\text {rd }}$ February $-5^{\text {th }}$ March 1984 by Western Geophysical Company of America for Seahawk Oil Australia Ltd in PPL38206. Further information regarding 
the acquistion of S84 can be found in Petroleum Report 1027 (Geophysical Service International, 1984).

\section{Solander-85}

The Solander-85 survey was shot in 1984 by BP Oil Exploration Co. NZ Ltd. in PPL38206. Dropcore samples were also taken. The main goal was to determine suitable structures for drilling petroleum exploration well Solander-1. Full information regarding the Solander-85 survey can be found in Petroleum Report 1121 (BP Oil Exploration Co NZ Ltd, 1985).

\section{S86}

The S86 survey was shot from $6^{\text {th }}-15^{\text {th }}$ February 1986 by BP Oil Exploration Company of New Zealand Ltd. in PPL38206. Further information regarding the acquisition of S86 can be found in Petroleum Report 1165 (Clark, 1986). Line S86-34 provides a seismic tie from the Parara-1 petroleum exploration well to newly acquired seismic data during MGL1803 (Fig. 1.1).

\section{LM06}

The LM06 survey was shot from $7^{\text {th }}-23^{\text {rd }}$ May 2006 by L\&M Petroleum in PEP38228. Further information regarding the acquisition of LM06 can be found in Petroleum Report 3397 (L\&M Petroleum, 2006).

\subsubsection{Petroleum exploration data summary}

All open-access seismic reflection data are located in Fig. 1.5, which shows that there is extensive petroleum industry coverage of shallow water offshore Fiordland, but little coverage south of $\sim 46.5^{\circ} \mathrm{S}$. Most of the regional seismic data within this area was acquired before 1975 and is of low quality. Survey MGL1803 provides the first robust basis for regional stratigraphic correlations and mapping in this previously unexplored area. 


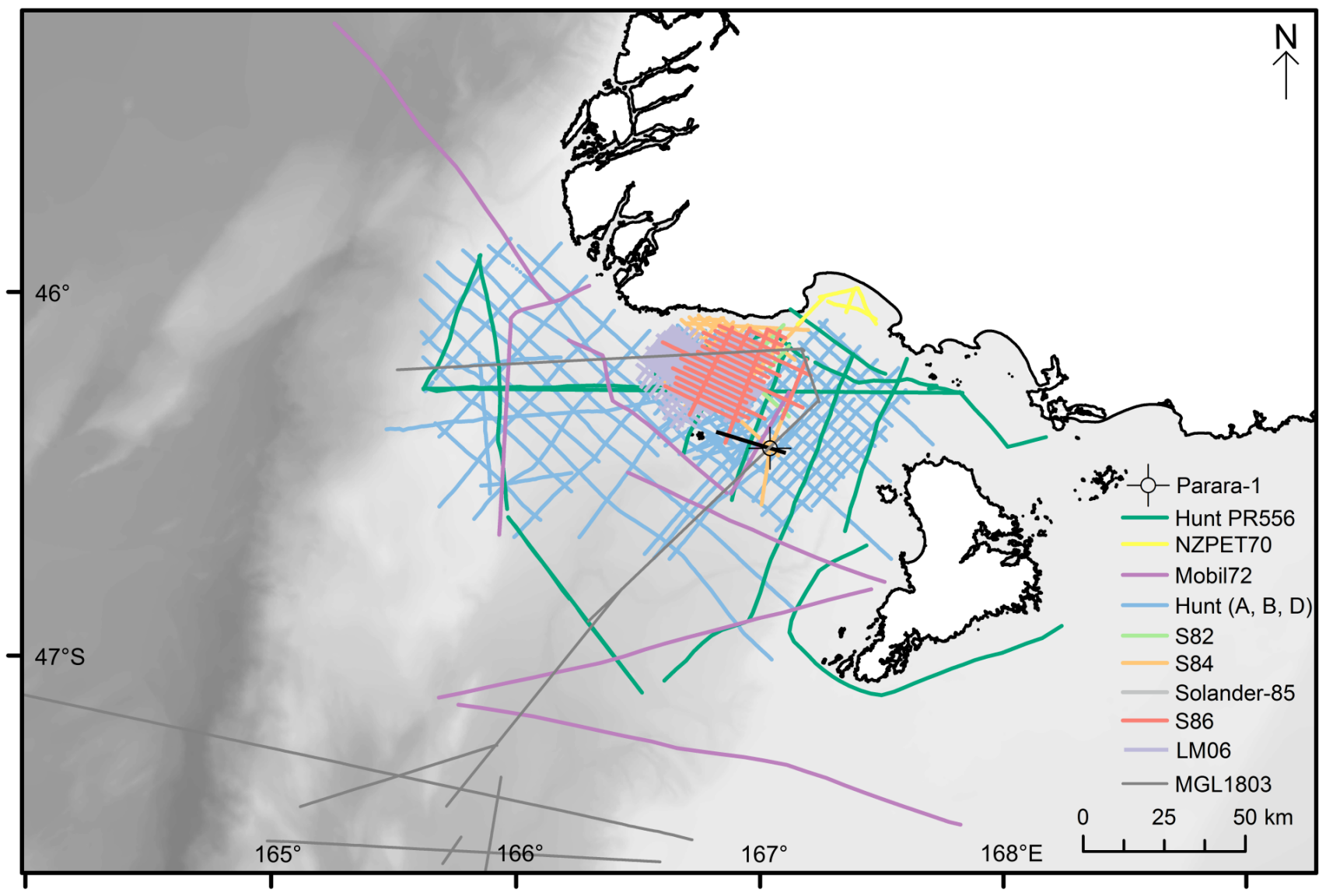

Fig. 1.5: Location of petroleum industry seismic data available from the NZPEM database. MGL1803 seismic lines are shown in dark grey. The black line indicates line S86-34, which intersects the Parara-1 well (labelled), and forms a cornerstone for correlating well strata to newly acquired seismic data to the south 


\subsubsection{Data quality control}

\section{Data polarity}

The polarity of the S86 survey differed to that of the seismic data acquired during MGL1803 (and the reprocessed EW9601 data). As line S86-34 was pivotal to tying sequences to Parara-1, a $180^{\circ}$ phase rotation was applied to this line. S86-34 was then saved as a new line. This phase shifted line was interpreted alongside the MGL1803 data.

\section{Misties analysis}

A mistie in seismic data is defined as a misplacement of horizons where two lines intersect. It is caused by improper static corrections or migration of either or both lines (Herron and Latimer, 2011). Migration differences occur between surveys, especially if acquisition parameters are varied within a survey. Removing misties allow for alignment of reflections between datasets. Within SeisWare ${ }^{\mathrm{TM}}$, a -37 ms bulk shift was applied to line S86-34 to align the seafloor and other reflections at depth with line M18-17c.

\subsection{Methods}

This section summarises seismic acquisition, seismic processing and principles of sequence stratigraphy that were used in this thesis.

\subsubsection{Seismic reflection: data acquisition}

Seismic reflection surveying is a commonly used geophysical technique for imaging the subsurface. It involves a seismic energy source and (typically) multiple receivers (hydrophones), which detect energy after it reflects off sub-surface layers (Kearey et al., 2002). Marine seismic reflection data acquisition involves towing the seismic source and a streamer comprising hydrophones behind a vessel. It is less labourious to acquire marine seismic reflection data than terrestrial data, though issues from swell and marine mammal observations can impede 
acquisition.

Seismic reflection imaging works on the premise that rocks have different elastic properties (Goranson, 2002) and hence acoustic impedances $(Z)$, which is an inherent property of a given rock dependent on the product of its density $(\rho)$ and p-wave velocity $(v)$ (Eqn. 1.1).

$$
Z=\rho \times v
$$

The greater the impedance contrast between different rock layers, the greater the amplitude of energy reflected from the layer boundary (Kearey et al., 2002). For a wave at a given angle of incidence $\left(\theta_{1}\right)$, energy is reflected from the interface at $\theta_{1}$ and transmitted at a given angle of refraction $\left(\theta_{2}\right)$, according to Snell's Law (Eqn. 1.2). Zoeppritz equations can be used to determine the amplitude of reflected and refracted waves at a layer interface (Sheriff and Geldart, 1995). At normal incidence, these equations simplify to Eqn. 1.3.

$$
\begin{gathered}
\frac{\sin \theta_{1}}{\sin \theta_{2}}=\frac{v_{1}}{v_{2}} \\
R=\frac{Z_{2}-Z_{1}}{Z_{2}+Z_{1}}
\end{gathered}
$$

In Eqn. 1.3, the ratio of impedance contrasts ( $Z$, see Eqn. 1.1) gives rise to the reflection co-efficient $(R)$, which ranges from -1 to 1 . When $\mathrm{R}$ is close to 0 , most energy is transmitted across an interface; when closer to -1 or +1 , more energy is reflected from the interface. The sign of $\mathrm{R}$ dictates a reflection's polarity in a seismic section, where negative values produce a reverse polarity reflection and vice-versa (Kearey et al., 2002). Reflections from rock interfaces then recorded as traces or "wiggles" by hydrophones on the streamer. The magnitude of pressure changes depends on the amount of energy received. Reflections can be primary (reflected off a single rock interface) or secondary if reflected off more than one interface e.g. "multiples" are reflected off the sea surface and seabed, and may also have reflected off a rock interface (AKA peg-leg multiples). Secondary reflections may obscure primary reflections in a seismic section, 
and, during processing, are removed as best as possible.

Multiple hydrophones are often used within a streamer. This allows for data stacking, which improves image data quality by increasing signal:noise. The common mid-point (CMP) stacking method is based on sorting source-receiver pairs from different shots to image a common depth point (CDP, Fig. 1.6).
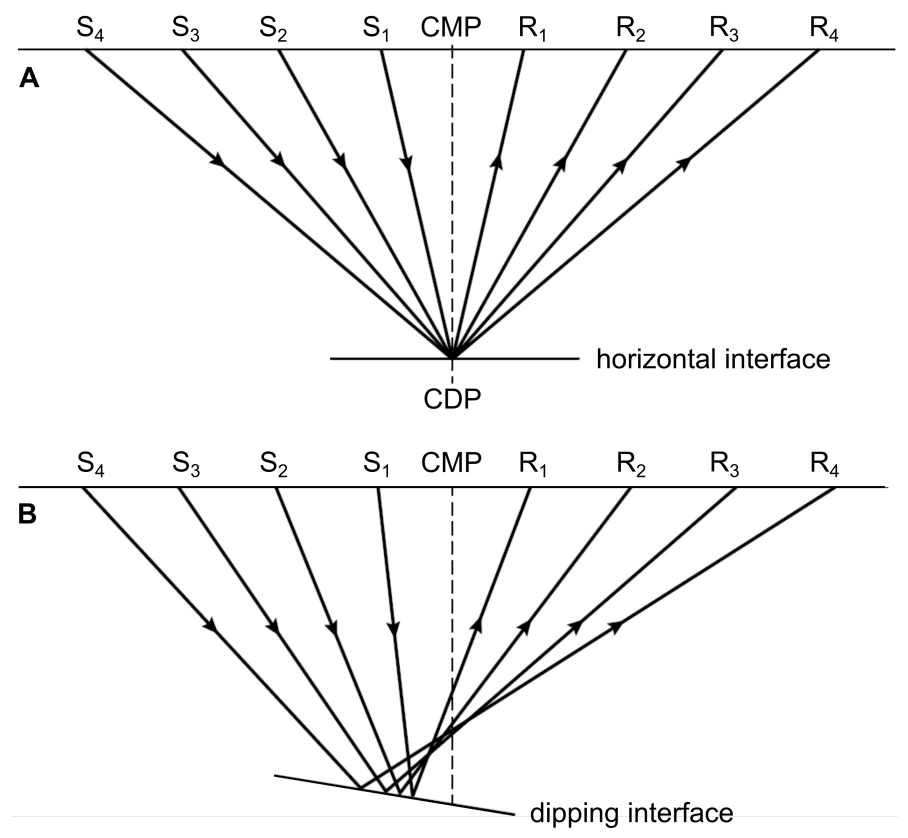

Fig. 1.6: Common mid-point (CMP) method, where, in the case of a horizontal reflector (Panel $A)$, source $(S)$ and receiver $(R)$ pairs sample the same common depth point $(C D P)$. For dipping interfaces (Panel B), the CMP method starts to break down. Adapted from Kearey et al. (2002)

Dipping reflectors are common so this needs to be accounted for in processing by applying pre-stack time migration methods. The number of raypaths that sample the same CDP is known as the fold (Eqn. 1.4, Kearey et al., 2002).

$$
\text { Fold }=\frac{\text { Receiverspacing } \times \# \text { receivers }}{2 \times \text { shotspacing }}
$$

During MGL1803, the nominal fold of the data was 126 for lines shot with the $12.6 \mathrm{~km}$ streamer, and 40 for lines acquired with the $4 \mathrm{~km}$ streamer (see Table 4.1). 


\subsubsection{Seismic reflection: data processing}

\section{Reformatting, resampling and geometry}

Demultiplex format segd data are first converted to segy data with header information. They are then resampled from their original sample rate (frequency of data recording in time) to a lower sample rate. The resampling process optimises storage space for recording traces, and also removes some high frequency noise from the raw data. The maximum resolvable frequency (Nyquist frequency, $f_{N}$ ) is half the reciprocal of sample rate ( $\delta$ t, Eqn. 1.5).

$$
f_{N}=\frac{1}{2 \times \delta t}
$$

For seismic data acquired at $2 \mathrm{~ms}$ sample rate, resampling to 4 ms means $f_{N}=125 \mathrm{~Hz}$, which is greater than the maximum frequency expected from reflected rays ( 100 Hz; Onajite, 2013). Resampling also reduces processing time. Data acquired during MGL1803 were resampled from $2 \mathrm{~ms}$ to $4 \mathrm{~ms}$ (Chapter 4 ).

Acquisition geometry, with GPS recorded by ship and tail buoy (Fig. 4.2, Panel F) and depth and headings indicated by streamer birds (Fig. 4.2, Panel D) is necessary for spatially defining the data in terms of shot-receiver configuration for each trace, which is important for shot gathers and later processing stages such as CMP sorting.

2. Trace editing, filtering and amplitude recovery

Alongside multiple energy (see subsection 1.6.1), other unwanted energy, such as direct arrivals through water, refractions through sediment and low/high frequency noise may exist in the dataset. Noisy traces may be present, due to poor depth control, excessive swell noise, faulty equipment, etc. In Fig. 1.7, examples of unwanted energy are highlighted. Direct and refracted arrivals can be removed by muting. Some noise can be removed by frequency filtering. Noisy traces can be removed by trace editing. 


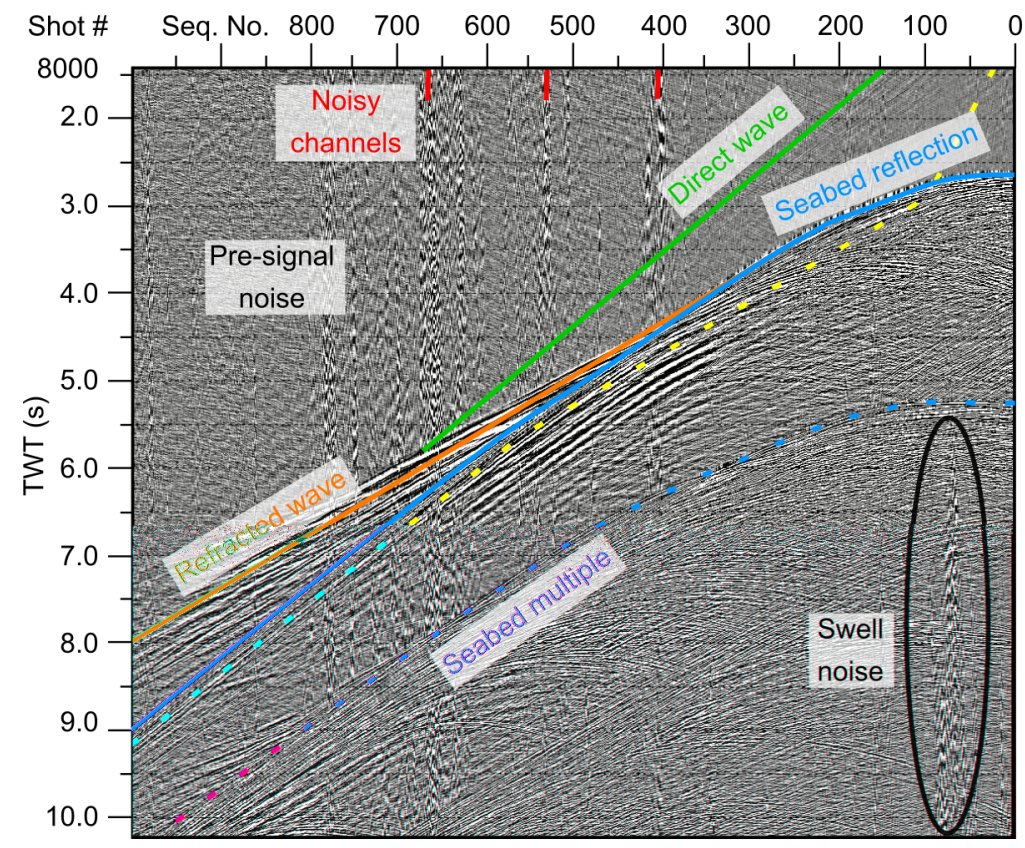

Fig. 1.7: Shot 8000 from line M18-01, where the pre-processed data contain a variety of extraneous energy (labelled). The dashed yellow line shows an example of a mute that may be picked to remove unwanted energy

The amplitude of reflection events from depth are low due to energy decrease associated with spherical divergence of energy from the seismic source, and from attenuation within strata. To account for this, an amplitude gain scalar that is a function of travel time is applied (Yilmaz, 2001; Kearey et al., 2002).

\section{Deconvolution and CMP sorting}

A widely used method of multiple removal is predictive or gap deconvolution. This involves attempting to replicate the source wavelet to identify repetitions in the dataset (e.g. Fig. 1.7). It involves a "gap" to exclude high amplitude events, an operator length over which the trace is correlated with itself and a design/application window. Predictive deconvolution is also beneficial for improving vertical resolution (Yilmaz, 2001; Kearey et al., 2002).

As per Fig. 1.6, data can now be sorted to their assumed CDP according to the CMP method, so data may be stacked later. Sorting enables generation of a brute stack, which is a stacked section created with a crude velocity model, which allows for a preliminary view of the data (see Fig. 4.4). 


\section{Velocity analysis}

A refined velocity model for the data is created by fitting hyperbolae to reflection events. Once picked, it means data can be stacked, which greatly increases signal:noise. Velocities that "flatten" reflection hyperbolae are known as stacking velocities, which tend to increase with depth, due to increased sediment compaction (Kearey et al., 2002). Velocity inversions do occur in nature, but may also relate to multiple energy that remains in the dataset. For onboard processing of Line P1 and MGL1803 data (Chapter 3 and Chapter 4 respectively), stacking velocity picks were made based on semblance, which is a measure of coherence within a CDP gather (Yilmaz, 2001, see Fig. 1.8). Achieving this corrects for the hyperbolic raypath of reflections, and means normal moveout (NMO) has been removed (Kearey et al., 2002). Multiple events remain hyperbolic and so, at greater offsets, will destructively stack (Fig. 1.8, Panels A \& D). An inside mute at small offsets (small NMO) can aid multiple removal. Shallow

reflections are corrected more (greater NMO correction) than deeper reflections (Yilmaz, 2001), resulting in an apparent change in frequency and "smearing", especially at far offsets. To prevent detrimental effects of this during stacking, an NMO stretch mute is picked.

\section{Radon demultiple}

Despite muting and stacking, there may still be residual multiple energy in the dataset. During MGL1803, a radon demultiple process was employed to help remove this energy. This works on the basis that primary reflections and multiple events will plot separately in terms of hyperbolic moveout when transformed into the $\tau$-p domain using a forward transform (Yilmaz, 2001; Foster and Mosher, 1992). From this separation, multiples can be discriminated from primary events, and an inverse transformation of the multiples and subtraction from the dataset can be performed.

\section{Migration}

In Fig. 1.6, travel times to source-receiver combinations that are evenly spaced will differ due to the dipping reflector. Migration is the process of correctly repositioning this energy in space such that it represents a true vertical travel time to an interface (Kearey et al., 2002). Onboard MGL1803, FK migration was employed. This involves transformation of data into the 
frequency-wavenumber domain, which is possible assuming a constant medium velocity. The reader is directed to Stolt (1978), Sheriff and Geldart (1995) and Yilmaz (2001) for comprehensive coverage of FK migration. 
CDP $5500-5507$
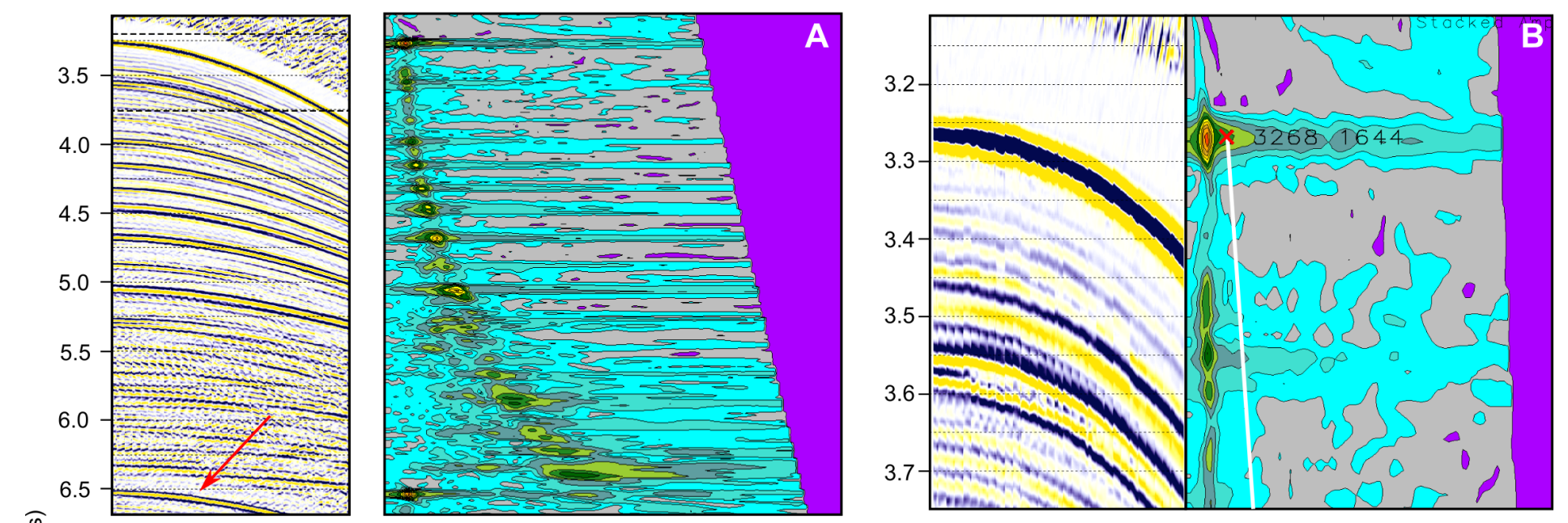

$\stackrel{5}{5}$
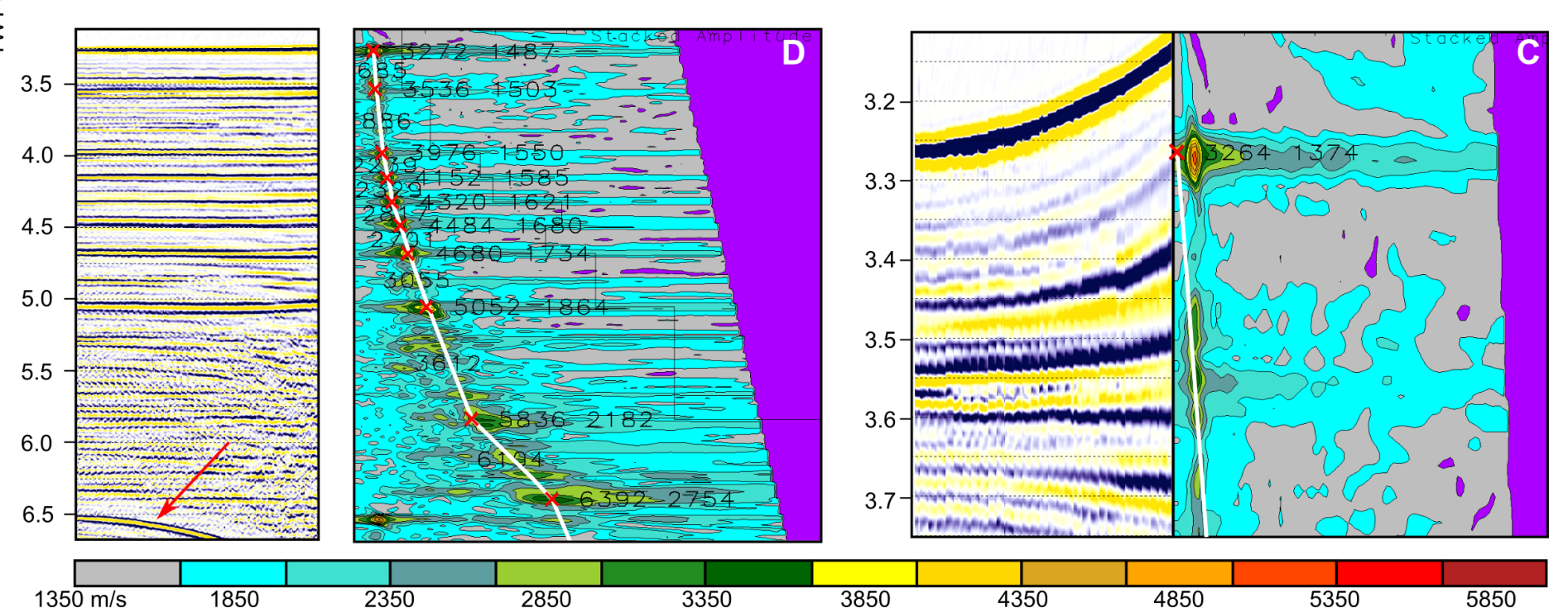

Fig. 1.8: Velocity model picking using semblance in Echos. Panel A shows a supergather of 8 CDPs and the corresponding semblance display; CDP location is shown in Fig. 4.8. Panels B and C illustrate cases where seafloor stacking velocity estimates have been overestimated $(1644 \mathrm{~m} / \mathrm{s})$ and underestimated $(1374 \mathrm{~m} / \mathrm{s})$ respectively. In these examples, stacking will lead to poor signal:noise. Panel D shows a suitable set of stacking velocity picks. Multiple reflection in Panels $A$ and $D$ (red arrow) remain hyperbolic, while primary events are flattened. Modified from Echos Velocity Analysis Tool 


\subsubsection{Principles of seismic stratigraphy}

Processing of data acquired during MGL1803 enables seismic mapping. An objective was to map sequence and megasequence boundaries across the study area. The scientific goals were: correlation of stratigraphy from north to south of the study area; and interpretation of the depositional history of Solander Trough. Megasequence boundaries are linked to major tectonic/sediment supply changes, and are mapped as unconformable surfaces marked by stratal termination relationships and changes in stacking patterns, as shown in Fig. 1.9.

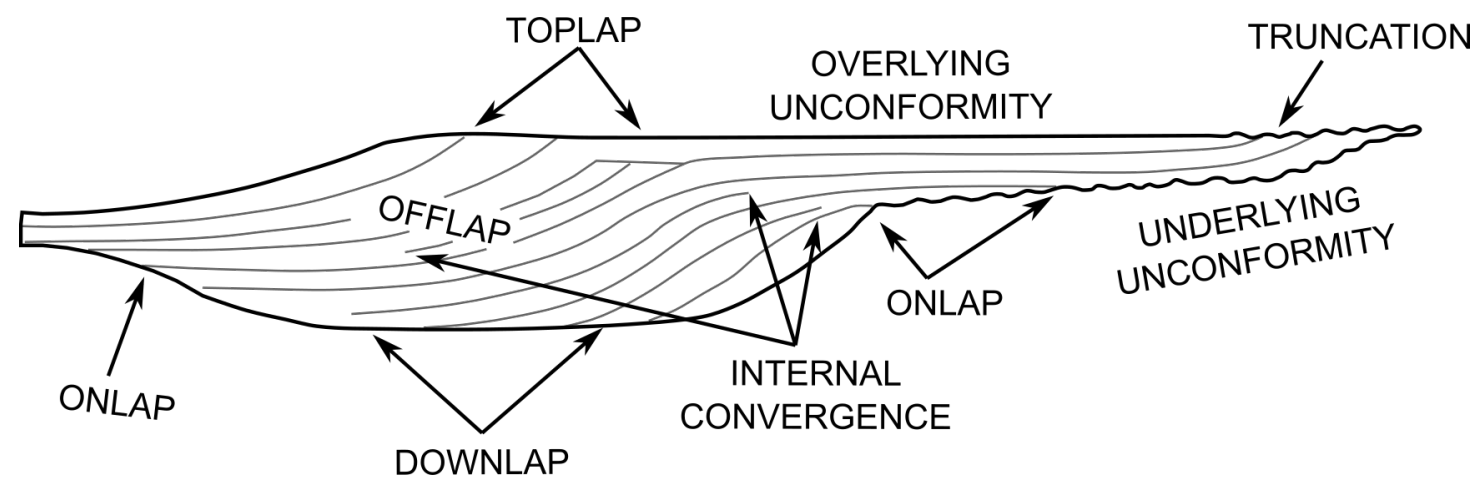

Fig. 1.9: Stratigraphic relationships used for seismic mapping. Adapted from Mitchum et al. (1977)

In Fig. 1.9, onlap and offlap are defined as up-dip truncations of strata against a basal and overlying surface respectively. Their presence defines unconformity bound depositional sequences (Christie-Blick, 1991). Downlapping is defined where strata terminate against a basal surface at a steeper dip than the surface. Christie-Blick (1991) states that a sequence may exhibit both onlapping and downlapping basal terminations.

Sequence boundaries were mapped using characteristics such as reflection amplitude, continuity and polarity (Sheriff and Geldart, 1995), in addition to the relationships shown in Fig. 1.9. The principles outlined above enabled correlation of units, in spite of several structural barriers (see Chapter 5 and Chapter 6). 


\subsection{Thesis Objectives}

The main objectives of this thesis are:

1. Re-process Line P1 data acquired during the EW9601a survey (Chapter 3).

2. Process data acquired during voyage MGL1803 (Chapter 4).

3. Integrate well (Chapter 2) and previously acquired seismic data with MGL1803 data in order to build a seismic stratigraphy for the Solander Trough (Chapter 5).

4. Use seismic stratigraphy, well data and swath bathymetry data to develop a depositional model and basin history for Solander Trough (Chapter 6).

Note: For reference, a copy of the New Zealand Geological Time Scale is provided in Appendix 1, Fig. $1 A-1$. 
Introduction 


\section{Chapter 2}

\section{Petroleum Industry Well Data}

\subsection{Introduction}

This chapter outlines the petroleum well data from two explorations boreholes in the offshore Fiordland region. Parara-1 was completed in 1976 and Solander-1 was drilled in 1985 (Fig. 2.1). Well biostratigraphy provides the only stratigraphic control. In this thesis, data from Parara-1 are highly important as they can be tied to the MGL1803 survey, they sample a thick Neogene sequence and complexity associated with the Solander Fault is avoided.

\subsection{Parara-1: Summary}

Complete data for Parara-1 are found in Petroleum Report 673: Well Completion Report (PPL 38206, Hunt International Petroleum Company, 1976). Parara-1 was drilled in 1975-1976 and is located $22 \mathrm{~km}$ ESE of Solander Island (Fig. 2.1) in $147.5 \mathrm{~m}$ of water. It aimed to test the hydrocarbon potential of the upthrown side of a reverse-fault bound anticline (Parara Anticline) that afforded $>2.1 \mathrm{~km}$ of vertical closure, by targeting Pleistocene-Oligocene limestone and sandstone reservoirs. Having reached basement rock, no significant hydrocarbon shows were encountered, and the well was plugged and abandoned at $3800.5 \mathrm{~m} \mathrm{BKB}$ as a dry hole. Paleogene sediments contained carbonaceous material, minor coal and dead oil (Fig. 2.2). 


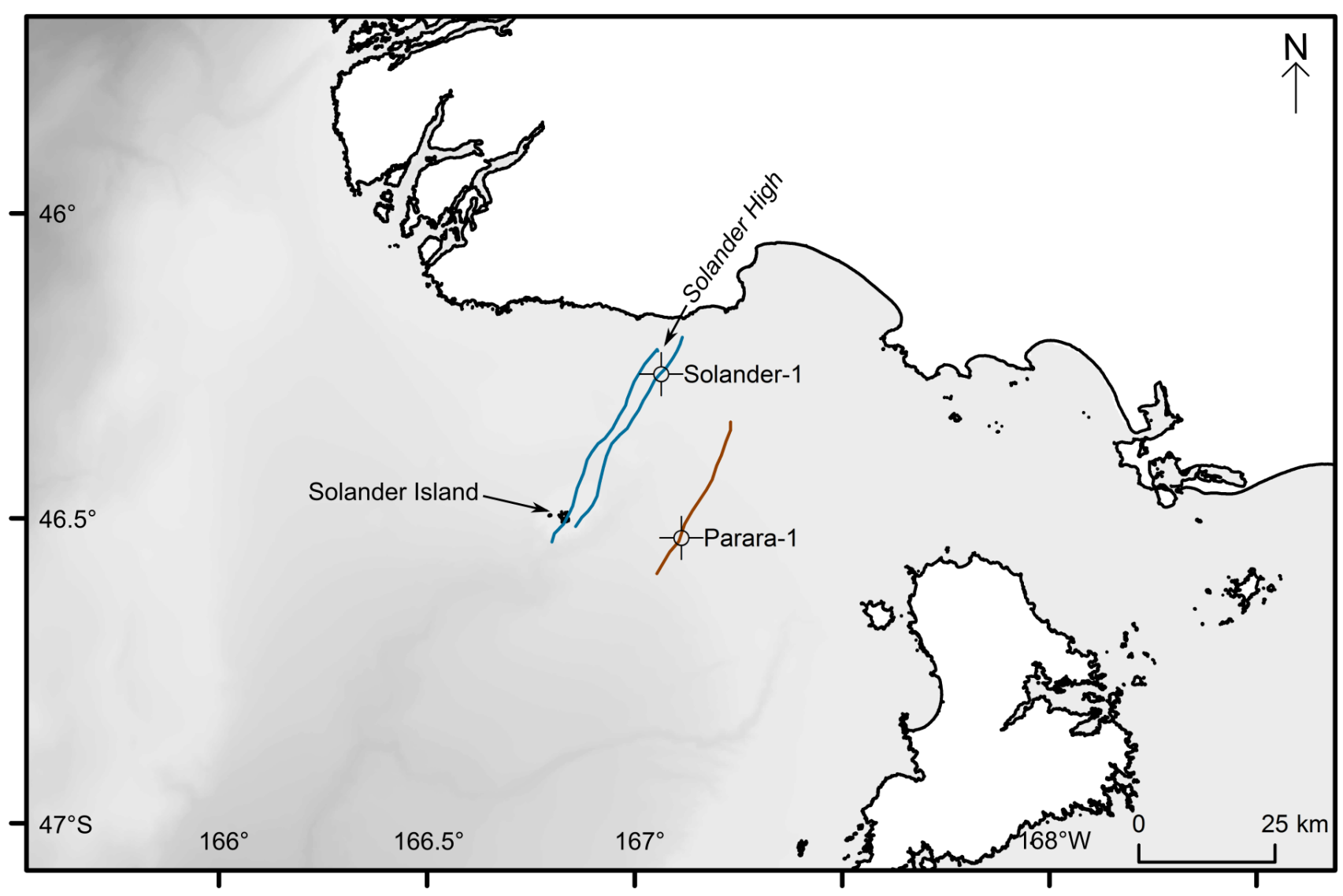

Fig. 2.1: Location of Parara-1 and Solander-1 petroleum wells. Blue lines = Solander Faults; red line $=$ Parara Fault

\subsubsection{Parara-1 stratigraphy}

The Pleistocene to mid Miocene stratigraphy of Parara-1 comprises predominantly outershelf to bathyal clays and shales, with rare fine sands. From the mid Miocene to Oligocene, strata are fine-grained shelfal deposits with calcareous material present. All older strata are terrestrial in origin, mostly comprising sands and coal measures, with the well terminating in metamorphic basement. Table 2.1 summarises the chronostratigraphy of Parara-1. 


\begin{tabular}{lcc}
\hline \multicolumn{1}{c}{$\begin{array}{c}\text { Chronostratigraphic } \\
\text { interval }\end{array}$} & $\begin{array}{c}\text { Depth range } \\
(\mathrm{m} \mathrm{BKB})\end{array}$ & $\begin{array}{c}\text { Thickness } \\
(\mathrm{m})\end{array}$ \\
\hline Pleistocene/Wanganui & $493.7-835$ & 341.3 \\
Pliocene/Wanganui & $835-1557.5$ & 722.5 \\
Miocene/Taranaki & $1557.5-1841$ & 283.5 \\
Miocene/Southland & $1841-2659.6$ & 787.6 \\
Miocene/Pareora & $2659.6-2834.6$ & 206 \\
Oligocene/Landon & $2834.6-2993.7$ & 159.1 \\
Eocene/Arnold & $2993.7-3179$ & 185.3 \\
Eocene/Dannevirke & $3179-3358.8$ & 179.8 \\
Paleocene?/l. Dannevirke to & $3358.8-3779.4$ & 420.6 \\
Maastrichtian?/Mata & $3779.4-3800.5$ & 21.1 \\
Paleozoic & &
\end{tabular}

Table 2.1: Parara-1 chronostratigraphic divisions. $m$ BKB = metres below kelly bushing

\section{Unit 1: Quaternary - Pleistocene (493.7-835 m BKB)}

Highly fossiliferous deepwater clays and siltstones with little induration were common. Carbonaceous material was present near the base, with methane gas observed in the mudstream.

\section{Unit 2: Pliocene - Wanganui (Wm, Wp, Wo, 835-1557.5 m BKB)}

The entire Pliocene section comprises mid-deep shelf deposits of highly fossiliferous clays and siltstones with little induration. The lower half of this unit contains rare loosely cemented fine sand lenses. Carbonaceous material was determined to be the source of minor methane readings.

\section{Unit 3: Late Miocene (Taranaki, Tk - Tt, 1557.5-1841 m BKB)}

This unit comprises deep shelf clays and siltstones with rare sand lenses, where soft shales indicate more induration. Carbonaceous materials were the assumed source of methane in the mud stream. The Tongaporutuan is thinner than expected, where the Kapitean is well defined, potentially due to a period of erosion or non-deposition. Increased glauconite indicates "...a break in the sedimentary sequence." (Hunt International Petroleum Company, 1976, pg. 18). An unconformity identified on seismic line S86-34 at the top late Miocene which is "...reasonably

be assumed to be early Kapitean to Tongaporutuan in age." (Hunt International Petroleum Company, 1976, pg. 18).

\section{Unit 4: Mid Miocene (Southland, Sw, Sl, Sc, 1841-2659.6 m BKB)}

Outer shelf to bathyal clays and siltstones grade downhole to mid-outer shelf shales, indurated 
clays, well cemented fine sandstones and rare microcrystalline limestones. Traces of lignite and coal are present in very thin lenses.

\section{Unit 5: Early Miocene (Pareora, Pl, Po, 2659.6-2834.6 m BKB)}

This unit comprises mid-outer shelf deposits of soft-medium firm shales with rare sandstone and limestone lenses and continuous scattered carbonaceous material. Methane gas was present.

\section{Unit 6: Oligocene (Landon, Lw, Ld, Lwh, 2834.6-2993.7 m BKB)}

Very shallow water deposits grade to deep water outer shelf deposits, comprising soft shales and clays with increased sand inclusions at depth. Limestones grade to marls, with minor coal inclusions. A hiatus at this time may mark Solander Basin flooding, as all older rocks are terrestrial. Glauconite and pyrite increase, and clays become more kaolinite toward to the base of this unit. Basal sandstone has a kaolinitic and limey matrix with thin coal inclusions. Gas readings were slight to nil. Logs indicate these sands are water bearing.

\section{Unit 7: Eocene (Arnold, Ar, Ak, Ab, 2993.7-3179 m BKB)}

This unit contains sandstones with kaolinite and rare marl, where the basal $30 \mathrm{~m}$ is nearly entirely coal measures. Materials ranged from soft brown peat to black brittle coal interbedded in sands and shales. No gas was recorded, with slight gas odours from sidewall cores. Sandstone porosities were 15-25\%, but electric logs indicated they were water bearing.

\section{Unit 8: Eocene (Dannevirke, unknown stages, 3179-3358.8 m BKB)}

The upper $31 \mathrm{~m}$ of continuous sandstones contained a few dense microcrystalline limestone inclusions. Sands are very kaolinitic with occasional shale inclusions and abundant carbonaceous zones but become coarser with depth. Secondary mica traces increase with depth. The entire interval has sporadic zones of carbonaceous materials and adjacent stained sand with dull orange fluorescence. No gas was recorded, though sidewall cores have good gas odour, with methane pentane detected. Porosities range from $20 \%$ down to $5 \%$ at the base of the interval, and electric logs indicate total water saturation.

Unit 9: Paleocene? - Maastrichtian? (l. Dannevirke to Mata, 3358.8-3779.4 m BKB)

Coarse kaolinitic sandstone grades down to a granitic wash set in a kaolinitic matrix. The upper 
zone of the granitic wash is coloured with ferrigenous staining which gradually disappears with depth. Metamorphic alterations were noted. Biotite, chlorite and occasional hornblende suggest secondary mineralisation. The entire interval contained inclusions of red and green waxy shales. Sonic $\log$ indicated low porosities of $\pm 5 \%$, with occasional thin zones of $10-12 \%$ porosity. The entire section was water bearing.

\section{Unit 10: Paleozoic (Wet Jacket/Bradshaw formation (3779.4-3800.5 m BKB)}

This unit comprised dark green to black gneiss with evidence of weathering. After $6 \mathrm{~m}$ of gneiss, a highly weathered, $3 \mathrm{~m}$ zone of pink kaolinitic granite wash and gneiss was encountered. The remainder of the rock drilled was dark green gneiss with some signs of weathering.

\subsubsection{Parara-1 downhole observations}

Fig. 2.2 summarises the wireline log data obtained from Parara-1. In summary, bit size, caliper width, bulk density, borehole sonic, gamma ray, neutron porosity, resistivity and spontaneous potential $\operatorname{logs}$ were run. Data were plotted from the las file for Parara-1, also from NZP\&M. A checkshot survey was also conducted. Using the Parara-1 well summary sheet provided by NZP\&M, these checkshot data were plotted and one way travel times (OWT) from the seafloor were calculated, using a KB datum elevation of $31 \mathrm{~m}$, water depth of $147.5 \mathrm{~m}$, horizontal shot-well offset of $37.9 \mathrm{~m}$ and a shot depth of $10.6 \mathrm{~m}$. Results are shown in Table 2.2. 


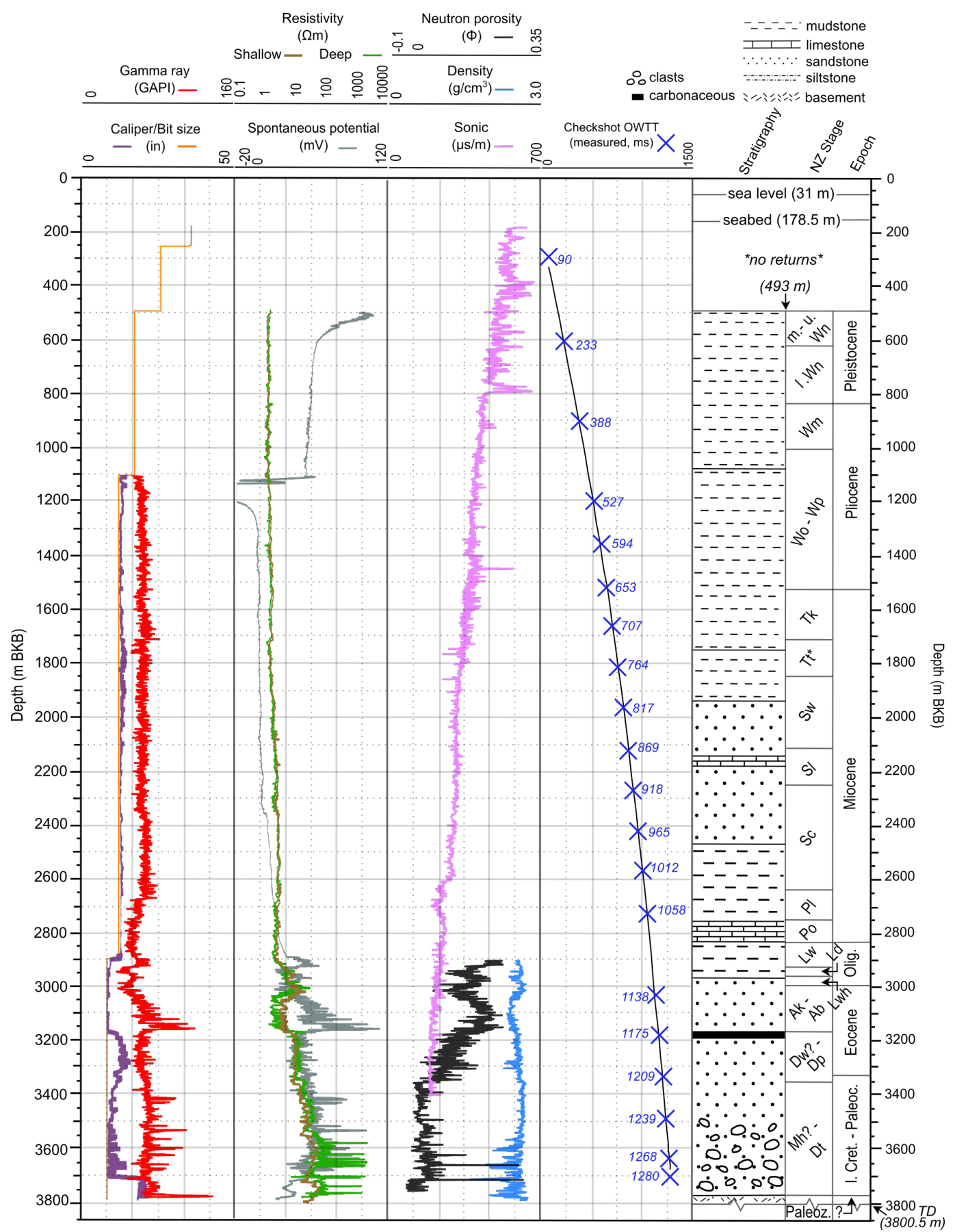

Fig. 2.2: Digitised wireline log data for Parara-1, sourced from NZPESM. One-way travel times to checkshot data below the seafloor are plotted. Also shown is lithologic data with New Zealand stages and international age constraints provided from fossil records (note that these time scales were accurate at the time of data acquisition). A $3^{\text {rd }}$ order polynomial (Eqn. 2.1) has been fitted to checkshot data, which provides a time to depth relationship for strata in Parara-1 and strata mapped in Solander Trough. Tt* indicates poor representation of the Tongaporutuan 
From checkshot data one way travel times from the seafloor, a third order polynomial representing a depth-OWT relationship (Eqn. 2.1) and its derivative representing a velocity function (Eqn. 2.2) was calculated:

\begin{tabular}{cclcc}
\hline $\begin{array}{c}\text { Depth } \\
(\mathrm{m}, \mathrm{BKB})\end{array}$ & $\begin{array}{c}\text { OWT } \\
(\mathrm{s})\end{array}$ & $\begin{array}{c}\text { Depth } \\
(\mathrm{m}, \mathrm{bsf})\end{array}$ & $\begin{array}{c}\text { OWT } \\
(\mathrm{s}, \mathrm{bsf})\end{array}$ & $\begin{array}{c}\text { Incidence } \\
\text { angle }\left(^{\mathrm{o}}\right)\end{array}$ \\
\hline 310 & 0.180 & 131.5 & 0.09 & 8.1 \\
616 & 0.324 & 437.8 & 0.23 & 3.8 \\
919 & 0.479 & 740.5 & 0.39 & 2.5 \\
1219 & 0.618 & 1040.7 & 0.53 & 1.9 \\
1381 & 0.685 & 1202.2 & 0.59 & 1.6 \\
1533 & 0.744 & 1354.9 & 0.65 & 1.5 \\
1678 & 0.798 & 1499.4 & 0.71 & 1.3 \\
1829 & 0.855 & 1650.3 & 0.76 & 1.2 \\
1981 & 0.908 & 1802.7 & 0.82 & 1.1 \\
2134 & 0.960 & 1955.1 & 0.87 & 1.0 \\
2286 & 1.009 & 2107.5 & 0.92 & 1.0 \\
2438 & 1.056 & 2259.9 & 0.96 & 0.9 \\
2591 & 1.103 & 2412.3 & 1.01 & 0.9 \\
2743 & 1.149 & 2564.7 & 1.06 & 0.8 \\
3048 & 1.229 & 2869.5 & 1.14 & 0.7 \\
3200 & 1.266 & 3021.9 & 1.17 & 0.7 \\
3353 & 1.300 & 3174.3 & 1.21 & 0.7 \\
3505 & 1.330 & 3326.7 & 1.24 & 0.6 \\
3658 & 1.359 & 3479.1 & 1.27 & 0.6 \\
3725 & 1.371 & 3546.2 & 1.28 & 0.6 \\
\hline
\end{tabular}

Table 2.2: Calculated OWTs below the seafloor from the Parara-1 checkshot survey

$$
\begin{aligned}
& \text { Dept }_{\mathrm{bsf}}=663.1\left(t^{3}\right)-193.4\left(t^{2}\right)+1906.9(t) \\
& \frac{\partial D e p t h_{\mathrm{bsf}}}{\partial t}=1989.3\left(t^{2}\right)-389.8(t)+1906.9
\end{aligned}
$$

In Eqns. 2.1 and 2.2, $\mathrm{t}=$ OWT below seafloor in ms. Eqn. 2.1 can be used to infer depth to interfaces below the seafloor. Eqn. 2.2 allows for interval velocities to be computed; these are shown in Table 2.3. The difference in observed and calculated depths is plotted in Fig. 2.3. 


\begin{tabular}{ccccc}
\hline $\begin{array}{c}\text { Depth } \\
(\mathrm{m} \mathrm{bsf})\end{array}$ & $\begin{array}{c}\text { OWT } \\
\text { (s bsf })\end{array}$ & $\begin{array}{c}\text { Depth } \\
\text { (m bsf, calc. })\end{array}$ & $\begin{array}{c}\Delta \text { Depth } \\
\text { (m obs. }- \text { proj. })\end{array}$ & $\begin{array}{c}\mathrm{V}_{\text {int }} \\
(\mathrm{m} / \mathrm{s}, \text { calc. }\end{array}$ \\
\hline 131.5 & 0.09 & 166.5 & -35.0 & 1888 \\
437.8 & 0.23 & 441.4 & -3.6 & 1925 \\
740.5 & 0.39 & 748.9 & -8.4 & 2056 \\
1040.7 & 0.53 & 1047.7 & -7.0 & 2255 \\
1202.2 & 0.59 & 1202.8 & -0.6 & 2379 \\
1354.9 & 0.65 & 1346.8 & 8.2 & 2502 \\
1499.4 & 0.71 & 1485.2 & 14.2 & 2627 \\
1650.3 & 0.76 & 1639.0 & 11.3 & 2772 \\
1802.7 & 0.82 & 1789.8 & 12.9 & 2918 \\
1955.1 & 0.87 & 1945.5 & 9.6 & 3072 \\
2107.5 & 0.92 & 2099.8 & 7.7 & 3227 \\
2259.9 & 0.96 & 2255.2 & 4.7 & 3385 \\
2412.3 & 1.01 & 2418.2 & -5.9 & 3552 \\
2564.7 & 1.06 & 2585.5 & -20.8 & 3724 \\
2869.5 & 1.14 & 2895.9 & -26.4 & 4042 \\
3021.9 & 1.17 & 3048.4 & -26.5 & 4198 \\
3174.3 & 1.21 & 3193.6 & -19.3 & 4346 \\
3326.7 & 1.24 & 3326.0 & 0.7 & 4480 \\
3479.1 & 1.27 & 3457.8 & 21.3 & 4614 \\
3546.2 & 1.28 & 3513.5 & 32.6 & 4670 \\
\hline
\end{tabular}

std. dev. $=17.0 \mathrm{~m}$

Table 2.3: Calculated interval velocities for the Parara-1 well using Eqn. 2.2

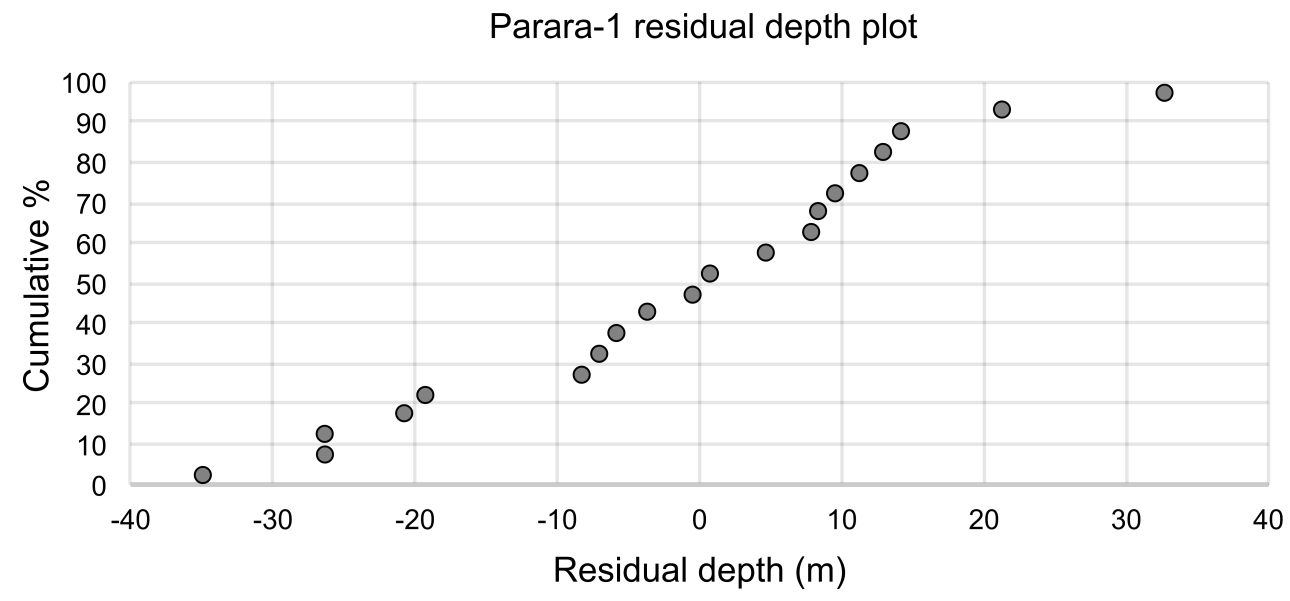

Fig. 2.3: Residual plot of observed less calculated depths from Eqn. 2.1

A standard deviation of $17.0 \mathrm{~m}$ and Fig. 2.3 indicate that the depth model created using the checkshot data is sound. This modelled relationship can be used to infer time-depth relationships for strata to the south of Parara-1. 


\subsection{Solander-1: Summary}

Complete information for Solander-1 is found in Petroleum Report 1149: Well Completion Report (PPL 38206, Engmann and Fenton, 1986). Solander-l was drilled in 1985, $31.5 \mathrm{~km}$ NNE of Solander Island and aimed to test for hydrocarbons in a fault bound anticline with a forecasted Eocene reservoir. The well reached a TD of 2017 m BRT in igneous basement after 24 days of drilling. There were no shows and logs showed that sandstones were water bearing. The well was plugged and abandoned as a dry hole.

\subsubsection{Solander-1 stratigraphy}

Table 2.4 summarises the chronostratigraphy of Solander-1, which is followed by lithologic descriptions. Fig. 2.4 outlines the well lithostratigraphy, chronostratigraphy and wireline logs.

\begin{tabular}{ccc}
\hline Chronostratigraphy & $\begin{array}{c}\text { Thickness } \\
(\mathrm{m})\end{array}$ & $\begin{array}{c}\text { Tops } \\
(\mathrm{m} \mathrm{BRT})\end{array}$ \\
\hline $\begin{array}{c}\text { Pliocene-Miocene } \\
\text { Kapitean }\end{array}$ & 689 & 178 \\
\hline Miocene & & \\
Waiauan & 172 & 867 \\
Lillburnian & 210 & 1039 \\
Clifdenian & 25 & 1249 \\
Altonian & 82 & 1274 \\
Otaian & 16 & 1356 \\
\hline Oligocene & & \\
Waitakian? & 455 & 1372 \\
Waitakian-Whaingaroan? & 144 & 1827 \\
\hline
\end{tabular}

Table 2.4: Solander-1 chronostratigraphic divisions. $m$ BRT $=$ metres below rotary table

\section{Pliocene - Miocene (178-1372 mBRT)}

This sequence consists of mostly calcareous mudstone and siltstone with an unconformity bound sandstone/conglomerate interval from 867-1039 mBRT. Mud and silt sequences above sands provide adequate seal rocks. Log analysis shows that the sands and conglomerates have good porosity and show evidence of permeability. 


\section{Oligocene (1372-1971 mBRT)}

The upper succession is a thin sandy limestone overlying a thick, pebbly sandstone sequence, the contact of which is probably conformable. Logs and cores indicate this sequence is very poor reservoir with low log porosities and negligible permeability. This sequence was deposited in a restricted shelf marine environment.

The lower succession comprises siltstone overlain by coal measures and basal conglomerate. Geochemical analysis suggests gas and condensate prone coals with some source potential, but the thin $2.75 \mathrm{~m}$ interval makes it insignificant. This sequence was deposited in a transitional environment with intermittent marine connection and includes reworked Eocene deposits.

\section{Basement (1971-TD)}

The upper part of the sequence consists of granite-granodiorite which shows evidence of weathering. At TD, the basement is dioritic.

\subsubsection{Solander-1 downhole observations}

Fig. 2.4 summarises the wireline log data obtained from Solander-1. Bit size, caliper width, cable tension, resistivity, sonic and spontaneous potential were plotted from the Solander-1 las file; gamma ray and bulk density were digitised from well log sheets. Similar to subsection 2.2.2, the Solander-1 well summary sheet compiled by NZP\&M enabled checkshot data (relative to the seafloor) to be calculated. A rotary table elevation of $26.8 \mathrm{~m}$, water depth of $79.4 \mathrm{~m}$, horizontal shot-well offset of $60 \mathrm{~m}$ and a shot depth of $10.6 \mathrm{~m}$ were used. Results are shown in Table 2.5. 


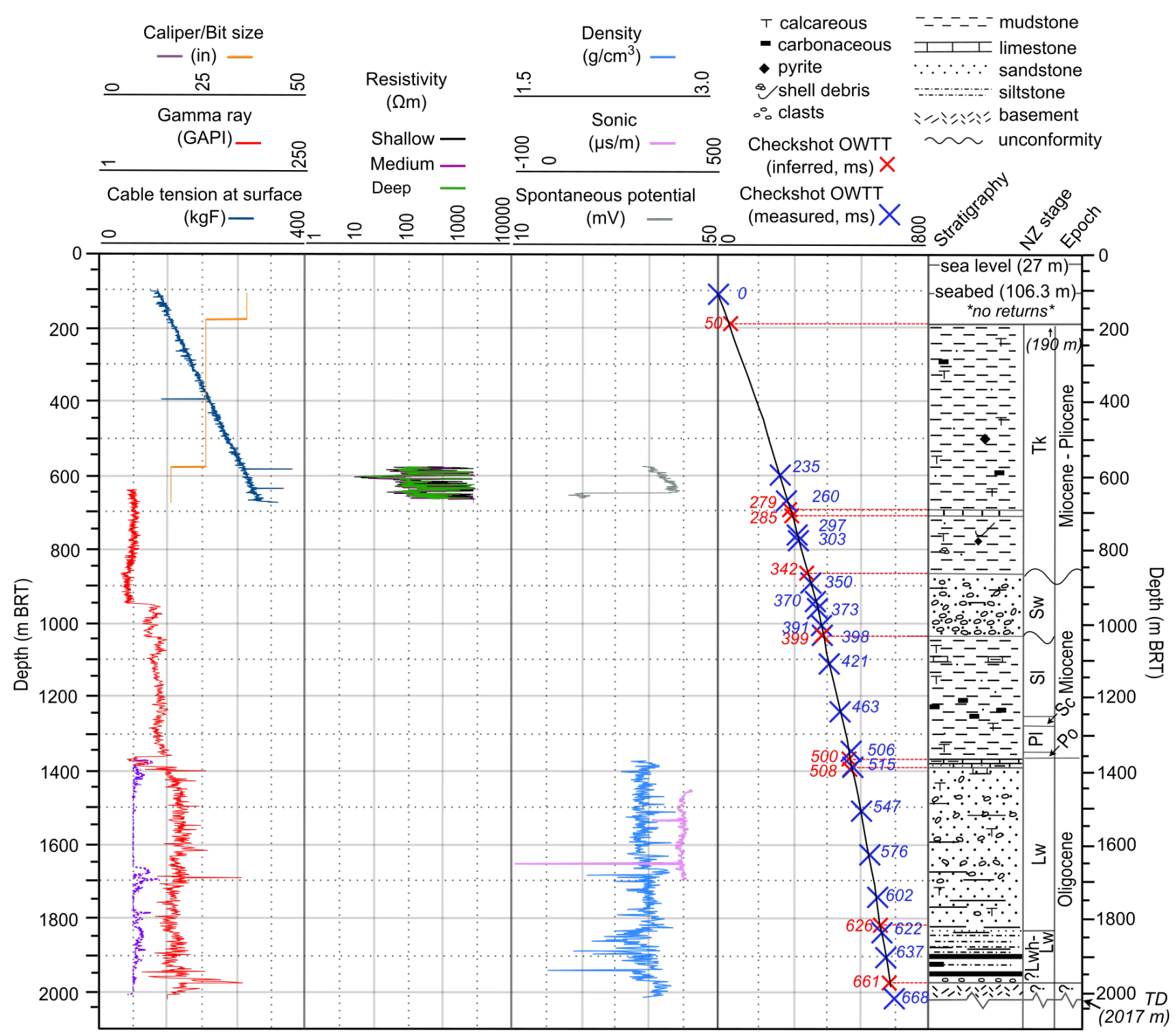

Fig. 2.4: Digitised wireline log data for Solander-1, sourced from Petroleum Report log enclosures of Engmann and Fenton (1986) and NZPEM. Travel times to checkshot data below the seafloor are plotted. Also shown is lithologic data with New Zealand stages and international age constraints provided from fossil records (note that these time scales were accurate at the time of data acquisition). A $3^{\text {rd }}$ order polynomial (Eqn. 2.4) has been fitted to checkshot data 


\begin{tabular}{ccccc}
\hline $\begin{array}{c}\text { Depth } \\
(\mathrm{m} \mathrm{BRT})\end{array}$ & $\begin{array}{c}\text { OWT } \\
(\mathrm{s})\end{array}$ & $\begin{array}{c}\text { Depth } \\
(\mathrm{m} \mathrm{bsf})\end{array}$ & $\begin{array}{c}\text { OWT } \\
(\mathrm{s} \mathrm{bsf})\end{array}$ & $\begin{array}{c}\text { Incidence angle } \\
\left({ }^{\circ}\right)\end{array}$ \\
\hline 106.2 & 0.064 & 0.0 & 0.025 & 38.9 \\
582 & 0.285 & 475.8 & 0.236 & 6.2 \\
655 & 0.309 & 548.8 & 0.260 & 5.5 \\
745 & 0.346 & 638.8 & 0.297 & 4.8 \\
765 & 0.353 & 658.8 & 0.304 & 4.7 \\
890 & 0.4 & 783.8 & 0.351 & 4 \\
950 & 0.42 & 843.8 & 0.370 & 3.7 \\
960 & 0.423 & 853.8 & 0.374 & 3.7 \\
1016 & 0.441 & 909.8 & 0.391 & 3.5 \\
1041 & 0.448 & 934.8 & 0.398 & 3.4 \\
1110 & 0.471 & 1003.8 & 0.421 & 3.2 \\
1235 & 0.513 & 1128.8 & 0.463 & 2.9 \\
1359 & 0.556 & 1252.8 & 0.506 & 2.6 \\
1390 & 0.565 & 1283.8 & 0.515 & 2.5 \\
1510 & 0.597 & 1403.8 & 0.547 & 2.3 \\
1625 & 0.626 & 1518.8 & 0.576 & 2.2 \\
1745 & 0.652 & 1638.8 & 0.602 & 2 \\
1834 & 0.672 & 1727.8 & 0.622 & 1.9 \\
1894 & 0.687 & 1787.8 & 0.637 & 1.8 \\
2017 & 0.718 & 1910.8 & 0.668 & 1.7 \\
\hline
\end{tabular}

Table 2.5: Calculated OWTs from the Solander-1 checkshot survey

A third order polynomial measuring OWTs from the seafloor is shown in Eqn. 2.3, and its derivative representing an interval velocity function below the seafloor (Eqn. 2.4) was calculated.

$$
\begin{aligned}
& \text { Depth }_{\mathrm{bsf}}=1610.4\left(t^{3}\right)+331\left(t^{2}\right)+1925.7(t) \\
& \frac{\partial \operatorname{Depth}_{\mathrm{bsf}}}{\partial t}=4831.2\left(t^{2}\right)+662(t)+1925.7
\end{aligned}
$$

As above, a time to depth conversion comparison, as well as interval velocities, are shown in Table 2.6. 


\begin{tabular}{ccccc}
\hline $\begin{array}{c}\text { Depth } \\
\text { (m bsf })\end{array}$ & $\begin{array}{c}\text { OWT } \\
\text { (s bsf })\end{array}$ & $\begin{array}{c}\text { Depth } \\
(\mathrm{m} \text { bsf, calc. })\end{array}$ & $\begin{array}{c}\Delta \text { Depth } \\
\text { (m obs. - proj. })\end{array}$ & $\begin{array}{c}\mathrm{V}_{\text {int }} \\
(\mathrm{m} / \mathrm{s}, \text { calc. })\end{array}$ \\
\hline 0 & 0.03 & 0.0 & 0.0 & 1656 \\
475.8 & 0.24 & 492.0 & -16.2 & 2462 \\
548.8 & 0.26 & 549.4 & -0.6 & 2553 \\
638.8 & 0.3 & 641.3 & -2.5 & 2694 \\
658.8 & 0.3 & 659.3 & -0.5 & 2721 \\
783.8 & 0.35 & 784.4 & -0.6 & 2901 \\
843.8 & 0.37 & 839.4 & 4.4 & 2976 \\
853.8 & 0.37 & 848.8 & 5.0 & 2989 \\
909.8 & 0.39 & 900.7 & 9.1 & 3057 \\
934.8 & 0.4 & 921.3 & 13.5 & 3084 \\
1003.8 & 0.42 & 990.5 & 13.3 & 3172 \\
1128.8 & 0.46 & 1123.5 & 5.3 & 3333 \\
1252.8 & 0.51 & 1269.0 & -16.2 & 3497 \\
1283.8 & 0.52 & 1300.7 & -16.9 & 3531 \\
1403.8 & 0.55 & 1417.3 & -13.5 & 3654 \\
1518.8 & 0.58 & 1528.2 & -9.4 & 3765 \\
1638.8 & 0.6 & 1632.1 & 6.7 & 3864 \\
1727.8 & 0.62 & 1714.9 & 12.9 & 3941 \\
1787.8 & 0.64 & 1778.8 & 9.0 & 3998 \\
1910.8 & 0.67 & 1915.8 & -5.0 & 4117 \\
\hline
\end{tabular}

std. dev. $=9.8 \mathrm{~m}$

Table 2.6: Calculated interval velocities for the Solander-1 well using Eqn. 2.4 
The difference in observed and calculated depths is plotted in Fig. 2.5. A standard deviation of $9.8 \mathrm{~m}$ and Fig. 2.5 indicate that the depth model created using the checkshot data is sound. However, structural complexities associated with Solander Anticline means the Parara timedepth model is preferred.

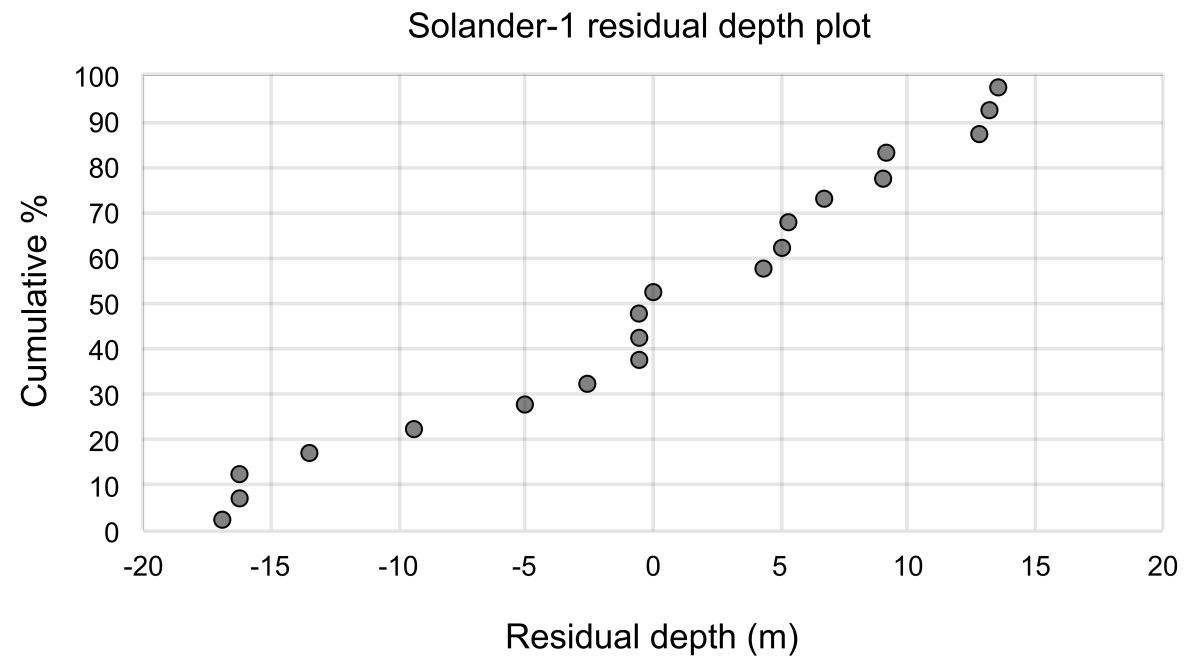

Fig. 2.5: Residual plot of observed less calculated depths from Equation 2.3

\subsection{Chapter Conclusion}

This chapter has covered the petroleum borehole data available in the offshore Fiordland region, where lithostratigraphy, chronostratigraphy and wireline log data have been summarised for both Solander-1 and Parara-1. For this thesis, data provided by Parara-1 well is integral to providing stratigraphic and chronostratigraphic correlations to MGL1803 seismic. Data from Solander-1 are less critical as correlations from this well along the newly acquired data are poor. 


\section{Chapter 3}

\section{Voyage EW9601a}

\subsection{Chapter Purpose}

This chapter details the acquisition parameters and re-processing sequence for "Line P1" of seismic research voyage EW9601a. Because Line P1 runs sub-perpendicular to the axis of Solander Basin, it allows for a cross-sectional view of the basin stratigraphy, when combined with seismic line M18-17b. Line P1 is the only previous high quality seismic line across Solander Trough, south of Stewart Island.

Firstly, background information regarding the acquisition of EW9601a is outlined. Prevoyage processing using GLOBE Claritas and onboard processing using Echos by Paradigm Geophysical is covered. Lastly, the result of this processing sequence is compared to the original processing provided by Melhuish et al. (1999). Acknowledgement is made to Wanda Stratford of GNS Science, who facilitated access to the raw data from EW9601a, and the science party members onboard MGL1803, who contributed to the additional onboard processing.

\subsection{Introduction to EW9601a}

The $640 \mathrm{~km}$ long survey EW9601a (Fig. 3.1) was conducted aboard the R/V Maurice Ewing in 1996. EW9601a aimed to constrain the crustal and upper mantle structure of the 
offshore region and to investigate plate motion partitioning (Melhuish et al., 1999). EW9601a is comprised of segments P1, P2 and P3 (Fig. 3.1). Line P1 is $302 \mathrm{~km}$ long and begins on the southern Stewart Island continental shelf and continues across the Solander Basin. The line then traverses the Puysegur-Fiordland subduction zone. Then, Line P2 continues along Resolution Ridge, and Line P3 concludes the survey west of Dagg Sound on the Fiordland coast. For this thesis, Line P1 will be used, as Lines P2 and P3 extend beyond the study area. Acquisition parameters for EW9601a are shown in Table 3.1. The processing sequence employed by Melhuish et al. (1999) is summarised in Appendix 2, Table 2A-1.

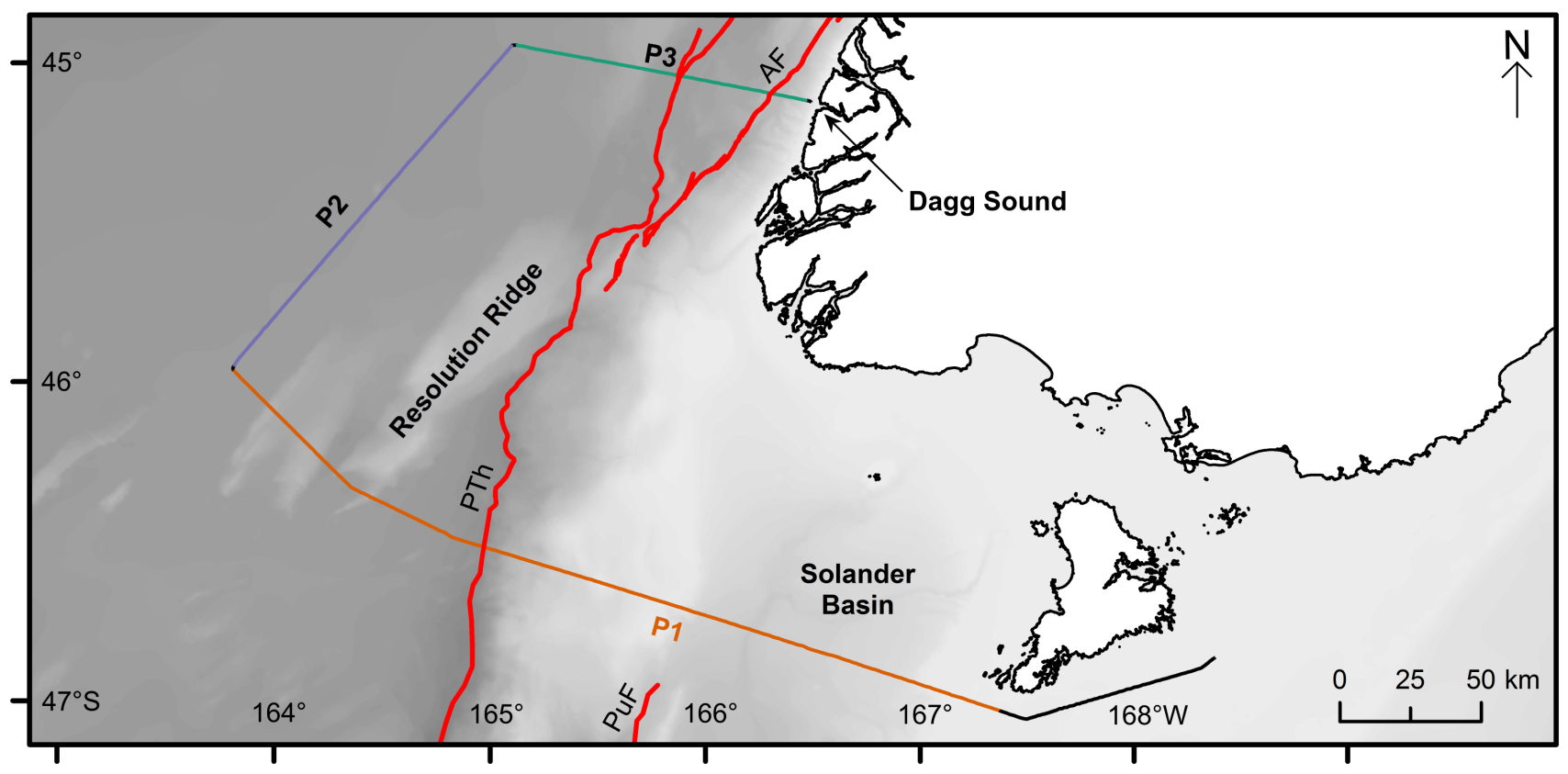

Fig. 3.1: Location of seismic survey EW9601a (black line), which comprises lines P1, P2 and P3. Line P1 is shown in orange (data prior to Line P1 were unavailable); this is the portion of EW9601a processed in this thesis. Solander Basin, Resolution Ridge and Dagg Sound are labelled for context. PTh=Puysegur Thrust, AF=Alpine Fault, PuF=Puysegur Fault 


\begin{tabular}{ll}
\hline \multicolumn{1}{c}{ Parameter } & \multicolumn{1}{c}{ Value } \\
\hline Record length & $16 \mathrm{~s}$ \\
Sample rate & $2 \mathrm{~ms}$ \\
Number of channels & 160 \\
Near offset & $25.9 \mathrm{~m}$ \\
Far offset & $4000.9 \mathrm{~m}$ \\
Group interval & $25 \mathrm{~m}$ \\
Shot interval & $25 \mathrm{~m}$ \\
Source array & $20 \mathrm{airguns}$ \\
Source volume & $8495 \mathrm{in}^{3}$ \\
Streamer tow depth & $8 \mathrm{~m}$ \\
\hline
\end{tabular}

Table 3.1: Acquisition parameters for EW9601 (see Sutherland and Melhuish, 2000, for full details)

\subsection{Pre-MGL1803: EW9601a Data Processing}

Line P1 raw data comprised individual segd files. Wanda Stratford of GNS Science provided these data. Also provided by Stratford were: a summary Excel sheet "4008923 DATA LIST.xls" containing reel numbers, start \& end FFIDs, and start \& end shot point numbers for each tape reel; and the cruise report for EW9601a. Transcription errors from the cruise report, where shot point ranges for certain reels were incorrectly documented, were identified and fixed. The cruise report outlined that Line P1 comprises reels 0603-0746. Though only reels 0637-0746 were available, they provide sufficient coverage for the aims of this thesis.

As part of initial data quality control, trace header information for segd files for Line P1 was examined. As per the acquisition parameters, there should only exist a maximum of 160 traces per shot (see Table 3.1). It was found that for a single shot, more than 160 channels were present in the dataset. This is illustrated in Fig. 3.2, where a GLOBE Claritas shot gather and associated header information are shown. 


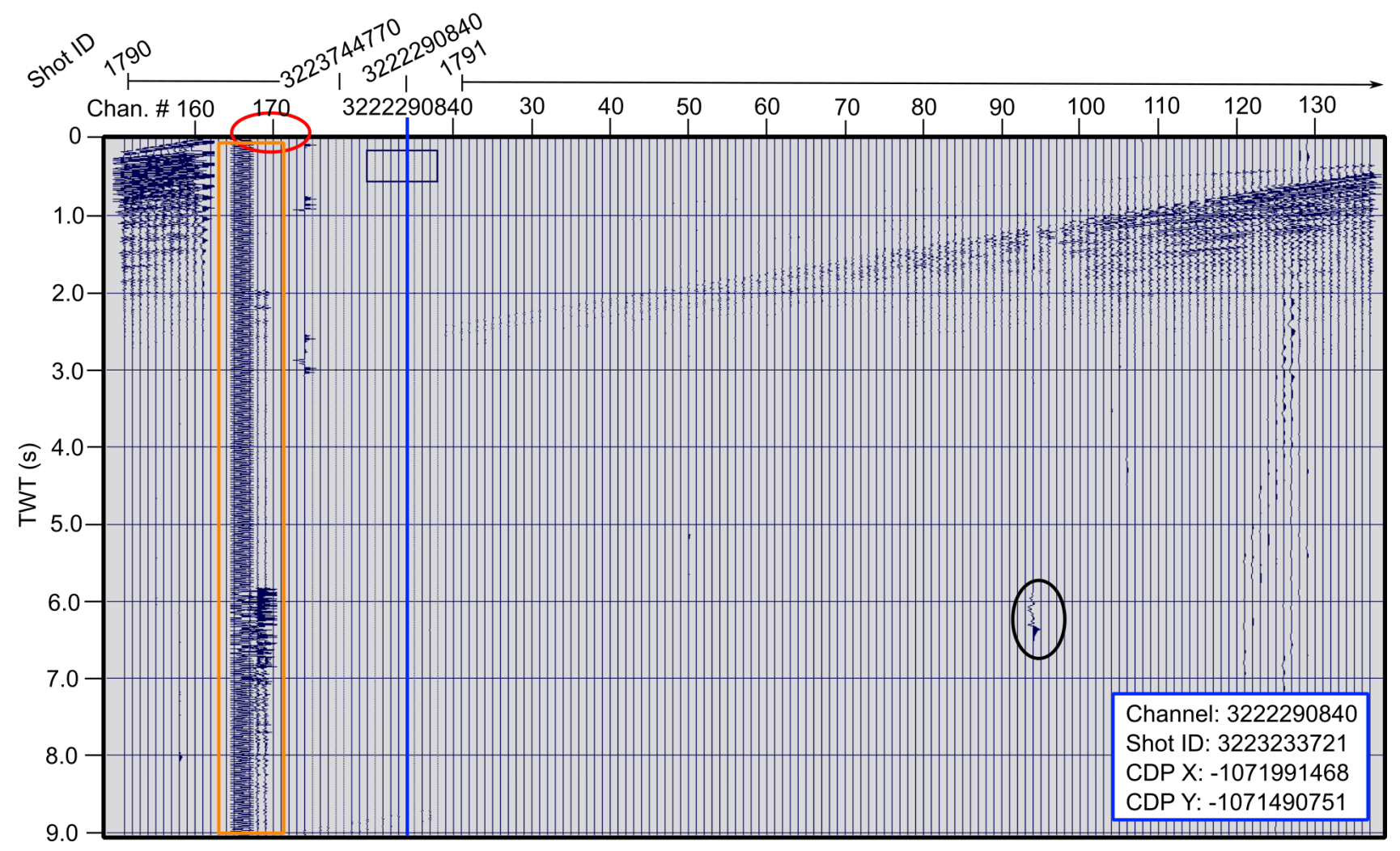

Fig. 3.2: Reel 0637 of Line P1 showing shots 1790-1791. Firstly, the total number of channels exceeds 160, as shown by the red circle. Data for channel numbers $>160$ may contain excessive noise (orange box). Some channels appear "normal"; however they have dubious trace header information such as CDP coordinates (see Channel 3222290840 - blue line; inset blue box). The black circle represents "spikiness" in Channel 94

This initial reading of shots shows that there are spurious auxiliary channels in the datasets. Similar flaws are present throughout other tapes. Therefore, before combining each tape into a single segd file, seismic job "EW9601_ prevoyage.job" was created in GLOBE Claritas to minimise this issue.

\subsubsection{Seismic job EW9601_prevoyage.job}

EW9601_prevoyage.job was applied to tape reels 0637-0746 for bad trace removal (see Table 3.2). With the knowledge that only 160 channels should exist for each reel, channels 2-161 were identified and kept (03 TREMOVE). Using header information for each shot and by examining each trace, any "non-data traces" were removed (04 TREMOVE). Running EW9601_prevoyage.job produced segd files (07 WRITESEGY), with the naming convention "Puysegur_xxxx_converted.sgy", where "xxxx" refers to the tape reel number. 
To identify further bad channels in the datasets, each rewritten segd file (i.e. Puysegur_xxxx_converted.sgy) was read into EW9601_prevoyage.job with only data reading jobs active (01 SEISJOB; 02 READSEGY and 06 XVIEW). Within each shot of a tape reel, "spiky" and noisy channels were identified. These channels, such as Channel 94, Fig. 3.2, were examined and logged. This process was repeated for tape reels 0637-0746. These channels were flagged for later removal during MGL1803.

After completing channel identification, the terminal command "ls *.sgy > Line_P1.sfl" inserted each segy file into an .sfl file (a Claritas readable list file). This command enabled all tapes to be read by Claritas simultaneously. Subsequently, these reels were run through a job "EW9601_shot_writesegy.job" (see Table 3.3). This job first reads in the list comprising each tape reel, then produces the segy file "EW9601_p1_shots.sgy". This file is the final version that was processed during MGL1803.

\begin{tabular}{ll}
\hline \multicolumn{1}{c}{ Module name } & \multicolumn{1}{c}{ Job: EW9601_prevoyage.job } \\
\hline 01 SEISJOB & Defines project name, line name etc. \\
02 READSEGY & Reads in Line_P1.sf \\
03 TREMOVE & Keeps traces 2-161 \\
04 TREMOVE & Removes traces where trace type $\neq 1$ \\
05 SETLASTTR & Sets last trace flag for the last trace of a shot as ShotID \\
06 XVIEW & Interactive seismic display \\
07 WRITESEGY & Writes a segy output as "Puysegur_xxx__converted.sgy" \\
\hline
\end{tabular}

Table 3.2: Explanation of modules employed in EW9601_prevoyage.job. See Table 2A-2 for module parameters 


\begin{tabular}{lc}
\hline \multicolumn{2}{c}{ Job: EW9601_shot_writesegy.job } \\
\hline \multicolumn{1}{c}{ Module Name } & \multicolumn{1}{c}{ Module Description } \\
\hline 01 SEISJOB & Defines project name line name etc. \\
02 READSEGY & Reads segy formatted recording data from list file \\
03 WRITESEGY & Writes a combined segy output as "Line_P1.sgy" \\
\hline
\end{tabular}

Table 3.3: Explanation of modules used in EW9601_shot_writesegy.job. See Table 2A-3 for module parameters

\subsection{Line P1: MGL1803 Processing Sequence}

During MGL1803, EW9601_p1_shots.sgy was processed with Echos software by Paradigm Geophysical. Processing was completed with shell scripts compiled by Steffen Saustrup of UTIG. In some cases, including velocity analysis, scripts were run manually. Each script created an Echos processing job that could also be run manually. The following sections outline the processing steps.

\subsubsection{Geometry and GIN}

The job "ew9601_geometry.dat" reads in segy data and assigns geometry to the dataset. In this job, the "MKDATA" module records the sample rate and record length. Furthermore, the "MARINE" module accounts for 2D seismic marine geometry and records the survey's acquisition parameters. These modules are summarised in Table 3.4.

Further trace information is read in by "GIN" within the job "ew9601-p_gin.dat". The module "DSOUT" writes the data in shot format. This job is shown in Table 3.5.

\subsubsection{Trace editing, deconvolution, sorting}

In addition to trace editing in Section 3.3.1, further trace editing is achieved in the job "ew9601_p1c_edit_decon_sort.dat" using the "EDIT" module. This next step of trace editing is more rigorous, where each shot for Line P1 was examined and spurious channels identified. 


\begin{tabular}{cc}
\hline & \multicolumn{1}{c}{ Job: ew9601_geometry.dat } \\
\hline Module Name & \multicolumn{1}{c}{ Module Description } \\
\hline MKDATA & $\begin{array}{l}\text { Reads in data recording parameters (record length, } \\
\text { trace offsets, receiver/shot spacing etc.) }\end{array}$ \\
\hline MARINE & $\begin{array}{l}\text { Assigns acquisition geometry to data } \\
\text { (channel \#, channel spacing, shot spacing etc.) }\end{array}$ \\
\hline
\end{tabular}

Table 3.4: List of modules in the geometry job. See Table 2A-4 for module parameters

\begin{tabular}{cl}
\hline \multicolumn{1}{c}{ Job: GIN } \\
\hline Module Name & \multicolumn{1}{c}{ Module Description } \\
\hline GIN & $\begin{array}{l}\text { Reads in trace information of seismic data from } \\
\text { tape reels }\end{array}$ \\
\hline DSOUT & Writes a segy shot output "ew9601-p1c_shots.segy" \\
\hline
\end{tabular}

Table 3.5: List of modules in the GIN job. See Table 2A-5 for module parameters

This is particularly important as this job also involves deconvolution and sorting, which are heavily affected by poor traces. Table 3.6 details modules of note within this job; a full list of modules is shown in Table 2A-6.

Using "FILTER", a Butterworth filter was applied to the data. Data were then resampled ("RESAMP"). "GAIN" allows for amplitude recovery at depth. Two iterations of gap deconvolution (gap lengths of 75 and $24 \mathrm{~ms}$ provided suitable results) are then implemented using "MCDECON". Data could then be sorted into CDPs using "SORT". A segy file containing these sorted data was then produced using "DSOUT". 


\begin{tabular}{cl}
\hline & \multicolumn{1}{c}{ Job: ew9601_p1c_edit_decon_sort.dat } \\
\hline Module Name & \multicolumn{1}{c}{ Module Description } \\
\hline DSIN & $\begin{array}{l}\text { Inputs seismic data from "ew9601-p1c_shots } \\
\text {.segy" }\end{array}$ \\
\hline EDIT* & $\begin{array}{l}\text { Flags and removes channels for a given shot, or } \\
\text { removes channels for a given CDP }\end{array}$ \\
\hline FILTER & $\begin{array}{l}\text { Applies a 5-85 Hz Butterworth filter to the data, } \\
\text { with 2 db/octave tapering }\end{array}$ \\
\hline RESAMP & Resamples the data from 2 ms to 4 ms \\
\hline GAIN & Applies a t t.5 spherical divergence correction to the data \\
\hline MCDECON & $\begin{array}{l}\text { Applies predictive deconvolution, with a gap length=75/ } \\
24 \text { ms, operator length=450 ms, design window=3500 ms } \\
\text { and application window of 0-16 s }\end{array}$ \\
\hline SORT & Sorts data to CDPs, with 200 traces/CDP \\
\hline DSOUT & Writes a segy sorted output "ew9601-p1c_decon_cdps.sgy" \\
\hline
\end{tabular}

Table 3.6: Explanation of key modules used in "ew9601_p1c_edit_decon_sort.dat" job. *The "EDIT" module removes numerous shot-channel and channel-CDP pairs - see the link in Table 2A-6 and for module parameters

Fig. 3.3 shows an example of bad channels in a shot gather. If bad traces are not removed, they produce unwanted artefacts that appear as vertical "stripes" in a migrated section (Fig. 3.4 ), which obscures primary reflections. This results in a lower quality migrated section. 


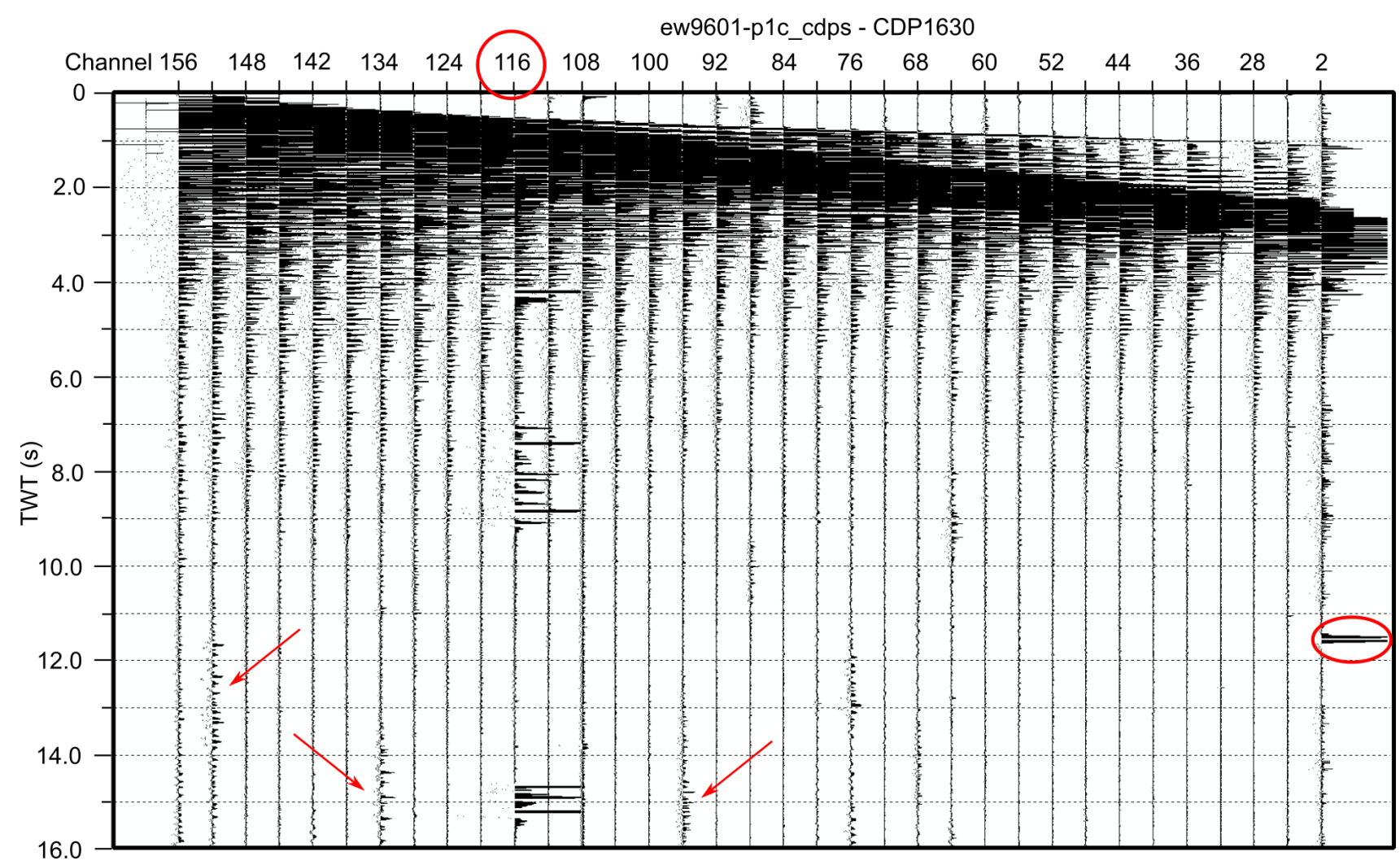

Fig. 3.3: Examples of spiky and noisy channels for CDP 1630 on Line P1. Spiky and noisy channels are circled and arrowed (channels 2, 96, 116, 134 and 154) 


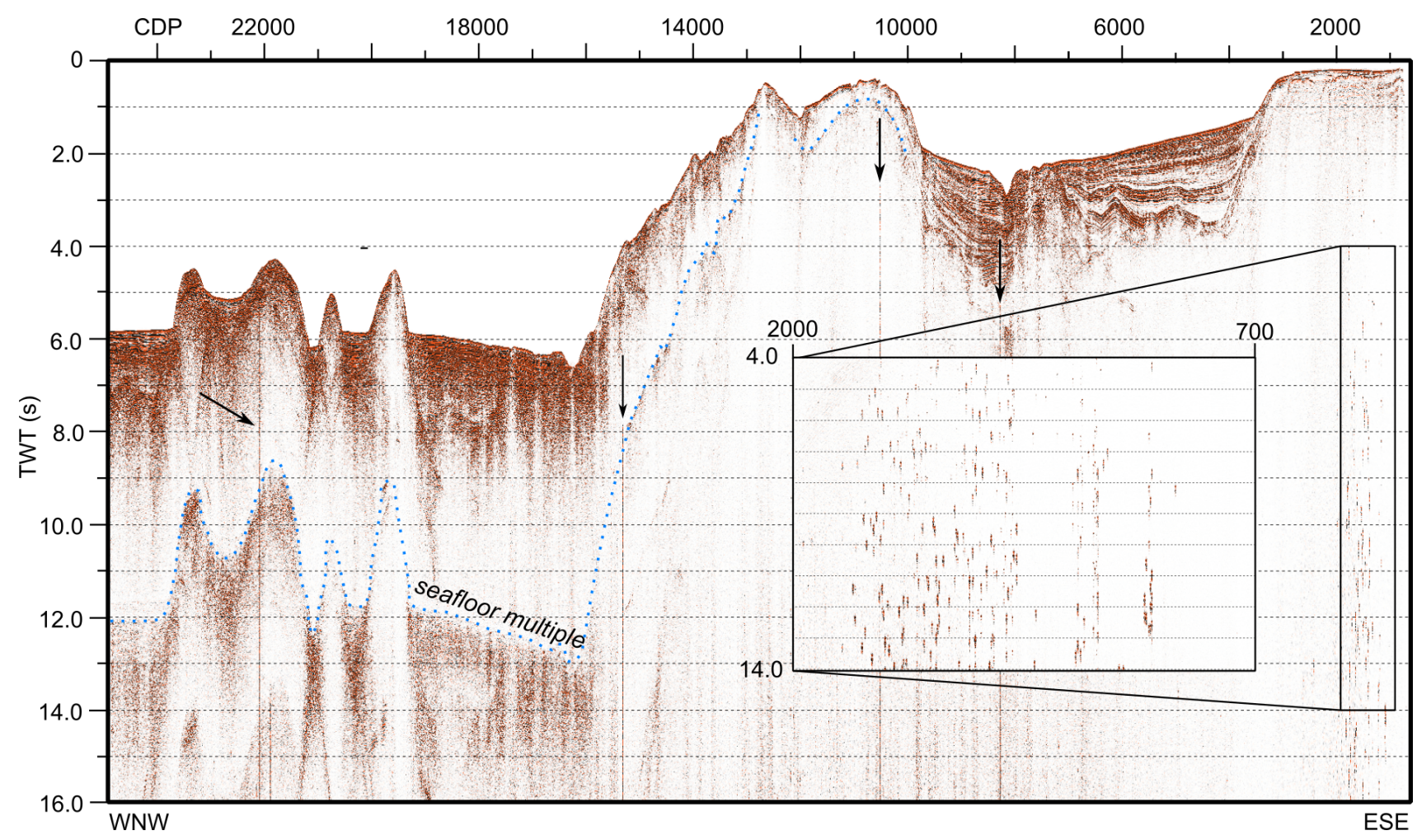

Fig. 3.4: FK migrated section of seismic Line P1 showing artefacts in the stacked section (arrowed). A zoom in on these artefacts is shown inset. These artefacts result from improper trace removal, indicating that there are still suspect traces present in the data

Though the artefacts in Fig. 3.4 appear minor, they affect imaging at depth and also present a problem when scaling the data and for later migration. In Echos, traces were able to be removed for certain CDPs e.g. channel 154 in Fig. 3.3; they could also be removed from all CDPs in the dataset e.g. channel 116 in Fig. 3.3. Random noise like channel 154 was cause for removal from specific CDPs, whereas consistently damaging traces like channel 116 warranted complete removal. Table $2 \mathrm{~A}-6$ in Appendix 2 provides a URL to a file containing all traces removed. 


\subsubsection{Velocity picking}

A robust velocity model for stacking purposes was then produced. The job "ew9601p_velocity.dat" reads in 15 CDPs simultaneously and calculates a single semblance plot ("DSIN"), increasing the signal:noise and allowing for greater confidence in picks. Picks were made every 200 CDPs, or every $2.5 \mathrm{~km}$. A Butterworth filter ("FILTER") and an automatic gain control ("AGC") were employed to aid picks. The job then saves the velocity model picked ("VELDEF"). This information is shown in Table 3.7. Fig. 3.5 shows the velocity model picked.

\begin{tabular}{cl}
\hline & \multicolumn{1}{c}{ Job: ew9601-p_velocity.dat } \\
\hline Module Name & \multicolumn{1}{c}{ Module Description } \\
\hline DSIN & $\begin{array}{c}\text { Inputs 15 CDPs from "ew9601-p1c } \\
\text { _decon_cdps.sgy" }\end{array}$ \\
\hline FILTER & $\begin{array}{l}\text { Applies a 5-35 Hz Butterworth filter to the data, } \\
\text { with 3 db/octave tapering }\end{array}$ \\
\hline AGC & Applies a scaling gain to the dataset \\
\hline VELDEF & $\begin{array}{l}\text { Allows for velocity model picking, and outputs a } \\
\text { velocity file "stacking_stef" }\end{array}$ \\
\hline
\end{tabular}

Table 3.7: Explanation of modules used in "ew9601-p_velocity.dat". See Table 2A-7 for module parameters 


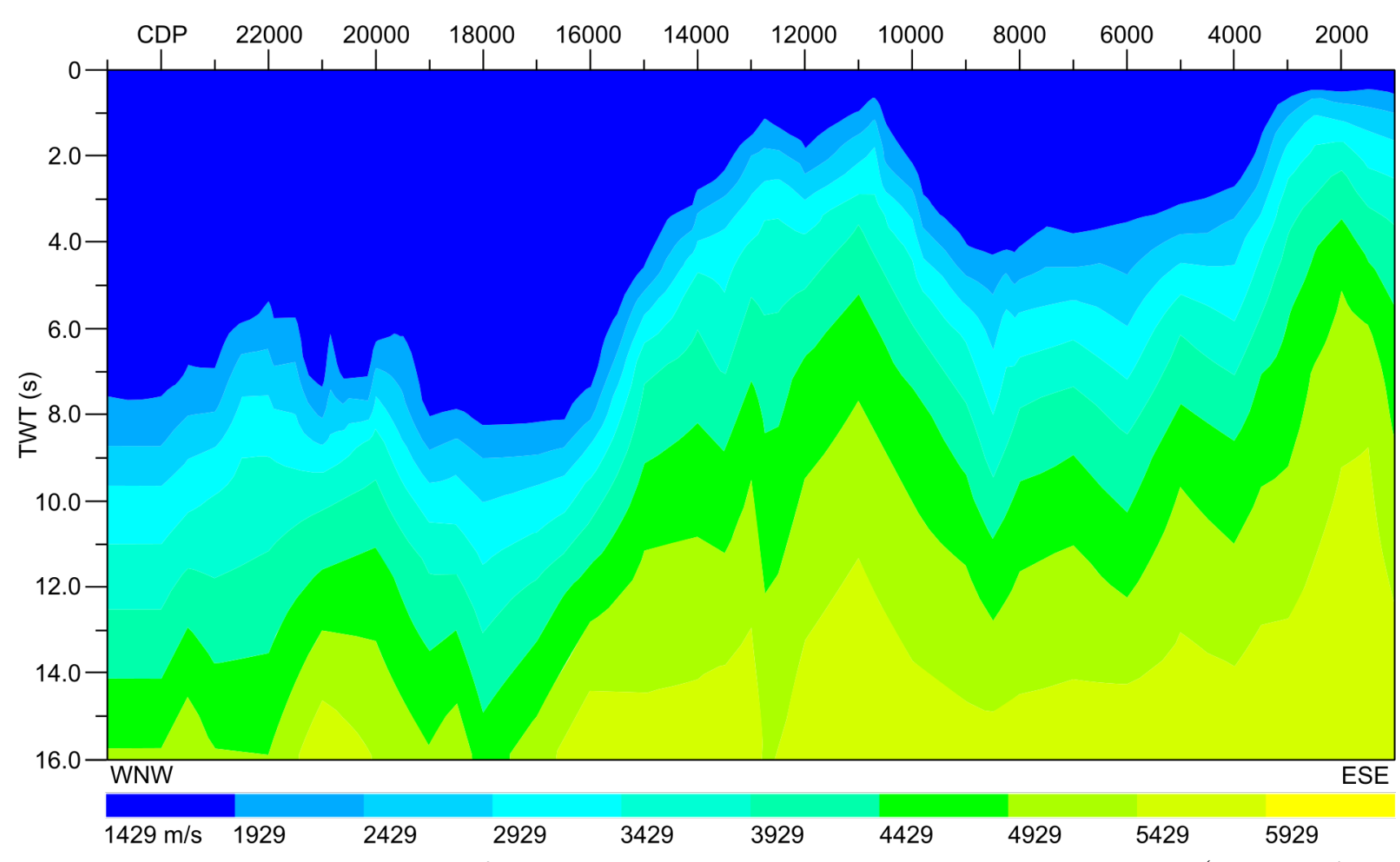

Fig. 3.5: Velocity model picked for Line P1, using the job ew9601-p_velocity.dat (adapted from Echos velocity picking tool)

\subsubsection{Radon demultiple}

Multiple attenuation can be attempted with radon demultiple. A complementary multiple removal method, it is particularly useful if any multiples are not removed by stacking. Radon demultiple is achieved with the job "ew9601-radonstack.dat". In this job, "DSIN" inputs "ew9601-p1c_decon_cdps.sgy", and "NMO" reads in the stacking velocity model. NMO is applied using "NMO OVCAPP", with an overcorrection applied (OVCAPP) to aid multiple removal. NMO is required by Echos prior to forward radon parabolic transformation, which is applied using "RADNPAR". "DSOUT" then outputs "EW9601_p1_radon_cdps". Table 3.8 details the modules and parameters used to achieve this. Note that stacking is completed in the subsequent migration job. 


\begin{tabular}{cl}
\hline \multicolumn{2}{c}{ Job: ew9601-radonstack.dat } \\
\hline Module Name & \multicolumn{1}{c}{ Module Description } \\
\hline DSIN & $\begin{array}{l}\text { Inputs "ew9601-p1c_steffen_decon_- } \\
\text { cdps.sgy" }\end{array}$ \\
\hline NMO & Input velocity model "stacking_stef" \\
\hline NMO OVCAPP & $\begin{array}{l}\text { Applies NMO, and an overcorrection } \\
\text { to aid multiple removal }\end{array}$ \\
\hline RADNPAR & Applies forward radon demultiple \\
\hline GOUT & $\begin{array}{l}\text { Outputs a segy file "EW9601 } \\
\text { _p1.radon.cdps.segy" }\end{array}$ \\
\hline
\end{tabular}

Table 3.8: Explanation of modules used in "ew9601-radonstack.dat". See Table 2A-9 for module parameters

\subsubsection{Migration}

The job "ew9601-steffen_radonstack.dat" applies an FK migration. Firstly, the spherical divergence correction was removed with the "GAIN" module. The velocity model was then applied and the data stacked using "STACK". The "FILTER" module applied a series of Butterworth filters, with different time ranges and frequency bands. Next, the "MIGDMO" module applies an FK migration to the dataset. This form of migration applies a constant velocity (in this case $1500 \mathrm{~m} / \mathrm{s}$ ) in the FK domain. A $1000 \mathrm{~ms} \mathrm{AGC} \mathrm{was} \mathrm{then} \mathrm{applied} \mathrm{to} \mathrm{the} \mathrm{data} \mathrm{to} \mathrm{scale}$ the final output, which is then written to a segy file "EW9601-p1c.decon.radon.fkmig.agc.segy" with the "GOUT" module. These parameters and values are shown in Table 3.9. 


\begin{tabular}{cl}
\hline & Job: ew9601-steffen_radonstack.dat \\
\hline Module Name & \multicolumn{1}{c}{ Module Description } \\
\hline DSIN & Inputs "EW9601_p1.radon.cdps.segy" \\
\hline GAIN & Removes and applies spherical divergence correction \\
\hline NMO & Input velocity model"stacking_stef" \\
\hline MUTE & NMO stretch and inside mute application \\
\hline STACK & Stacks traces in the dataset \\
\hline MUTE & NMO stretch and inside mute re-application \\
\hline FILTER & $\begin{array}{l}\text { Applies Butterworth filters, for a range of frequencies } \\
\text { and time windows }\end{array}$ \\
\hline MIGDMO & Post-stack FK dip moveout migration \\
\hline AGC & 1000 ms sliding window AGC, for final scaling \\
\hline GOUT & $\begin{array}{l}\text { Outputs a final segy file "EW9601-p1c.decon. } \\
\text { radon.fkmig.agc.segy" }\end{array}$ \\
\hline
\end{tabular}

Table 3.9: Explanation of modules in "ew9601-steffen_radonstack". See Tables 2A-9, 2A-9 and 2A-9 for module parameters

\subsection{Comparison of Processing Results}

A key difference between the processing results from Melhuish et al. (1999) and MGL1803 processing is the marked improvement in data quality in the newly processed line. Reflections in the Melhuish et al. (1999) section (Fig. 3.6) suffer from relatively low amplitudes, making small scale features more difficult to resolve. For example, at CDP 4500-4900 in Fig. 3.6, at approximately $2.5 \mathrm{~s}$ TWT, strata appear to be continuous and of similar amplitude. However, the equivalent location from MGL1803 processing (Fig. 3.7) reveals that these strata are actually more chaotic and more variable in amplitude. The same comparison can be made to the east of the basin, where internal stratigraphy is much better resolved in Fig. 3.7 than Fig. 3.6. Migration also resolves steeper dips more accurately with less diffracted energy in the MGL1803 section. However, one aspect where the original section is slightly better than the newer section is that multiple energy is more suppressed. Despite this, the section processed onboard MGL1803 is an overall superior quality output. 


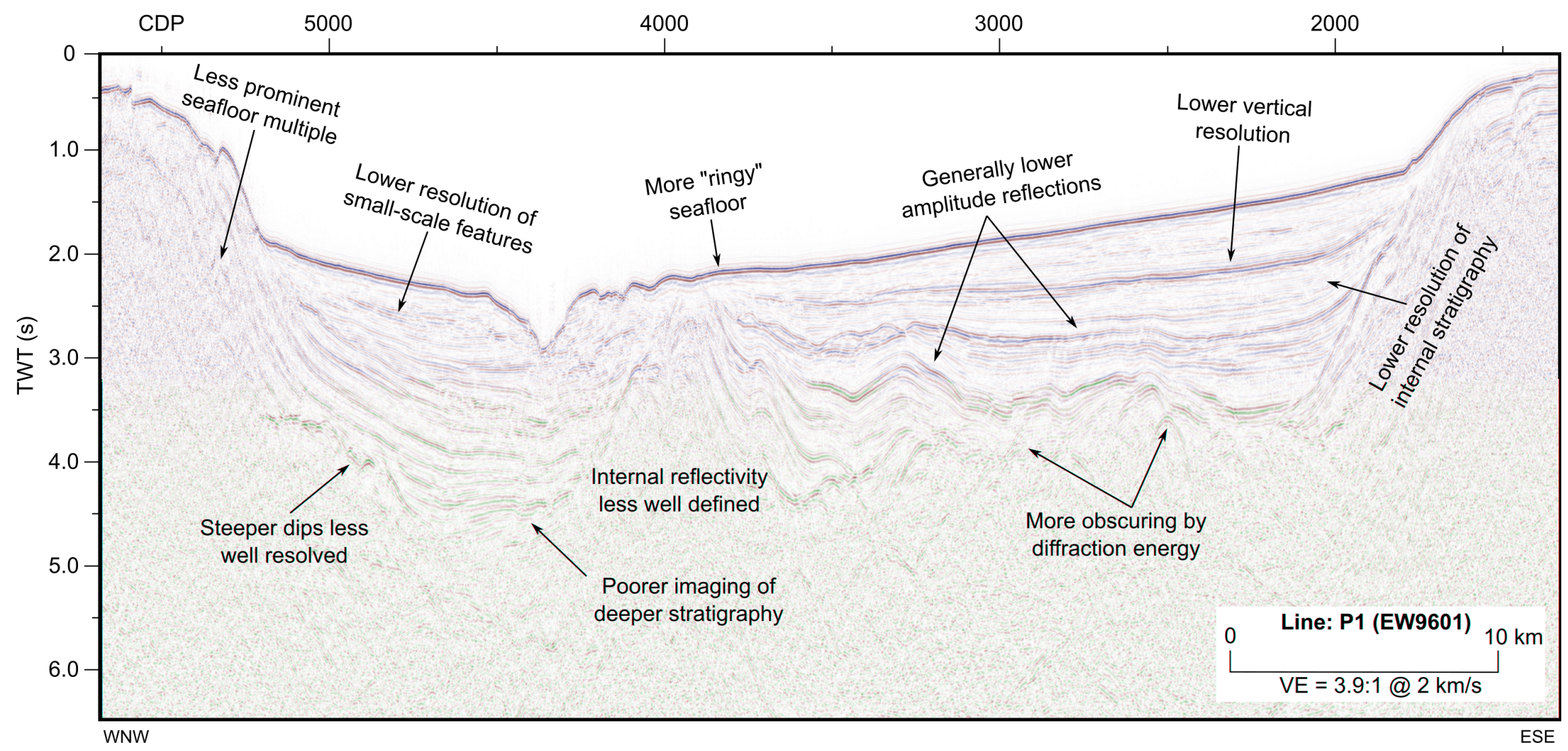

Fig. 3.6: Processed segment of Line P1, processed by (Melhuish et al., 1999, see Table 2A-1 for processing sequence). Labelled are areas of comparison to Fig. 3.7 


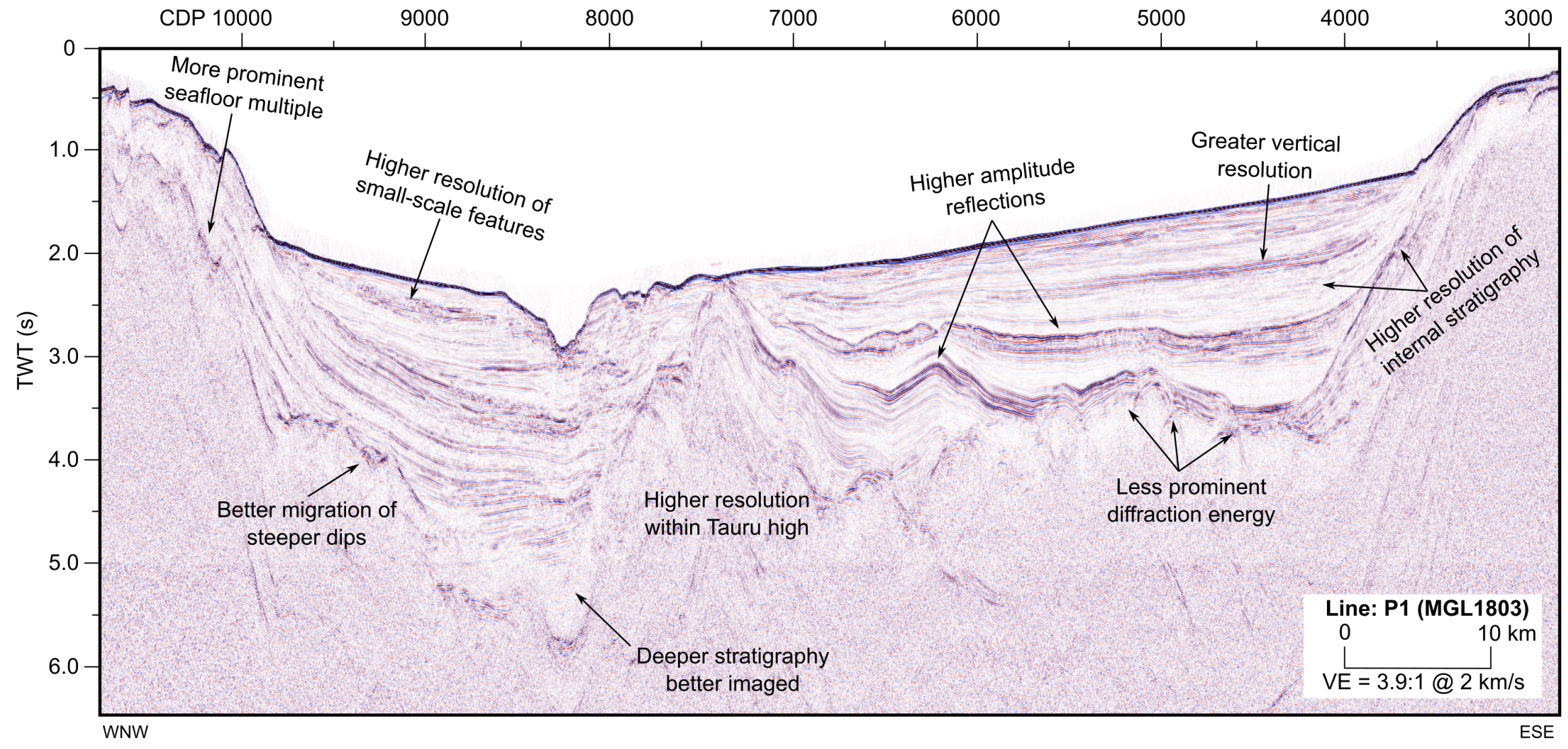

Fig. 3.7: Processed segment of Line P1, processed aboard MGL1803 (see section 3.4). Labelled are areas of comparison to Fig. 3.6 


\subsection{Chapter Conclusion}

This chapter has summarised pre-voyage and onboard processing of Line P1 from EW9601a. Pre-MGL1803 trace editing was employed, with onboard processing including geometry definition, further trace editing, resampling, filtering deconvolution, stacking, migration and scaling for final output. This reprocessing has yielded an output of higher quality than that of the original processing by Melhuish et al. (1999). 
Voyage EW9601a 


\section{Chapter 4}

\section{Voyage MGL1803}

\subsection{Background Information}

A key objective of voyage MGL1803 was the acquisition and processing of 2D seismic reflection data. These data are beneficial for providing the first stratigraphic correlations from Solander Trough to the shallow water petroleum industry seismic reflection and well data in the north. Interpretations of these data will also assist researchers at UTIG and CalTech for further research such as subduction zone initiation. This section outlines the acquisition and onboard processing of these MGL1803 seismic reflection data. I thank fellow science party members for their contribution to processing.

\subsubsection{Summary of MCS data}

Locations of all seismic reflection lines are shown in Fig. 4.1 below. Highlights included lines M18-17c, M18-17b, M18-01, M18-23ab and M18-14, which provided a tie from Parara-1 to strata at Puysegur Ridge at the western edge of line M18-14. This map also shows the proposed 2D survey versus actual coverage of MGL1803 seismic data. In total, $1265.21 \mathrm{~km}$ of data were acquired. 

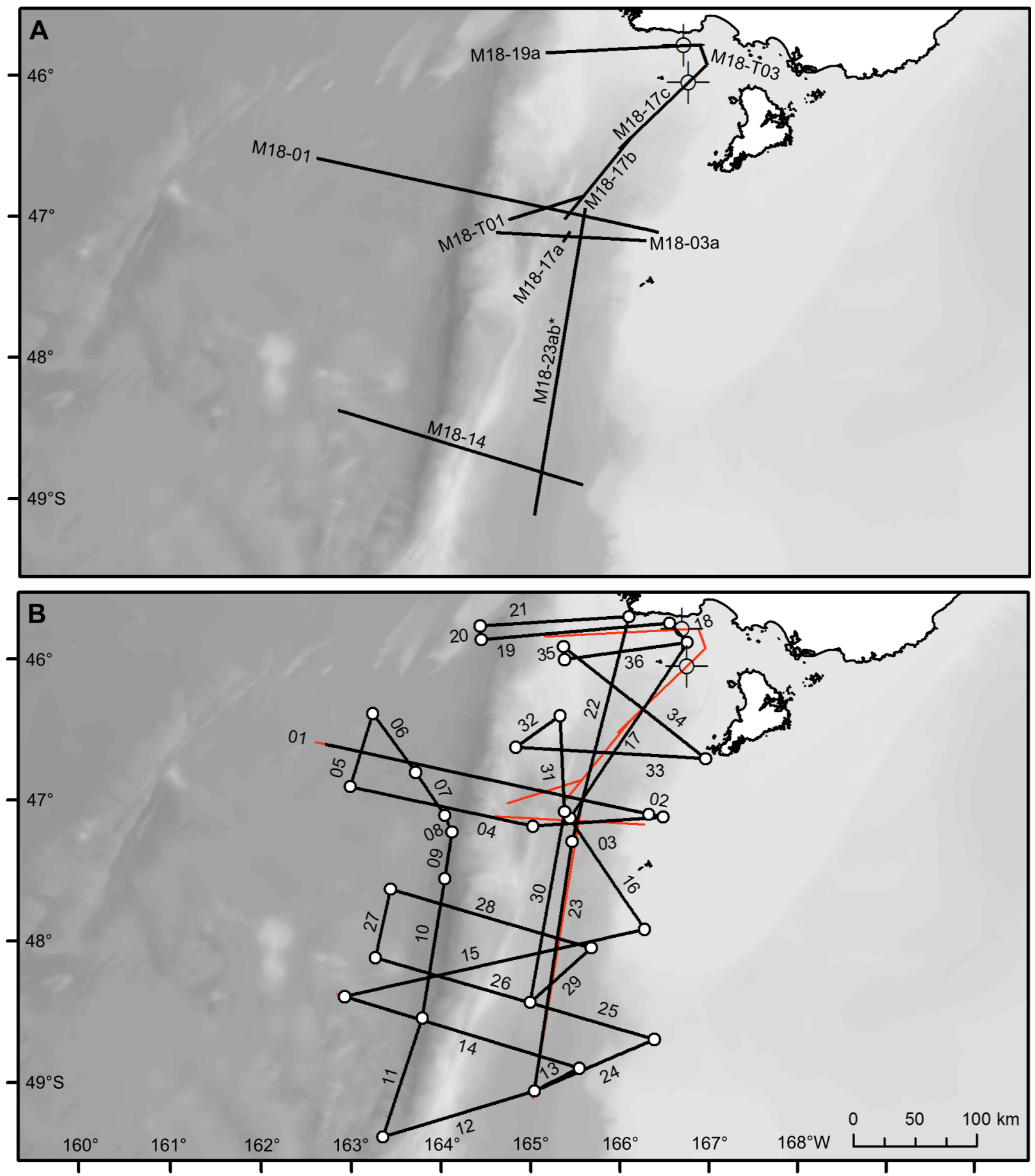

Fig. 4.1: Actual (Panel A, coverage=1265.21 km) vs. proposed (Panel B, coverage=4348.89 $\mathrm{km}$ ) location of $2 D$ seismic lines for voyage MGL1803. For comparison, actual seismic acquired is shown in red in Panel B. Labelled are Parara-1 and Solander-1, both dry and abandoned petroleum wells (see Fig. 2.1). M18-23ab*: indicates this line was acquired as two separate lines (M18-23a and M18-236), and has been processed as a single line 
The proposed 2D MCS lines totalled $4934 \mathrm{~km}$. The $70 \%$ reduction in seismic data coverage was mostly due to weather, amid fears of equipment damage and health and safety concerns. The first weather delay occurred on 24-02-2018, where $~ 18$ hours were spent on the lee side of Auckland Island. The most significant weather delay was spent from 11-03-2018 to 16-03-2018, sheltering behind Stewart Island from 4-11 m swells and 25-40 knot winds. Though depleted, the seismic reflection data acquired provide unique downdip imagery of Solander Trough; ties to Puysegur Ridge enable a new stratigraphic and tectonic history to be defined (see Chapter 6).

\subsection{Seismic Data Acquisition Parameters}

The following sections outline acquisition parameters for each of the seismic lines shot in Fig. 4.1 above.

\subsubsection{Seismic source}

Source for MGL1803 consisted of four sub-arrays, each containing 9 active guns and one backup gun. Each sub-array comprised 1,650 in ${ }^{3}$, for a total of 6,600 $\mathrm{in}^{3}$ for all 36 guns. For M18-17b however, shotpoints 29466-29718 were only shot with arrays 1 \& 2, totalling 3120 in $^{3}$. Shot interval was $50 \mathrm{~m}$, with a 14-16 s record length allowing for deep crust and upper mantle imaging. The seismic source was towed at $9 \mathrm{~m}$ depth with the aid of flotations. This was monitored using depth indicators, as well as acoustic transponders on each sub-array. To help maintain this depth, vessel speed was kept at 4-5 knots; this speed also minimised cable tension. The source array was towed at a distance of $220 \mathrm{~m}$ from the stern. The array and flotations are shown in Fig. 4.2, Panels A and B. 


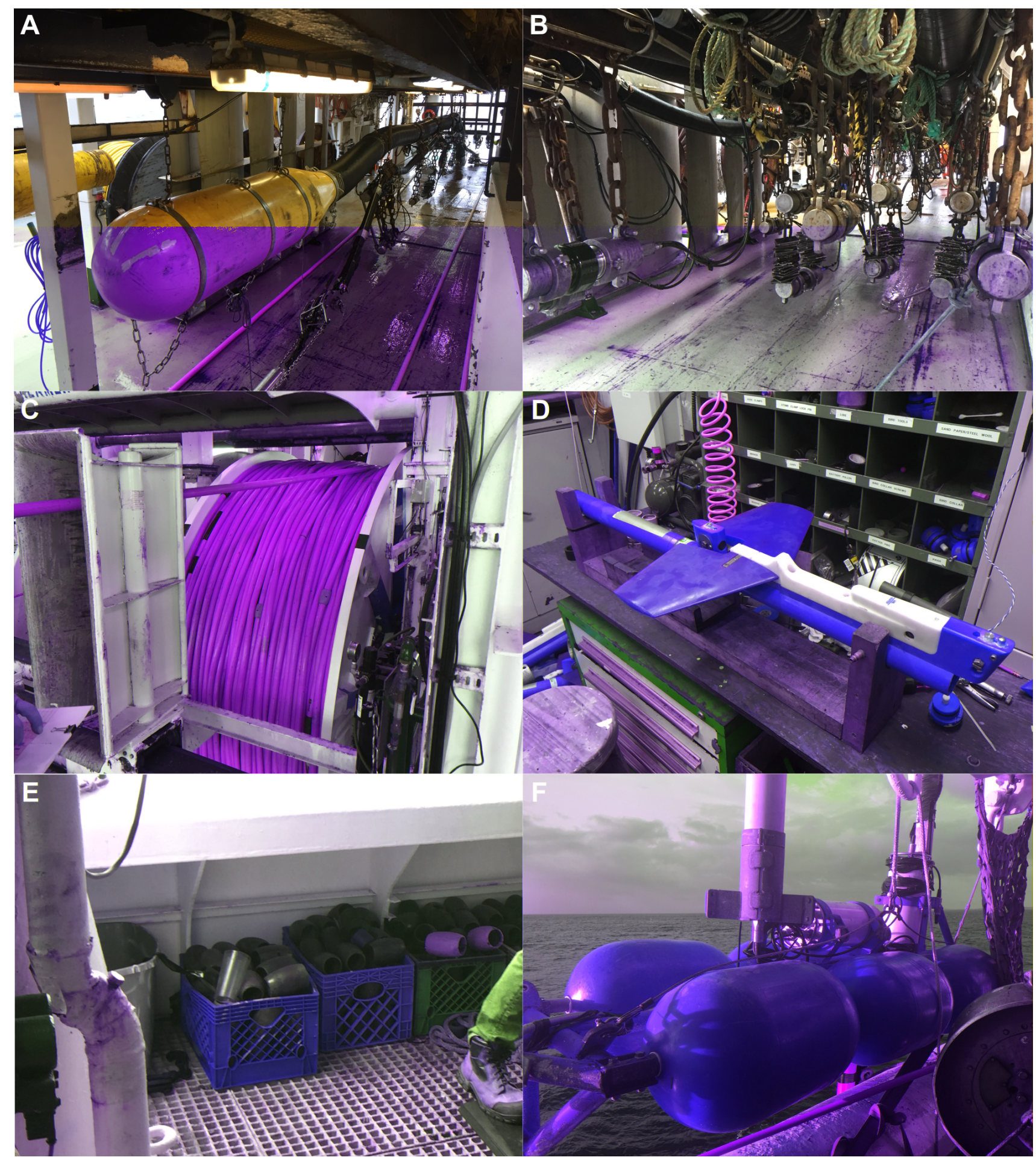

Fig. 4.2: Seismic acquisition equipment used during MGL1803. Air gun array flotation devices (Panel A), air gun array (Panel B), seismic streamer (Panel C), streamer bird (Panel D), streamer weights (Panel E) and tail buoy (Panel F) 


\subsubsection{Seismic streamer}

A single streamer cable was run during MGL1803. This cable was either $12 \mathrm{~km}$ or $4 \mathrm{~km}$ long, where a $4 \mathrm{~km}$ streamer was used after M18-23b due to inclement weather, which would have severely damaged the cable. A $4 \mathrm{~km}$ streamer takes much less time to deploy and recover, given an average deployment and recovery rate of $1 \mathrm{~km} / \mathrm{h}$. Streamer depth was changed from $9 \mathrm{~m}$ to $18 \mathrm{~m}$ to reduce swell noise (Table 4.1). Each streamer contained compass birds and weights, for maintaining streamer depth and providing weight to prevent resurfacing of the streamer respectively. A tail buoy attached to the end of the streamer provided flotation but also provided positioning via GNSS, and contained an acoustic transponder to communicate with the guns and the ship's bridge. The above equipment is shown in Fig. 4.2.

\subsubsection{Summary acquisition parameters}

This section outlines the source and streamer acquisition parameters for MGL1803. Fig. 4.3 summarises the source-streamer configuration for MGL1803. Table 4.1 shows source and streamer acquisition parameters for each of the 2D seismic lines acquired on MGL1803.

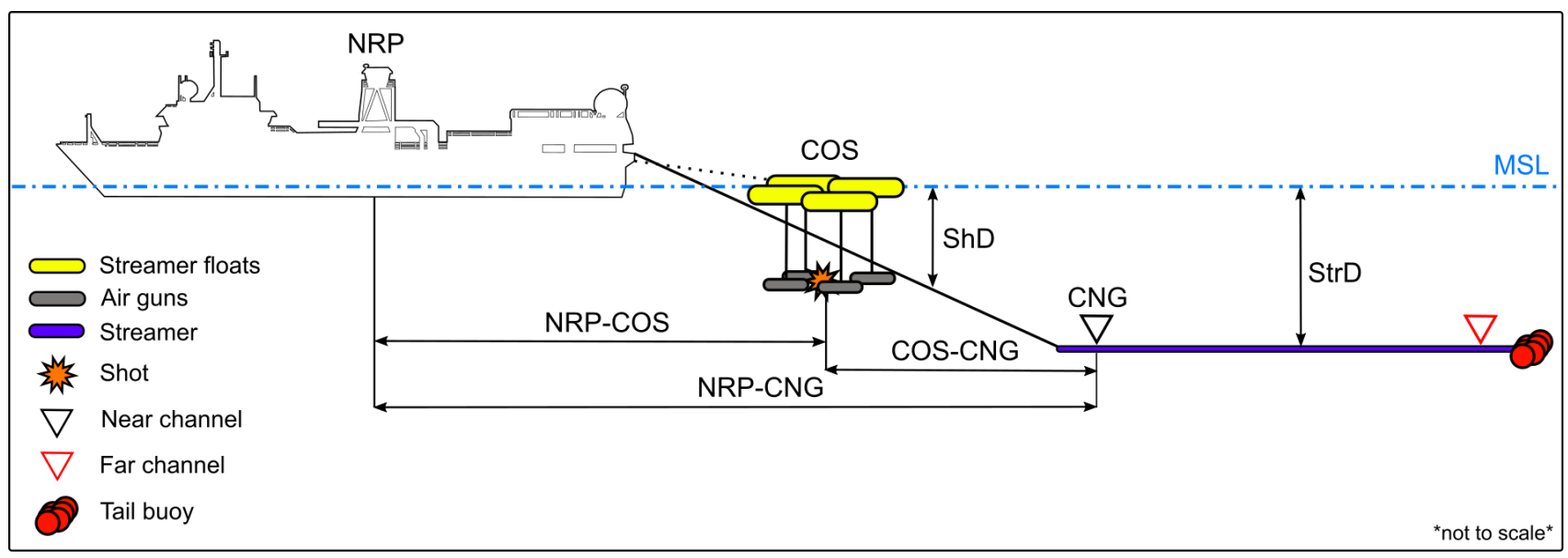

Fig. 4.3: Source and streamer configurations for acquired seismic data. NRP= Navigation Reference Point, $C O S=$ Centre of Source, CNG=Centre of Near Group, ShD=Shot depth $(9 \mathrm{~m})$, StrD=Streamer depth $(10-18 \mathrm{~m}) . \quad M S L=$ Mean Sea Level. For 12 km streamer: NRP-COS=220.0 $\mathrm{m}, N R P-C N G=422.0 \mathrm{~m}, C O S-C N G=202.0 \mathrm{~m}$. For $4 \mathrm{~km}$ streamer: NRP-COS=220.0 m, NRP$C N G=405.2 \mathrm{~m}, C O S-C N G=185.2 \mathrm{~m}$ 


\begin{tabular}{cccccccc}
\hline Line name & $\begin{array}{c}\text { Number of } \\
\text { channels }\end{array}$ & $\begin{array}{c}\text { Channel } \\
\text { spacing }(\mathrm{m})\end{array}$ & $\begin{array}{c}\text { Streamer } \\
\text { length }(\mathrm{km})\end{array}$ & $\begin{array}{c}\text { Streamer } \\
\text { depth }(\mathrm{m})\end{array}$ & $\begin{array}{c}\text { Record } \\
\text { length }(\mathrm{s})\end{array}$ & $\begin{array}{c}\text { Source } \\
\text { volume }\left(\text { in }^{3}\right)\end{array}$ & $\begin{array}{c}\text { Line } \\
\text { length }(\mathrm{km})\end{array}$ \\
\hline M18-01 & 1008 & 12.5 & 12.6 & 10,12 & 16 & 6600 & 281.6 \\
M18-03a & 1008 & 12.5 & 12.6 & 12 & 16 & 6600 & 121.25 \\
M18-14 & 1008 & 12.5 & 12.6 & 18,14 & 16 & 6600 & 206.2 \\
M18-17a & 324 & 12.5 & 4 & 14 & 14 & 6600 & 10 \\
M18-17b & 324 & 12.5 & 4 & 14,18 & 14 & $6600^{*}$ & 83.95 \\
M18-17c & 324 & 12.5 & 4 & 14,18 & 14 & 6600 & 96 \\
M18-19a & 324 & 12.5 & 4 & 14 & 14 & 6600 & 122.85 \\
M18-23a* & 1008 & 12.5 & 12.6 & 12,18 & 16 & 6600 & 174.85 \\
M18-23b* & 1008 & 12.5 & 12.6 & 18 & 16 & 6600 & 76.3 \\
M18-T01 & 1008 & 12.5 & 12.6 & 12 & 16 & 6600 & 63.35 \\
M18-T03 & 324 & 12.5 & 4 & 14 & 14 & 6600 & 15.75 \\
\hline
\end{tabular}

Table 4.1: Summary acquisition parameters for all 2D seismic lines acquired during voyage MGL1803. *Line M18-17b was partly shot at 3120 $\mathrm{in}^{3}$. **Lines M18-23a and M18-23b were later combined into line M18-23ab 


\subsection{MGL1803 Shipboard Processing Sequence}

This section details the onboard processing sequence that was undertaken using Echos by Paradigm Geophysical. Processing steps were implemented as shell scripts written by Steffen Saustrup of UTIG. These scripts created Echos processing jobs that were run using terminal commands. MGL1803 provided an ideal opportunity to process 2D seismic data as they were being acquired. Each processing job will be explained in detail, with examples shown.

\subsubsection{Pre-processing of M18-03a and M18-23a}

During acquisition of lines M18-03a and M18-23a (the former to become M18-23ab), marine mammal sightings required source power-downs as part of marine mammal protection. This involved lowering source volume from $6600 \mathrm{in}^{3}$ to $40 \mathrm{in}^{3}$. This is reflected in shot gathers where reflections are comparatively less prominent than previous shots. The $40 \mathrm{in}^{3}$ shots are known as mitigation shots, where low volume shots are meant to encourage mammals to migrate away from the mitigation radius as defined by marine mammal observation guidelines.

After the initial $40 \mathrm{in}^{3}$ mitigation shot, the guns are all slowly warmed up to full volume. This is called the ramp-up sequence, which takes around 20 minutes to complete. For some shots during the ramp up sequence, there were 2 FFID values assigned to a single shot. An example of this is shown in Fig. 4.4. Trace header information revealed that both shots had the same shot number but different FFID values and time stamps. It was suspected that though shots are recorded at $50 \mathrm{~m}$ increments, during the ramp up sequence the ship's recording system changes to record shots every $20 \mathrm{~s}$. Thus, whenever a $50 \mathrm{~m}$ shot recording coincided with a 20 s recording, a gather will appear to comprise 2 shots. Further evidence of this is that both shots contain the same reflections in a shot gather, which suggests that they correspond to the same surveying location. This phenomenon only occurs during the ramp up sequence and is only present on M18-03a and M18-23a. 


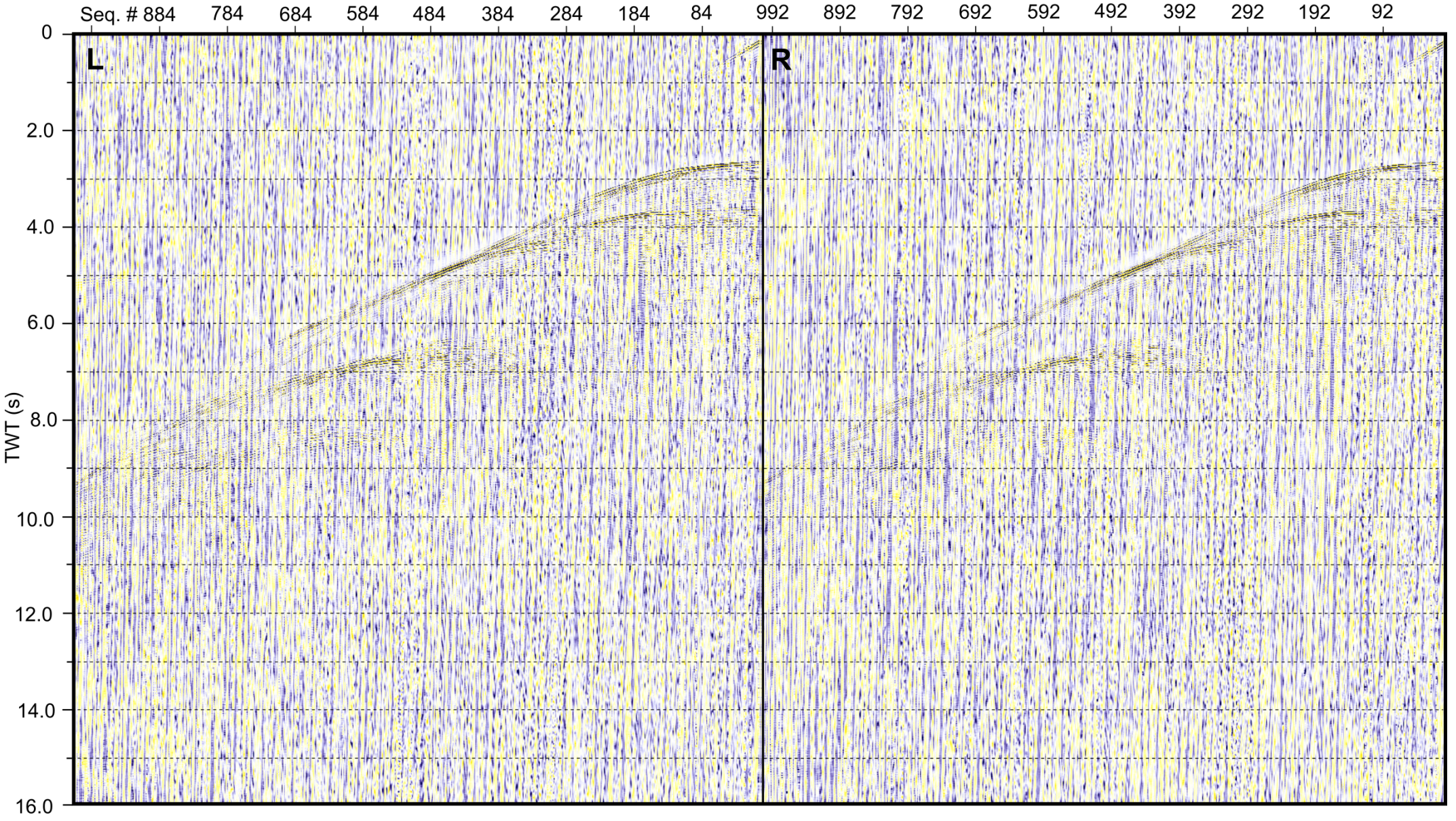

Fig. 4.4: "View Data" window in Echos showing Shot 11477 for line M18-03a, where there exists two shots recorded for a single FFID, where there should be one 
To determine whether or not to delete data, all shots corresponding to a double shot were removed. On an FK migrated section, this had the effect shown in Fig. 4.5 below:

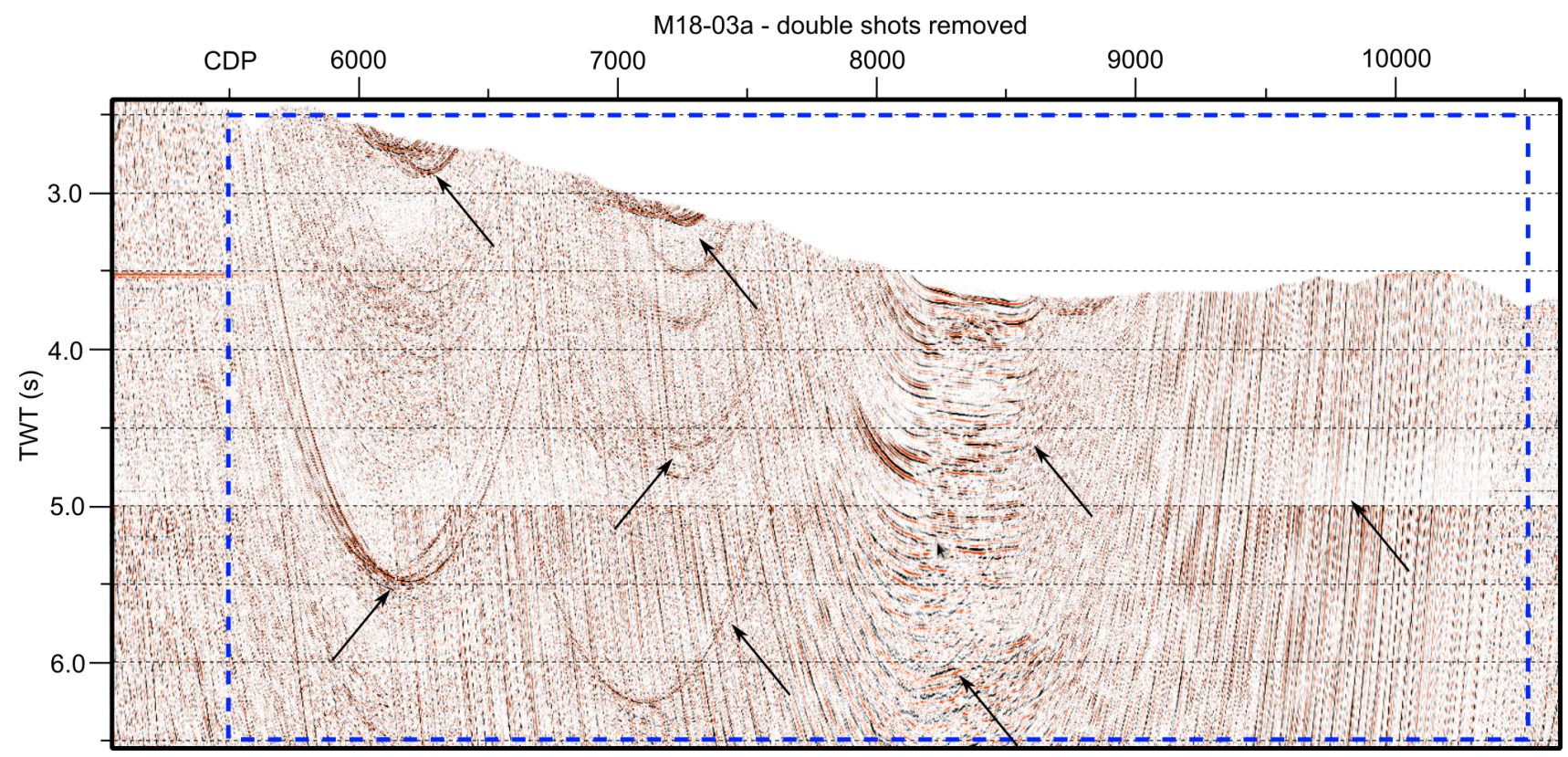

Fig. 4.5: The effect of removing the shot where the double FFID problem occurred. Removal of these shots has resulted in "migration swings" where migration attempts to account for the missing data. This is similar to what occurs at the ends of seismic lines where there are insufficient data for migration. The dashed blue box outlines the extent shown in Fig. 4.7

Fig. 4.5 shows that complete removal of the entire shot was detrimental to the migration process. Therefore, the solution was to determine which FFID was best to remove from the dataset. Shot interval was $50 \mathrm{~m}$, or $\sim 20 \mathrm{~s}$ between shots. Within Echos' View Data, trace header information showed the time of a given shot. Therefore, any shots that were $20 \mathrm{~s}$ apart were non-duplicates. In some cases, a good shot was preceded by two double shots; therefore the preceded good shot was examined. By calculating decimal times for shots, the "right panel" (see Panel B, Fig. 4.4) was determined to be the duplicate shot. As the two shots had different FFID values, FFIDs corresponding to the right hand panels were identified and removed in the "EDIT" module in Echos. An example of a removed shot is shown in Fig. 4.6. After all double shots were removed, the data were stacked and an FK migrated section was produced. A comparison between two migrated sections, one with and one without inclusion of the double shots, is shown in Fig. 4.7. 


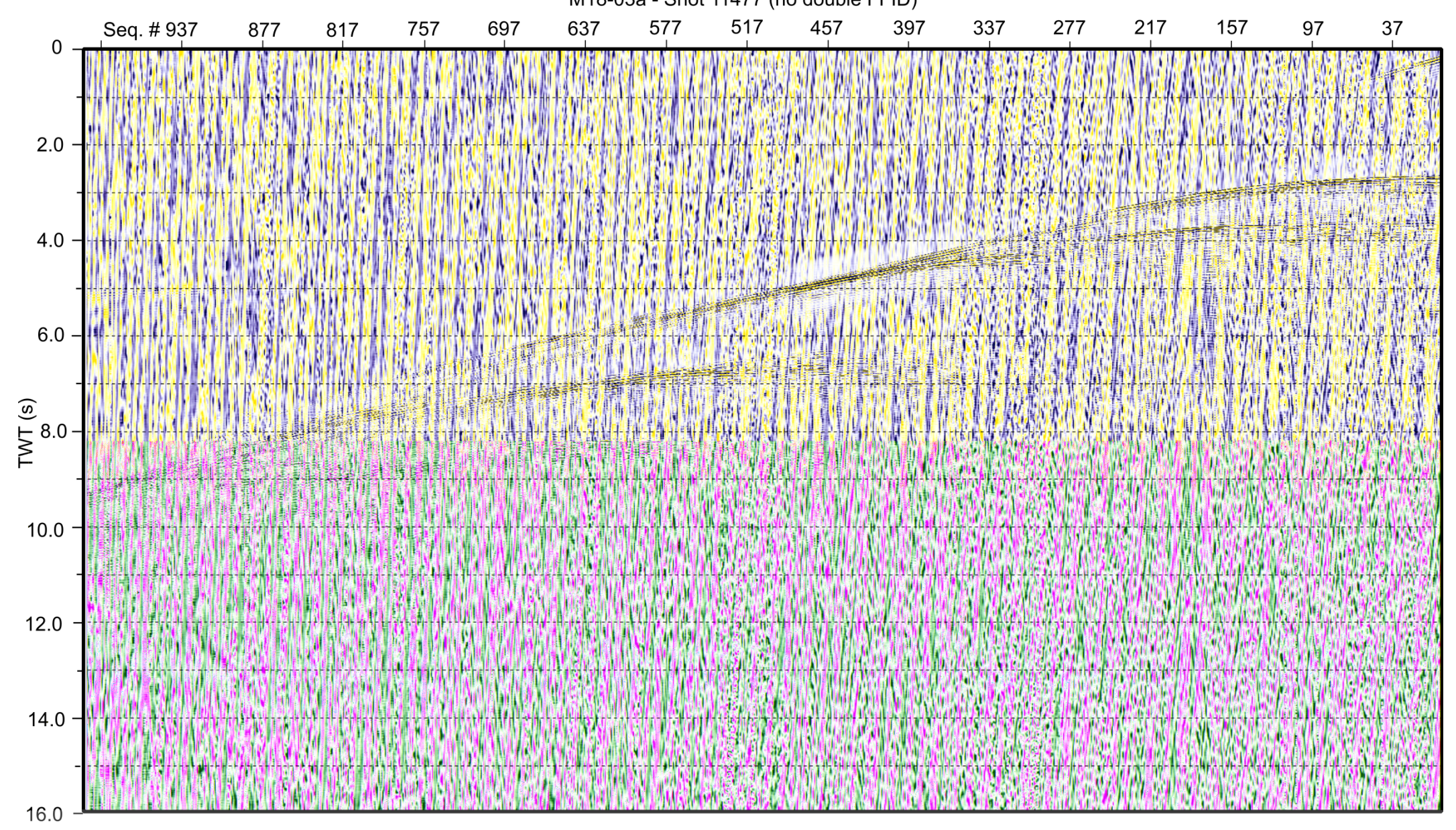

Fig. 4.6: Shot 11477 (refer to Fig. 4.4) showing the effect of removing the repeated "shot" from the dataset 


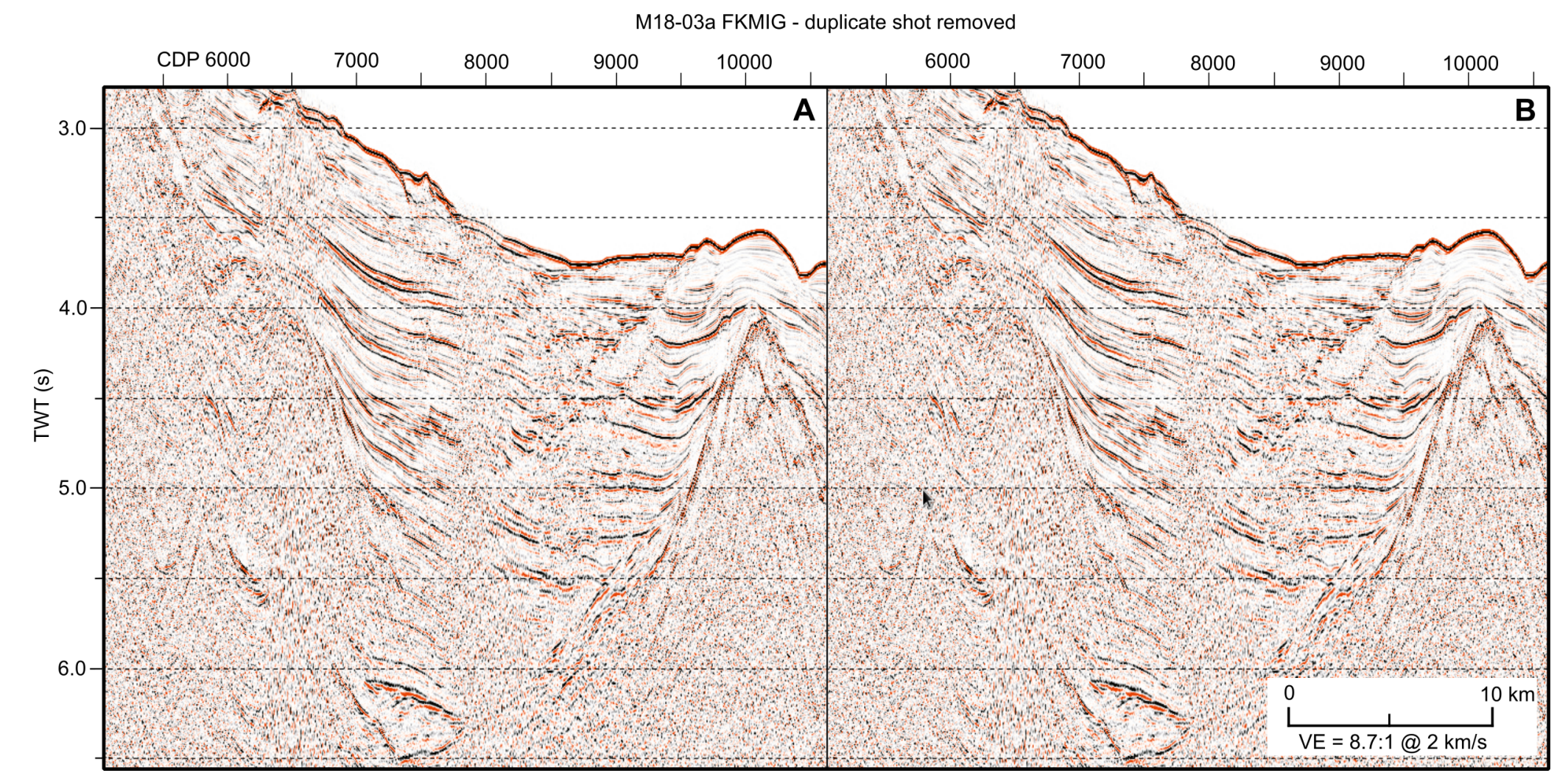

Fig. 4.7: Comparison between FK migrated section, line M18-03a, with duplicate FFIDs removed (Panel A) and without duplicate FFIDs removed (Panel B). The extent is shown in Fig. 4.5 
The comparison shown in Fig. 4.7 shows little, if any, discernible difference between two migrated sections. Therefore removal of the duplicate shot yielded no improvement to the quality of these datasets, and it was ultimately determined by UTIG processors that the doubled FFIDs should remain in the data. Despite the lack of improvement, it was important to verify for ourselves and for future processing that there would at least be no detrimental impact on data quality.

\subsubsection{SEGD: data read and resample}

The "SEGD" job reads in the .segd data from the ship's tape reels. These are copied from the ship's servers using the "segd_rsync.csh"shell script. This script was able to be run as the data were acquired, allowing for continuous real-time processing. The next shell script, "segdinSISIE.csh", converts the tape reel data into shot format. Using the "SEGD" module (Table 4.2), this process reads in the sample rate, record length and number of channels for a given tape reel range. The "RESAMP" module resamples data to $4 \mathrm{~ms}$, and a shot file in segy format is produced ("GOUT").

\begin{tabular}{cl}
\hline & \multicolumn{1}{c}{ Job: MCSxxx_SEGD } \\
\hline Module Name & \multicolumn{1}{c}{ Module Description } \\
\hline SEGD & Transforms trace from SEG-D for Echos processing \\
\hline RESAMP & Resamples data from 2 to 4 ms \\
\hline DSOUT & Write out shot domain data as "MCSxxx.shots"1 \\
\hline
\end{tabular}

Table 4.2: Explanation of modules used in the "SEGD" job. See Table 3A-1 for module parameters. 1 "xxx" refers to the line number 


\subsubsection{Marine geometry}

2D seismic marine geometry is then assigned to the shot gathers using the "geometry" job, implemented with the script "geometrySISIE.csh". This job reads in acquisition parameters using "MKDATA", inputs a rough velocity model using "VFNDEF" and applies direct wave mute, brute mute and an inside trace mute to the data (Table 4.3).

\begin{tabular}{cc}
\hline & Job: MCSxxx_geometry.dat ${ }^{1}$ \\
\hline Module Name & \multicolumn{1}{c}{ Module Description } \\
\hline MKDATA & Assigns marine geometry to the data \\
\hline VFNDEF & Stores time/velocity pairs into the vertical function repository \\
\hline VFNDEF & Applies direct wave mute, brute mute and inside mute files \\
\hline
\end{tabular}

Table 4.3: Explanation of modules used in the "geometry" job. See Table 3A-2 for module parameters. 1 "xxx" refers to the line number

\subsubsection{Brute stack}

A brute stack was produced with the job "MCSxxx_brutestack.dat"; modules are shown in Table 4.4. In this job, shot data are read in ("DSIN") and trace edits ("EDIT") are applied. Low and high frequency noise is filtered using a Butterworth filter ("FILTER"). The data are then sorted to CDPs ("SORT") and a rough velocity model is applied to allow for stacking ("NMO"; "STACK"). A brute stack is then produced ("DSOUT"). This brute stack shown in Fig. 4.8. 


\begin{tabular}{cl}
\hline & \multicolumn{1}{c}{ Job: MCSxxx_brutestack.dat ${ }^{1}$} \\
\hline Module Name & \multicolumn{1}{c}{ Module Description } \\
\hline DSIN & Inputs "MCSxxx.shots" \\
\hline EDIT & Removes bad/noisy traces \\
\hline FILTER & $\begin{array}{l}\text { Applies a } 5-85 \mathrm{~Hz} \text { Butterworth filter, } \\
\text { with } 12 \mathrm{db} / \text { octave tapering" }\end{array}$ \\
\hline SORT & Sorts data into CDPs \\
\hline NMO & Inputs velocity model "brutestack_vels_seafloor" \\
\hline STACK & Stacks data within CDPs \\
\hline DSOUT & Writes a brute stack output "MCSxxx.brutestack"1 \\
\hline
\end{tabular}

Table 4.4: Explanation of modules in "MCSxxx_brutestack.dat". See Table 3A-3 for module parameters. ${ }^{1}$ "xxx" refers to the line number

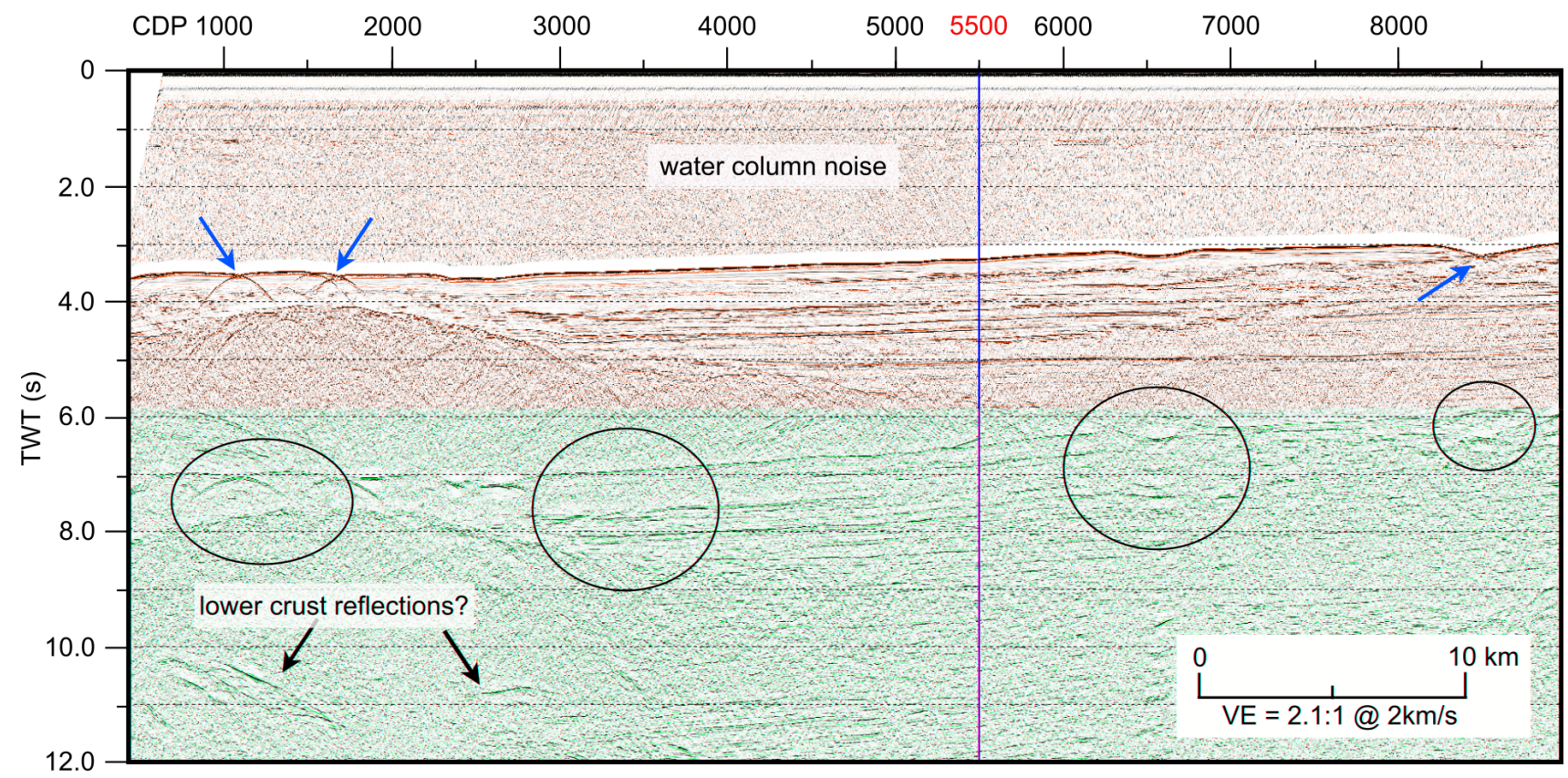

Fig. 4.8: Brute stack along line M18-17b produced with the brutestack job. Black circles/arrows show multiple energy and blue arrows denote diffraction energy. The blue line refers to the location of velocity model picks in Fig. 1.8

Though riddled with multiple energy and unmigrated energy, a brute stack allows a preliminary view of the stratigraphy and any potential tectonic features. It also allowed for picking of a seafloor horizon, which was useful for deconvolution in subsequent processing. 


\subsubsection{Deconvolution and CDP sorting}

After applying geometry to the data, we now begin pre-stack processing with the "MCSxxx_deconcdpsort.dat" job, implemented using the shell script "sortSISIE.csh". This job reads in shot data with "DSIN" and applies trace edits with "EDIT". After filtering ("FILTER"), amplitude recovery is employed using the "GAIN". Two iterations of gap deconvolution (gap lengths of 75 and $24 \mathrm{~ms}$ ) are then applied using "MCDECON". Traces were then sorted to CDPs using "SORT". Data were then written to a new file with "DSOUT". Table 4.5 outlines summarises key modules within this job.

\begin{tabular}{cl}
\hline & \multicolumn{1}{c}{ Job: MCSxxx_deconcdpsort.dat ${ }^{1}$} \\
\hline Module Name & \multicolumn{1}{c}{ Module Description } \\
\hline DSIN & Inputs "MCSxxx.shots"1 \\
\hline EDIT & Removes bad/noisy traces \\
\hline FILTER & $\begin{array}{l}\text { Applies a } 7-85 \mathrm{~Hz} \text { Butterworth filter, } \\
\text { with 12 db/octave tapering }\end{array}$ \\
\hline GAIN & Applies a t ${ }^{1.5}$ spherical divergence correction \\
\hline MCDECON & $\begin{array}{l}\text { Applies predictive deconvolution with a gap length=75/24 ms, } \\
\text { operator length=450 ms, design window }=3500 \mathrm{~ms},\end{array}$ \\
\hline application window=0-14/16 s ${ }^{2}$
\end{tabular}

Table 4.5: Explanation of modules in the "MCSxxx_deconcdpsort.dat" job. See Table 3A-4 for module parameters. ${ }^{1}$ xxx refers to line number. ${ }^{2}$ see Table 4.1 for acquisition parameters 


\subsubsection{Velocity picking}

In the job "MCSxxx_veldef.dat", a more robust and accurate velocity model is created. Final velocity models had picks made every 1000, 500 then finally 250 CDPs, or at $3.125 \mathrm{~km}$ resolution. Data were read in using "DSIN", and after direct wave muting ("MUTE") and filtering ("FILTER"), velocity picks could be made using semblance plots. These comprised 8 CDPs in a "supergather", producing a higher signal:noise and thus allowing for more accurate picks. A 300 ms AGC ("AGC") was also added to aid visualisation of semblance spectra. "VELDEF" then saved the completed velocity model. Modules are summarised in Table 4.6. The velocity model picked is shown below in Fig. 4.9.

\begin{tabular}{cl}
\hline & \multicolumn{1}{c}{ Job: MCSxxx_veldef.dat ${ }^{1}$} \\
\hline Module Name & \multicolumn{1}{c}{ Module Description } \\
\hline DSIN & $\begin{array}{l}\text { Inputs MCSxxx.decon.cdps"1 } \\
\text { over a given range at a specified CDP increment }\end{array}$ \\
\hline MUTE & Applies a direct wave mute \\
\hline FILTER & $\begin{array}{l}\text { Applies an 8-50 Hz Butterworth filter for 0-2 s } \\
\text { and an 8-35 Butterworth filter for 1-14/16 s }\end{array}$ \\
\hline AGC & Applies a 300 ms sliding window AGC \\
\hline VELDEF & $\begin{array}{l}\text { Allows for velocity model picking and outputs a } \\
\text { velocity file "MCSxx__stackvels"1 }\end{array}$ \\
\hline
\end{tabular}

Table 4.6: Explanation of modules in the MCSxxx_veldef.dat job. See Table 3A-5 for module parameters. ${ }^{1}$ xxx refers to line number. ${ }^{2}$ see Table 4.1 for acquisition parameters 


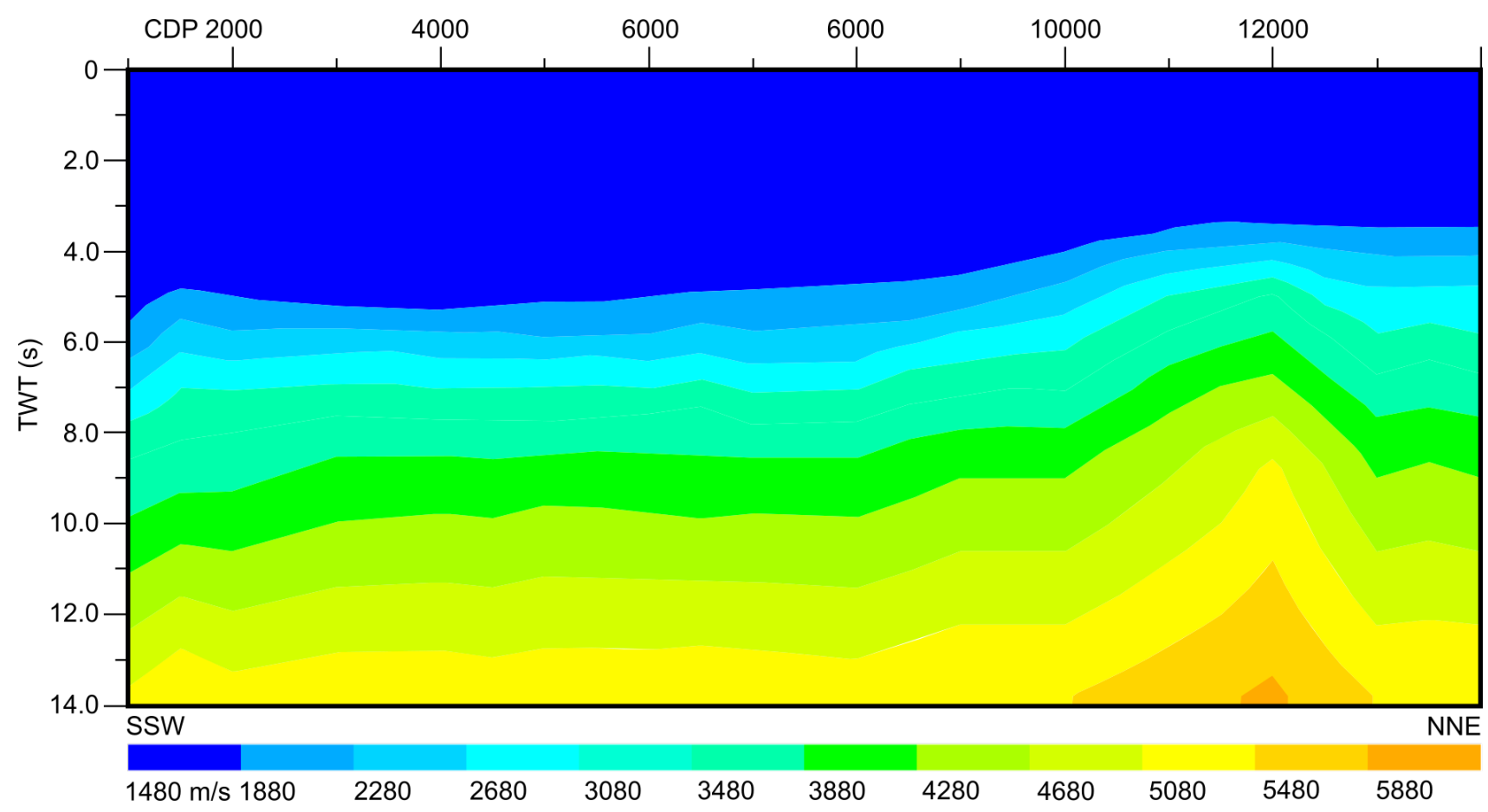

Fig. 4.9: Velocity model picked for line M18-17b, using the job MCS17b_veldef.dat (adapted from Echos velocity picking tool)

\subsubsection{Radon demultiple}

After creating a superior velocity model, the job "MCSxxx_radonmultiple.dat" aims to remove multiple energy data using a radon parabolic transformation. "DSIN" reads in "MCSxxx.decon.cdps". Data are then NMO corrected using the velocity model produced with "MCSxxx_veldef.dat". NMO stretch is muted ("MUTE"). "RADNPAR" then employs radon parabolic transformation. FK filtering ("FKFILT") removes any residual noise. The data are then written out using "DSOUT". Modules in this job are shown in Table 4.7. 


\begin{tabular}{cl}
\hline & \multicolumn{2}{c}{ Job: MCSxxx_radon.dat ${ }^{1}$} \\
\hline Module Name & \multicolumn{1}{c}{ Module Description } \\
\hline NMO & Inputs velocity model "MCSxxx_stackvels"1 \\
\hline MUTE & Removes NMO stretch \\
\hline RADNPAR & Applies forward radon demultiple \\
\hline FKFILT & Rejects traces that dip from 0.572-0.888 ms/trace \\
\hline DSOUT & Outputs "MCSxxx.decon.radon.cdps"1 \\
\hline
\end{tabular}

Table 4.7: Explanation of modules in the "MCSxxx_radon.dat" job. See Table 3A-6 for module parameters. ${ }^{1}$ xxx refers to line number

\subsubsection{Stacking, migration and scaling}

The job "MCSxxx_Radon_stack.dat" stacks, migrates and scales the data for final output. "DSIN" reads in "MCSxxx.decon.radon.cdps". NMO correction is applied using "NMO", NMO stretch is removed with "MUTE", and data subsequently stacked using "STACK". A Butterworth filter ("FILTER") constrains multiple frequency ranges for multiple time ranges. "MIGDMO" them employs F-K dip moveout correction and migration. For final scaling, a 1000 ms sliding window AGC ("AGC") is applied. Lastly, segy format data are output using "GOUT". Table 4.8 describes relevant modules for this job.

\begin{tabular}{|c|c|}
\hline \multicolumn{2}{|r|}{ Job: MCSxxx_Radon_stack ${ }^{1}$} \\
\hline Module Name & Module Description \\
\hline DSIN & Inputs "MCSxx.decon.radon.cdps.sgy"1 \\
\hline NMO & MCSxxx_stackvels ${ }^{1}$ \\
\hline MUTE & MCSxxx_stackmute ${ }^{1}$ \\
\hline STACK & Stacks Data \\
\hline FILTER & Applies Butterworth filters for a range of frequencies and time windows \\
\hline MIGDMO & Post-stack F-K dip moveout correction and migration \\
\hline AGC & 1000 ms sliding window AGC \\
\hline GOUT & Final segy output "MCSxxx_decon.radon.fkmig.agc.segy"1 \\
\hline
\end{tabular}

Table 4.8: Explanation of modules in the "MCSxxx_Radon_stack.dat" job. See Tables 3A-7. 3A-8 and 3A-9 for module parameters. ${ }^{1}$ xxx refers to line number 


\subsection{Chapter Conclusion}

This chapter has covered the acquisition and processing sequence employed aboard MGL1803 for the newly acquired seismic data. In summary, data were: resampled; assigned marine geometry; filtered with deconvolution; stacked with a refined velocity model; migrated; and lastly scaled for final interpretation. 


\section{Chapter 5}

\section{Seismic Stratigraphy}

\subsection{Introduction}

This chapter summarises stratal correlations and relationships made using SeisWare ${ }^{\mathrm{TM}}$. A key objective of this project is to map sequence and megasequence boundaries from the Parara-1 well in the north, to the southern-most line M18-14. This provides a framework for interpreting depositional and tectonic mechanisms in the study area. Assignment as a sequence or megasequence boundary is justified in each section.

Providing reliable correlations from Parara-1 presented a significant challenge, as sedimentary and structural barriers affect continuity of sequence and megasequence boundaries. Tauru High produced significant uncertainty for correlations due to the difference in accommodation space created on either side of the high, due to a change from Paleogene extension to Neogene compression (see Sutherland and Melhuish, 2000). Therefore, nomenclature for two sub-basins (north and south of Tauru High) are defined. For example, "U-SLN3-2a" refers to a unit in the northern Solander sub-basin, within megasequence $\# 3$, overlying sequence $\# 2$, of facies variation "a". Age inferences are discussed in Chapter 6. 


\section{$5.2 \quad$ Northern Sub-basin}

This section details the seismic stratigraphy north of Tauru High. It focuses on mapping results from lines S86-34 and M18-17c. In this northern region, four megasequence boundaries are identified and eight seismic units distinguished. They can be mapped into the Parara and Hautere sub-basins to the north and onto Solander Anticline (Fig. 5.2).

\subsubsection{SLN1-1}

U-SLN1-1 comprises low continuity, high to moderate amplitude reflections. U-SLN1-1 locally thickens towards Tauru High and the Parara Fault (line M18-17c, Fig. 5.1; line S86-34, Fig. 5.2 respectively). The inferred northeastern dips of the Tauru Fault and Parara Fault, in combination with stratal fanning and unit thickening toward the faults, implies increasing accommodation space and tilting from normal faulting during deposition of U-SLN1-1.

North of Tauru High, around CDP 1500 (line M18-17c, Fig. 5.1), U-SLN1-1 downlaps a low continuity, moderate to high amplitude, positive polarity reflection, interpreted as seismic basement. Stratal onlap occurs further north at CDP 3200, and at Parara Anticline on both lines M18-17c and S86-34. North of Parara Anticline, stratal relationships are uncertain due to poor basement imaging. This is also the case west and east of Parara-1 (line S86-34, Fig. 5.2), though strata lie parallel to basement from CDP 750-1250.

This basement surface is defined as a megasequence boundary as it is onlapped/downlapped by overlying U-SLN1-1. Additionally, onlap of U-SLN2-1 is observed on line M18-17c (Fig. 5.1, subsection 5.2.2). 


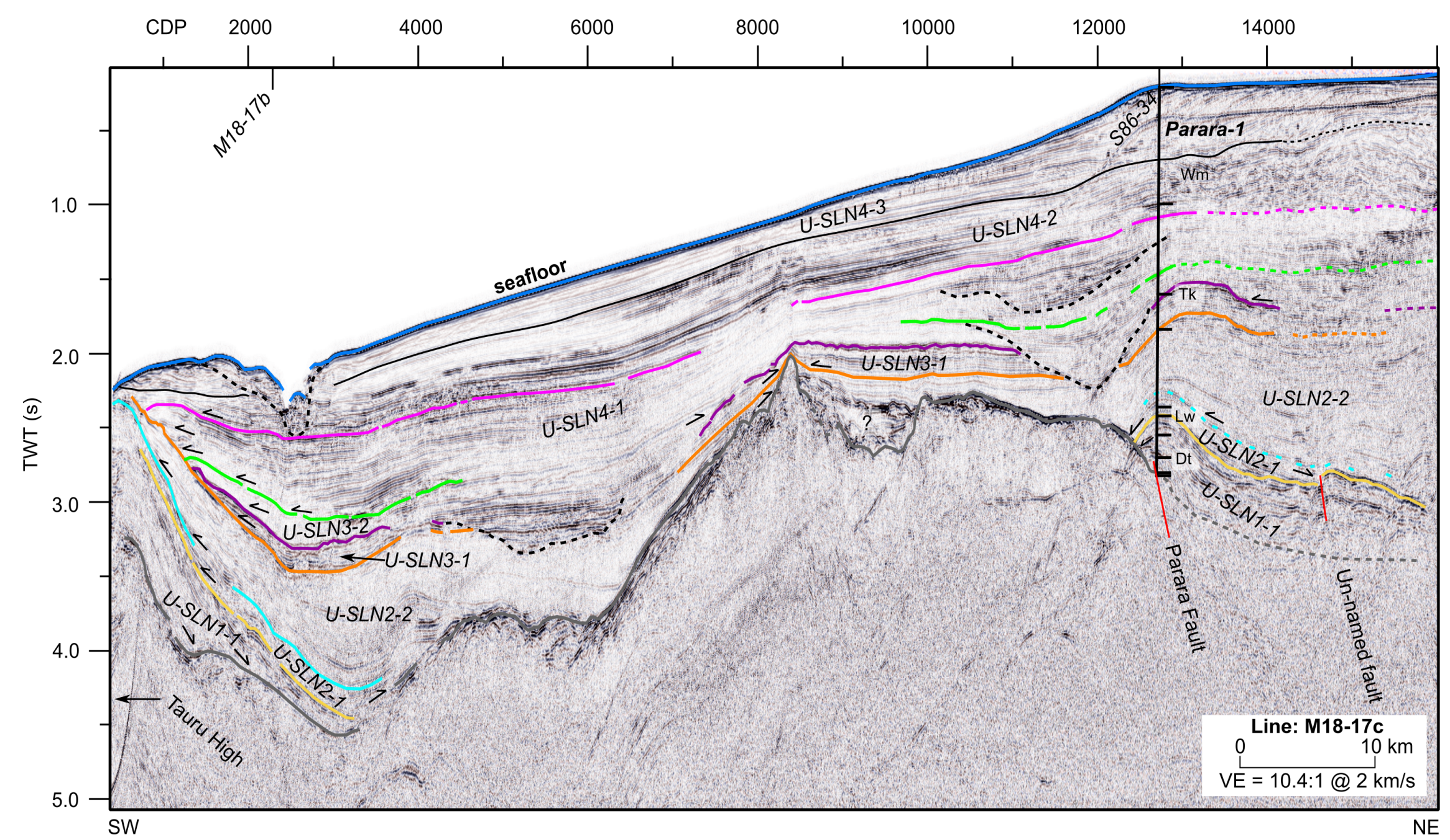

Fig. 5.1: Seismic stratigraphy for line M18-17c, northern Solander Basin. Stratal onlap is shown with small arrows. Stratigraphic terminations are indicated by dashed black lines. Biostratigraphic stages in the Parara-1 well (labelled in bold) are dashed, and correspond to: Seafloor, Mangapanian (Wm), Kapitean (Tk), Waiauan, Altonian, Waitakian (Lw), Whaingaroan, Teurian (Dt) and top Paleozoic. Faults are indicated by red lines. VE = vertical exaggeration, see Fig. 1.1 for line location 


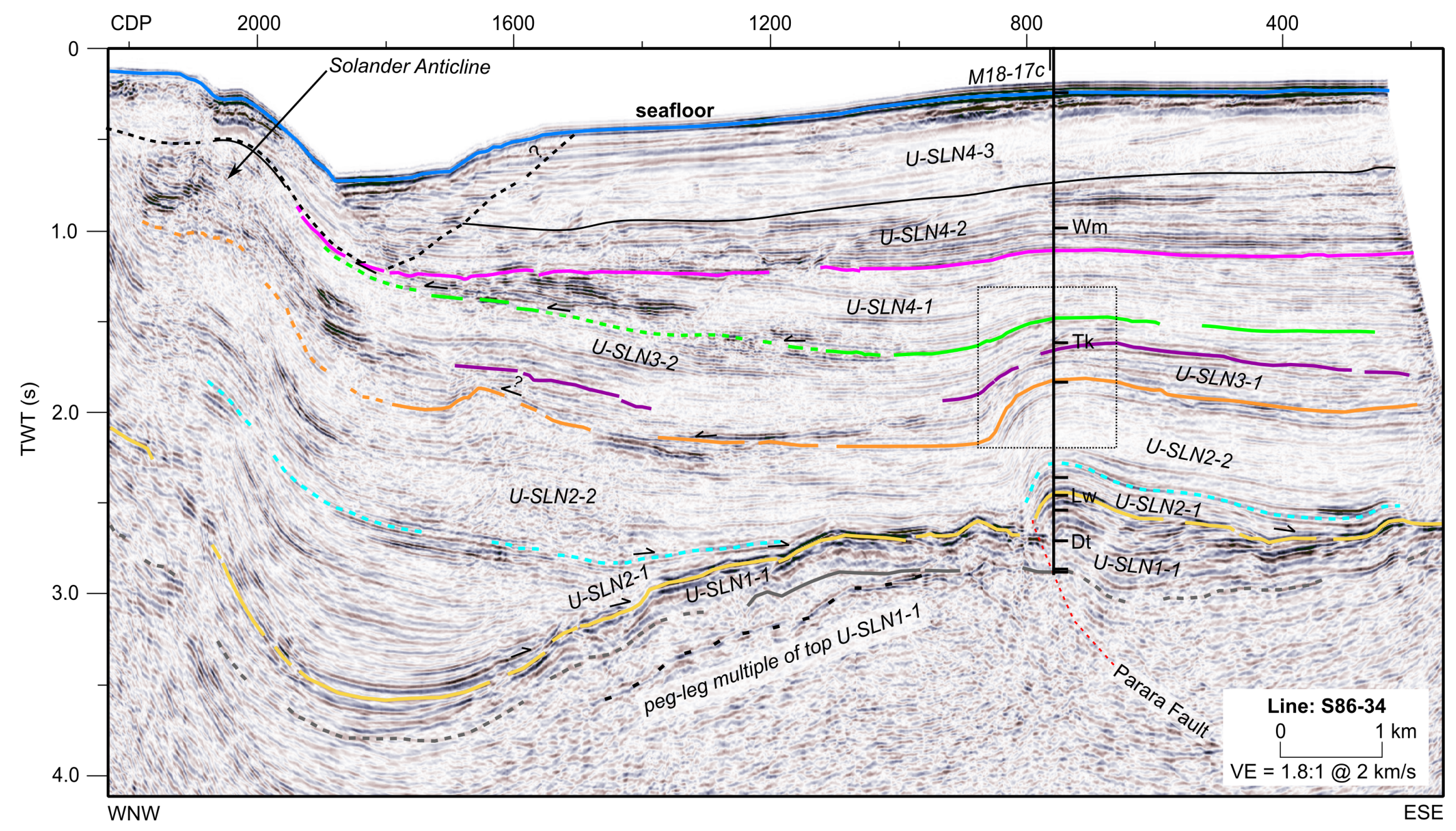

Fig. 5.2: Seismic stratigraphy for line S86-34, northern Solander Basin. Stratal onlap is shown with small arrows. Stratigraphic terminations are indicated by dashed black lines. Biostratigraphic stages in the Parara-1 well are dashed, and correspond to: Seafloor, Mangapanian (Wm), Kapitean (Tk), Waiauan, Altonian, Waitakian (Lw), Whaingaroan, Teurian (Dt) and top Paleozoic. Faults are indicated by red lines. The black dotted box shows the extent of the inset shown in Fig. 6.15. VE = vertical exaggeration, see Fig. 1.1 for line location 


\subsubsection{SLN2-1}

Reflections within U-SLN2-1 are moderate to low amplitude, with high continuity. U-SLN2-1 is not present from $\sim$ CDP 4000-12400 (line M18-17c, Fig. 5.1). Thinning toward Tauru High is observed, and on line S86-34 (Fig. 5.2), U-SLN2-1 thickens west of Parara Anticline. These thickness observations contrast to underlying U-SLN1-1, which thickens in an opposite direction to U-SLN2-1 (Fig. 5.1, CDP 0-3500; Fig. 5.2, CDP 0-750).

U-SLN2-1 strata onlap basement north of Tauru High and on the southern limb of Parara Anticline (Fig. 5.1). On the northern flank of Tauru High at $\sim$ CDP 1500, strata onlap a high continuity, high amplitude, positive polarity reflection. Further onlap of U-SLN2-1 onto this reflection occurs north of Parara Anticline at $\sim \mathrm{CDP} 14400$ (line S86-34, Fig. 5.2). However, this reflection downlaps basement on the southern limb of the anticline. Here, the relatively planar basement surface from CDP 10000-12500 implies erosion of strata down to basement, possibly due to thinning on the footwall of the fault during its extensional phase (Sutherland et al., 2006). Therefore, south of this to $\sim$ CDP 3200, this surface was not mapped. U-SLN2-1 strata also onlap this basal reflection west of Parara Anticline, and downlap it east of Parara Anticline (line S86-34, Fig. 5.2). On line S86-34, the basal reflection is mapped as a high continuity, high amplitude reflection.

Onlap and downlap of U-SLN2-1 strata onto the basal reflection, and opposite thickening and onlap direction to underlying SLN1-1 is justification for classification of the basal reflection as a megasequence boundary.

\subsubsection{SLN2-2}

Unit U-SLN2-2 comprises reflections that are moderate to low amplitude and of variable continuity. Strata north of Tauru High are locally folded at $\sim$ CDP 4000 (line M18-17c, Fig. 5.1); no evidence of localised folding is observed at Parara Anticline (line S86-34, Fig.5.2), where strata are parallel. Similar to U-SLN2-1, U-SLN2-2 thickens north of Tauru High and Parara Anticline, which implies a northern sedimentary source. 
On the northern flank of Tauru High (line M18-17c, Fig. 5.1), U-SLN2-2 onlaps a moderate continuity, high amplitude, reverse polarity reflection. This basal reflection is not mapped between $\sim$ CDP 4200-12350, and on this line, has been tentatively mapped at Parara Anticline on the basis of its high amplitude and reverse polarity. Here, onlap is inferred on the southern limb of Parara Anticline. U-SLN2-2 strata are interpreted to onlap this basal reflection west of the anticline (line S86-34, Fig. 5.2), though no onlap is observed to the east. On line M18-17c, north of CDP 4200, U-SLN2-2 strata onlap basement.

The basal surface is designated a sequence boundary with only local onlap by U-SLN2-2, though it is regionally mappable based on continuity and seismic character.

\subsubsection{SLN3-1}

U-SLN3-1 has moderate amplitude, low to moderate continuity internal reflections north of Tauru High to the paleochannel beginning at CDP 4700 (line M18-17c, Fig. 5.1). North of this paleochannel, strata are more continuous and planar. U-SLN3-1 is a relatively thin unit on line M18-17c, though thickening occurs north of Tauru High (CDP 1350-3800, Fig. 5.1); north of this it thins against a basement high at CDP 8400. U-SLN3-1 then thickens toward Parara Anticline. Thickness variations at Parara-1 (Fig. 5.1) are unclear due to further channelisation at CDP 12000. On line S86-34 (Fig. 5.2) strata are more continuous and planar. Slight thickening occurs west of Parara Anticline; farther west of this it appears to thin, and to the east, thickening is observed.

Onlapping of U-SLN3-1 strata onto a low continuity, low to moderate amplitude, positive polarity reflection is observed on the northern flank of Tauru High from CDP 800-1300 (Fig. 5.1). Onlap is also observed at the basement high at CDP 8400. The basal surface marks the onset of a long-lived channel system north of Tauru High ( CDP 4700-7000, Fig. 5.1), as well as adjacent to Parara Anticline. West of Parara-1, U-SLN3-1 strata onlap this basal reflection.

The basal surface is determined as a megasequence boundary. There is widespread onlap of U-SLN3-1 strata, as discussed in sub-sections 5.2.5, 5.2.6 and 5.2.7, and onlap of strata overlying U-SLN3-1 is observed on the northern flank of Tauru High (Fig. 5.1). Furthermore, U-SLN3-1 
is interpreted as growth strata related to folding of Tauru High (see section 6.4, Chapter 6).

\subsubsection{SLN3-2}

Reflections within U-SLN3-2 are low to moderate amplitude, and mostly continuous. Amplitudes are lowest from $\sim$ CDP 1200 to $\sim$ CDP 3600, and from CDP 8400 to CDP 11000 (line M18-17c, Fig. 5.1). Slight thickening north (line M18-17c, Fig. 5.1) and west (line S86-34, Fig. 5.2) of Parara Anticline is observed. The basal boundary with U-SLN3-1 becomes indistinct due to channelisation, but is still mappable elsewhere.

From CDP 1800-2400 (line M18-17c, Fig. 5.1) U-SLN3-2 strata onlap a low continuity, high amplitude, reverse polarity reflection. South of this to $\sim$ CDP 1340, strata lie parallel to this reflection and beyond this, U-SLN3-2 onlaps the underlying megasequence boundary. Further north, onlap onto this high amplitude, reverse polarity reflection is observed at $\sim$ CDP 7300, as well as north of Parara Anticline. Poor imaging of this basal surface on line S86-34 (Fig. 5.2) makes stratal relationship inferences difficult.

There is onlap of U-SLN3-2 onto the basal surface, though this reflection is poorly imaged and does not appear to be related to any major geologic event. Therefore, it is assigned sequence boundary status.

\subsubsection{SLN4-1}

U-SLN4-1 consists of reflections of low to moderate amplitude that are mostly continuous. This unit thickens north of Tauru High and south of Parara Anticline (line M18-17c, Fig. 5.1), and on line S86-34 (Fig. 5.2), it pinches out west of Parara Anticline. A paleochannel feature at CDP 11500 (approx. $1.5 \mathrm{~s}$ TWT) is present within U-SLN4-1 (line M18-17c, Fig. 5.1). These channel deposits comprise higher amplitude reflections that dip to the south. Similar high amplitude reflections visible at CDP 1500, 1.25 s TWT on line S86-34 may be part of the same channel system (Fig. 5.2).

East of Solander Anticline (line S86-34, Fig. 5.2), U-SLN4-1 strata onlap a low continuity, 
moderate to low amplitude, reverse polarity reflection. An active channel, visible in seafloor morphology, is inferred to be the modern depositional analogue of what created the high amplitude channel reflections mentioned above. It is theorised that, during its early stages of growth, uplift and folding of Solander Anticline facilitated development of this channel, thus this basal surface is related to activity on the Solander Anticline. Further onlap of U-SLN4-1 onto this reflection is observed north of Tauru High (line M18-17c, Fig. 5.1). Onlap of these strata onto the megasequence SLN3 is observed.

The basal surface is given megasequence boundary status, based on onlap of U-SLN4-1 at Solander Anticline and at Tauru High.

\subsubsection{SLN4-2}

U-SLN4-2 deposits underlying the modern continental slope between the northern end of line M18-17c and the intersection with line S86-34 are of variable amplitude but high continuity (Fig. 5.1). By comparison, below the modern continental shelf, reflections are moderate amplitude, with some low and high amplitude variations, and strata have moderate continuity. On line S8634 (Fig. 5.2), reflections are moderate amplitude, with some lower amplitude events. East of Parara-1, reflections are more continuous than those west of $\sim$ CDP 1100 . The unit is truncated by a modern channel at CDP 1700-1920 on line S86-34 (Fig. 5.2), and is truncated by a modern channel at CDP 2500 on line M18-17c (Fig. 5.1, see swath bathymetry in Fig. 6.5). U-SLN4-2 is thickest to the north (Fig. 5.1) and east (Fig. 5.2) of Parara-1, and thins southward to Tauru High (Fig. 5.1) and west toward Solander Anticline (Fig. 5.2).

Minor onlap of U-SLN4-2 onto a high continuity, moderate to low amplitude, reverse polarity reflection occurs north of Tauru High at CDP 1600 (Fig. 5.1). These strata mostly lie parallel to this basal surface; this basal relationship is also observed on line S86-34 adjacent to Solander Anticline (Fig. 5.2).

The basal surface is assigned sequence boundary status, as there is minimal evidence for significant regional tectonic change related to its occurrence. 


\subsubsection{SLN4-3}

U-SLN4-3 is differentiated from underlying U-SLN4-2 strata on the basis of its high continuity, low to moderate amplitude reflections. It is intersected by channels that truncate U-SLN4-2 strata. Continental slope deposits of U-SLN4-2 are continuous, low amplitude reflections that grade into moderate amplitude, stacked clinoforms beneath the continental shelf (north of CDP 12500, line M18-17c, Fig. 5.1, see seismic image Fig. 6.12). These prograding shelf deposits are also imaged on line S86-34 (east of CDP 800, Fig. 5.2), where they grade westward into continuous, parallel reflections beneath the continental slope. Seabed pockmarks occur at CDP 9600-11200 (line M18-17c, Fig. 5.1). U-SLN4-3 thins to the south (Fig. 5.1), and to the west (Fig. 5.2). 


\subsection{Southern Sub-basin}

This section describes the seismic stratigraphy of southern Solander sub-basin, south of Tauru High. It presents mapping results from lines M18-17b, M18-01, M18-23ab and M18-14. In the southern region, three megasequence boundaries and seven sequences are identified.

\subsubsection{SLS1-1}

U-SLS1-1 consists of low amplitude, low continuity reflections that are locally folded on line M18-17b at CDP 8000 and onlap basement south of Tauru High (Fig. 5.3). The intersection of line M18-17b and M18-01 occurs on a basement high with minimal sedimentary cover, so the thickness of this unit is uncertain on line M18-01 (Fig. 5.4), where reflections are low to moderate amplitude, mostly continuous and onlap basement.

Further to the south on line M18-23ab (Fig. 5.5), U-SLS1-1 is confidently mapped, where it comprises high to moderate amplitude reflections with high continuity, where basement onlap is observed. A tie to line M18-14 (Fig. 5.6) is possible, despite basement topography from CDP 28800-34000 on line M18-23ab (equivalent basement topography from CDP 4200-6500 on line M18-14, Fig. 5.6). U-SLS1-1 is mapped to Puysegur Ridge at the western edge of Fig. 5.6, where folding at $\sim \mathrm{CDP} 13000$ is observed (Fig. 5.7). U-SLS1-1 is variable in thickness, it thickens locally in sub-basins e.g. CDP 35500, line M18-23ab (Fig. 5.5); CDP 7800, line M18-14 (Fig. 5.6).

The base of U-SLS1-1 is seismic basement, which is a low continuity, moderate amplitude, positive polarity reflection. Basement is poorly imaged within Tauru High ( CDP 9500-11500, Fig. 5.3), though it is clearly differentiable from overlying strata on the basis of its reflection characteristics and chaotic internal reflectivity. U-SLS1-1 strata onlap basement on all southern lines, and basement onlap of strata overlying U-SLS1-1 is also observed. 


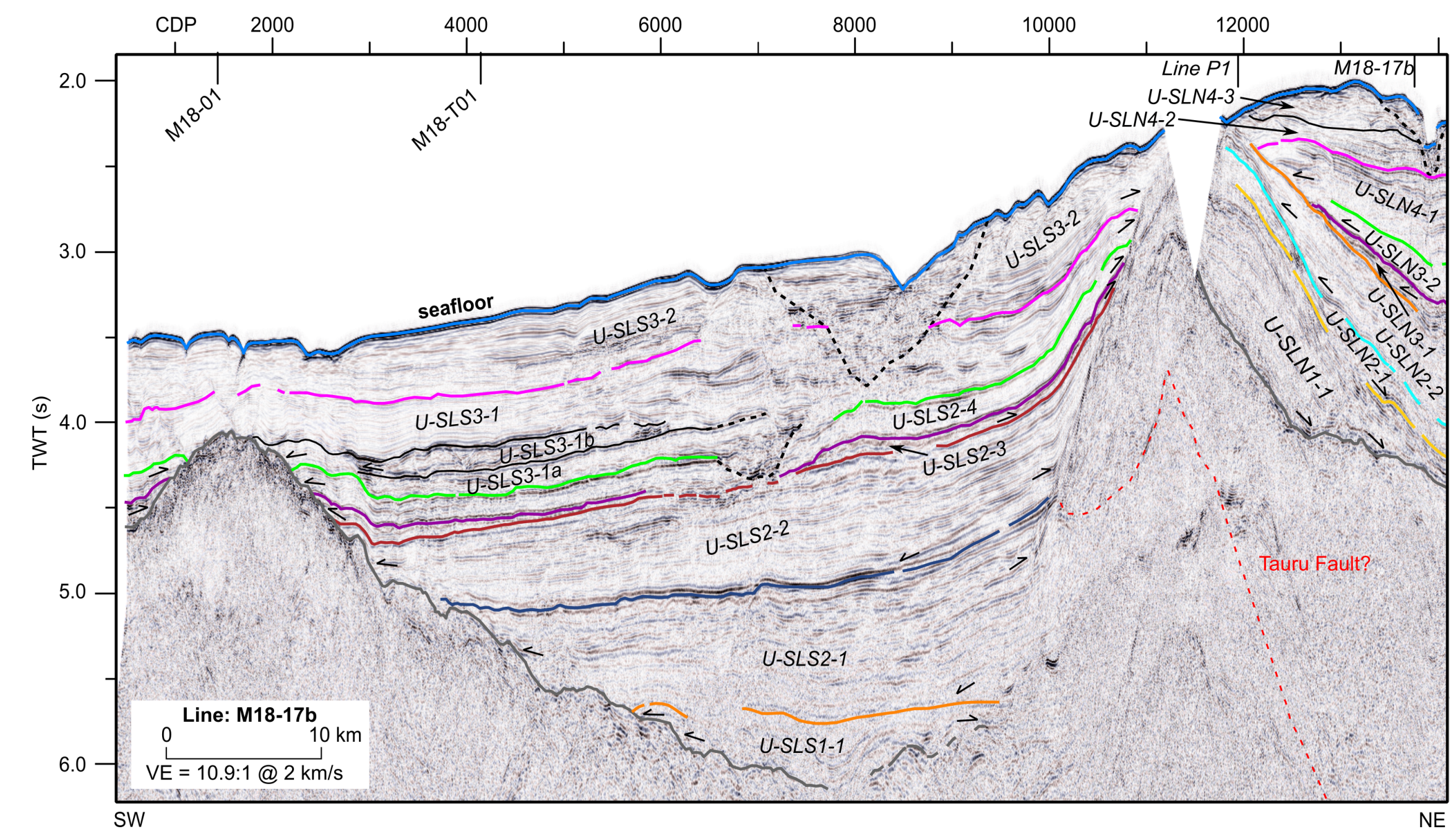

Fig. 5.3: Seismic stratigraphy for line M18-17b, southern Solander Basin. Stratigraphic onlap and downlap are shown with small arrows. Stratigraphic terminations are indicated by dashed black lines. Faults are indicated by red lines. VE = vertical exaggeration, see Fig. 1.1 for location 


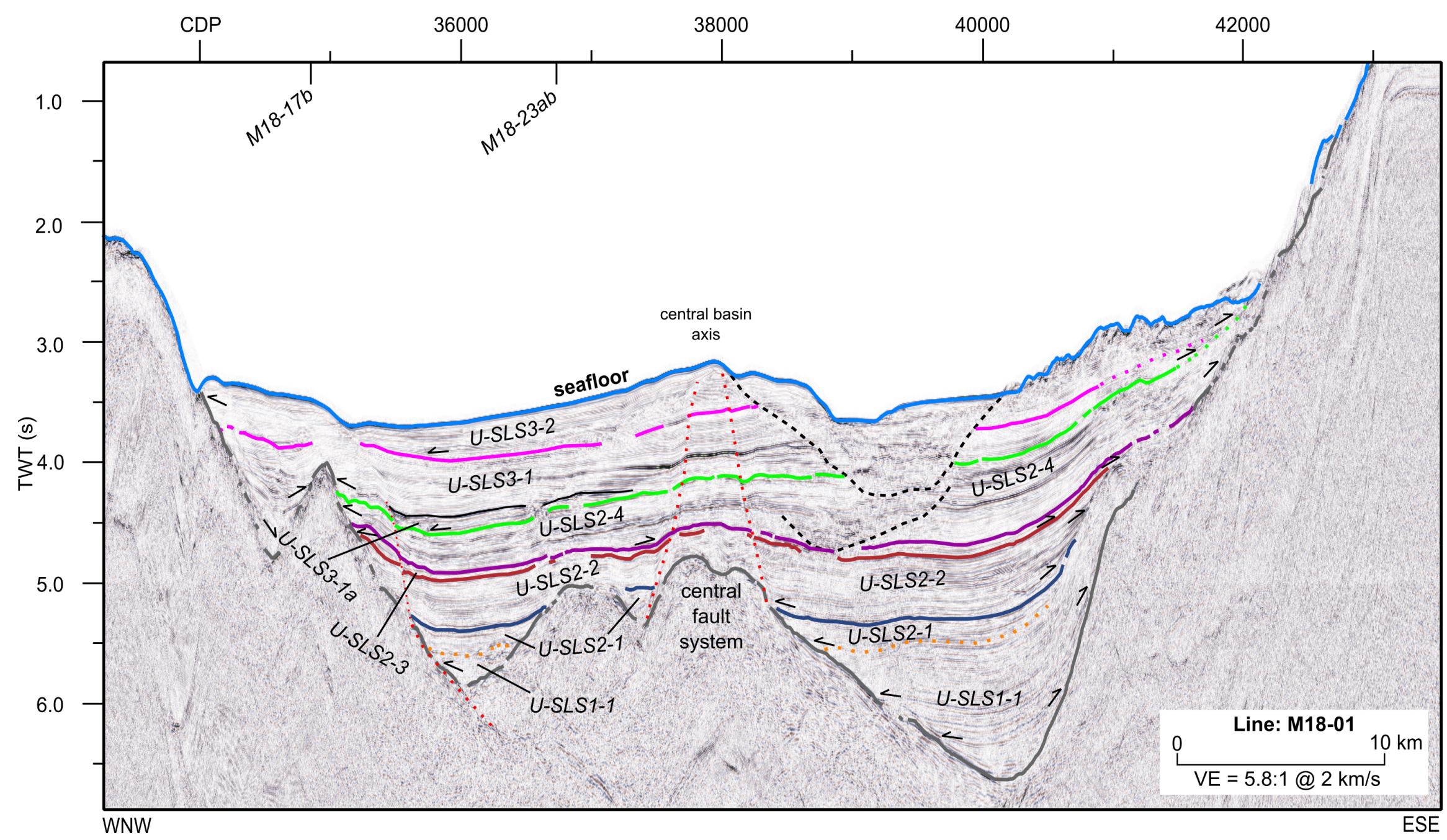

Fig. 5.4: Seismic stratigraphy for line M18-01, southern Solander Basin. Stratigraphic onlap is shown with small arrows. Stratigraphic terminations are indicated by dashed black lines. Faults are indicated by red lines. VE = vertical exaggeration, see Fig. 1.1 for line location 


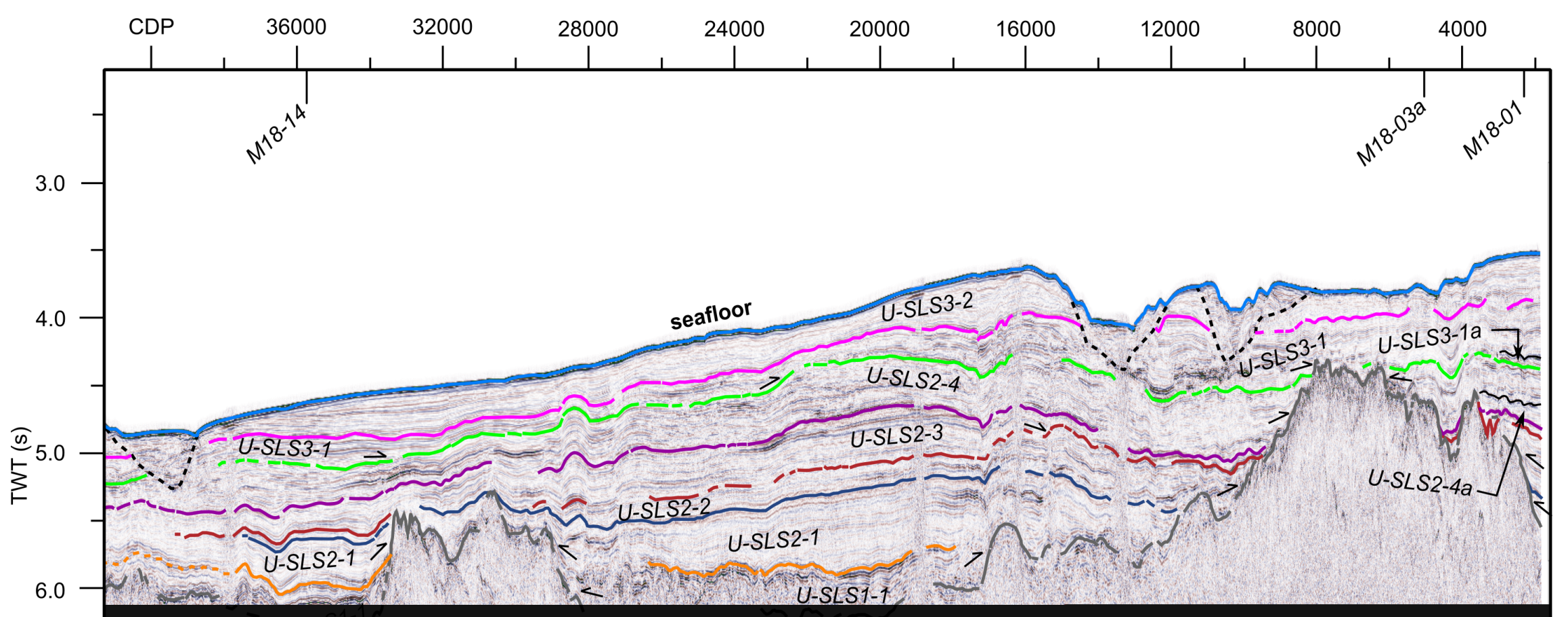

Fig. 5.5: Seismic stratigraphy for line M18-23ab, southern Solander Basin. Stratigraphic onlap is shown with small arrows. Stratigraphic terminations are indicated by dashed black lines. VE = vertical exaggeration, see Fig. 1.1 for line location 


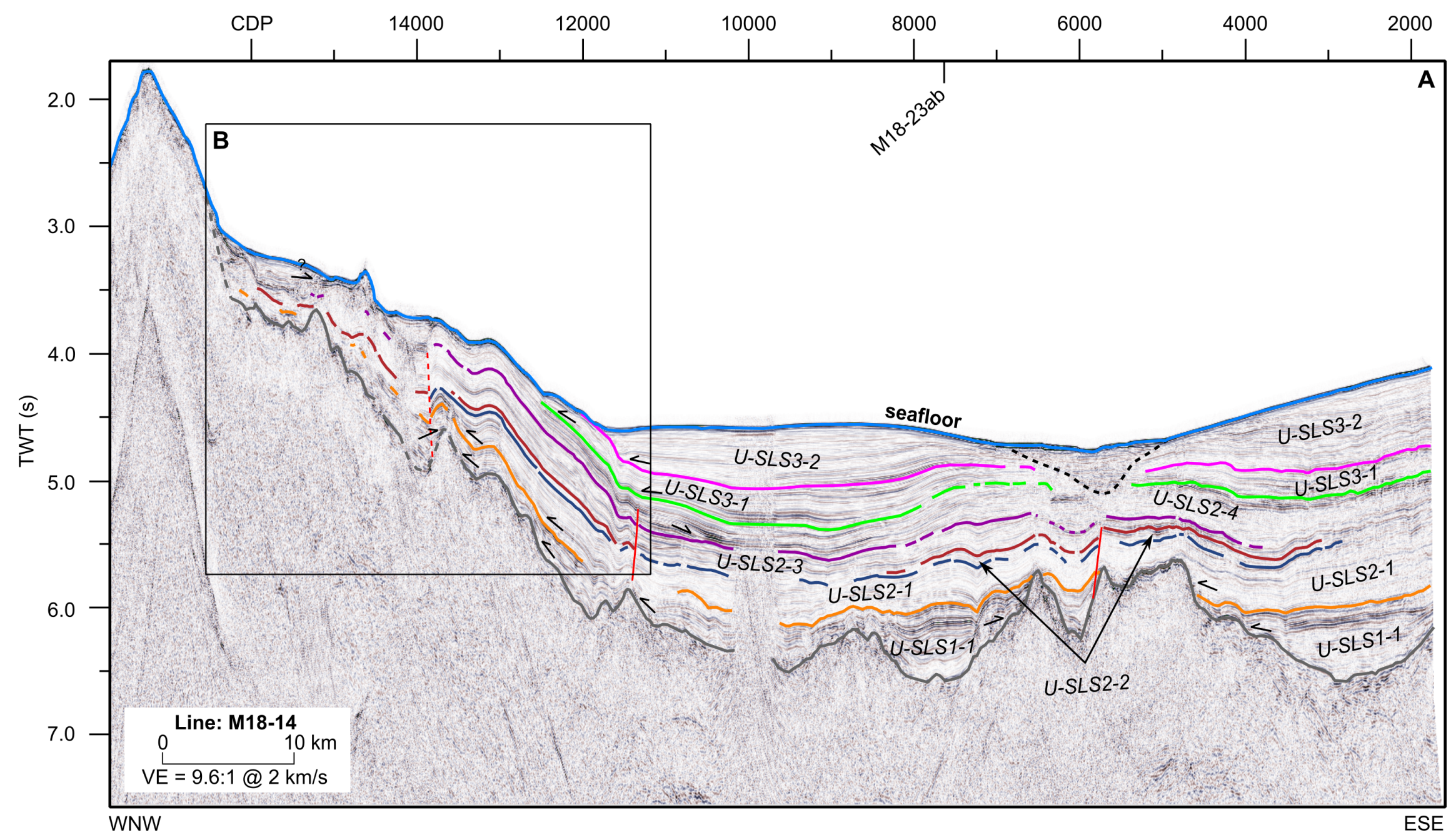

Fig. 5.6: Seismic stratigraphy for line M18-14, southern Solander Basin. Stratigraphic onlap is shown with small arrows. Stratigraphic terminations are indicated by dashed black lines. The black box shows the extent of Fig. 5.7. Faults are indicated by red lines. $V E=$ vertical exaggeration, see Fig. 1.1 for line location 


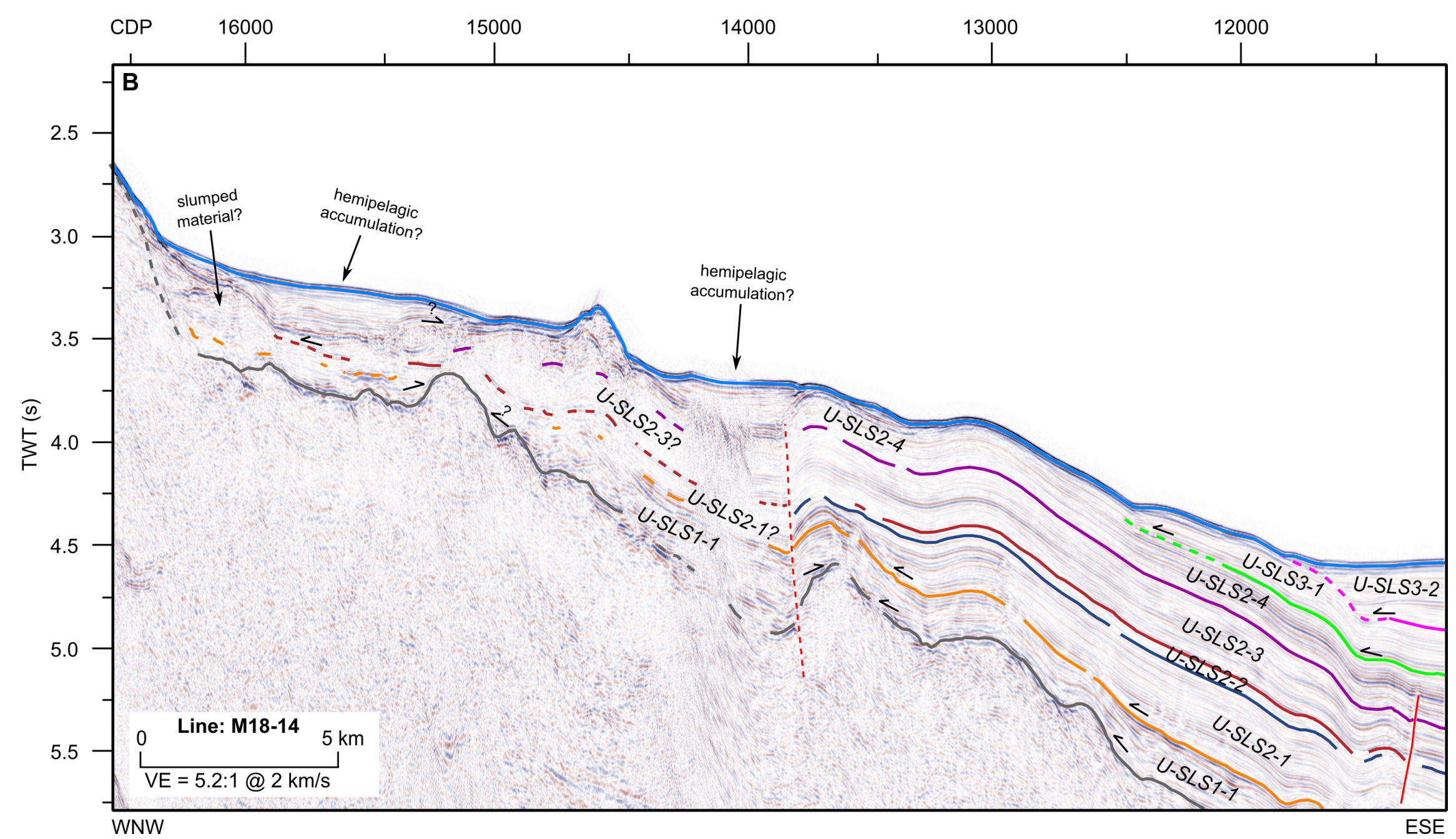

Fig. 5.7: Seismic stratigraphy for Puysegur Ridge, line M18-14, southern Solander Basin. Stratigraphic onlap is shown with small arrows. $V E=$ vertical exaggeration, see Fig. 5.6 for figure location 


\subsubsection{SLS2-1}

U-SLS2-1 comprises low continuity, moderate to low amplitude reflections on line M18-17b (Fig. 5.3). There is poor basal constraint on line M18-01 (Fig. 5.4); though where observed, reflections have high continuity and are of moderate to low amplitude. Despite volcanic basement at the northern end of line M18-23ab (Fig. 5.5), U-SLS2-1 is mappable to the south of this line, where reflections have high continuity and low to moderate amplitude. U-SLS2-1 is mapped further west onto line M18-14 (Fig. 5.6), where reflections are continuous and low to moderate amplitude. Faulting occurs at $\sim$ CDP 5750. The sequence is folded at around CDP 11500, and on the eastern flank of Puysegur Ridge from CDP 13000-13750 (Fig. 5.6). Correlations west of $\sim$ CDP 13850 were not made due to reverse faulting. U-SLS2-1 is thickest immediately south of Tauru High (Fig. 5.3). South of this, it tends to thin towards basement topography, with the most pronounced thinning occurring on the eastern flank of Puysegur Ridge, where it is uncertainly mapped (Fig. 5.7).

U-SLS2-1 strata downlap a continuous, low amplitude, positive polarity reflection south of Tauru High to $\sim$ CDP 8000 on line M18-17b (Fig. 5.3). South of CDP 8000, strata lie parallel to this basal reflection, though onlap onto basement occurs at the south of the line. West of the "central fault system" on line M18-01 (Fig. 5.4), U-SLS2-1 strata onlap basement where topography creates discrete sub-basins (e.g. CDP 36000; CDP 37350). East of this, strata onlap basement, though at the eastern edge of the line, basal relationships are unclear.

Further basement onlap occurs onto volcanic highs from CDP 2000-12000 and CDP 2900033500 to the south of the study area (line M18-23ab, Fig. 5.5). Onlap onto basement occurs at CDP 4700 on line M18-14 (Fig. 5.6), and farther west at Puysegur Ridge, strata onlap the low amplitude, positive polarity reflection identified south of Tauru High on line M18-17b (Fig. $5.3)$.

The basal reflection is distinguished as a megasequence boundary. At Tauru High, this surface represents the onset of reverse reactivation on Tauru High, as noted by the significant amount of footwall accommodation space created as well as downlapping relationships. Additionally, onlapping at Puysegur Ridge indicates that deposition in the southern Solander Trough began 
at this time, suggesting incipient growth of Puysegur Ridge (see section 6.5).

\subsubsection{SLS2-2}

South of Tauru High (line M18-17b, Fig. 5.3) and across the axis of the basin (line M18-01, Fig. 5.4), U-SLS2-2 consists of moderate to low amplitude reflections with high continuity. Along the axis of Solander Trough (line M18-23ab, Fig. 5.5), U-SLS2-2 comprises low to moderate amplitude reflections of low continuity. Stratigraphic pinchout occurs at a volcanic high at CDP 31000 (Fig. 5.5), though U-SLS2-2 is mapped to line M18-14 (Fig. 5.6). On this line, this unit is near reflection free: any reflections are low amplitude but have high continuity. Faulting of this unit occurs at $\sim$ CDP 5750. U-SLS2-2 is folded at CDP 11500; further folding is observed from 〜CDP 13000-13750. U-SLS2-2 is not mapped west of CDP 13850 due to reverse faulting. U-SLS2-2 is thickest in the northeast of the basin (Figs. 5.3 and 5.4), and markedly thin on the flank of Puysegur Ridge (Figs. 5.6 and 5.7).

Downlap of U-SLS2-2 strata occurs around CDP 9000 on line M18-17b (Fig. 5.3). This downlap surface is a continuous, high amplitude, reverse polarity reflection. South of this, strata are parallel with this reflection, which becomes lower amplitude and less continuous. However, onlap of U-SLS2-2 occurs at CDP 40700 on line M18-01 (Fig. 5.4). Onlap onto basement is observed at the southern end of line M18-17b, as well as to the west of the basin on line M18-01 (Fig. 5.4). In the centre of line M18-01 (axis of Solander Trough, Fig. 5.4), U-SLS2-2 onlaps basement (CDP 37500-38500). Volcanics from CDP 2000-12000 and CDP 29000-33500 along line M18-23ab (Fig. 5.5) are onlapped by U-SLS2-2.

This basal surface has been assigned sequence boundary status. Though first mapped based on the downlap relationships observed on line M18-17b, there are minimal terminations of USLS2-2 on this basal reflection.

\subsubsection{SLS2-3}

Across the entire southern area, U-SLS2-3 comprises moderate to low amplitude reflections that are continuous. In the southernmost study area (line M18-14, Fig. 5.6), strata are faulted at 
$\sim$ CDP 5750. On the same line, folding of this unit at the base of Puysegur Ridge ( CDP 11500) and on its eastern flank from $\sim$ CDP 13000-13750) is observed. U-SLS2-3 is comparatively thin on lines M18-17b (Fig. 5.3) and M18-01 (Fig. 5.4). South of CDP 14000 on line M18-23ab (Fig. 5.5), U-SLS2-3 thickens markedly. On line M18-14, this unit thins to the east and thickens towards Puysegur Ridge, though there are uncertainties in mapping of the basal reflection on the eastern flank of Puysegur Ridge.

At CDP 9500 on line M18-17b, onlap of U-SLS2-3 strata onto a continuous, high amplitude, positive polarity reflection occurs (Fig. 5.3). Further onlap onto this basal surface occurs to the east on line M18-01 (Fig. 5.4) and at $\sim \mathrm{CDP} 15000$ on line M18-23ab (Fig. 5.5). Elsewhere, these strata parallel this basal reflection. South of CDP 15000 on line M18-23ab, this surface is low continuity and low amplitude. U-SLS2-3 onlaps volcanic basement to the south of Tauru High on line M18-17b, and to the west of the basin on line M18-01. Southward on line M18-23ab, onlap onto volcanic basement occurs from CDP 4600-9300, and although no basement onlap is observed in the southernmost study area, onlap onto the basal reflection is inferred on Puysegur Ridge (line M18-14, Fig. 5.7).

The basal surface is mapped as a sequence boundary, based on high continuity and different internal stacking patterns above (U-SLS2-4) and below (U-SLS2-2).

\subsubsection{SLS2-4}

U-SLS2-4 comprises low to moderate amplitude, continuous reflections across the entire southern sub-basin. In the centre of line M18-17b, channelisation geometry is first observed at CDP $6500, \sim 4.25 \mathrm{~s}$ TWT (Fig. 5.3). East of the central fault system on line M18-01 (Fig. 5.4), further channelisation of this sequence is observed from CDP 38500-39500, 4.5 $\mathrm{s}$ TWT and from CDP 39000-39500, 4.0 s TWT. Near its upper bounding surface, minor channelisation also occurs at CDP 37500, line M18-23ab (Fig. 5.5) and CDP 6000, line M18-14 (Fig. 5.6). Folding of this unit and underlying units at the base of Puysegur Ridge ( $\sim \mathrm{CDP}$ 11400) ceased during deposition of this sequence (Fig. 5.6, see also Fig. 5.7), suggesting syntectonic deformation. Further folding of U-SLS2-4 is observed from $\sim$ CDP 13000-13750. USLS2-4 is thickest on the east of line M18-01, thins along the axis of Solander Trough (line 
M18-23ab), and is thinnest on Puysegur Ridge.

U-SLS2-4 is largely parallel with its basal reflection, which is a continuous, moderate to high amplitude, reverse polarity reflection across the southern region. Minor onlap onto this surface occurs adjacent to the central fault system on line M18-01 (CDP 37500, Fig. 5.4), and east of Puysegur Ridge (line M18-14, CDP 11500, Fig. 5.6). Basement onlap is prominent in the south sub-basin (Figs. 5.3, 5.4, 5.5 and 5.6).

The basal surface has been demarked as a sequence boundary, with different stacking and reflection character of underlying (U-SLS2-3) and overlying (U-SLS3-1) units. Minimal stratal terminations are observed.

\subsubsection{SLS3-1}

On line M18-17b, U-SLS3-1 comprises moderate to low amplitude reflections of variable continuity. Within U-SLS3-1, facies U-SLS3-1a and U-SLS3-1b are identified on this line (Fig. 5.3). Facies U-SLS3-1a is mapped from CDP 35500-37400 on line M18-23ab (Fig. 5.5). U-SLS31a contains moderate to low amplitude reflections of moderate continuity, whereas U-SLS3-1b consists of higher amplitude reflections of lower continuity. Both have limited extent north of CDP 7000 on line M18-17b, and both onlap basement to the south of M18-17b. Along line M18-01, U-SLS3-1 strata are of similar amplitude to line M18-17b, with high continuity (Fig. 5.4). Farther south at CDP 39000, channelisation is observed. Along strike of Solander Trough (line M18-23ab, Fig. 5.5), U-SLS3-1 is comprised of low to moderate amplitude reflections that have low continuity. Channelisation (with seabed expression) of this unit is mapped at CDP 10200 and 13600; further channelisation is observed at the southern end of the line at CDP 39500. U-SLS3-1 is mapped to line M18-14 (Fig. 5.6), where strata are moderate to low amplitude and are continuous. A modern channel at CDP 5800 incises this unit, south of which strata are mapped to CDP 12500, at the foot of Puysegur Ridge (see also Fig. 5.7).

Onlap onto a basal surface was identified east of Puysegur Ridge at CDP 11200 and 12500 (Fig. 5.6), where reflection is variably continuous, low amplitude, and reverse polarity. It is of moderate to low amplitude and low continuity along the axis of the study area (line M18-23ab, 
Fig. 5.5). Though mostly parallel with this surface, basal onlap of U-SLS3-1 is observed along line M18-23ab at CDP 23000 and 32600. Further west on line M18-01, onlap of U-SLS3-1 onto this surface occurs at CDP 35750 and CDP 41000-41500 (Fig. 5.4). Strata lie parallel to this surface south of Tauru High (line M18-17b, Fig 5.3). Overall, this unit is of relatively consistent thickness, though thickening occurs adjacent to Puysegur Ridge on line M18-14 (Figs. 5.6 and $5.7)$.

Across lines M18-17b, M18-01 and M18-23ab, onlap of U-SLS3-1 onto basement is observed, though notably these strata do also overlie basement topography. This is observed from CDP 1100-2200 (line M18-17b, Fig. 5.3), CDP 35000 (line M18-01, Fig. 5.4) and CDP 7200-8100 (line M18-23ab, Fig. 5.5).

Designation of this basal surface as megasequence status is justified from onlap and growth of U-SLS3-1 strata next to Puysegur Ridge. The onset of channelisation within this unit provides further evidence.

\subsubsection{SLS3-2}

South of Tauru High on line M18-17b, U-SLS3-2 encompasses moderate to low amplitude reflections of high continuity (Fig. 5.3), with little variation across Solander Trough (line M1801, Fig. 5.4). At the western edge of the basin (line M18-01), active scouring by a channel occurs (CDP 33950), and immediately east of this, sediment drift deposits are present (see swath bathymetry, Fig. 6.10). To the east, strata are channelised at CDP 39400, and toward the Campbell Plateau, eroded topography of U-SLS3-2 produce irregular seafloor morphology (see swath bathymetry, Fig. 6.3). Along line M18-23ab (Fig. 5.5), U-SLS3-2 comprises low to moderate amplitude, low continuity reflections. Active channelisation of this sequence is observed at CDP 10200 and 13600 (Fig. 6.8), and to the south of the line at CDP 39500. Further channelisation occurs to the west along line M18-14 (CDP 5800, Fig. 5.6; see swath bathymetry, Fig. 6.9). On this line, reflections are low to moderate amplitude with good continuity. This unit is of variable thickness across the southern study area.

Basal onlap of U-SLS3-2 onto a continuous, low amplitude, reverse polarity reflection is 
observed at CDP 11500 on line M18-14 (Fig. 5.6). Northward on line M18-23ab, onlap is observed at CDP 22900 (Fig. 5.5) and further west on line M18-01 at CDP 35850 (Fig. 5.4). Elsewhere, U-SLS3-2 strata lie parallel to this reflection. Unlike underlying strata, onlap of USLS3-2 onto basement is limited to the western margin of line M18-01 (Fig. 5.4). To the east of this line, despite poor mapping of the base of SLN3, U-SLS3-2 is interpreted to unconformably overlie U-SLS2-4 strata.

\subsection{Chapter Conclusion}

This chapter has summarised the seismic stratigraphy mapping of seismic data acquired during MGL1803. In the northern sub-basin, four megasequences are mapped, with eight sequences defined. Mapping in the southern sub-basin has identified three megasequences, with seven sequences correlated. This mapping has provided the first stratigraphic analysis from Parara-1 to Solander Trough. 


\section{Chapter 6}

\section{Discussion}

\subsection{Introduction}

This chapter presents geological interpretations for Solander Trough. The first section covers active seabed processes in the study area, as imaged by seismic and high resolution $(\sim 10 \mathrm{~m})$ swath bathymetry data acquired during MGL1803. In Appendix 4, Fig. 4A-1 provides a location for each image. The second section discusses the development of Parara Anticline. Similarly, the third section models the evolution of Tauru High. The final section is a regional basin synthesis, where a stratigraphic and tectonic evolution interpretation for Solander Trough is provided.

\subsection{Present Day Depositional Mechanisms}

\subsubsection{Tasman Sea}

Tasman Sea, located between Australia and New Zealand (Fig. 1.4), is an area of high biologic productivity (Jitts, 1965; Hassler et al., 2014). Despite this, ACC circulation initiation around 34 Ma (Barker et al., 2007; Katz et al., 2011) means that sediments are swept eastward, localising sedimentation to small depocentres. This is illustrated in swath data at the western ends of lines M18-01 and M18-14 (Figs. 6.1 and 6.2). 


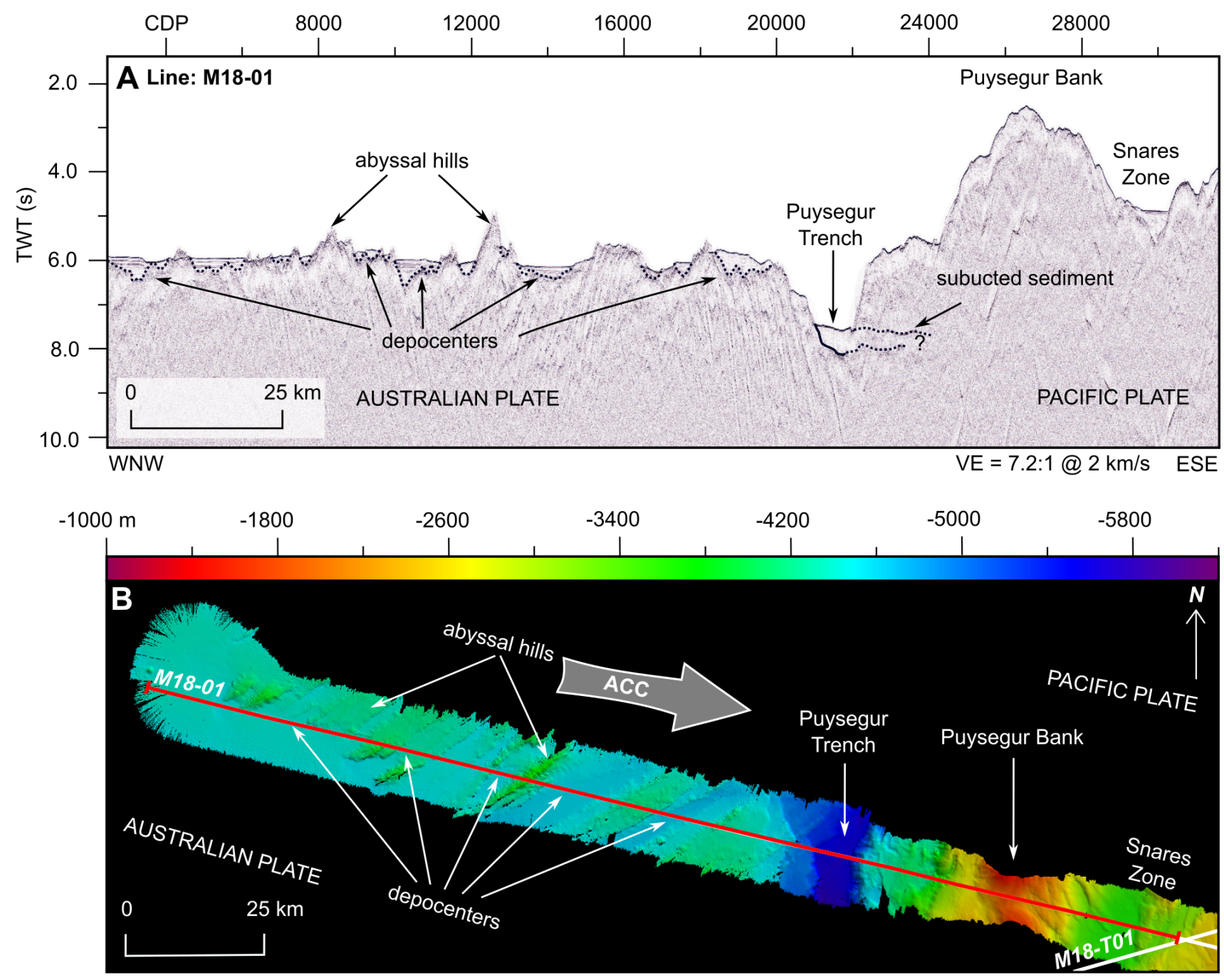

Fig. 6.1: Deposition on Tasman Sea oceanic crust, line M18-01. Panel A shows depocentres in seismic (dotted lines), and Panel B shows them in swath bathymetry. Easterly ACC circulation (Panel B) localises sedimentation to accommodation space in lee of abyssal hills (e.g Buck et al., 2005). The red line in Panel B shows the extent of Panel A. See Fig. 4A-1 for location 


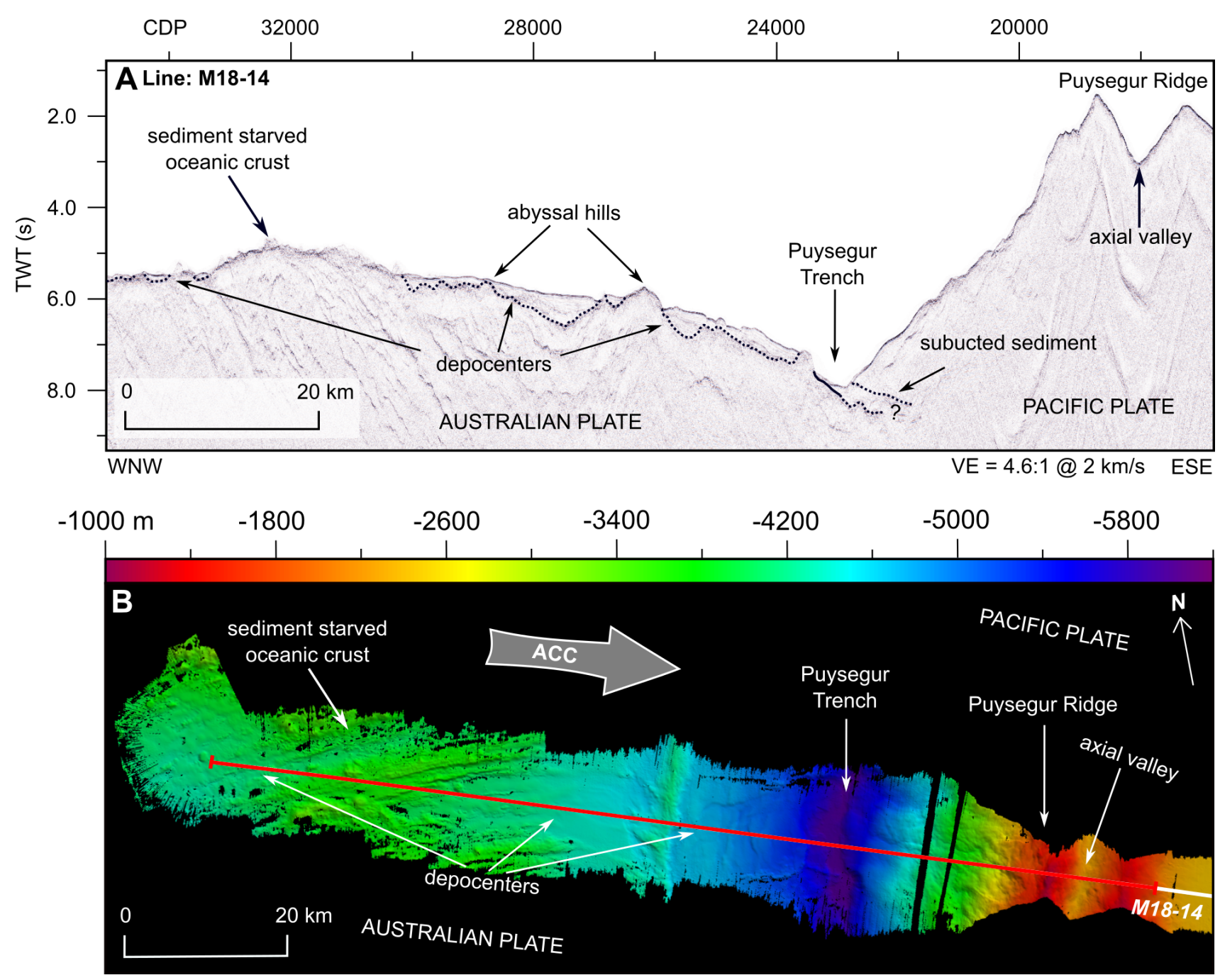

Fig. 6.2: Deposition on Tasman Sea oceanic crust, line M18-14. Panel A shows depocentres in seismic (dotted lines), and Panel B shows them in swath bathymetry. Easterly ACC circulation (Panel B) localises sedimentation to accommodation space in lee of abyssal hills (e.g Buck et al., 2005). The red line in Panel B shows the extent of Panel A. See Fig. 4A-1 for location

In Figs. 6.1 and 6.2, relatively thin $(<400 \mathrm{~m})$ of sediment accummulates in depressions in lee of abyssal hills, which are topographic features associated with normal fault blocks and/or volcanic edifices created parallel to mid-ocean ridge axes (Malinverno and Cowie, 1993). This submarine topography also trends parallel to magnetic anomalies associated with mid-ocean ridge spreading (e.g. Barker et al., 2008). It is interpreted that the ACC transports most sediment away from the Tasman Sea floor, resulting in near zero sedimentary cover in the abyssal ocean. 


\subsubsection{Solander Trough}

\section{Sediment Gravity Flows}

Examples of active erosion in the form of sediment gravity flows occur on the eastern margin of Solander Trough, on the Campbell Plateau continental slope. Features are shown in Fig. 6.3 (line M18-01), and Fig. 6.4 (line M18-03a).

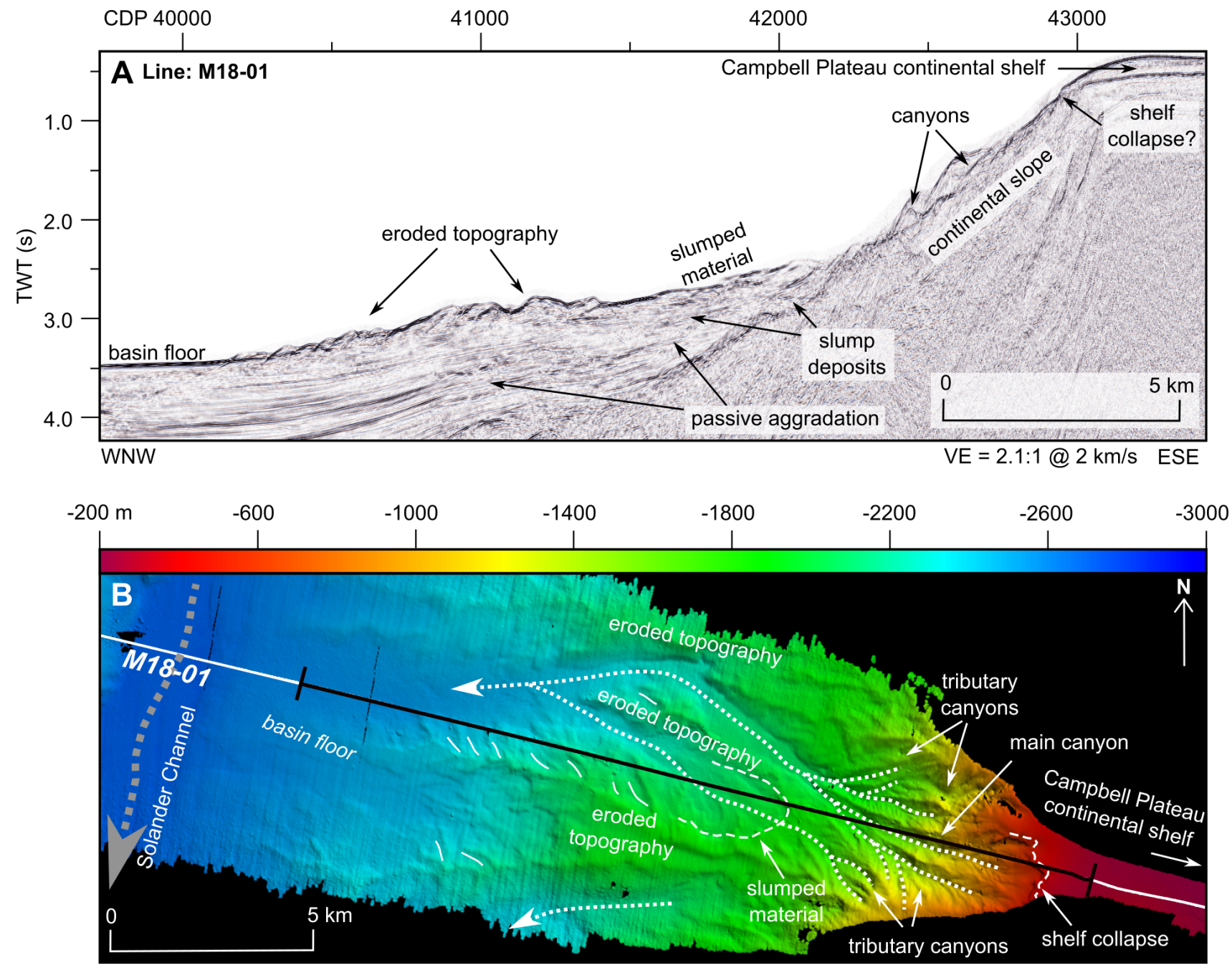

Fig. 6.3: Canyon system that has developed on the Campbell Plateau continental slope on line M18-01, shown in seismic (Panel A) and swath bathymetry (Panel B). In Panel B, dotted white lines indicate sediment gravity flow pathways, solid white lines indicate erosion by bottom currents and dashed white lines show slope failure. The grey dotted line shows the flow of Solander Channel. The black line in Panel B shows the extent of Panel A. See Fig. 4A-1 for location

Figs. 6.3 and 6.4 are located on the eastern edges of lines M18-01 and M18-03a respectively. 


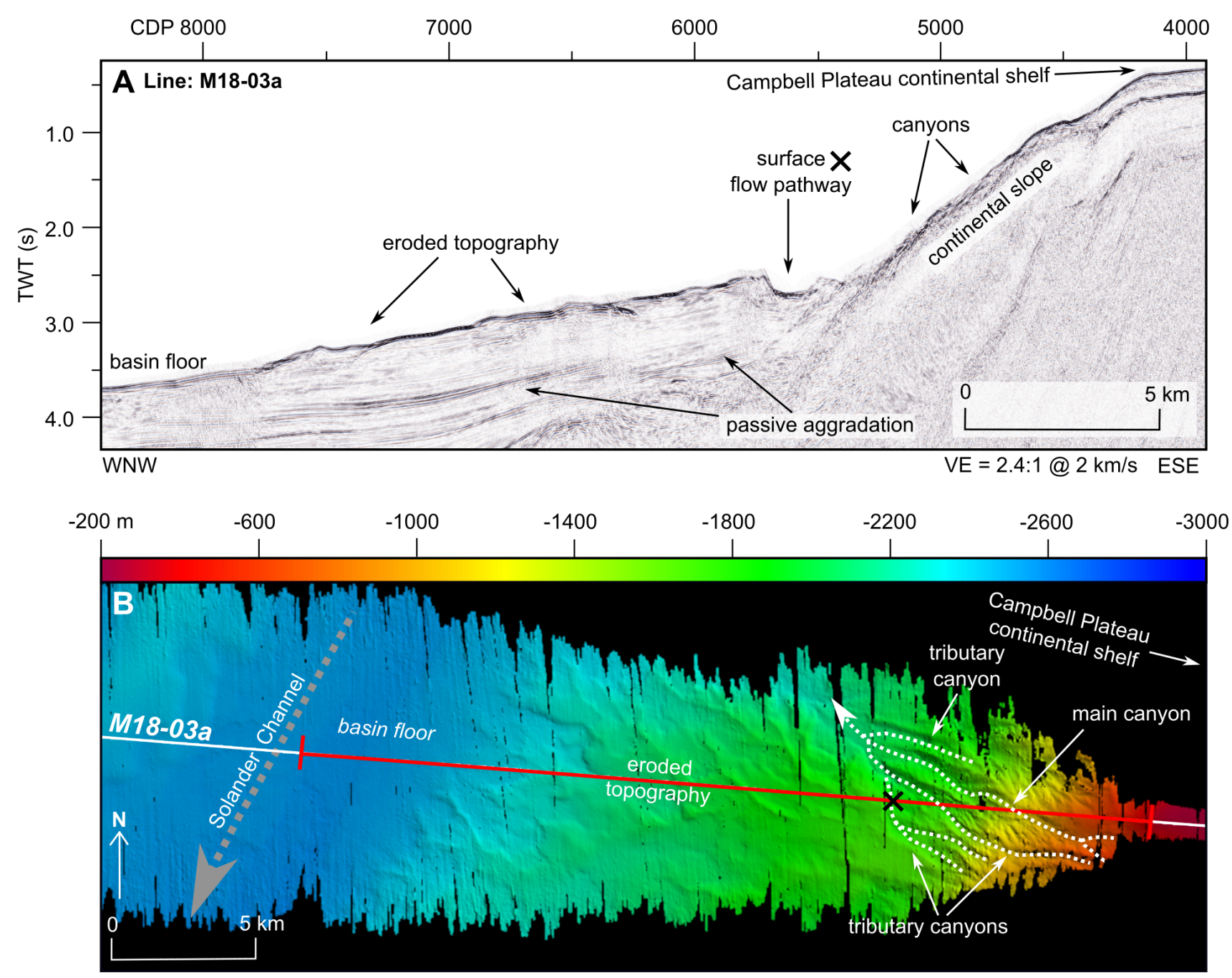

Fig. 6.4: Canyon system that has developed on the Campbell Plateau continental slope on line M18-03a ( 12 km south of Fig. 6.3), shown in seismic (Panel A) and in swath bathymetry (Panel B). In Panel B, dotted white lines indicate sediment gravity flow pathways. The black cross marks a tributary canyon that has incised eroded topography. The grey dotted line shows the flow of Solander Channel. The red line in Panel B shows the extent of Panel A. See Fig. 4A-1 for location

A main canyon has been identified, with several smaller, "tributary" canyons that join the main canyon downslope of the shelf break. These canyons provide a conduit for sediment transport from the continental shelf to the deep ocean, which may be as turbidite flows (e.g. Carter et al., 1996a). If exposed during periods of low sea level, there is potential for fluvial deposition directly to canyon systems, and potentially the basin floor (e.g. Carter and McCave, 1997).

Canyons from the continental slope develop basinward into relatively flat-lying, sediment bare topography that is heavily eroded. On Fig. 6.3, these surfaces are rilled on their northern 
side. This suggests that there is significant scouring of this topography by south flowing bottom currents. Lack of rilling on Fig. 6.4 suggests a weakening/redirection of bottom currents, though a tributary canyon that incises eroded topography is noted (Panel B). Other features of note on Fig. 6.3 include shelf collapse at the shelf break, and slumped material at the foot of the canyon system. In both examples, general aggradation of sediment (unrelated to canyon-derived sediment gravity flows) may be the result of north to south deposition and/or settling of material as a result of $\mathrm{ACC}$ flow in the lee of Puysegur Ridge.

\section{Channelisation}

Numerous channel features were identified in swath bathymery data. These are mostly related to scouring by Solander Channel, a $>450 \mathrm{~km}$ long, sinuous feature that extends from the Stewart Island continental shelf and terminates in the Emerald Basin south of the study area (Fig. 6.5, Carter et al., 1996a, see Fig. 1.1 for location). From the Stewart Island continental shelf, a tributary channel to Solander Channel has been identified (Fig. 6.5). 

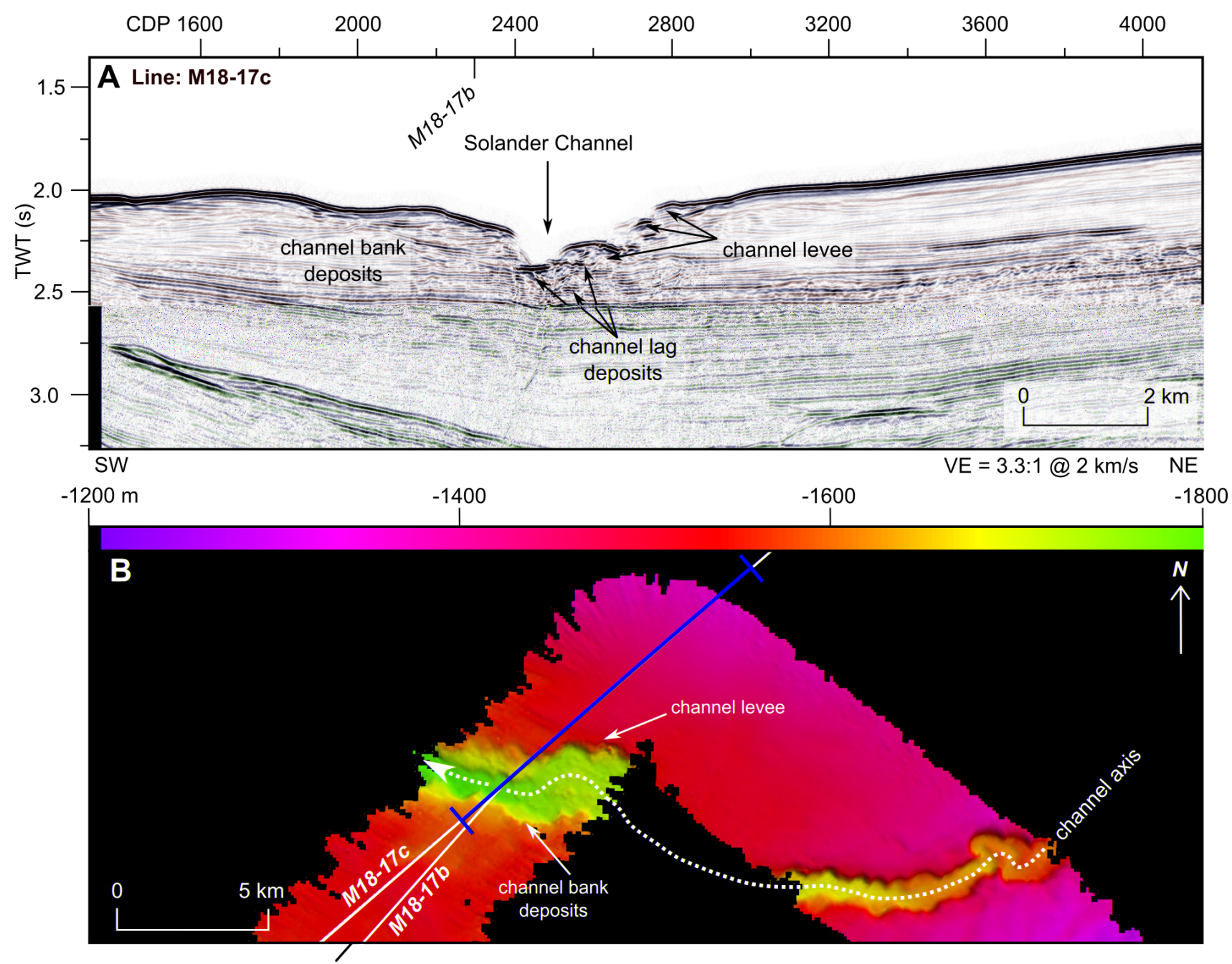

Fig. 6.5: Tributary channel to Solander Channel, line M18-17c, shown in seismic (Panel A) and in swath bathymetry (Panel B). The red line in Panel B shows the extent of Panel A. See Fig. 4A-1 for location

This northeast-west flowing channel is asymmetric in profile. Its eastern margin is marked by successive build-up of levee deposits. This side is slightly elevated: analysis by Carter and Carter (1988) suggests preferential levee development on the east is due to Coriolis deflection. Eastward flowing STF waters may also help aggrade these levees (see Fig. 1.4). Channel lag deposits indicate lateral migration of Solander Channel over time. Its v-shaped profile suggests a relatively high amount of vertical erosion to lateral erosion.

Fig. 6.6 illustrates a less developed channel adjacent to Solander Channel, on line M1817b. These channels, located south of Tauru High, show a drastically different morphology and evolution history. 


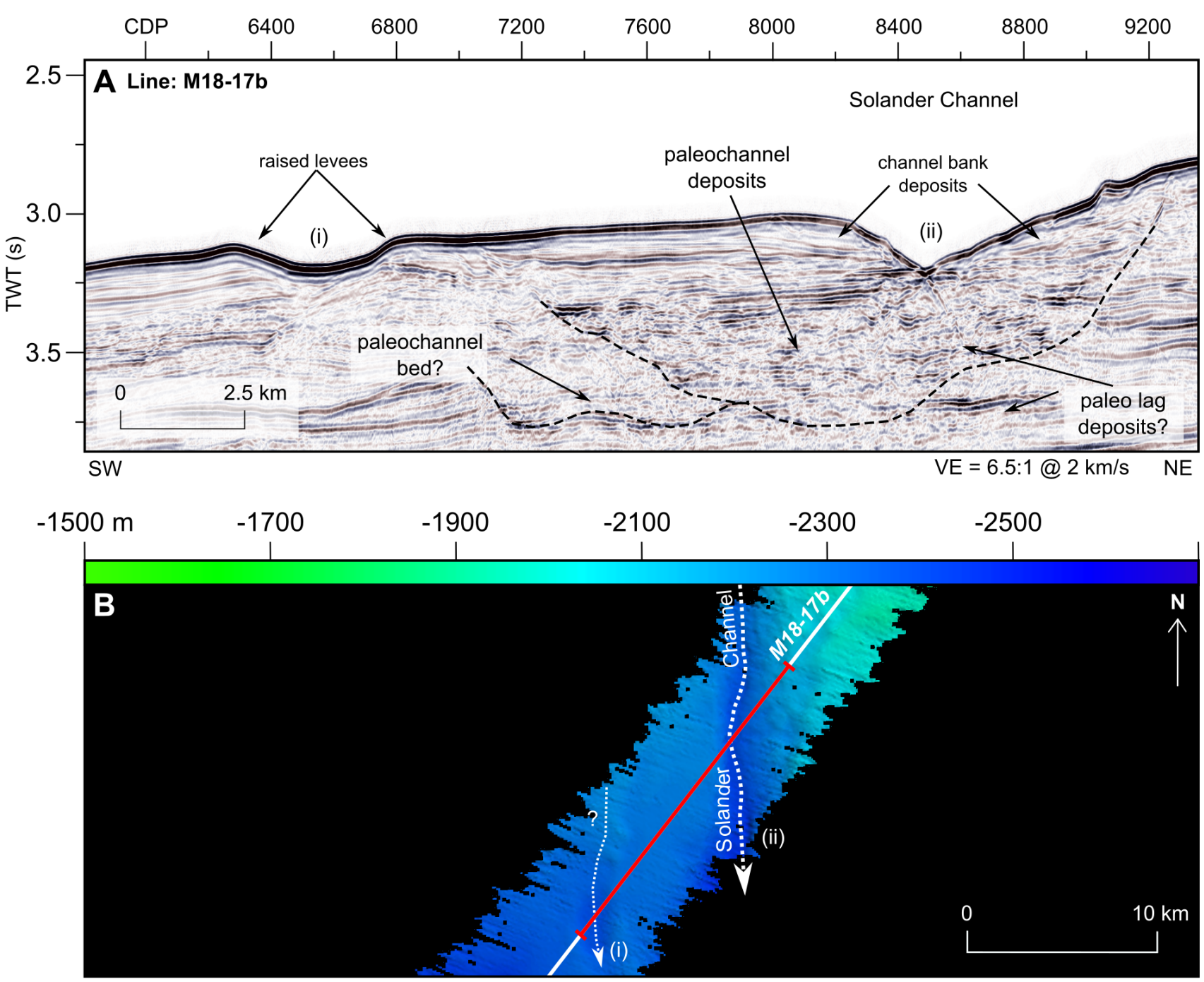

Fig. 6.6: Channels shown on line M18-17b, in seismic (Panel A) and swath bathymetry (Panel B). Channel (i) and Solander Channel (ii) show different morphologies and evolution histories. The red line in Panel B shows the extent of Panel A. See Fig. 4A-1 for location

Channel (i) in Fig. 6.6 has a gentler profile than Solander Channel (ii). It also has a less developed evolution, as evidenced by the lack of paleo lag deposits, compared to Solander Channel (ii), where extensive lateral paleo lag deposits indicate lateral migration over time (Panel A, Fig. 6.6). This suggests channel (i) is younger than Solander Channel, thus is interpreted as a tributary channel. A shared characteristic of both channels is the slightly elevated eastern margin, indicating preferential deposition on this margin (Carter and Carter, 1988).

Fig. 6.7 presents a view of Solander Channel perpendicular to the axis of Solander Trough. 


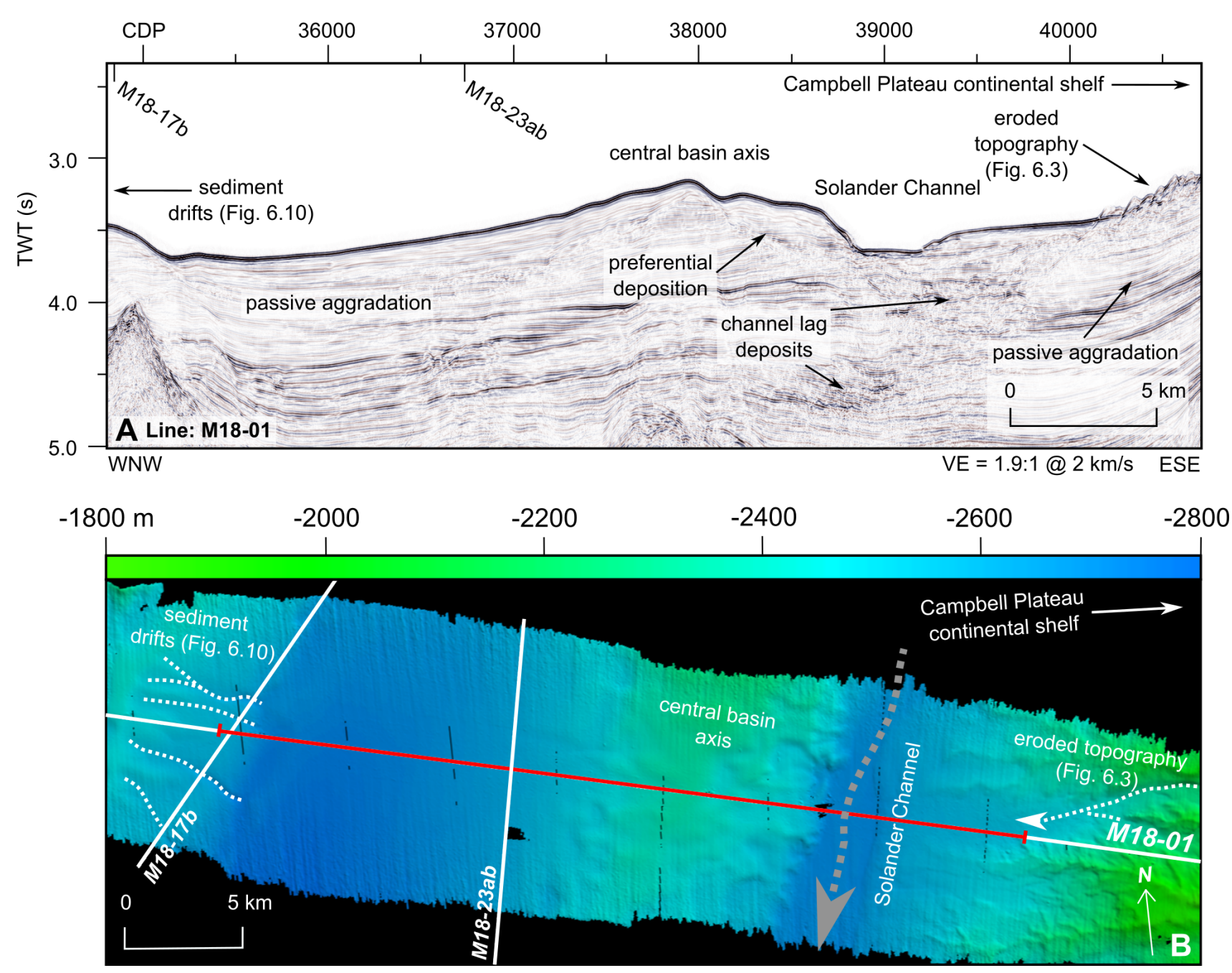

Fig. 6.7: Solander Channel as shown on line MCS01, with a secondary across-basin channel to the west. Panel A shows these features in seismic; Panel B shows them in swath bathymetry. Sediment drifts (Fig. 6.10) and eroded topography (Fig. 6.3) are labelled, where dotted white lines indicate sediment gravity flow pathways. The red line in Panel B shows the extent of Panel A. See Fig. 4A-1 for location

Solander Channel's varied history is shown by the laterally and vertically migrating channel lag deposits, marked by high amplitude reflections (Panel A, Fig. 6.7). An elevated western margin contradicts Figs. 6.5 and 6.6 (see Carter and Carter, 1988). Here, it is proposed that the elevated central basin axis (see Fig. 5.4) is the main contributor to an elevated channel margin, rather than preferential deposition to the east due to the Coriolis force. Note that sediment drifts (Fig. 6.10) and eroded topography (Fig. 6.3) are labelled to the west and east respectively: these features are discussed in the next section.

On line M18-23ab, a two-channel system is illustrated in Fig. 6.8. 


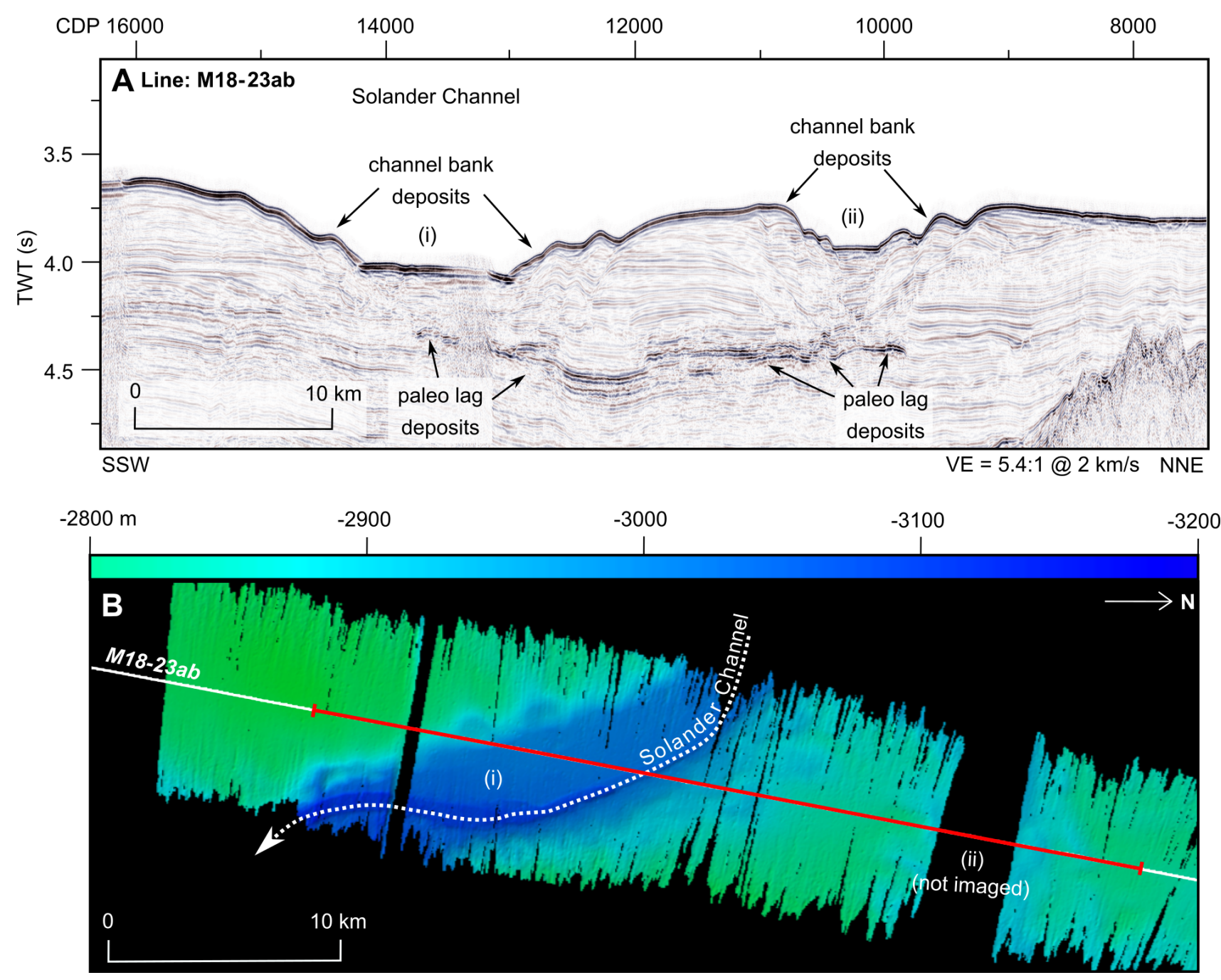

Fig. 6.8: Solander Channel (i) and a more developed channel (ii) on line M18-23ab, shown in seismic (Panel A) and in swath bathymetry (Panel B). Note channel (ii) was not recorded in swath bathymetry. The red line in Panel B shows the extent of Panel A. See Fig. $4 A-1$ for location

Though this contrast in morphologies is not as pronounced as Fig. 6.6, Solander Channel is broader in profile and has less developed channel bank deposits (Panel A). By comparison, channel (ii) is more vertically incised, has more developed channel bank deposits, and deeper paleo lag deposits. This indicates longer-lived channelisation by (ii) compared to Solander Channel. Channel (ii) was not imaged in swath bathymetry.

At the southern end of the study area, Solander Channel has been identified on lines M1823ab and M18-14 (Fig. 6.9). In Panel B, incision of the Campbell Plateau continental shelf is observed to the east of line M18-14, facilitating sediment transport from the shelf to the deep ocean by sediment gravity flow mechanisms. 

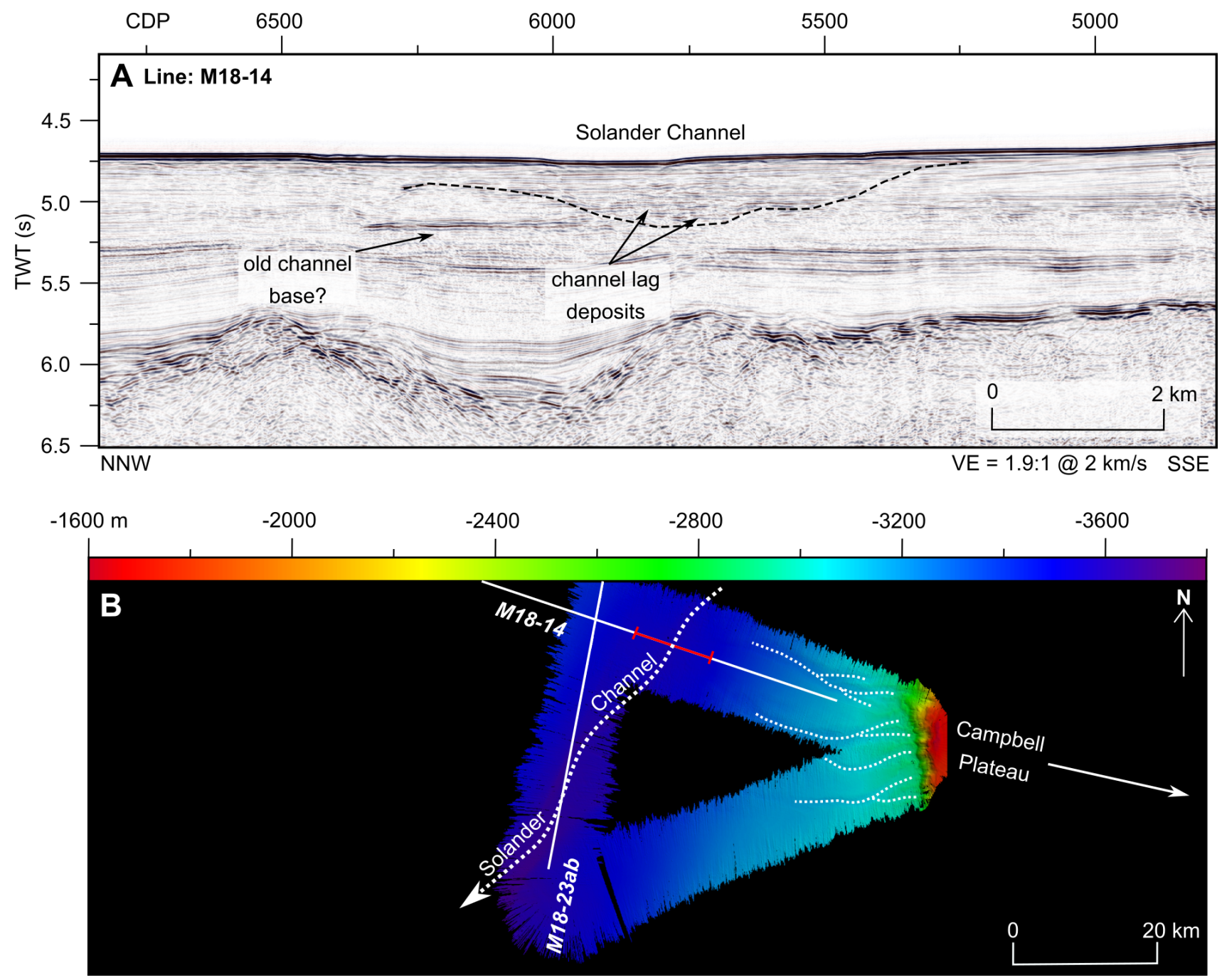

Fig. 6.9: Solander Channel as shown in seismic (Panel A) and swath bathymetry (Panel B). To the east of Panel B, incision of the Campbell Plateau continental slope is observed. Dotted white lines indicate sediment gravity flow pathways. The red line in Panel B shows the extent of Panel A. See Fig. 4A-1 for location 


\section{Sediment Drifts}

Fig. 6.10 displays sedimentary drifts on line M18-01. These undulatory bedforms are related to moating around a topographic high (McCave and Tucholke, 1986).

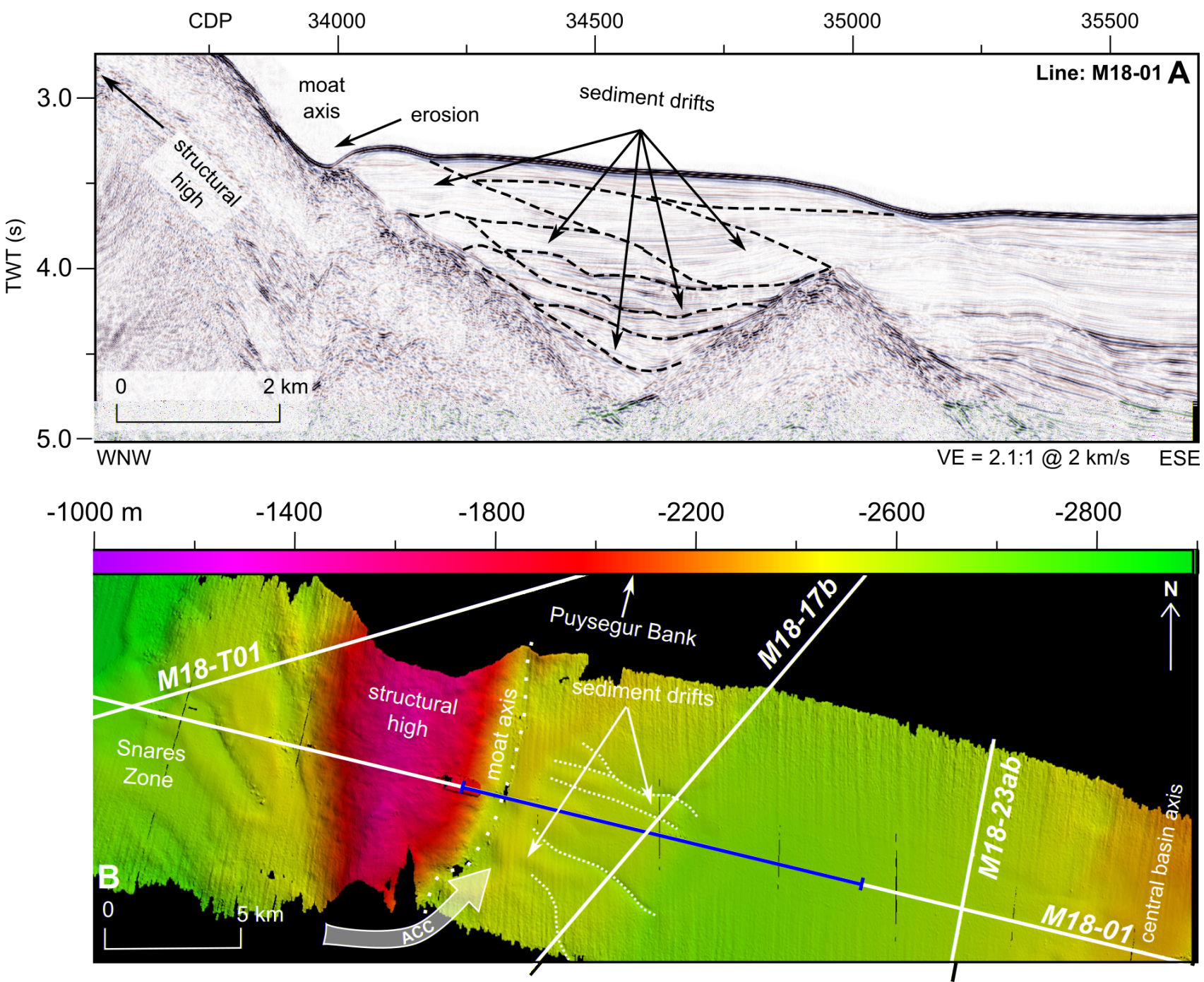

Fig. 6.10: Sediment drifts on line M18-01, shown in seismic (Panel A) and in swath bathymetry (Panel B). Sediment gravity flow pathways are indicated by the heavily dotted white lines (Panel $B)$, whereas moat scouring is marked by the lightly dotted line. ACC deflection is shown in Panel B. The red line in Panel B shows the extent of Panel A. See Fig. 4A-1 for location

In this example, sediment drifts are deposited adjacent to a moat. It is proposed that acceleration of strong, easterly ACC flow around a structural high has encouraged moating at its base (Fig. 6.10, Panel B), due to a topographic gap in the Snares Zone. Here, it is theorised that the growth of Puysegur Ridge and subsequently the Snares Zone led to development of this structural high. Deposition of sediment drifts perpendicular to moating occurs (e.g. Stow et al., 
2002). In seismic (Panel A), these drifts are somewhat lenticular, concave-up features: these drifts are a type of contourite drift defined as "elongate mound drifts" by (Stow et al., 2002).

Another example of sediment drifts is shown on line M18-03a (Fig. 6.11), approximately $22 \mathrm{~km}$ south of Fig. 6.10. These drifts are smaller in amplitude and wavelength. Here, a less prominent moat adjacent to the structural high (Panel B) indicates less seafloor erosion, probably due to the lower erosive energy of deflected ACC flow.

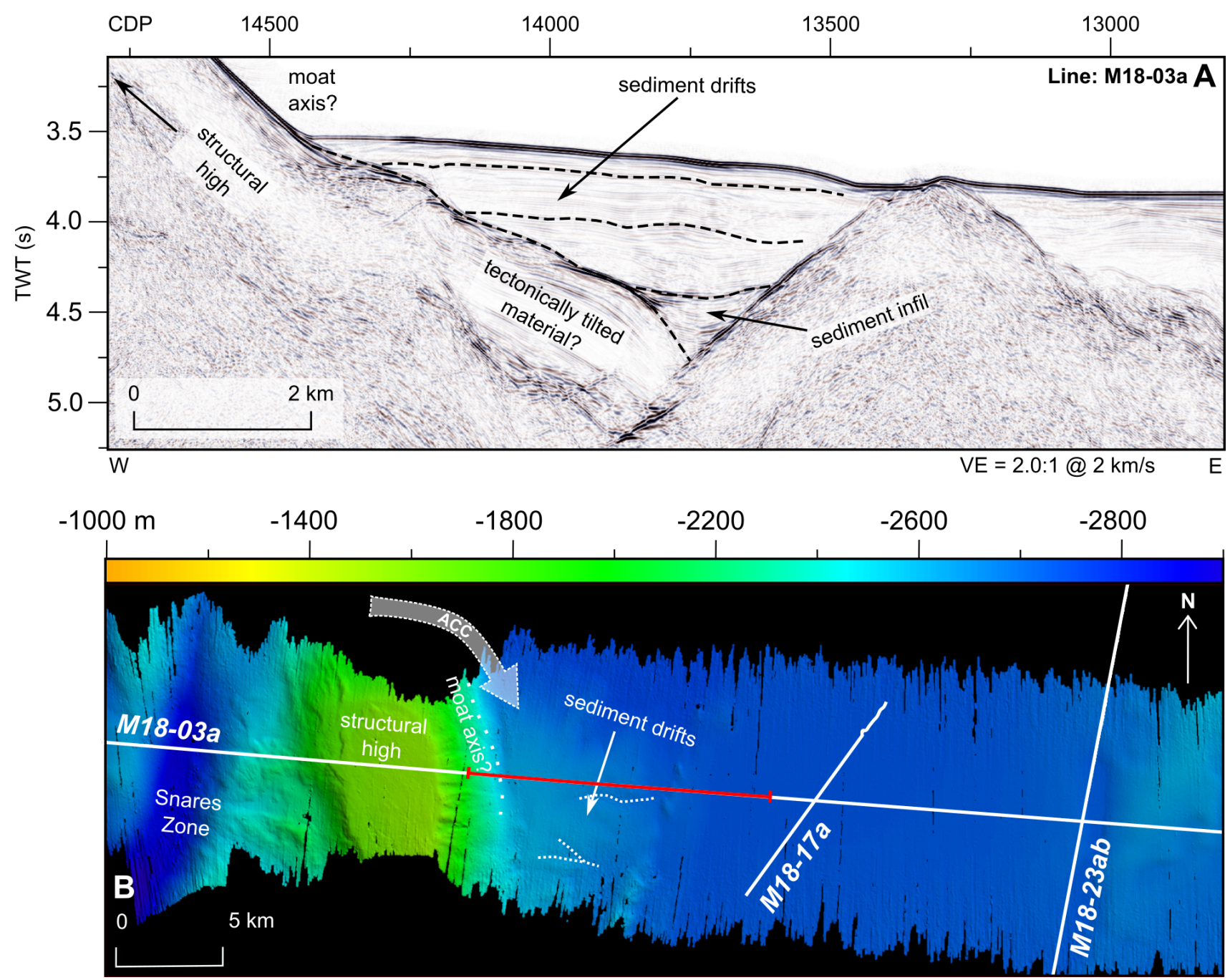

Fig. 6.11: Sediment drifts on line M18-03a, shown in seismic (Panel A) and in swath bathymetry (Panel B). Sediment gravity flow pathways are indicated by the heavily dotted white lines (Panel $B)$, whereas moat scouring is marked by the lightly dotted line. Note the less pronounced moat compared to Fig. 6.10. ACC deflection is shown in Panel B. The red line in Panel B shows the extent of Panel A. See Fig. 4A-1 for location 


\subsubsection{Modern shelf and slope}

Swath bathymetry imaged the continental shelf south of Fiordland at depths $>70 \mathrm{~m}$, showing that it dips at $<1^{\circ}$, landward of the shelf break. The shelf transitions to the continental slope, which is relatively steeper at around $1^{\circ}$. West of Puysegur Bank, the continental slope transitions to the Puysegur Trench; slopes steepen markedly from 3-4 to a maximum of around $9^{\circ}$.

On the present day continental shelf on lines M18-17c and S86-34, prograding shelves have been imaged as part of sequence U-SLN4-2 (Figs. 6.12 and 6.13).

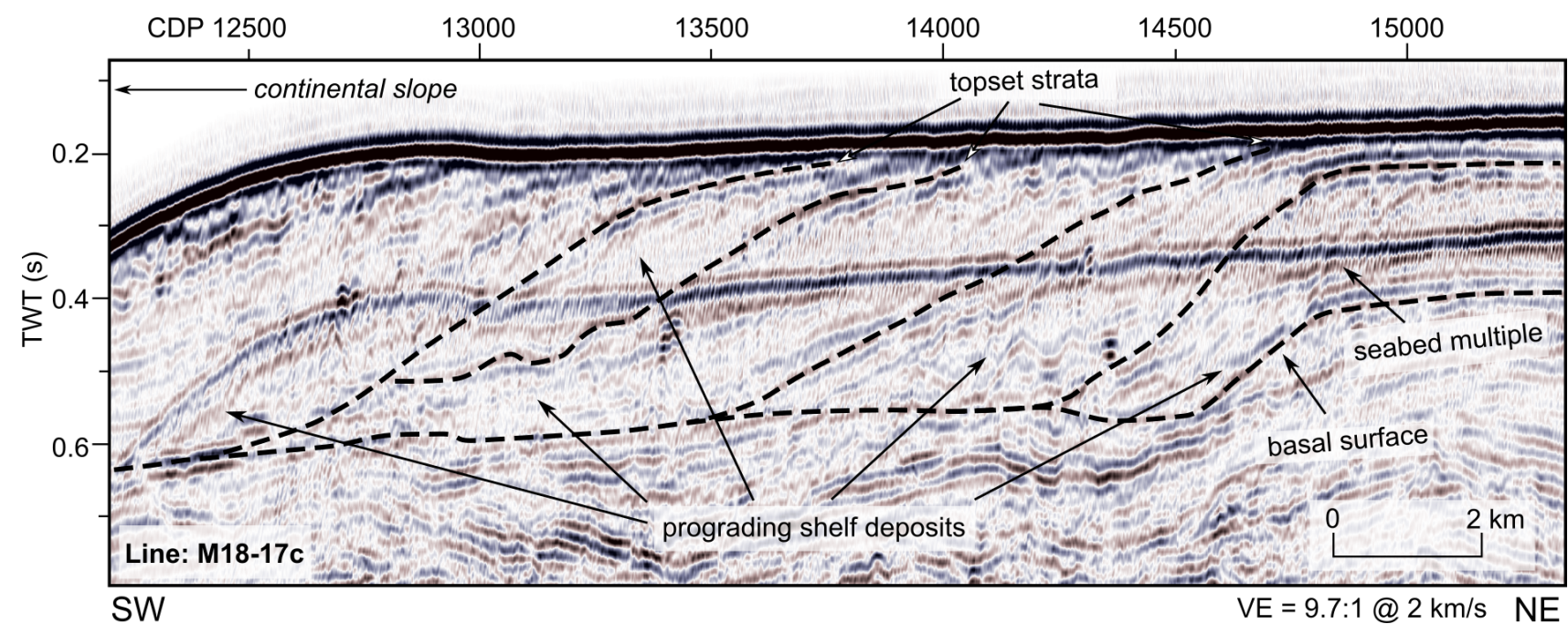

Fig. 6.12: Prograding shelf deposits on line M18-17c, illustrating a sigmoidal clinoform pattern (see Mitchum et al., 1977). See Fig. 4A-1 for location

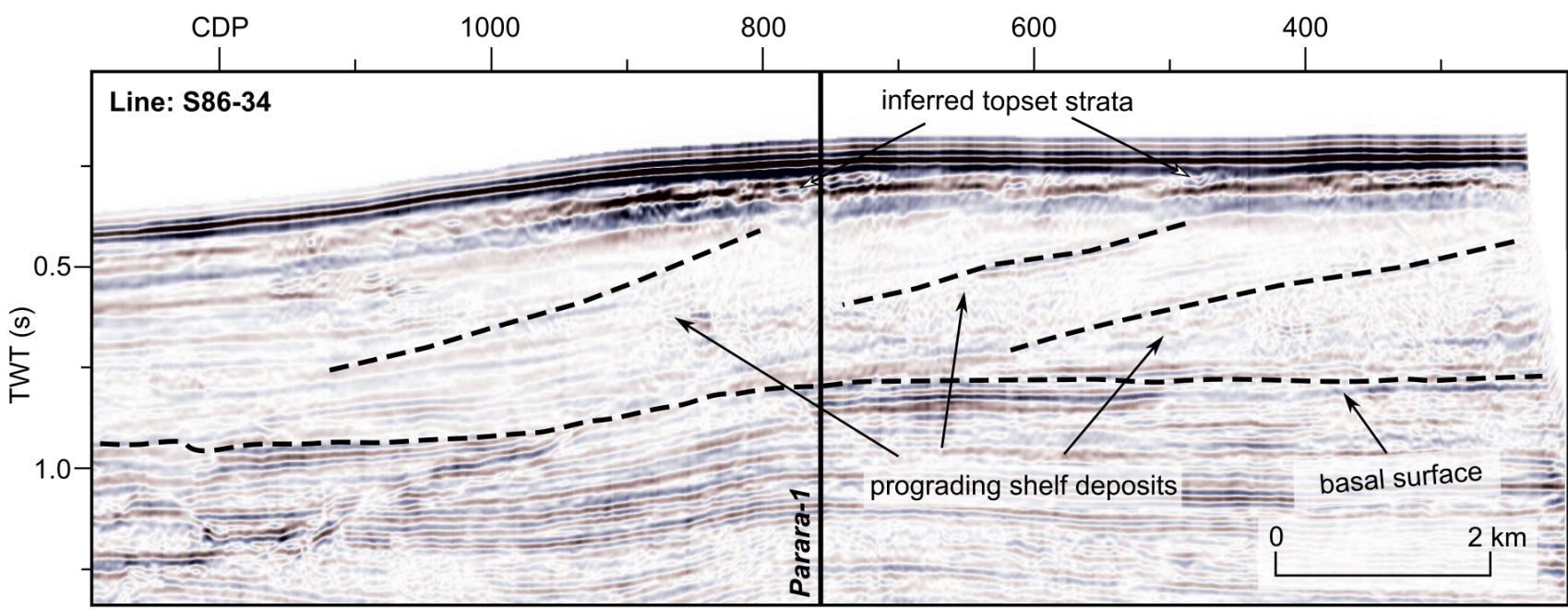

WNW

$\mathrm{VE}=3.7: 1 @ 2 \mathrm{~km} / \mathrm{s}$ ESE

Fig. 6.13: Prograding shelf deposits on line S86-34, illustrating a sigmoidal clinoform pattern (see Mitchum et al., 197r). See Fig. 4A-1 for location 
Strata in Figs. 6.12 and 6.13 illustrate a characteristic sigmoidal clinoform geometry with relatively thin upper and lower portions at shallow dips, and a thicker central section (Mitchum et al., 1977). This prograding shelf pattern indicates deposition at $<1^{\circ}$ dip. The upper (topset) strata are parallel to the upper surface of the beds; according to Mitchum et al. (1977), this indicates continued aggradation of the upper portions of the beds simultaneously with middle segment progradation (see also Fulthorpe and Carter, 1991). The lower strata downlap the basal surface. Mitchum et al. (1977) state that this shelf configuration implies a combination of low sediment input, rapid basin subsidence and/or rapid sea level rise.

\subsubsection{Pockmarks}

Further to the south on the modern day continental slope (line M18-17c), pockmark features are evident in seismic and swath bathymetry. These oval-shaped depressions are up to $200 \mathrm{~m}$ wide and tens of metres deep (Fig. 6.14).

Pockmarks are typically the result of fluid (e.g. hydrocarbon, volcanic, groundwater) escaping from strata below, producing concave depressions, according to Hovland et al. (2002), who classify elongate pockmarks based on their asymmetry. Their north to south elongation (Panel B) direction indicate bottom current direction (e.g. Boe et al., 1998). These pockmarks are located $\sim 18 \mathrm{~km}$ southeast of Solander Island, so one possibility for their existence is volcanic gas expulsion or hydrothermal dewatering (Ondréas et al., 2018). Another possibility is ther-

mal maturation of Cretaceous coal measures present in the north by Solander-1 (Shaheen and Hutson, 1989), due to heat input from Solander Island volcano (Reay and Parkinson, 1997). 


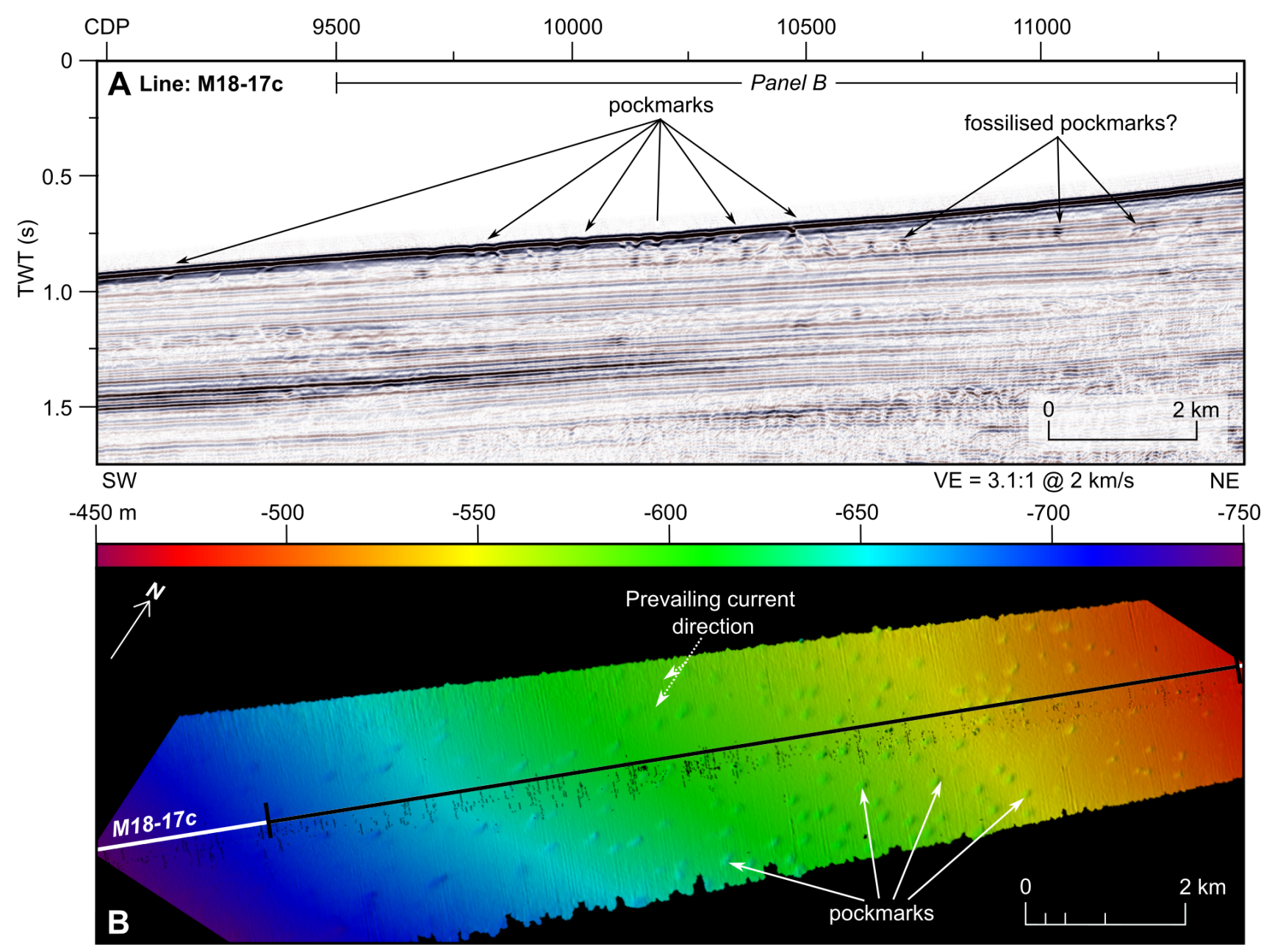

Fig. 6.14: Pockmark features shown in seismic (Panel A) and swath bathymetry data (Panel B). The black line in Panel B shows the extent of Panel A. See Fig. 4A-1 for location 


\subsection{Parara Anticline: Age Control of SLN Stratigraphy}

Parara Anticline was initially a target for the Parara-1 exploration well (see Chapter 2). MGL1803 and S86 survey data (see Chapter 1) illustrate its development from a Paleogene extensional fault to a Miocene compressional fault. Using age control provided from Parara-1, the analysis below discusses this evolution. Findings constrains and improve on the PaleogeneNeogene evolution of Parara Anticline (e.g. Turnbull et al., 1993; Sutherland et al., 2006).

\subsubsection{Pre-inversion}

U-SLN1-1 growth strata show evidence of early activity as a normal fault (Fig. 6.15). Of Paleogene age, U-SLN1-1 thickens toward the Parara Fault, as a result of increase accommodation space on the hanging wall. U-SLN1-1 reaches a maximum thickness of $952 \mathrm{~m}$ in the footwall of the Parara Fault, with thinning and onlap onto basement to the south.

U-SLN2-1, deposited from $\sim 23-15 \mathrm{Ma}$, overlies these growth strata. It is thickest at $\sim 315$ $\mathrm{m}$ at the crest of Parara Anticline. Thinning to $\sim 250 \mathrm{~m}$ south of the anticline on line M18-17c indicates north to south deposition, and implies a relative lack of accommodation space on the footwall of the anticline during this time. The Parara Fault was inactive during the earliest mid Miocene.

An increase in sediment supply during the mid Miocene (Norris et al., 1978) saw thickening of U-SLN2-2, which was deposited from 15-11 Ma (Fig. 6.15). On Fig. 6.15, north of Parara1, U-SLS2-2 reaches a maximum thickness of $>1200 \mathrm{~m}$; to the south strata are only $\sim 870 \mathrm{~m}$. This indicates that accommodation space at the Parara Anticline was still greater to the north. Therefore, reverse reactivation of the Parara Fault had not occurred in the mid Miocene.

\subsubsection{Inversion and post-tectonic phase}

Units U-SLN3-1 and U-SLN3-2 suggest that from $~ 11$ Ma, increased reverse throw on the Parara Fault resulted in greater accommodation space to the south of Parara Anticline. This is 
evidenced by southward thickening of these strata, and relative thinning to the north. Thickening is most prominent where channelisation of strata has occurred at CDP 13000 on line M1817c (Fig. 6.15). It is interpreted that elevation created by hanging wall thrusting allowed for initiation of this channel in the topographic low, with continual thrusting creating more accommodation space, encouraging further channel development, as well as thickening of USLN3-1 and U-SLN3-2.

The end of reverse movement at Parara-1 is interpreted as $\sim 7$ Ma. On line S86-34 (Fig. 5.2, see also inset in Fig. 6.15), U-SLN3-1 strata are non-parallel at $\sim$ CDP $800(\sim 1.8 \mathrm{~s}$ TWT), whereas U-SLN3-2 strata are internally parallel at the same location ( 1.6 s TWT). Here, it is proposed that accommodation space was created during deposition of U-SLN3-1 from $\sim 11-$ $7 \mathrm{Ma}$; in other words, U-SLN3-1 is syn-tectonic with reverse movement on the Parara Fault. U-SLN3-2, deposited from $\sim 7-5 \mathrm{Ma}$, represents sedimentary infill of this accommodation space after deposition of U-SLN3-1 i.e. after reverse movement on the Parara Fault. This therefore constrains timing of reverse movement on the Parara Fault as $\sim 11-7$ Ma. These age estimates improve on previous analyses of Parara Anticline growth (e.g. Turnbull et al., 1993; Sutherland et al., 2006).

U-SLN4-1, U-SLN4-2 and U-SLN4-3 strata are undeformed relative to underlying strata, indicating a tectonically quiescent earliest Pliocene-Recent sequence. 


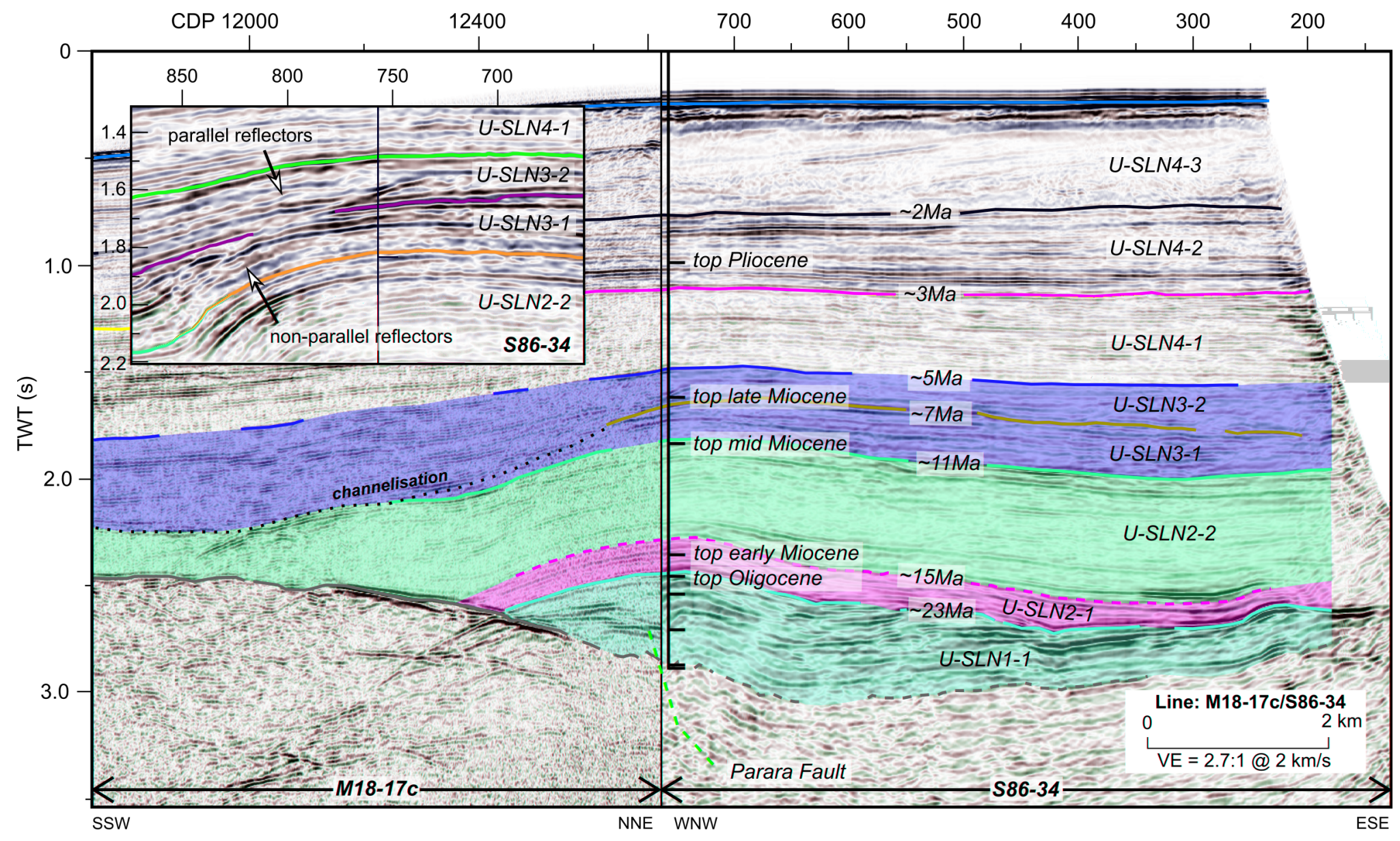

Fig. 6.15: Changing tectonic regime at Parara Anticline from Paleogene extension to late Neogene compression. Southward thickening of U-SLN3-1 and U-SLN3-2, deposited from 11-5 Ma, indicate increasing accommodation space on the footwall of the Parara fault after late Miocene reactivation as a reverse fault. The inset shows internal reflection character of U-SLN3-1 and U-SLN3-2 strata, which provided constraints for reverse movement (U-SLN3-1) and passive infill (U-SLN3-2). The extent of this inset is shown in Fig 5.2 


\subsection{Tauru High: SLN-SLS Correlation}

Tauru High is a barrier to sediment transport and hence stratal continuity, and is the rea-

son for defining separate northern and southern stratigraphic units. Despite this, mapping of stratigraphic reflections has enabled a geologic evolution model for Tauru High (Fig. 6.16) to be made. In this section, I analyse the stratigraphy either side of Tauru High and make correlations between the north and south sub-basins. Refer to Fig. 6.17 (Panel A) for a view of the internal structure of Tauru High.

\subsubsection{Before inversion}

The Tauru Fault developed as a listric fault in an extensional setting during the Paleogene (see Sutherland and Melhuish, 2000). Evidence for its listric nature is U-SLN1-1 fanning growth strata adjacent to the fault (Fig. 6.16, Panel A). This occurs due to accommodation space creation, and block rotation of the hanging wall (van der Pluijm and Marshak, 2004).

Downlapping of U-SLN2-1 strata (deposited from $\sim 23-15 \mathrm{Ma}$ ) onto U-SLN1-1 is observed; this and slight northward thickening indicates southward deposition (Fig. 6.16, Panel A). The lack of U-SLN1-1 or U-SLN2-1 strata on the footwall suggests either erosion of these units or minimal accommodation space created on the footwall, or both. The geometrical relationships suggest no Tauru Fault movement. Overlying U-SLN2-1, U-SLN2-2 was deposited from 15-11 Ma, where the upper age of this unit ( $11 \mathrm{Ma})$ is based on ties to Parara-1. These strata downlap U-SLN2-1 north of the Tauru Fault, with basement onlap observed south of the fault (Fig. 6.16, Panel A). During this passive phase, north to south deposition is implied due to southward thinning of U-SLN2-2. Its presence on the hangingwall implies there was accommodation space prior to thrusting.

In the southern sub-basin, U-SLS1-1 is the correlative of U-SLN2-2. As discussed in following subsections, as well as subsections 5.2.4 and 5.3.2 of Chapter 5, the upper reflection of these units marks a megasequence boundary at Parara-1 and Tauru High respectively, related to the onset of reverse reactivation of these structures. This places the upper age of U-SLS1-1 as $\sim 11$ 
Ma. 
A: Before Inversion

$11 \mathrm{Ma}$

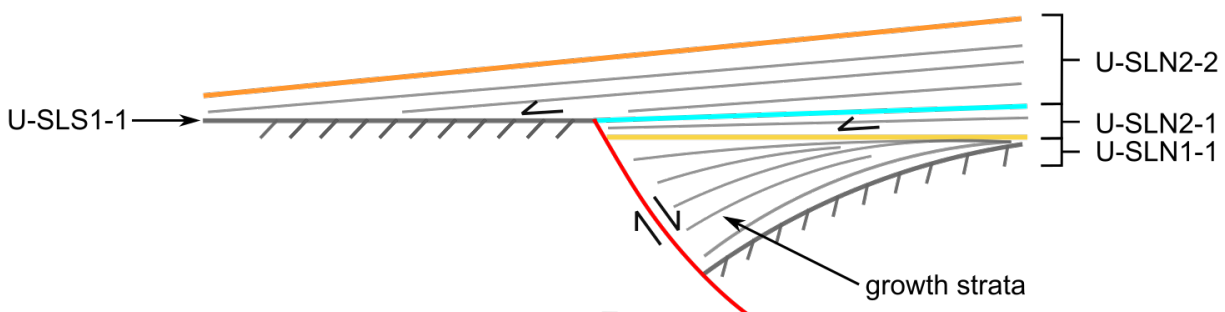

Tauru Fault

\section{B: End-inversion}

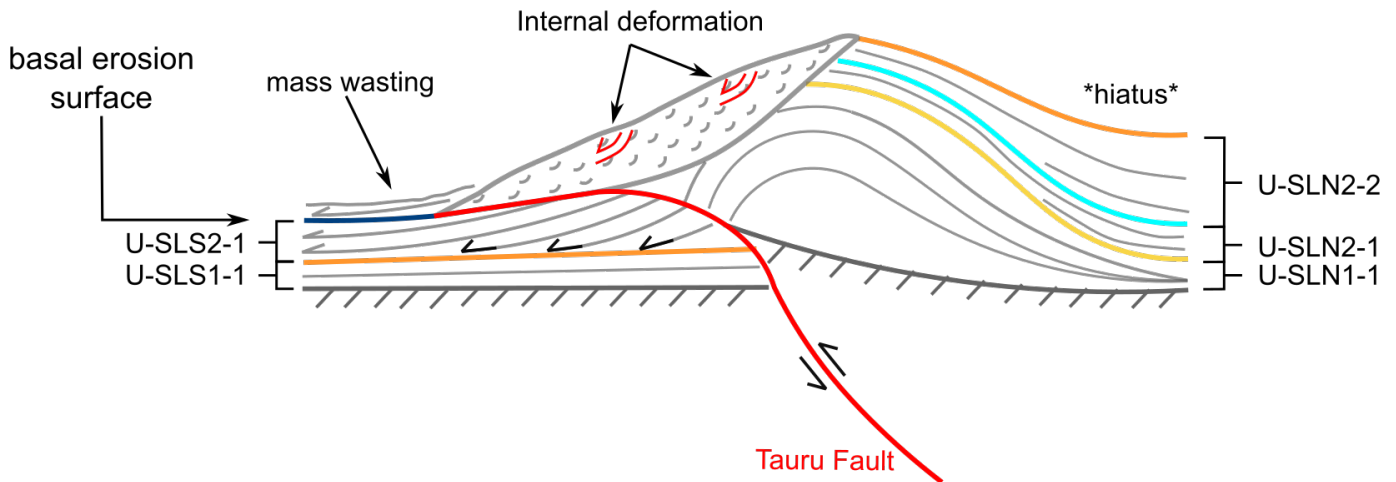

\section{C: Post-inversion}

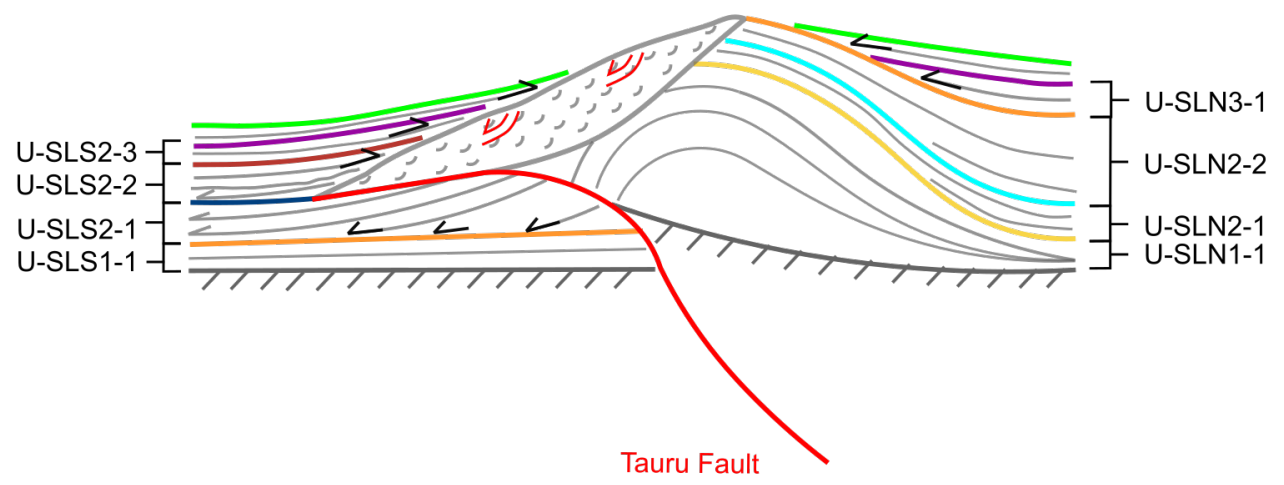

SW

Fig. 6.16: Evolution of Tauru High from the Paleogene to the present day. Initial growth was as an extensional feature (Panel A), after which changing stress conditions led to compressional folding of the hanging wall. Oversteepening caused collapse of hanging wall strata as a soft sediment slump (Panel B). Stratal onlap Tauru High indicating that its growth precedes deposition of onlapping strata (Panel C). Stratal onlap and downlap are shown with black arrows. Internal deformation is shown by red curved arrows. Units defined in Chapter 5 are labelled 


\subsubsection{End inversion}

Soon after deposition of U-SLN2-2/U-SLS1-1 ( $11 \mathrm{Ma}$ ), inversion of the Tauru Fault began. This saw the advent of development of Tauru High as an anticlinal structure, with associated folding of strata within the hanging wall. As a result of folding, it is theorised that incipient collapse of hanging wall strata occurred (e.g. Bonini et al., 2000). Elevated hanging wall topography was conducive to progressive erosion of hanging wall strata, which were re-deposited as downlapping U-SLS2-1 strata on the footwall of the anticline (Fig. 6.16, Panel B).

Sustained compression saw increased folding and hence increased steepening of hanging wall strata. Deposition was preferential on the footwall due to accommodation space created, accounting for the depositional hiatus (equivalent of U-SLN3-1) on the hanging wall (Fig. 6.16, Panel B). Oversteepened strata became gravitationally unstable and slumped southwards onto the downlapping U-SLS2-1 strata, with internal deformation inferred. The fault plane, without brittle strata to propagate into, developed along the failure plane of the slumped material. Coincident with this collapse is mass wasting of sediment as U-SLS2-2 to the south (Fig. 6.16, Panel B). This is evidenced by the basal high amplitude, reverse polarity reflection (section 5.3.3). These mass wasting strata locally downlap this basal surface (see Fig. 6.17, CDP 8000--9000, Panel A). On line M18-17b, from CDP 3600-7000, 5 s TWT, erosion of underlying U-SLS2-1 strata is noted, which may be the result of mass wasting (see Fig. 5.3, Chapter 5).

In Fig. 6.16, the age of this gravitational collapse is unclear, due to a lack of tie to Parara1. Here, I propose that it occurs at $\sim 9$ Ma i.e. the age at the base of U-SLS2-2 is 9 Ma. In Chapter 5, a moderate to high amplitude, reverse polarity reflection defines the base of U-SLN3-2 (section 5.2.5) in the northern sub-basin. A similarly moderate to high amplitude, reverse polarity reflection marks the base on U-SLS2-4 (section 5.3.5) in the southern sub-basin. From this and the similar seismic character of U-SLN3-2 and U-SLS2-4 strata, the base of both units is interpreted as a correlative surface. A tie to Parara-1 provides an age of $\sim 7 \mathrm{Ma}$ for this basal reflection. Assuming an approximately linear sedimentation rate between this basal surface and the base of U-SLS2-1 (i.e. the beginning of tectonic deformation at $~ 11 \mathrm{Ma}$ ), this suggests an age of $\sim 9$ Ma for the base of U-SLS2-2. 


\subsubsection{Post-inversion}

The main phase of compression on the Tauru Fault ended at $\sim 9$ Ma. In the northern sub-basin, this is evidenced by onlap of U-SLN3-2 strata onto underlying U-SLN3-1. Onlap of U-SLS2-2, U-SLS2-3 and U-SLS2-4 onto Tauru High occurs the southern sub-basin (Fig. 6.16, Panel C). Basin fill in both sub-basins was therefore deposited in a passive tectonic environment, with relatively little tilting or deformation.

U-SLS2-3 was probably deposited just before 7 Ma. The base of U-SLN3-2 and U-SLS2-4 is a correlative surface, thus these units are correlatives of each other. The base of U-SLN4-1 in the northern sub-basin is a low to moderate amplitude, reverse polarity reflection, which has been tied to Parara-1 and is a megasequence boundary related to onset of reverse reactivation and channelisation at Solander Anticline (subsection 5.2.6). The base of U-SLS3-1 is a low amplitude, reverse polarity reflection. Similarities in thickness and the basal surface of these strata suggests that they are correlative packages. Tying this basal reflection to Parara-1 yields an age of $\sim 5$ Ma.

Lastly, U-SLN4-2 and U-SLN4-3 are interpreted as the correlative units of U-SLS3-2. Both northern units and U-SLS3-2 overlie a low amplitude, reverse polarity reflection, with high continuity reflections. The basal surface of these strata is mapped at Parara-1, where an age of $\sim 3 \mathrm{Ma}$ is determined.

\subsubsection{Age correlation model}

Analysis of the evolution of Tauru High has provided age correlation from the northern subbasin to the southern sub-basin. This allows for ages determination of strata as far south as $\sim 49.5^{\circ} \mathrm{S}$, which is the southern-most age correlation using seismic data ever made in this region. Fig. 6.16 (Panel B) illustrates these age correlations, relative to the seismic units identified in Chapter 5 . 


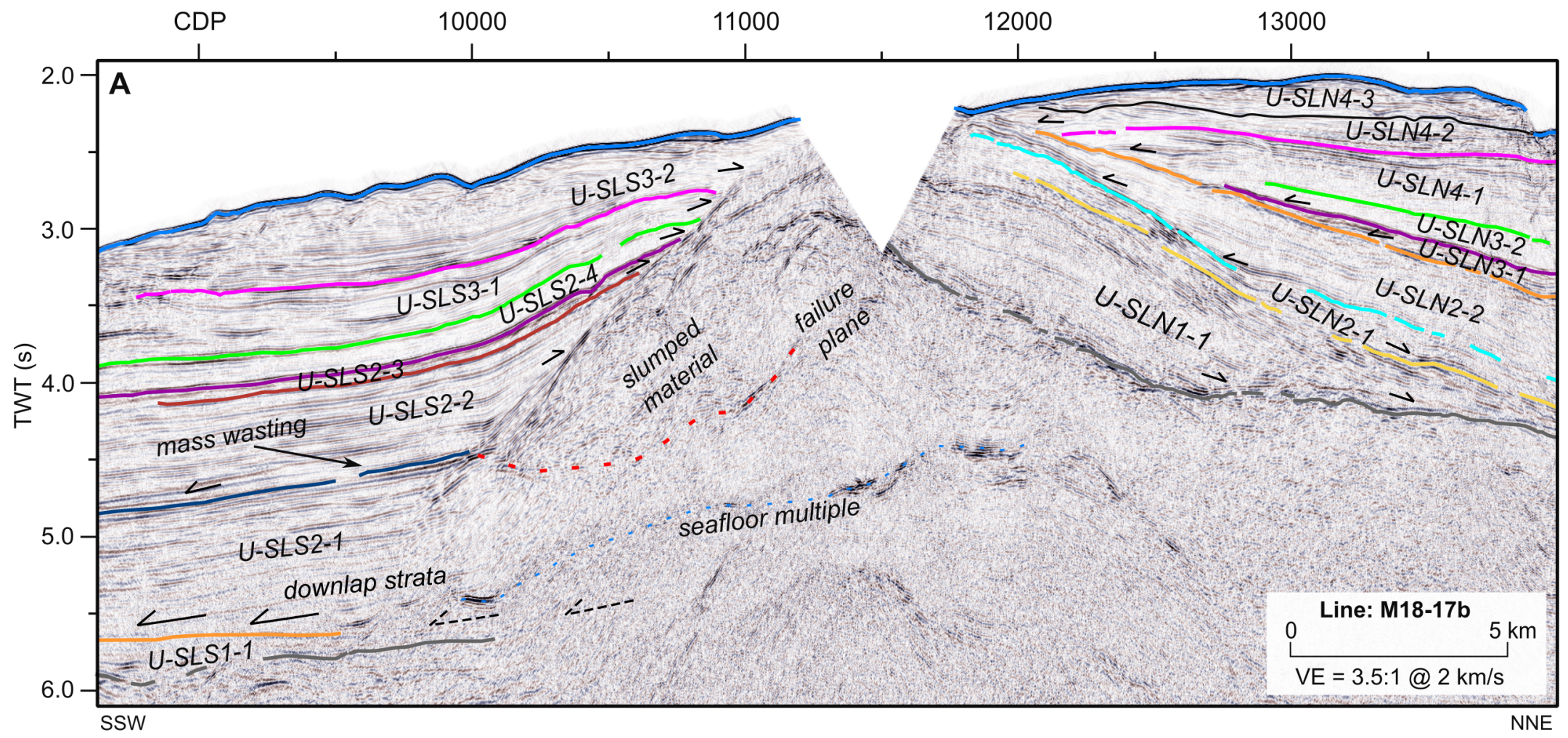

B

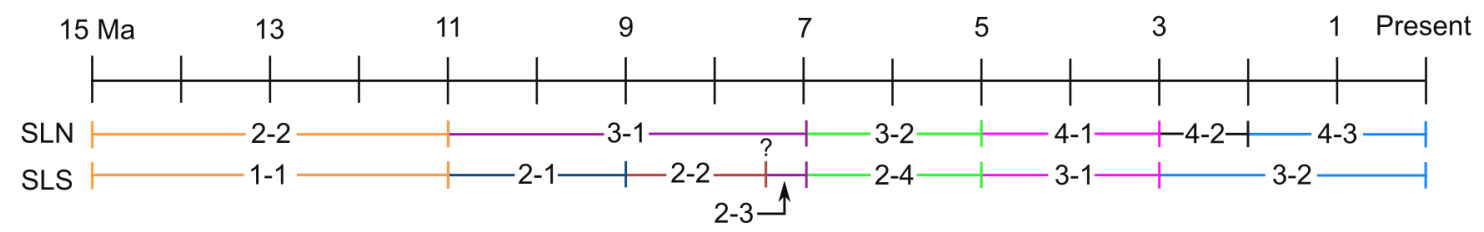

Fig. 6.17: Modern day setting of Tauru High (Panel A). Labelled are stratal relationships to the north and south, the slump failure plane and associated basal erosion surface, slumped material, growth strata and mass wasting strata. Panel B summarises age correlations of strata tied to Parara-1 in the northern sub-basin (SLN) to strata south of Tauru High in the southern sub-basin $(S L S)$ 


\subsection{Basin Analysis}

The following section summarises the regional basin evolution of Solander Trough, using a synthesis of previous chapters. Paleogeographic reconstructions for certain time periods are shown in Fig. 6.18.

\subsection{1 pre-40 Ma}

During the early Cretaceous, rifting related to (but pre-dating) rifting of Zealandia from Gondwana saw development of half-grabens. After cessation of Tasman seafloor spreading (Gaina et al., 1998; Laird and Bradshaw, 2004), further rifting in the Eocene and Oligocene due to southward migration of the Euclidean pole (Turnbull et al., 1993; Sutherland, 1995) saw further development of extensional basins around New Zealand and changes in Eocene plate boundary configuration.

Cretaceous sediment is present in onshore Fiordland in fault-bound grabens (Norris and Turnbull, 1993). Paleocene strata are not present in the onshore region, probably due to nondeposition/peneplanation related to Tasman Sea rifting (Turnbull et al., 1993; Uruski and Turnbull, 1990). Paleocene strata are interpreted in the Parara-1 well "...from association with regional geology, samples and electric log characteristics" (Hunt International Petroleum Company, 1976, pg. 14), though this is contradicted by biostratigraphy results within the same report, which indicates a late Eocene age for the oldest strata.

During the Eocene, fluvial and lacustrine deposition dominated the onshore region, with some shallow marine strata deposited in Te Anau Basin (Turnbull et al., 1993, Fig. 6.18, Panel D). In the offshore realm, Eocene strata were encountered at Parara-1 (Hunt International Petroleum Company, 1976, see also Fig. 2.2), comprising kaolinitic sandstones with coal measures, suggesting non-marine deposition. Non-marine Eocene deposition was also interpreted from onshore seismic data (Turnbull et al., 1993). The Eocene is partly represented by U-SLN1-1 (see Chapter 5). Growth strata against the Parara Fault (Fig. 6.15) and the Tauru Fault (Fig. 6.16) (e.g. Sutherland et al., 2006) indicate deposition contemporaneous with normal faulting. Though the 
Solander Fault was active as a normal fault, the adjacent Solander High was an elevated area of non-deposition (Fig. 6.18). The Eocene section of U-SLN1-1 is interpreted as low amplitude, more discordant reflections that suggest a higher energy, non-marine depositional setting (Sangree and Widmier, 1979). Eocene normal faulting is recognised onshore, with some inferred reactivation of Cretaceous normal faults (Uruski and Turnbull, 1990).

Regional subsidence was concurrent with normal faulting, and Oligocene deepening of basins saw a shift from terrestrial to marine deposition (Norris and Turnbull, 1993; Turnbull et al., 1993). During the Oligocene, transgression flooded the Fiordland region. Onshore geology in the Te Anau and Waiau sub-basins record sea level rise, shown as an upward fining sequence of turbiditic sands to bioclastic limestone toward the late Oligocene, indicating maximum transgression around this time (Norris and Turnbull, 1993), and a marine connection of the Te Anau and Waiau basins (Uruski and Turnbull, 1990). In the offshore area, this sequence of upward fining clastic to carbonate facies is observed in Balleny Basin (Norris and Turnbull, 1993) and Solander-1 (Engmann and Fenton, 1986) (see also Fig. 2.4). Though carbonate facies are not observed before the Otaian at Parara-1 (Fig. 2.2), general upward fining of U-SLN1-1 from coarser turbidite facies is interpreted from well logs. At Solander-1, the Oligocene is interpreted as a terrestrial sequence, which indicates that the Solander High was emergent during Oligocene transgression (Norris and Turnbull, 1993, see Fig. 6.18). The Oligocene section of U-SLN11 comprises higher amplitude, concordant reflections, which indicates a comparatively lower energy depositional environment.

U-SLN1-1 strata have no age correlative mapped south of Tauru High (see Chapter 5). In Fig. 6.18, the ACC, which developed around the Eocene/Oligocene boundary (Barker et al., 2007; Katz et al., 2011) is interpreted to have scoured/re-transported sediment derived from the north and any biogenic sediment. Schuur et al. (1998) observed similar erosion of sediment down to basement at $\sim 53.5^{\circ} \mathrm{S}$ due to a gap in the Macquarie Ridge Complex, enabling erosion by strong ACC waters. Additionally, a lack of Cretaceous/Eocene rift basins in this southern area implies a lack of accommodation space for sediments (Fig. 6.18). 

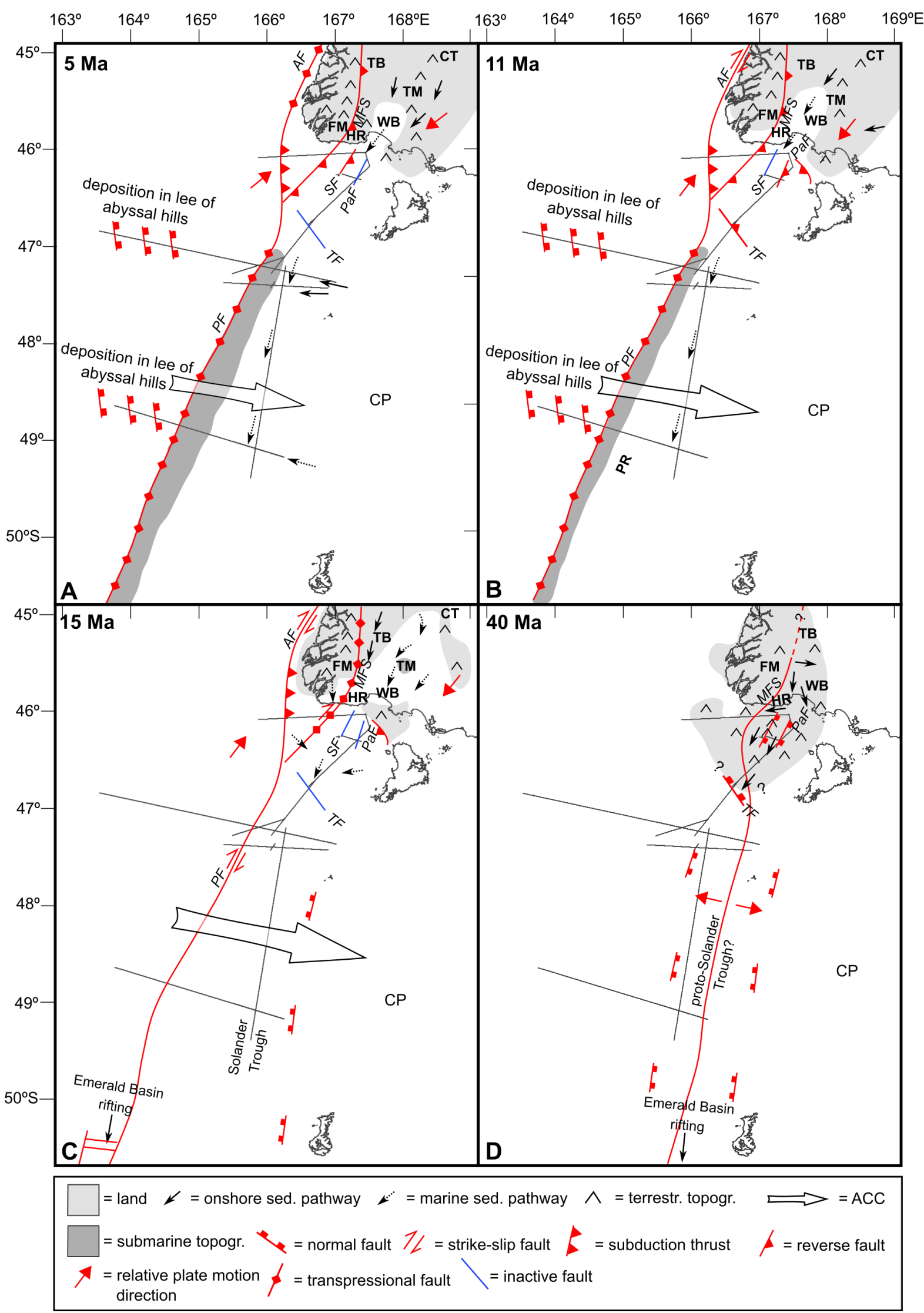

Fig. 6.18: (Caption on next page) 
Fig. 6.18: Paleogeographic reconstructions for the offshore and southernmost onshore Fiordland region. Time intervals represented are: $5 \mathrm{Ma}$ (Panel A); $11 \mathrm{Ma}$ (Panel B); $15 \mathrm{Ma}$ (Panel C); $40 \mathrm{Ma}$ (Panel D). Onshore reconstructions are based on Turnbull et al. (1993), and plate boundary reconstructions are from Lebrun et al. (2003) and Sutherland et al. (2006). Bold abbreviations are location names: CT=Caples Terrane; FM=Fiordland Margin; HR=Hump Ridge; $P R=$ Puysegur Ridge; TM=Takitimu Mountains; $T B=$ Te Anau Basin; WB=Waiau Basin. Italicised abbreviations are faults: $A F=$ Alpine Fault; $M F S=$ Moonlight Fault System; PaF=Parara Fault; PuF=Puysegur Fault; PTh=Puysegur Thrust; SF=Solander Fault; TF=Tauru Fault

\subsubsection{3-11 Ma}

The early Miocene saw a major change in plate motions to strike-slip (Cande and Stock, 2004), and propagation of the Alpine Fault through New Zealand (Kamp, 1986; Sutherland et al., 2000). Transtensional faulting closer to the coast, related to increased convergence of the Pacific and Australian Plates (Walcott, 1978; Sutherland, 1995; Cande and Stock, 2004), resulted in uplift of southwestern Fiordland (e.g. Sutherland et al., 2009, see Fig. 6.18, Panel C). This provided a sediment source for the Te Anau and Waiau Basins, which were continually subsiding and subject to marine deposition (Uruski and Turnbull, 1990).

During the early Miocene, Oligocene carbonate sequences were overlain by clastic sediment. Major sediment sources in the onshore region included the Fiordland margin and the Caples Terrane in the northeast (see Fig. 1.2; Fig. 6.18), which provided significant clastic material that was deposited as bathyal turbidites in the Te Anau and Waiau basins (Turnbull et al., 1993). Early Miocene deep marine mudstones (Hunt International Petroleum Company, 1976; Turnbull et al., 1993) deposited as turbidite sequences at Parara-1 and Solander-1 (Norris and Turnbull, 1993) overlie Oligocene strata, which indicates rapid subsidence of these offshore basins despite the beginning of uplift in the onshore region (Sutherland et al., 2009). This subsidence is significant as the Solander High was emergent in the Oligocene (Turnbull et al., 1993). These turbidite sequences are interpreted to be sourced from the Fiordland margin and potentially the Caples Terrane in the north.

The mid Miocene saw significantly increased terrigenous input from uplifted sources such as the Caples Terrane, resulting in marine regression. For example, in northern Te Anau Basin, fluvial conglomerates overly shelfal early-mid Miocene deposits (Norris and Turnbull, 1993). 
Though still in a marine setting, stratigraphy at Parara-1 shows upward coarsening from clays and muds to more common sands and shales (Hunt International Petroleum Company, 1976). Solander-1 exhibits upward coarsening from silty muds to interbedded conglomerate and sands (Engmann and Fenton, 1986). This coarser material is inferred to be sourced from uplifted onshore areas.

In the northern sub-basin, the interval 23-11 Ma comprises U-SLN2-1 and U-SLS2-2 (see also Fig. 6.17, Panel B). U-SLN2-1, deposited from $\sim 23-15 \mathrm{Ma}$, is solely present at Parara Anticline and Tauru High. This implies that deposition was localised in depressions. Nondeposition of U-SLN2-1 strata south of Tauru High implies a lack of depocentre, potentially from lack of accommodation space on the footwalls of Parara Anticline or Tauru High. Additionally, during this time, the ACC was unimpeded by topography in the southern sub-basin during deposition of U-SLN2-1, causing re-transportation of strata of this age (Fig. 6.18, Panel B). If Puysegur Ridge acts as a barrier to ACC flow, similar to the Macquarie Ridge Complex to the south (e.g. Schuur et al., 1998), it implies that Puysegur Ridge was not developed at 15 Ma.

U-SLN2-2, on the other hand, is a noticeably thicker sedimentary unit at Parara Anticline and north of Tauru High (Fig. 5.1). It was deposited from $\sim 15$ Ma to 11 Ma; its deposition indicates a significant increase in sedimentation rates after deposition of U-SLN2-1 (i.e. after $\sim 15 \mathrm{Ma}$ ). Its correlative unit south of Tauru High, U-SLS1-1, is much thinner and is locally folded. U-SLS1-1 strata are mappable to Puysegur Ridge (Figs. 5.6 and 5.7), which implies that Puysegur Ridge has begun to develop after 15 Ma. Contrasting with U-SLN2-1, the presence of U-SLS1-1 strata south of Tauru High indicates that growth of Puysegur Ridge provided sufficient impedance of the ACC, which in turn allowed for deposition and preservation of U-SLS1-1 strata.

\subsubsection{1-5 Ma}

During the late Miocene and early Pliocene, sediments became folded and thrust up above sea level (e.g. Sutherland et al., 2009). Offshore basins were still subsiding irrespective of onshore uplift in locations like the Fiordland Margin (Sutherland et al., 2009): this is due to compressive development of the Pacific-Australian plate boundary further to the west of Fiordland (Sutherland et al., 2006), as well as accommodation of plate motions by the Moonlight and Hollyford 
Fault Systems to the north (see Fig. 1.2, Turnbull et al., 1993). The late Miocene saw reactivation of normal faults as compressional features (see sections 6.3 and 6.4, and Fig. 6.18, Panel B).

Late Miocene onshore sediments are characterised by terrestrial deposition, typically in lacustrine and swampy settings (Norris and Turnbull, 1993; Turnbull et al., 1993). Major onshore sediment sources in the north imply north to south sediment flow to offshore basins. Maximum uplift of Hump Ridge north of Stewart Island occurred (Fig. 6.18, Panel B), and continued growth of the Parara and Solander Anticlines saw mass flow deposits sourced from these structures (Turnbull et al., 1993). At Parara-1, U-SLN3-1 channelisation southwest of the anticline is observed, a result of the topographic low created from uplift (see section 6.3; Fig. 6.15). At Parara-1 and Solander-1, shelfal muds dominate the late Miocene-earliest Pliocene sequence (Hunt International Petroleum Company, 1976; Engmann and Fenton, 1986), which may be attributed to continued subsidence of offshore basins.

In the northern sub-basin, this time interval is composed of U-SLN3-1 and U-SLN3-2 strata. U-SLN3-1 was deposited from $\sim 11$ Ma to $\sim 7 \mathrm{Ma}$, and U-SLN3-2 from $\sim 7$ Ma to $\sim 5$ Ma. At Tauru High, U-SLN3-1 strata are of note as the equivalent units south of Tauru High, U-SLS2-1, U-SLS2-2 and U-SLS2-3, encompass the same time interval as U-SLN3-1. As per section 6.4, this represents a significant increase in accommodation space south of Tauru High, indicating that there were several kilometres of accommodation space creation to the south during deposition of these three units. The presence of U-SLS2-1, U-SLS2-2 and U-SLS2-3 at Puysegur Ridge, suggests deposition during Puysegur Ridge growth. This means that Puysegur Ridge was continually developing from $\sim 11$ Ma to $\sim 3$ Ma.

\subsection{4 $5 \mathrm{Ma}-$ present}

During the Pliocene to Pleistocene, uplift in the modern onshore setting shaped modern topography (Sutherland et al., 2009; Turnbull et al., 1993, see also Fig. 6.18, Panel A). Along with Solander Island and Little Solander Island (Reay and Parkinson, 1997), other subductionrelated volcanism included submarine Pliocene volcanics imaged on seismic data west of the offshore Moonlight Fault System (Sutherland et al., 2006). Further to the south, the Snares Zone 
marks a change from strike-slip faulting on the Puysegur Fault, south of $47^{\circ} \mathrm{S}$, to subduction at the Puysegur Trench (Lamarche and Lebrun, 2000). Uplift is ongoing to the present day (e.g. Kim and Sutherland, 2004).

Terrestrial to shallow marine Pliocene claystones and sandstones in the onshore region are restricted to Te Anau and Waiau Basins. These deposits unconformably underlie Pleistocene glacial sediment, though raised beach deposits in the southern Waiau Basin overlie these Pliocene strata (Turnbull et al., 1993). Glacial scouring shaped onshore ranges like Fiordland and Caples Terrane (Norris and Turnbull, 1993, see also Fig. 1.2). Pliocene to Pleistocene sediments at Parara-1 comprise deepwater claystones and siltstones (Hunt International Petroleum Company, 1976). Interestingly, a Pliocene-Recent sequence was not encountered at Solander-1 which has been attributed to "...uplift and erosion" by Engmann and Fenton (1986).

In the northern sub-basin, this time period comprises U-SLN4-1, U-SLN4-2 and U-SLN4-3. These units were deposited from $\sim 5 \mathrm{Ma}$ to $\sim 3 \mathrm{Ma}, \sim 3 \mathrm{Ma}$ to $2 \mathrm{Ma}$ and $\sim 2 \mathrm{Ma}$ to the present, respectively. The onset of reverse reactivation of the Solander Fault occurs at $\sim 5 \mathrm{Ma}$, which is evidenced by channelisation of U-SLN4-1 strata, likely within a topographic low created by uplift (similar to U-SLN3-1 strata). SLN4 strata are rich in foraminifera at Parara-1 (Hunt International Petroleum Company, 1976); reflections within these units are also low amplitude and continuous. These observations indicate hemipelagic sedimentation (Sangree and Widmier, 1977). U-SLN4-3, shaped by modern-day processes, shows evidence of fluid escape structures (Fig. 6.14) and active channelisation (Fig. 6.5). Also, on the modern-day continental shelf (Fig. 6.12 and Fig. 6.13), stacked clinoforms indicate shelf progradation during deposition of this unit. Correlatives of these strata south of Tauru High are U-SLS3-1 and U-SLS3-2, deposited from $\sim 5$ Ma to $\sim 3$ Ma and $\sim 3$ Ma to $\sim 2$ Ma, respectively. Active channelisation, sedimentation and erosion of these strata is discussed in section 6.2.2. In Appendix 4, Fig. 4A-2 also shows active sedimentation and erosion. U-SLS3-1 onlaps strata uplifted on Puysegur Ridge (Fig. 5.7), suggesting that a new phase of significant folding and uplift of Puysegur Ridge occurred at $\sim 5$ Ma. U-SLS3-2 onlaps U-SLS3-1 on this line; this suggests that by $\sim 3 \mathrm{Ma}$, the eastern margin of Puysegur Ridge was significantly uplifted and deposition is now preferentially on the basin floor, due to the previously mentioned increased impedance of the ACC by Puysegur Ridge. 


\section{Chapter 7}

\section{Conclusions}

This study has provided new geologic insights into the evolution of Solander Trough. The thesis objectives outlined in section 1.7 have all been addressed.

\subsection{Thesis Objectives}

\section{Reprocessing of Line P1}

In Chapter 3, 2D seismic reflection data acquired during voyage EW9601a in 1996 were reprocessed prior to and during MGL1803. The processing sequence has resulted in a seismic section of superior quality to the original results of Melhuish et al. (1999).

2. Acquisition and processing of $2 \mathrm{D}$ seismic reflection data

Chapter 4 covered the acquisition and processing of 2D seismic reflection acquired during voyage MGL1803 in 2018. These data provided the first seismic data tie from northern preexisting petroleum industry seismic and well data to Solander Trough, south of $\sim 46.5^{\circ} \mathrm{S}$.

3. Seismic stratigraphy of Solander Trough

The first seismic stratigraphic analysis of Solander Trough was achieved by combining MGL1803 2D seismic reflection, petroleum industry seismic reflection and petroleum well data (Chapter 5). A northern sub-basin and southern sub-basin stratigraphy is defined. Four megasequence boundaries and eight sequences are defined in the northern sub- 
basin; in the southern sub-basin, three megasequences boundaries and seven sequences are mapped.

4. Depositional model and basin history for Solander Trough

Discussion of Parara Anticline evolution provided depositional ages of seismic units. Analysis of Tauru High growth enabled age correlations of seismic units in the northern sub-basin to seismic units in the southern sub-basin.

Modern and past depositional processes were elucidated using seismic and high resolution swath bathymetry data. Combining these datasets with age-determined seismic stratigraphy provided a regional basin synthesis for Solander Trough. It was found that Solander Trough is a geologically young $(<\sim 15 \mathrm{Ma})$ sedimentary depocentre. Depositional sequences in the southern sub-basin have been influenced by interactions of terrestrial and biogenic sediment supply with current action and tectonics, namely the interaction between the ACC and Puysegur Ridge.

\subsection{Recommendations for Future Work}

The results presented lay a foundation for exciting future work in Solander Trough. Some potential future avenues include natural resource extraction (petroleum, manganese mining etc.), subduction initiation mechanisms (in the process of currently unpublished work by Gurnis et al.) and Integrated Ocean Discovery Program (IODP) drilling. IODP drilling remains a hopeful prospect for future work, especially for sampling the shallow sedimentary sequence present on Puysegur Ridge. Providing further age control to data acquired during MGL1803 would be a valuable venture and would help further understanding of Solander Trough evolution. 


\section{Appendices}

\section{Appendix: Introduction}
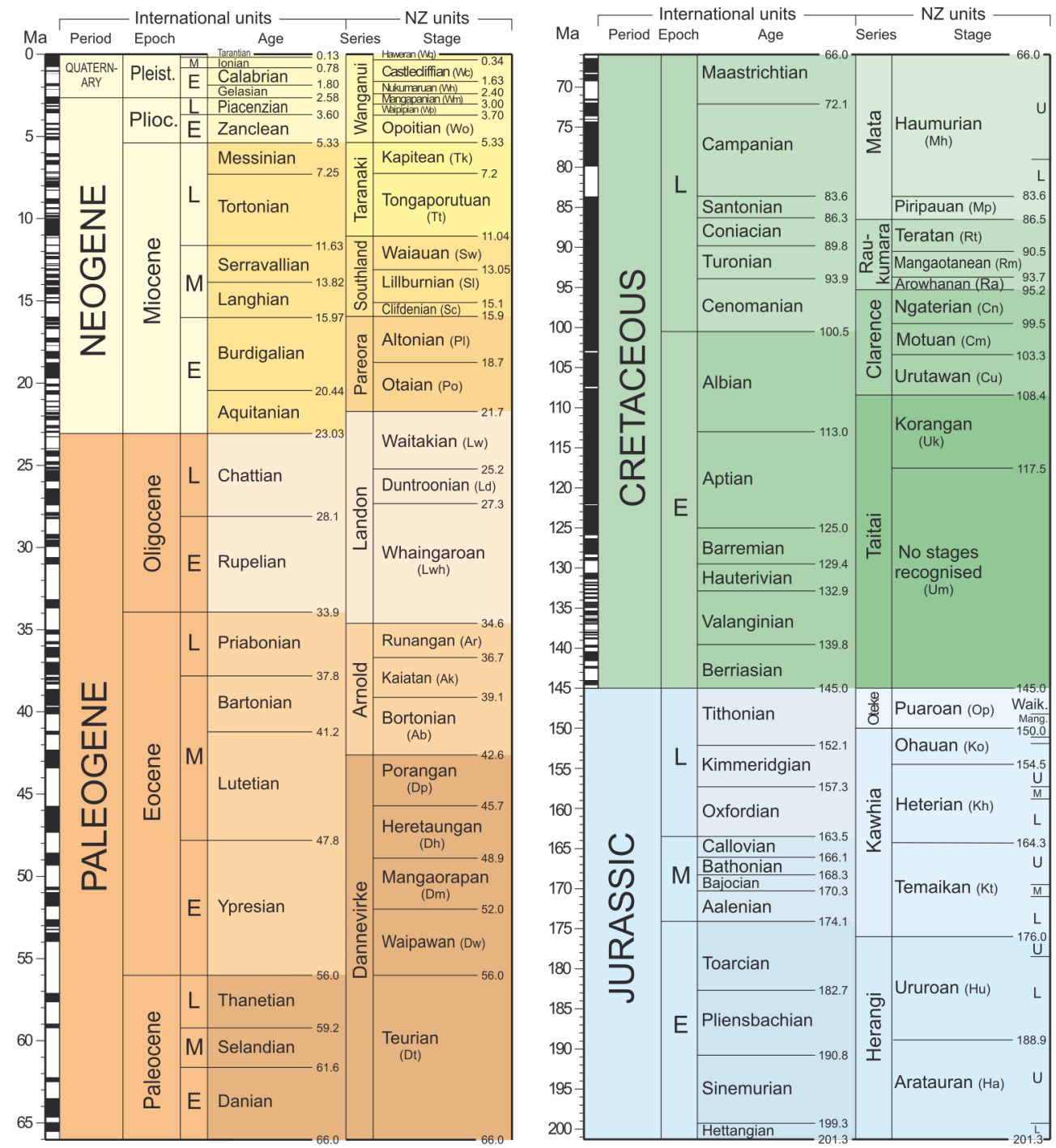

Fig. 1A-1: New Zealand geological stages, for the Jurassic to present. Adapted from Institute of Geological and Nuclear Sciences (2015) 


\begin{tabular}{|c|c|c|c|c|c|c|c|}
\hline Acquisition & Hunt PR556 & \multicolumn{2}{|c|}{ NZPET70 } & Mobil72 & Hunt A & Hunt B & Hunt D \\
\hline Vessel & M/V Teledex & \multicolumn{2}{|c|}{$?$} & $?$ & Aquatic Explorer & Aquatic Explorer & Aquatic Explorer \\
\hline Year & 1969 & \multicolumn{2}{|c|}{1970} & 1972 & $1970-1971$ & 1972 & $1972-1973$ \\
\hline Source & Hunt PR556 & \multicolumn{2}{|c|}{ NZPET70 } & Mobil72 & Hunt A & Hunt B & Hunt D \\
\hline Source type & sparker & \multicolumn{2}{|c|}{ airgun array } & airgun array & Aquapulse & Aquapulse & Aquapulse \\
\hline Source volume $\left(\mathrm{in}^{3}\right)$ & $\mathrm{N} / \mathrm{A}(120 \mathrm{~kJ})$ & \multicolumn{2}{|c|}{$40-160$} & $?$ & $\mathrm{~N} / \mathrm{A}$ & $\mathrm{N} / \mathrm{A}$ & $\mathrm{N} / \mathrm{A}$ \\
\hline Source depth $(\mathrm{m})$ & $?$ & \multicolumn{2}{|c|}{$?$} & 10.6 & 8 & 8 & 8 \\
\hline Shotpoint interval (m) & $?$ & \multicolumn{2}{|c|}{$?$} & $12 \mathrm{~s}$ & 22 & 23 & 22 \\
\hline Recording & Hunt PR556 & \multicolumn{2}{|c|}{ NZPET70 } & Mobil72 & Hunt A & Hunt B & Hunt D \\
\hline Record length (s) & 4 & \multicolumn{2}{|c|}{$5^{*}$} & 6 & 6 & 6 & 6 \\
\hline Sample Interval (ms) & $?$ & \multicolumn{2}{|c|}{$2-4$} & $?$ & 4 & 4 & 4 \\
\hline Fold & $?$ & \multicolumn{2}{|c|}{$1-6$} & 3 & 12 & 12 & 12 \\
\hline Cable & Hunt PR556 & \multicolumn{2}{|c|}{ NZPET70** } & Mobil72 & Hunt A & Hunt B & Hunt D \\
\hline \# Groups & 100 & 1 & $?$ & $?$ & 24 & 24 & 24 \\
\hline Group Spacing (m) & $?$ & $\mathrm{~N} / \mathrm{A}$ & 70.1 & 100 & 22 & 22 & 22 \\
\hline Near Offset (m) & $?$ & $?$ & $?$ & 301.8 & 297 & 297 & 297 \\
\hline Far offset $(\mathrm{m})$ & $?$ & $?$ & $?$ & 804.7 & 1830 & 1907 & 1830 \\
\hline Tow Depth (m) & $?$ & $?$ & $?$ & $?$ & 16 & 12 & 16 \\
\hline Streamer Length (m) & $?$ & $?$ & $?$ & $?$ & 1600 & 1600 & 1600 \\
\hline Publications & PR556 & \multicolumn{2}{|c|}{ PR538 } & PR738 & PR558, PR934 & PR620 & PR620, PR934 \\
\hline
\end{tabular}

Table 1A-1: Summary acquisition parameters for the "vintage surveys". Publications where further information can be found is provided. *Record length here is that shown in seismic data. **Some lines shot as single channel. ?'s refer to unknown data 


\begin{tabular}{|c|c|c|c|c|c|}
\hline Acquisition & S82 & $\mathrm{S} 84$ & Solander-85 & S86 & LM06 \\
\hline \multirow{2}{*}{ Vessel } & $\mathrm{M} / \mathrm{V}$ Geco & Western & $\mathrm{M} / \mathrm{V}$ Yardie & M/V Grant & $\mathrm{M} / \mathrm{V}$ Pacific \\
\hline & Kappa & Oddessey & Creek & Mariner & Titan \\
\hline Year & 1982 & 1984 & 1984 & 1986 & 2006 \\
\hline Source & $\mathrm{S} 82$ & $\mathrm{~S} 84$ & Solander-85 & $\mathrm{S} 86$ & LM06 \\
\hline Source type & Airgun array & Airgun array & sparker & Airgun array & Airgun array \\
\hline Source energy $\left(\mathrm{in}^{3}\right)$ & 2520 (20 guns) & 1530 (20 guns, 4 sub-arrays) & $27 \mathrm{~kJ}$ & 3000 (18 guns, 3 sub-arrays) & 3040 (26 guns) \\
\hline Source depth (m) & 6.5 & 6 & 3 & 7 & 4 \\
\hline Shotpoint interval (m) & 25 & 26.67 & 7.62 & 25 & 25 \\
\hline Recording & S82 & $\mathrm{S} 84$ & Solander-85 & $\mathrm{S} 86$ & LM06 \\
\hline Record length (s) & 5 & 6 & 2 & 6 & 8 \\
\hline Sample Interval (ms) & 2 & 2 & 1 & 2 & 2 \\
\hline Fold & 48 & 60 & 24 & 60 & 40 \\
\hline Cable & $\mathrm{S} 82$ & $\mathrm{~S} 84$ & Solander-85 & S86 & LM06 \\
\hline \# Groups & 96 & 240 & 24 & 120 & $324 \mid 480$ \\
\hline Group Spacing (m) & 25 & 26.67 & 15.24 & 25 & 12.5 \\
\hline Near Offset $(\mathrm{m})$ & 270 & 197 & 50 & 150 & 130 \\
\hline Far offset $(\mathrm{m})$ & 2651 & 3370.33 & 400.52 & 3125 & $4350 \mid 6000$ \\
\hline Tow Depth $(\mathrm{m})$ & 13 & $12 \pm 2$ & 4.5 & $6-9.1$ & 7 \\
\hline Streamer Length (m) & 2400 & $3200 \mathrm{~m}$ & 365.76 & 3000 & $4050 \mid 6000$ \\
\hline Publications & PR912 & PR1027 & PR1121 & PR1165 & PR3397 \\
\hline
\end{tabular}

Table 1A-2: Summarised acquisition parameters for the S82, S84, Solander-85, S86 and LM06 surveys 


\title{
2 Appendix: Voyage EW9601a
}

\subsection{Line P1 processing, employed by Melhuish et al. (1999)}

\author{
Process description
}

1. Resample to $4 \mathrm{~ms}$

2. Edit bad/dead traces

3. Static shift to correct for gun-receiver depth

4. Fill in missing traces to ensure standard geometry before CDP sort

5. Receiver array simulation - 1:3:1 mix of adjacent receivers

6. Gain recovery using spherical divergence correction

7. Wide bandpass filter (1-4-80-90 Hz) before deconvolution

8. Wiener deconvolution, gap $128 \mathrm{~ms}$, operator length $500 \mathrm{~ms}$

9. Wiener deconvolution, gap $28 \mathrm{~ms}$, operator length $200 \mathrm{~ms}$

10. Frequency filter $(5-8-25-30 \mathrm{~Hz})$

11. Sort to CMP domain

12. NMO velocities from semblance plots (every $1.25 \mathrm{~km}$ )

13. Whole trace balance before stack

14. Surgical front mute for shallow seafloor areas

15. Polygonal inner trace mute for multiple attenuation

16. Stack (40 fold)

17. Wiener deconvolution (100 ms gap, $500 \mathrm{~ms}$ operator)

18. Wiener deconvolution (200 ms gap, $800 \mathrm{~ms}$ operator)

19. Frequency filter $(5-10-25-35 \mathrm{~Hz})$

20. 5 trace weighted running mix as coherency filter

21. Resample to $8 \mathrm{~ms}$ and $2: 1$ trace sum prior to migration

22. Finite difference migration

23. 2 s AGC

24. Display

Table 2A-1: Processing sequence for Line P1 employed by Melhuish et al. (1999) 


\subsection{Processing sequence employed in this thesis}

\begin{tabular}{|c|c|c|c|}
\hline \multicolumn{4}{|c|}{ EW9601_prevoyage.job } \\
\hline \multicolumn{2}{|c|}{01 SEISJOB } & \multicolumn{2}{|c|}{02 READSEGY } \\
\hline $\begin{array}{c}\text { Parameter name } \\
\text { Linenum } \\
\text { ProcID } \\
\text { JCS_Tail } \\
\text { SEP_Logs }\end{array}$ & $\begin{array}{c}\text { Value ascribed } \\
\text { pateljite1 } \\
\text { pateljite1 } \\
<\text { SEQnum }> \\
\text { Yes }\end{array}$ & $\begin{array}{c}\text { Parameter name } \\
\text { Segyfile } \\
\text { PKeyname } \\
\text { SKeyname } \\
\text { RecType } \\
\text { Int_Format } \\
\text { Flt_Format } \\
\text { TrLength } \\
\text { SampRate }\end{array}$ & $\begin{array}{l}\text { Value ascribed } \\
\text { [segd name].sgy } \\
\text { ShotID } \\
\text { Channel } \\
\text { None } \\
\text { IBM } \\
\text { IBM } \\
16382 \\
2\end{array}$ \\
\hline \multicolumn{2}{|c|}{03 TREMOVE } & \multicolumn{2}{|c|}{04 TREMOVE } \\
\hline $\begin{array}{c}\text { Parameter name } \\
\text { Keyname } \\
\text { Keylist } \\
\text { Action }\end{array}$ & $\begin{array}{l}\text { Value ascribed } \\
\qquad \begin{array}{c}\text { FTrace } \\
2-160 \\
\text { Keep }\end{array}\end{array}$ & $\begin{array}{c}\text { Parameter name } \\
\text { Keyname } \\
\text { Keylist } \\
\text { Action }\end{array}$ & $\begin{array}{c}\text { Value ascribed } \\
\text { TrType } \\
2345678 \\
\text { Remove }\end{array}$ \\
\hline \multicolumn{2}{|c|}{05 SETLASTTR } & \multicolumn{2}{|c|}{06 XVIEW } \\
\hline $\begin{array}{c}\text { Parameter name } \\
\text { PKey }\end{array}$ & $\begin{array}{c}\text { Value ascribed } \\
\text { ShotID }\end{array}$ & $\begin{array}{c}\text { Parameter name } \\
\text { FoldMode } \\
\text { N_ENS }\end{array}$ & $\begin{array}{c}\text { Value ascribed } \\
\text { Single } \\
160\end{array}$ \\
\hline \multicolumn{2}{|c|}{07 WRITESEGY } & DispType & Beside \\
\hline Parameter name & Value ascribed & PseudoTrace & No \\
\hline Filename & [segd name]_converted.sgy & Mix_Seismic & No \\
\hline Revision_1 & No & HScale & 4 \\
\hline Format & IBM & VScale & 2.5 \\
\hline Endian & Big & Mode & VAWG \\
\hline RecType & None & HDR_Labels & ShotID Channel \\
\hline AmpScale & 1 & HDR_Freqs & 110 \\
\hline RCommand & stdinsegy & Colours & 0.00 .01732 \\
\hline
\end{tabular}

Table 2A-2: Explanation of parameters used in EW9601_prevoyage.job modules. Summarised steps are shown in Table 3.2 


\begin{tabular}{cc}
\hline EW9601_shot_writesegy.job \\
\hline \multicolumn{2}{c}{01 SEISJOB } \\
\hline Parameter name & Value ascribed \\
Linenum & pateljite1 \\
ProcID & $<$ SEQnum $>$ \\
JCS_Tail & Yes \\
SEP_Logs & \\
\hline \multicolumn{2}{c}{ 02 READSEGY } \\
\hline Parameter name & Value ascribed \\
listfile & Line_P1.sfl \\
PKeyname & ShotID \\
SKeyname & Channel \\
RecType & None \\
Int_Format & IBM \\
Flt_Format & IBM \\
TrLength & 16382 \\
SampRate & 2 \\
\hline 03 WRITESEGY \\
Rarameter name & Value ascribed \\
Filename & Line_P1.sgy \\
Revision_1 & No \\
Format & IBM \\
Endian & Big \\
RecType & None \\
AmpScale & 1 \\
RCommand & stdinsegy \\
\hline
\end{tabular}

Table 2A-3: Explanation of parameters used in EW9601_shot_writesegy.job modules. Summarised steps are shown in Table 3.3 


\begin{tabular}{lll}
\hline \multicolumn{2}{c}{ Job: } & ew9601_geometry.dat \\
\hline Module & \multicolumn{1}{c}{ Parameter } & Value \\
\hline \multirow{3}{*}{ MKDATA } & Sample rate & $4 \mathrm{~ms}$ \\
& Record ength & $6 \mathrm{~s}$ \\
& Data start time & $0 \mathrm{~s}$ \\
\hline \multirow{4}{*}{ MARINE } & Channels per shot & 161 \\
& Near channel \# & 161 \\
& Near trace offset & $25.9 \mathrm{~m}$ \\
& Receiver spacing & $25 \mathrm{~m}$ \\
& Shot interval & $50 \mathrm{~m}$ \\
& Starting shot \# & 51900 \\
\hline
\end{tabular}

Table 2A-4: Explanation of parameters used in ew9601_geometry.dat modules. Summarised steps are shown in Table 3.4

\begin{tabular}{lll}
\hline \multicolumn{2}{c}{ Job: GIN } \\
\hline Module & \multicolumn{1}{c}{ Parameter } & \multicolumn{1}{c}{ Value } \\
\hline \multirow{5}{*}{ GIN } & Sample rate & $2 \mathrm{~ms}$ \\
& Traces per ensemble & 161 \\
& Sort Key & SHOT \\
& Data read direction & INCR \\
& Tape Format & SEGY \\
& Header entry name & SHOT \\
& Byte location & 17 \\
& Byte length & 4 \\
& Header format & INT** \\
\hline DSOUT & Output fine name & ew9601-p1c_shots.sgy \\
\hline
\end{tabular}

Table 2A-5: List of modules and parameters in the "GIN" job. Summarised steps are shown in Table 3.5. ${ }^{*}=$ incrementing; $* *=$ integer 


\begin{tabular}{|c|c|c|}
\hline \multicolumn{3}{|c|}{ Job: ew9601_p1c_edit_decon_sort.dat } \\
\hline Module & Parameter & Value \\
\hline \multirow{2}{*}{ DSIN } & Input file & ew9601-p1c shots.sgy \\
\hline & Shot list & $52123-582 \overline{30}$ \\
\hline \multirow{4}{*}{ GEOMLD } & RadN & 99999 \\
\hline & RadP & $\mathrm{N} / \mathrm{A}$ \\
\hline & Keyname & shot \\
\hline & StaType & Normal \\
\hline \multirow{4}{*}{ EDIT* } & Shot & \\
\hline & Channel & * \\
\hline & Channel & range \\
\hline & CDP & \\
\hline FILTER & Butterworth & 52852 \\
\hline \multirow{2}{*}{ RESAMP } & Sample rate & $4 \mathrm{~ms}$ \\
\hline & Record length & $16 \mathrm{~s}$ \\
\hline \multirow{6}{*}{ REGLO } & XGate & $200 \mathrm{cdps}$ \\
\hline & MaxDip & 700 us \\
\hline & Fmax & $80 \mathrm{~Hz}$ \\
\hline & SKeyMin & -4026 \\
\hline & SKeyInc & 25 \\
\hline & NSKey & 161 \\
\hline \multirow{2}{*}{ GAIN } & Velocity function & stacking_stef \\
\hline & SphDiv & $\mathrm{t}^{1.5}-$ \\
\hline HEADPUT & \multicolumn{2}{|c|}{ Defines seafloor start time for decon } \\
\hline HDRMATH & \multicolumn{2}{|c|}{ Applies header info and math operations } \\
\hline STATIC & Offtime (remove) & $-500 \mathrm{~ms}$ \\
\hline \multirow{8}{*}{ MCDECON } & Gap Length & $75 \mathrm{~ms}$ \\
\hline & Op. length & $450 \mathrm{~ms}$ \\
\hline & Design window & $3500 \mathrm{~ms}$ \\
\hline & App. window & $0-16 \mathrm{~s}$ \\
\hline & Gap Length & $24 \mathrm{~ms}$ \\
\hline & Op. Length & $450 \mathrm{~ms}$ \\
\hline & Design Window & $3500 \mathrm{~ms}$ \\
\hline & Application Window & $0-16 \mathrm{~s}$ \\
\hline \multirow{2}{*}{ SORT } & Max \# Traces/ensemble & 200 \\
\hline & Sort Key & $\mathrm{CDP}$ \\
\hline DSOUT & Output file name & ew9601-p1c_decon_cdps.sgy \\
\hline
\end{tabular}

Table 2A-6: Explanation of parameters in "ew9601_p1c_edit_decon_sort.dat" job modules. Summarised steps are shown in Table 3.6. * see https://bit.ly/2ZF4SP0 for a full list of removed traces 


\begin{tabular}{cll}
\hline \multicolumn{3}{c}{ Job: ew9601-p_velocity.dat } \\
\hline Module & \multicolumn{1}{c}{ Parameter } \\
\hline \multirow{2}{*}{ DSIN } & Input file & ew9601-p1c_steffen_decon_cdps.sgy \\
\cline { 2 - 3 } & CDP list & $795-24805$ \\
& CDPs per group & 15 \\
& CDP increment & 200 \\
\hline \multirow{3}{*}{ FILTER } & Filter type & Butterworth \\
& Phase & Zero \\
& frequencies & 05353 \\
\hline AGC & \multicolumn{1}{c}{1000 ms sliding window AGC } \\
\hline VELDEF & Output file name & stacking_stef \\
\hline
\end{tabular}

Table 2A-7: Explanation of parameters used in "ew9601-p_velocity.dat". Summarised steps are shown in Table 3.7

\begin{tabular}{|c|c|c|}
\hline \multicolumn{3}{|c|}{ Job: ew9601-radonstack.dat } \\
\hline Module & Parameter & Value \\
\hline DSIN & $\begin{array}{l}\text { Input file } \\
\text { CDP list }\end{array}$ & $\begin{array}{l}\text { ew9601-p1c_steffen_decon_cdps.sgy } \\
705-25001\end{array}$ \\
\hline NMO & Velocity function & stacking_stef \\
\hline & Sample trace time to apply overcorrection & $500|1500| 2500|4500| 7000$ (ms) \\
\hline NMO OVCAPP & Offset at which to apply overcorrection & $\begin{array}{l}4200|4200| 4200|4200| 4200 \mid(\mathrm{ms}) \\
\end{array}$ \\
\hline & Amount of overcorrection to apply & $1500|1000| 300|200| 100$ (ms) \\
\hline HDRMATH & \multicolumn{2}{|c|}{ Header info and math operations } \\
\hline RADNPAR & $\begin{array}{l}\text { Forward } \\
\text { Max. offset } \\
\text { \# parabolas for use in the transform } \\
\text { Min. moveout at max. offset } \\
\text { Max.moveout at max. offset } \\
\text { Start-end times for operation } \\
\text { Inverse }\end{array}$ & $\begin{array}{l}\text { Transforms data to the tau-p domain } \\
4026 \mathrm{~m} \\
300 \\
100 \mathrm{~ms} \\
1000 \mathrm{~ms} \\
0-16000 \mathrm{~ms} \\
\text { Re-transforms data to x-t domain, with a } 50 \mathrm{~ms} \\
\text { ramp length }\end{array}$ \\
\hline DSOUT & Output file name & EW9601_p1_radon_cdps \\
\hline GOUT & Output file name & EW9601_p1.radon.cdps.segy \\
\hline
\end{tabular}

Table 2A-8: Explanation of parameters used in "ew9601-radonstack.dat" modules. Summarised steps are shown in Table 3.8 


\begin{tabular}{|c|c|c|}
\hline \multicolumn{3}{|c|}{ Job: ew9601-steffen_radonstack.dat } \\
\hline Module & Parameter & Value \\
\hline DSIN & $\begin{array}{l}\text { Input file } \\
\text { CDP list }\end{array}$ & $\begin{array}{l}\text { ew9601-p1c_steffen_radon_cdps.sgy } \\
705-25001\end{array}$ \\
\hline GAIN (removal) & $\begin{array}{l}\text { Velocity model applied pre-gain } \\
\text { removes velocity cmpt of sph. div. correction } \\
\text { removes time cmpt of sph. div. correction }\end{array}$ & $\begin{array}{l}\text { stacking_stef } \\
-2 \\
-1\end{array}$ \\
\hline GAIN (application) & Applies a scalar multiplier for traces & $t^{1.5}$ \\
\hline $\mathrm{NMO}$ & Applies NMO & stacking_stef \\
\hline MUTE & Applies an NMO stretch mute (stored in trace header) & ssmute \\
\hline MUTE & Applies an inner trace mute & INSIDE_MUTE \\
\hline STACK & Stacks traces in CDPs & $\mathrm{N} / \mathrm{A}$ \\
\hline HDRMATH & \multicolumn{2}{|c|}{ Applies header info and math operations } \\
\hline MUTE & \multicolumn{2}{|c|}{ Restores NMO stretch mute (from trace headers) } \\
\hline MUTE & \multicolumn{2}{|c|}{ Restores inner trace mute (from trace headers) } \\
\hline
\end{tabular}

Table 2A-9: Explanation of parameters used in "ew9601-steffen_radonstack.dat" job (DSIN-MUTE). Summarised steps are shown in Table 3.9 


\begin{tabular}{|c|c|c|}
\hline \multicolumn{3}{|c|}{ Job: ew9601-steffen_radonstack.dat (continued) } \\
\hline Module & Parameter & Value \\
\hline \multirow{12}{*}{ FILTER $^{*}$} & \multicolumn{2}{|c|}{ static time $=100 \mathrm{~ms}$} \\
\hline & $0-1000 \mathrm{~ms}$ application & $5-95 \mathrm{~Hz}$ filter - $12 \mathrm{db} /$ octave taper \\
\hline & $3000-5000 \mathrm{~ms}$ application & $5-65 \mathrm{~Hz}$ filter - $12 \mathrm{db} /$ octave taper \\
\hline & 8000 - $14000 \mathrm{~ms}$ application & 5 - $40 \mathrm{~Hz}$ filter - $12 \mathrm{db} /$ octave taper \\
\hline & \multicolumn{2}{|c|}{ static time $=3000 \mathrm{~ms}$} \\
\hline & $0-3500 \mathrm{~ms}$ application & $5-95 \mathrm{~Hz}$ filter - $12 \mathrm{db} /$ octave taper \\
\hline & $4500-5500 \mathrm{~ms}$ application & $5-65 \mathrm{~Hz}$ filter - $12 \mathrm{db} /$ octave taper \\
\hline & $8000-14000 \mathrm{~ms}$ application & 5 - $40 \mathrm{~Hz}$ filter - $12 \mathrm{db} /$ octave taper \\
\hline & \multicolumn{2}{|c|}{ static time $=5000 \mathrm{~ms}$} \\
\hline & 6000 - xxx ms application & $5-95 \mathrm{~Hz}$ filter - $12 \mathrm{db} /$ octave taper \\
\hline & $7000-7500 \mathrm{~ms}$ application & $5-60 \mathrm{~Hz}$ filter - $12 \mathrm{db} /$ octave taper \\
\hline & 9000 - 14000 ms application & 5 - $40 \mathrm{~Hz}$ filter - $12 \mathrm{db} /$ octave taper \\
\hline MUTE & \multicolumn{2}{|c|}{ Restores NMO stretch mute (from trace headers) } \\
\hline HDRMATH & \multicolumn{2}{|c|}{ Applies header info and math operations } \\
\hline DSOUT & Output file name & EW9601-p1c.decon.radon.velstack \\
\hline GOUT & Output file name & EW9601-p1c.decon.radon.velstack.segy \\
\hline
\end{tabular}

Table 2A-9: Explanation of parameters used in "ew9601-steffen_radonstack.dat" modules (FILTER-GOUT). Summarised steps are shown in Table 3.9 


\begin{tabular}{ccc}
\hline \multicolumn{2}{c}{ Job: ew9601-steffen_radonstack.dat (continued) } \\
\hline Module & Parameter & Value \\
\hline MIGDMO & USERVEL - Time|Velocity pairs & $\begin{array}{r}0|1500,100| 1500,1000|1500,2000| 1500,5000 \mid 1500 \\
8000|1500,10000| 1500,12000|1500,14000| 1500\end{array}$ \\
\hline MUTE & Restores inner trace mute (from trace headers) \\
\hline DSOUT & Output file name & EW9601-p1c.decon.radon.velstack.fkmig \\
\hline GOUT & Output file name & EW9601-p1c.decon.radon.fkmig.segy \\
\hline AGC & & 1000 ms sliding window AGC \\
\hline GOUT & Output file name & EW9601-p1c.decon.radon.fkmig.agc.segy \\
\hline
\end{tabular}

Table 2A-9: Explanation of parameters used in "ew9601-steffen_radonstack.dat" modules (FILTER-GOUT). Summarised steps are shown in Table 3.9 


\section{Appendix: Voyage MGL1803}

The user is refered to Echos by Paradigm internal help for detail explanation and requirements for each module hitherto described.

\begin{tabular}{lll}
\hline \multicolumn{3}{c}{ Job: MCSXXX_SEGD ${ }^{1}$} \\
\hline Module & \multicolumn{1}{c}{ Parameter } & \multicolumn{1}{c}{ Value } \\
\hline \multirow{3}{*}{ SEGD } & Sample rate & $2 \mathrm{~ms}$ \\
& Record length & $14-16 \mathrm{~s}^{1}$ \\
& \# Channels & $324-1008^{1}$ \\
& Data format (8058) & Demultiplexed 64-bit IEEE format \\
\multirow{2}{*}{ RESAMP } & Sample rate & $4 \mathrm{~ms}$ \\
& Record length & $14-16 \mathrm{~s}^{1}$ \\
\hline DSOUT & Output file name & MCSxxx.shots ${ }^{2}$ \\
\hline GOUT & Output file name & MCSxxx.segy \\
\hline
\end{tabular}

Table 3A-1: Explanation of parameters used in MCSxxx_SEGD ${ }^{1}$ modules. Summarised steps are shown in Table 4.2. ${ }^{1}$ xxx refers to line number; ${ }^{2}$ see Table 4.1 for acquisition parameters 


\begin{tabular}{lll}
\hline \multicolumn{2}{c}{ Job: MCSxxx_geometry.dat ${ }^{1}$} \\
\hline \multirow{2}{*}{ Module } & \multicolumn{1}{c}{ Parameter } & \multicolumn{1}{c}{ Value } \\
& \# shots & $\mathrm{xxx}^{2}$ \\
& \# channels & $324-1008$ \\
\multirow{2}{*}{ MKDATA } & Group interval & $12.5 \mathrm{~m}$ \\
& Shot spacing & $50 \mathrm{~m}$ \\
& First Shot \# & $\mathrm{xxx}^{2}$ \\
\hline \multirow{2}{*}{ VFNDEF } & Stores time/velocity pairs into the vertical & $0|1500,1000| 1500,2000|1500,3000| 1500$, \\
& function repository & $5000|1500,10000| 1500,15000 \mid 1500$ \\
\hline \multirow{2}{*}{ VFNDEF } & Stores time/velocity pairs for certain CDPs, & Model name: brutestack_vels_seafloor \\
& into the vertical function repository. & \\
\hline \multirow{2}{*}{ VFNDEF } & Direct wave mute file name & DWAVE_MUTE \\
\hline VFNDEF & Brute mute file name & BRUTE_MUTE \\
\hline \multirow{2}{*}{ VFNDEF } & Inside mute file name & INSIDE_MUTE \\
\hline
\end{tabular}

Table 3A-2: Explanation of parameters used in MCSxxx_geometry.dat ${ }^{1}$ modules. Summarised steps are shown in Table 4.3. ${ }^{1}$ xxx refers to line number; ${ }^{2}$ shot range varies by line; ${ }^{3}$ see Table 4.1 for acquisition parameters 


\begin{tabular}{cll}
\hline \multicolumn{3}{c}{ Job: MCSxxx_brute_stack.dat ${ }^{1}$} \\
\hline \multirow{2}{*}{ Module } & \multicolumn{1}{c}{ Parameter } & \multicolumn{1}{c}{ Value } \\
\hline \multirow{2}{*}{ DSIN } & Input file name & MCSxxx.shots ${ }^{1}$ \\
& Shot list & x- $\mathrm{x}^{2}$ \\
& Supergath. Channels & $1-200$ \\
\hline \multirow{2}{*}{ EDIT } & Shot range & $1-99999$ \\
& Removed channels & $1,13,21,45,93,109,117$ \\
\hline HDRMATH & \multicolumn{1}{c}{ Header info and math operations } \\
\hline FILTER & Butterworth & $5-85 \mathrm{~Hz}, 12$ db/octave taper \\
\hline \multirow{2}{*}{ GEOMLD } & Radius for trace spacing & $6.25 \mathrm{~m}$ \\
& Radius for CDP designation & $8000 \mathrm{~m}$ \\
\hline \multirow{2}{*}{ SORT } & Trace per CDP & 400 \\
& Offset order & 600000 \\
\hline NMO & Velocity model & brutestack_vels_seafloor \\
\hline MUTE & Brute mute name & BRUTEMUTE \\
\hline STACK & \multicolumn{2}{c}{ Stacks data in CDPs } \\
\hline DSOUT & Output file name & MCSxxx.brutestack ${ }^{1}$ \\
\hline
\end{tabular}

Table 3A-3: Explanation of parameters used in MCSxxx_brute_stack.dat modules. Summarised steps are shown in Table 4.4. ${ }^{1}$ xxx refers to line number, ${ }^{2}$ shot range varies by line 


\begin{tabular}{|c|c|c|}
\hline \multicolumn{3}{|c|}{ Job: MCSxxx_cdpsort.dat ${ }^{1}$} \\
\hline Module & Parameter & Value \\
\hline DSIN & $\begin{array}{l}\text { Input file name } \\
\text { Shot list }\end{array}$ & $\begin{array}{l}\text { MCSxxx.shots } \\
x-x^{2}\end{array}$ \\
\hline GEOMLD & $\begin{array}{l}\text { Radius for trace spacing } \\
\text { Radius for CDP designation }\end{array}$ & $\begin{array}{l}6.25 \mathrm{~m} \\
8000 \mathrm{~m}\end{array}$ \\
\hline EDIT & $\begin{array}{l}\text { Shot range } \\
\text { Removed channels }\end{array}$ & $\begin{array}{l}1-99999 \\
1,13,21,45,93,109,117\end{array}$ \\
\hline HDRMATH & \multicolumn{2}{|c|}{ Header info and math operations } \\
\hline FILTER & Butterworth & 7-85 Hz $12 \mathrm{db} /$ octave taper \\
\hline DEBIAS & \multicolumn{2}{|c|}{ Removes DC bias from data } \\
\hline & \multicolumn{2}{|c|}{ Equals the fold and regularises traces } \\
\hline REGLO & $\begin{array}{l}\text { Size of spatial gate for coherency analysis } \\
\text { Maximum dip of traces } \\
\text { Length of coherency smoothing wavelet }\end{array}$ & $\begin{array}{l}100 \\
1000 \mathrm{us} / \text { trace } \\
120 \mathrm{~ms}\end{array}$ \\
\hline GEOMLD & $\begin{array}{l}\text { Radius for trace spacing } \\
\text { Radius for CDP designation }\end{array}$ & $\begin{array}{l}6.25 \mathrm{~m} \\
8000 \mathrm{~m}\end{array}$ \\
\hline HEADPUT & \multicolumn{2}{|c|}{ Applies header info } \\
\hline GAIN & Applies a spherical divergence correction & $\mathrm{t}^{1.5}$ \\
\hline HDRMATH & \multicolumn{2}{|c|}{ Header info and math operations } \\
\hline STATIC & Applies a static shift to seismic data & $-500 \mathrm{~ms}$ \\
\hline MCDECON & $\begin{array}{l}\text { Gap Length } \\
\text { Op. Length } \\
\text { Design Window } \\
\text { Application Window }\end{array}$ & $\begin{array}{l}75 \mathrm{~ms} \\
450 \mathrm{~ms} \\
3500 \mathrm{~ms} \\
0-14 / 16 \mathrm{~s}^{3}\end{array}$ \\
\hline & $\begin{array}{l}\text { Gap Length } \\
\text { Op. Length } \\
\text { Design Window } \\
\text { Application Window }\end{array}$ & $\begin{array}{l}24 \mathrm{~ms} \\
450 \mathrm{~ms} \\
3500 \mathrm{~ms} \\
0-14 / 16 \mathrm{~s}^{3}\end{array}$ \\
\hline STATIC & Removes static shift from seismic data & $-500 \mathrm{~ms}$ \\
\hline SORT & $\begin{array}{l}\text { Trace per CDP } \\
\text { Offset order }\end{array}$ & $\begin{array}{l}400 \\
600000\end{array}$ \\
\hline DSOUT & Output filename & MCSxxx.decon.cdps ${ }^{1}$ \\
\hline GOUT & Output filename & MCSxxx.decon.cdps.segy ${ }^{1}$ \\
\hline
\end{tabular}

Table 3A-4: Explanation of parameters used in MCSxxx_brute_stack.dat modules. Summarised steps are shown in Table 4.5. ${ }^{1}$ xxx refers to line number; ${ }^{2}$ shot list varies by line; ${ }^{3}$ see Table 4.1 for acquisition parameters 


\begin{tabular}{cll}
\hline \multicolumn{2}{c}{ Job: MCSxxx_veldef.dat ${ }^{1}$} \\
\hline Module & \multicolumn{1}{c}{ Parameter } & \multicolumn{1}{c}{ Value } \\
\hline \multirow{3}{*}{ DSIN } & Input file & MCSxxx.decon.cdps ${ }^{1}$ \\
& CDP Range & $\mathrm{x}-\mathrm{x}^{2}$ \\
& Supergather & $8 \mathrm{CDPs}$ \\
& CDP increment & $1000 / 500 / 250$ \\
\hline MUTE & Direct wave mute application & DWAVE_MUTE \\
\hline \multirow{2}{*}{ FILTER } & \multicolumn{2}{c}{ Butterworth filter application } \\
\cline { 2 - 3 } & $0-2 \mathrm{~s} \quad 8-50 \mathrm{~Hz}$ \\
\hline AGC & $4-14 / 16 \mathrm{~s}^{3}$ & $8-35 \mathrm{~Hz}$ \\
\hline VELDEF & Output file name & \multicolumn{2}{c}{$300 \mathrm{~ms}$ sliding window AGC } \\
\hline
\end{tabular}

Table 3A-5: Explanation of parameters used in MCSxxx_veldef.dat modules. Summarised steps are shown in Table 4.6. ${ }^{1}$ xxx refers to line number; ${ }^{2}$ CDP range varies for velocity model picks; ${ }^{3}$ see Table 4.1 for acquisition parameters 


\begin{tabular}{|c|c|c|}
\hline \multicolumn{3}{|c|}{ Job: MCSxxx_radon.dat ${ }^{1}$} \\
\hline Module & Parameter & Value \\
\hline DSIN & Input file name & MCSxxx.decon.cdps.sgy ${ }^{1}$ \\
\hline HDRMATH & \multicolumn{2}{|c|}{ Header info and math operations } \\
\hline HDRMATH & \multicolumn{2}{|c|}{ Header info and math operations } \\
\hline MUTE & Applies a direct wave mute & DWAVE_MUTE \\
\hline NMO & Velocity file & MCSxxx_stackvels ${ }^{1}$ \\
\hline MUTE & Applies NMO stretch mute & MCSxxx_stackmute ${ }^{1}$ \\
\hline NMO OVCAPP & \multicolumn{2}{|c|}{ Applies an NMO overcorrection } \\
\hline RADONPAR & $\begin{array}{l}\text { Forward } \\
\text { Maximum offset within data } \\
\text { \# ensembles within a supergather for forward transform } \\
\text { Reference offset for moveout computations } \\
\text { \# parabolas for use in the transform } \\
\text { Min. moveout at max. offset } \\
\text { Max. moveout at max. offset } \\
\text { Start - end times for operation } \\
\text { Inverse }\end{array}$ & $\begin{array}{l}\text { Transforms data to tau-p domain } \\
4026 / 12800 \mathrm{~m}^{2} \\
1 \\
4026 / 12800 \mathrm{~m}^{2} \\
300 \\
200 \mathrm{~ms} \\
2500 \mathrm{~ms} \\
0-14 / 16 \mathrm{~s}^{2} \\
\text { Re-transforms data to x-t domain, } \\
\text { with a } 50 \mathrm{~ms} \text { ramp length }\end{array}$ \\
\hline FKFILT & $\begin{array}{l}\text { Dip filter taper } \% \\
\text { Low frequency protection } \\
\text { Lower dip range for rejection } \\
\text { Upper dip range for rejection }\end{array}$ & $\begin{array}{l}25 \% \\
5 \mathrm{~Hz} \\
0.572 \mathrm{~ms} / \text { trace } \\
0.888 \mathrm{~ms} / \text { trace }\end{array}$ \\
\hline NMO & \multicolumn{2}{|c|}{ Removes NMO overcorrection } \\
\hline NMO & Removes NMO corrections, prior to migration & MCSxxx_stackvels ${ }^{1}$ \\
\hline DSOUT & Output file name & MCSxxx.decon.radon.cdps ${ }^{1}$ \\
\hline GOUT & Output file name & MCSxxx.decon.radon.cdps.sgy ${ }^{1}$ \\
\hline
\end{tabular}

Table 3A-6: Explanation of parameters used in MCSxxx_radon.dat modules. Summarised steps are shown in Table 4.7. ${ }^{1}$ xxx refers to line number; ${ }^{2}$ see Table 4.1 for acquisition parameters 


\begin{tabular}{cll}
\hline \multicolumn{3}{c}{ Job: MCSxxx_Radon_stack ${ }^{1}$} \\
\hline Module & \multicolumn{1}{c}{ Parameter } & \multicolumn{1}{c}{ Value } \\
\hline DSIN & Input file & MCSxxx.decon.radon.cdps.sgy \\
\hline VFNDEF & Removes inside mute & INSIDE_MUTE \\
\hline NMO & Applies NMO & MCSxxx_stackvels ${ }^{1}$ \\
\hline MUTE & NMO stretch mute & MCSxxx_stackmute ${ }^{1}$ \\
\hline MUTE & Removes inside mute & INSIDE_MUTE \\
\hline STACK & Stacks traces in CDPs & N/A \\
\hline HEADPUT & & Applies header info \\
\hline MUTE & Restores inner mute & INSIDE_MUTE \\
\hline
\end{tabular}

Table 3A-7: Explanation of parameters used in MCSxxx_Radon_stack.dat" modules (DSIN-MUTE). Summarised steps are shown in Table 4.8. ${ }^{1}$ xxx refers to line number 


\begin{tabular}{|c|c|c|}
\hline \multicolumn{3}{|c|}{ Job: MCSxxx_Radon_stack ${ }^{1}$ (continued) } \\
\hline Module & Parameter & Value \\
\hline \multirow{6}{*}{ FILTER } & \multicolumn{2}{|c|}{ static time $=100 \mathrm{~ms}$} \\
\hline & $\begin{array}{l}0-1000 \mathrm{~ms} \text { application } \\
3000-5000 \mathrm{~ms} \text { application } \\
8000-14000 / 16000 \mathrm{~ms} \text { application }{ }^{2}\end{array}$ & $\begin{array}{l}\text { 5-95 Hz filter, } 12 \mathrm{db} / \text { octave taper } \\
5-65 \mathrm{~Hz} \text { filter, } 12 \mathrm{db} / \text { octave taper } \\
5-40 \mathrm{~Hz} \text { filter, } 12 \mathrm{db} / \text { octave taper }\end{array}$ \\
\hline & \multicolumn{2}{|c|}{ static time $=3000 \mathrm{~ms}$} \\
\hline & $\begin{array}{l}0-3500 \mathrm{~ms} \text { application } \\
4500-5500 \mathrm{~ms} \text { application } \\
8000-14000 / 16000 \mathrm{~ms} \text { application }{ }^{2}\end{array}$ & $\begin{array}{l}5-95 \mathrm{~Hz} \text { filter, } 12 \mathrm{db} / \text { octave taper } \\
5-65 \mathrm{~Hz} \text { filter, } 12 \mathrm{db} / \text { octave taper } \\
5-40 \mathrm{~Hz} \text { filter, } 12 \mathrm{db} / \text { octave taper }\end{array}$ \\
\hline & \multicolumn{2}{|c|}{ static time $=6000 \mathrm{~ms}$} \\
\hline & $\begin{array}{l}\text { 0-6000 ms application } \\
7000-7500 \mathrm{~ms} \text { application } \\
9000-14000 / 16000 \mathrm{~ms} \text { application }{ }^{2}\end{array}$ & $\begin{array}{l}\text { 5-95 Hz filter, } 12 \mathrm{db} / \text { octave taper } \\
5-60 \mathrm{~Hz} \text { filter, } 12 \mathrm{db} / \text { octave taper } \\
\text { 5-40 Hz filter, } 12 \mathrm{db} / \text { octave taper }\end{array}$ \\
\hline MUTE & \multicolumn{2}{|c|}{ Restores mute } \\
\hline HDRMATH & \multicolumn{2}{|c|}{ Applies header info and math operations } \\
\hline MUTE & \multicolumn{2}{|c|}{ Restores mute } \\
\hline MUTE & \multicolumn{2}{|c|}{ Restores mute } \\
\hline HDRMATH & \multicolumn{2}{|c|}{ Applies header info and math operations } \\
\hline DSOUT & Output file name & MCSxxx.decon.radon.velstack ${ }^{1}$ \\
\hline GOUT & Output file name & MCSxxx.decon.radon.velstack.segy ${ }^{1}$ \\
\hline
\end{tabular}

Table 3A-8: Explanation of parameters used in MCSxxx_Radon_stack.dat" modules (FILTER-GOUT). Summarised steps are shown in Table 4.8. ${ }^{1}$ xxx refers to line number. ${ }^{2}$ see Table 4.1 for acquisition parameters 


\begin{tabular}{clc}
\hline & \multicolumn{1}{c}{ Job: MCSxx__Radon_stack ${ }^{1}$ (continued) } \\
\hline & Min. \# CDPs in the data & 50000 \\
MIGDMO & \# of traces used each common offset, controls migration swings & 50000 \\
& Distance between traces & $12.5 \mathrm{~m}$ \\
& USERVEL - Time $\mid$ Velocity pairs & $0|1480,100| 1480,1000|1480,2000| 1480,5000 \mid 1480$, \\
MUTE & & $8000|1480,10000| 1480,12000 \mid 1480$ \\
\hline DSOUT & Output file name & Restore mute \\
\hline GOUT & Output file name & MCSxxx.decon.radon.velstack.fkmig ${ }^{1}$ \\
\hline AGC & & MCSxxx.decon.radon.velstack.fkmig.segy ${ }^{1}$ \\
\hline GOUT & Output file name & 1000 ms sliding window AGC \\
\hline
\end{tabular}

Table 3A-9: Explanation of parameters used in MCSxx__Radon_stack.dat modules (MIGDMO-GOUT). Summarised steps are shown in Table 4.8. ${ }^{1}$ xxx refers to line number 


\section{Appendix: Discussion}

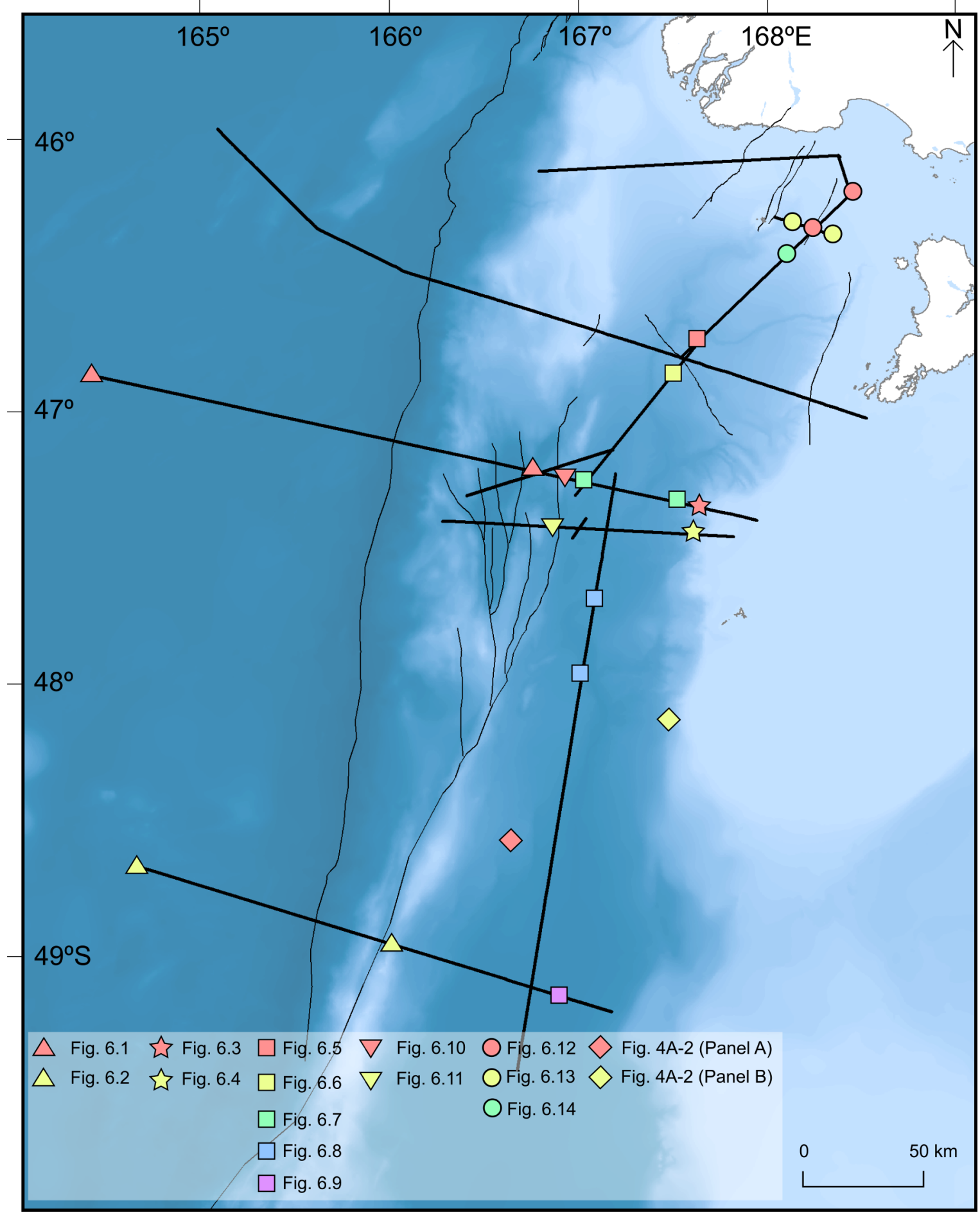

Fig. 4A-1: Locations of swath images discussed in section 6.2. Triangles=Tasman Sea; stars/squares/inverted triangles=Solander Trough; circles=modern shelf and slope; diamonds=features observed only in swath (see Fig. 4A-2. Faults are displayed as thin black lines) 


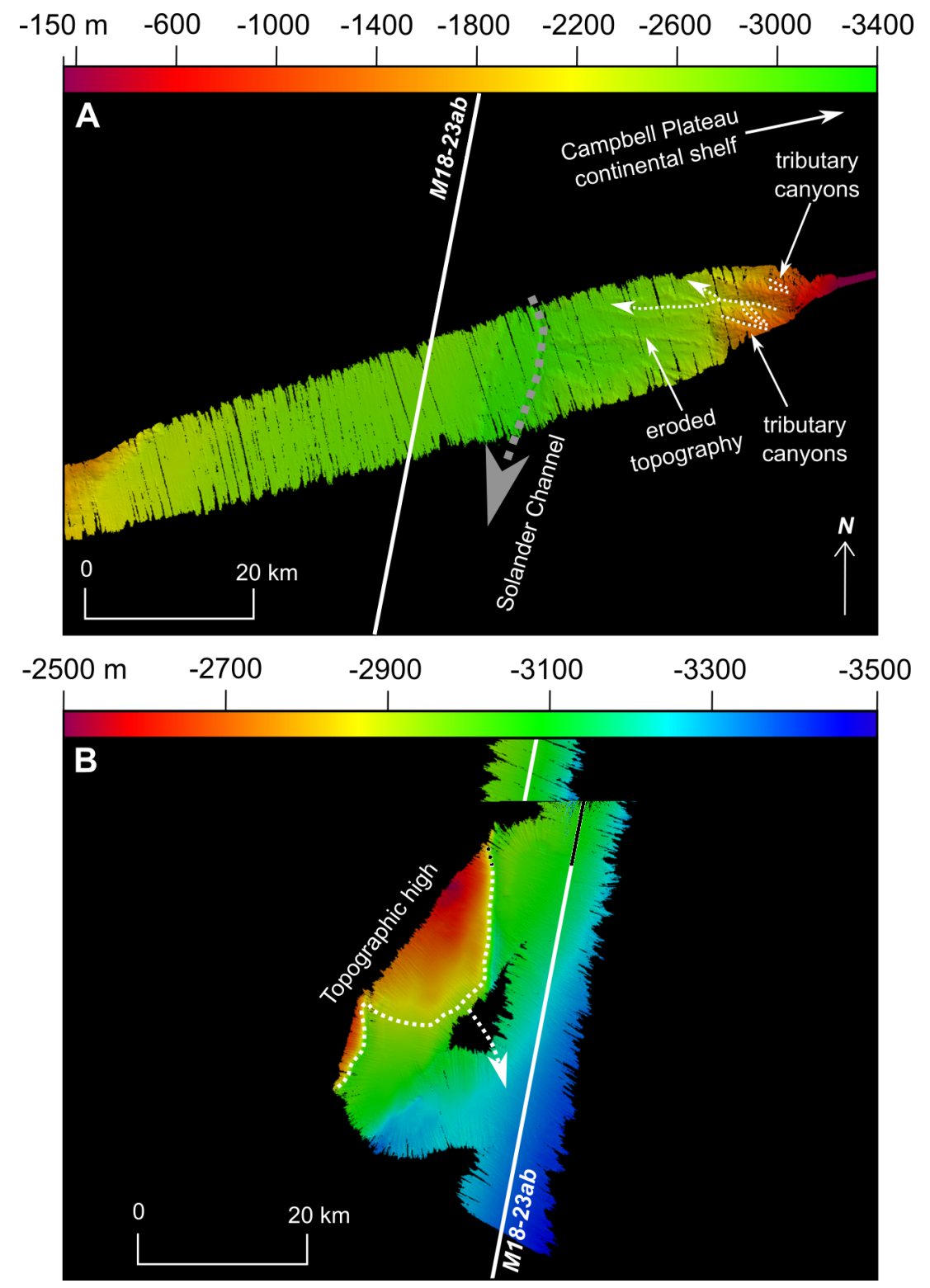

Fig. 4A-2: Erosion on the Campbell Plateau (Panel A) and a topographic high (Panel B). Explanation for Panel $A$ is as for Fig. 6.3. The topographic high in Panel $B$ is a potential source of sediment (shown by the dashed white arrow, see Fig. 6.18) 
A-24 


\section{Bibliography}

Ballance, P. F. (1976). Evolution of the Upper Cenozoic Magmatic Arc and plate boundary in northern New Zealand. Earth and Planetary Science Letters, 28(3):356-370.

Barker, D. H., Wood, R., and Sutherland, R. (2008). Transform and rift structure of Paleogene crust near resolution Ridge, Tasman Sea, southwest New Zealand. Geochemistry, Geophysics, Geosystems, 9(7):1-18.

Barker, P. F., Filippelli, G. M., Florindo, F., Martin, E. E., and Scher, H. D. (2007). Onset and role of the Antarctic Circumpolar Current. Deep-Sea Research Part II: Topical Studies in Oceanography, 54(21-22):2388-2398.

Boe, R., Rise, L., and Ottesen, D. (1998). Elongate depressions on the southern slope of the Norwegian Trench (Skagerrak): Morphology and evolution. Marine Geology, 146(1-4):191203.

Bonini, M., Sokoutis, D., Mulugeta, G., and Katrivanos, E. (2000). Modelling hanging wall accommodation above rigid thrust ramps. Journal of Structural Geology, 22(8):1165-1179.

BP Oil Exploration Co NZ Ltd (1985). PR1121 Site of Prospect 'A' Well Location PPL 38206.pdf.

Buck, W. R., Lavier, L. L., and Poliakov, A. N. (2005). Modes of faulting at mid-ocean ridges. Nature, 434:719-723.

Cande, S. C. and Stock, J. M. (2004). Pacific-Antarctic-Australia motion and the formation of the Macquarie Plate. Geophysical Journal International, 157(1):399-414.

Carter, L. and Carter, R. M. (1988). Late Quaternary development of left-bank-dominant levees in the Bounty Trough, New Zealand. Marine Geology, 78(3-4):185-197. 
Carter, L., Carter, R. M., McCave, I. N., and Gamble, J. (1996a). Regional sediment recycling in the abyssal Southwest Pacific Ocean. Geology, 24(8):735-738.

Carter, L., Garlick, R. D., Sutton, P., Chiswell, S., Oien, N. A., and Stanton, B. R. (1998). Ocean Circulation New Zealand. Technical report, NIWA, Wellington.

Carter, L. and McCave, I. N. (1997). The Sedimentary Regime Beneath the Deep Western Boundary Current Inflow to the Southwest Pacific Ocean. Journal of Sedimentary Research, Vol. 67(6):1005-1017.

Carter, R. M., Carter, L., and McCave, I. N. (1996b). Current controlled sediment deposition from the shelf to the deep ocean: The Cenozoic evolution of circulation through the SW Pacific gateway. Geologische Rundschau, 85(3):438-451.

Christie-Blick, N. (1991). Onlap, offlap, and the origin of unconformity-bounded depositional sequences. Marine Geology, 97(1-2):35-56.

Clark, G. (1986). Seismic supervision report PPL 38206. Technical report, Ministry of Economic Development.

Collot, J. Y., Lamarche, G., Wood, R. A., Delteil, J., Sosson, M., Lebrun, J.-F., and Coffin, M. F. (1995). Morphostructure of an incipient subduction zone along a transform plate boundary: Puysegur Ridge and Trench. Geology, 23(6):519-522.

Conway, C. E., Bostock, H. C., Baker, J. A., Wysoczanski, R. J., and Verdier, A. L. (2012). Evolution of Macquarie Ridge Complex seamounts: Implications for volcanic and tectonic processes at the Australia-Pacific plate boundary south of New Zealand. Marine Geology, 295-298:34-50.

Deacon, G. E. (1982). Physical and biological zonation in the Southern Ocean. Deep Sea Research Part A, Oceanographic Research Papers, 29(1):1-15.

Delteil, J., Collot, J.-Y., Wood, R., Herzer, R., Calmant, S., Christoffel, D., Coffin, M., Ferriere, J., Lamarche, G., Lebrun, J.-F., Mauffret, A., Pontoise, B., Popoff, M., Ruellan, E., Sosson, M., and Sutherland, R. (1996). From strike-slip faulting to oblique subduction: A survey of 
the Alpine Fault-Puysegur Trench transition, New Zealand, results of cruise Geodynz-sud leg 2. Marine Geophysical Researches, 18(2-4):383-399.

Engmann, L. A. and Fenton, P. H. (1986). Well Completion Report. Solander-1. PPL 38206. Technical report, Ministry of Economic Development.

Foster, D. J. and Mosher, C. C. (1992). Suppression of multiple reflections using the Radon transform. Geophysics, 57(3):386-395.

Frohlich, C., Coffin, M. F., Massell, C., Mann, P., Schuur, C. L., Davis, S. D., Jones, T., and Karner, G. (1997). Constraints on Macquarie Ridge tectonics provided by Harvard focal mechanisms and teleseismic earthquake locations. Journal of Geophysical Research, 102(B3):5029.

Fulthorpe, C. S. and Carter, R. M. (1991). Continental-shelf progradation by sediment-drift accretion. Geological Society of America Bulletin, 103(2):300-309.

Gaina, C., Müller, D. R., Royer, J.-Y., Stock, J., Hardebeck, J., and Symonds, P. (1998). The tectonic history of the Tasman Sea: A puzzle with 13 pieces. Journal of Geophysical Research: Solid Earth, 103(B6):12413-12433.

Geophysical Company of Norway (1982). Seismic Supervision Report-Solander Basin, Offshore New Zealand. PPL 38206. Technical report, Ministry of Economic Development.

Geophysical Service International (1984). Seismic Survey Processing \& Supervision Reports. Solander Basin PPL 38206. Technical report, Ministry of Economic Development.

Goranson, R. W. (2002). A note on the elastic properties of rocks. Journal of the Washington Academy of Sciences, 24(10):419-428.

Gurnis, M., Hall, C., and Lavier, L. (2004). Evolving force balance during incipient subduction. Geochemistry, Geophysics, Geosystems, 5(7).

Gurnis, M. and Stock, J. M. (2017). Collaborative Research: SISIE: South Island, New Zealand, Subduction Initiation Experiment. Technical report, California Institute of Technology, California. 
Hassler, C. S., Ridgway, K. R., Bowie, A. R., Butler, E. C. V., Clementson, L. A., Doblin, M. A., Davies, D. M., Law, C., Ralph, P. J., van der Merwe, P., Watson, R., and Ellwood, M. J. (2014). Primary productivity induced by iron and nitrogen in the Tasman Sea: an overview of the PINTS expedition. Marine and Freshwater Research, 65(6):517.

Herron, D. A. and Latimer, R. B. (2011). First Steps in Seismic Interpretation. Society of Exploration Geophysicists.

Hovland, M., Gardner, J. V., and Judd, A. G. (2002). The significance of pockmarks to understanding fluid flow processes and geohazards. Geofluids, 2(2):127-136.

Hunt International Petroleum Company (1970). PR556 Results of preliminary reconnaisance survey offshore South Island.pdf.

Hunt International Petroleum Company (1971). PR558 Preliminary Results of Geophysical Work in the Offshore waters South Island.pdf. Technical report, Ministry of Economic Development.

Hunt International Petroleum Company (1974). PR620 1972 - 1973 final seismic data.pdf.

Hunt International Petroleum Company (1976). Well completion report Parara-1. Technical report, Ministry of Economic Development.

Institute of Geological and Nuclear Sciences (2015). New Zealand's Geological Timescale.

Jitts, H. R. (1965). The summer characteristics of primary productivity in the Tasman and Coral seas. Marine and Freshwater Research, 16(2):151-162.

Kamp, P. J. (1986). Late Cretaceous-Cenozoic tectonic development of the southwest Pacific region. Tectonophysics, 121(2-4):225-251.

Katz, M. E., Cramer, B. S., Toggweiler, J. R., Esmay, G., Liu, C., Miller, K. G., Rosenthal, Y., Wade, B. S., and Wright, J. D. (2011). Impact of Antarctic Circumpolar Paleogene Ocean Structure. Science, 6033(332):1076-1080.

Kearey, P., Brooks, M., and Hill, I. (2002). An Introduction to Geophysical Exploration. Blackwell Science Ltd, 3rd edition. 
Kennett, J. P., Houtz, R. E., Andrews, P. B., Edwards, A. R., Gostin, V. A., Hajos, M., and Perch-Nielsen, K. (1975a). Deep Sea Drilling Project Site 277 Report. Technical report, Gradute School of Oceanography.

Kennett, J. P., Houtz, R. E., Andrews, P. B., Edwards, A. R., Gostin, V. A., Hajos, M., and Perch-Nielsen, K. (1975b). Deep Sea Drilling Project Site 278 Report. Technical report, Graduate School of Oceanography.

Kennett, J. P., Houtz, R. E., Andrews, P. B., Edwards, A. R., Gostin, V. A., Hajos, M., and Perch-Nielsen, K. (1975c). Deep Sea Drilling Project Site 279 Report. Technical report, Graduate School of Oceanography.

Kim, K. J. and Sutherland, R. (2004). Uplift rate and landscape development in southwest Fiordland, New Zealand, determined using 10Be and 26Al exposure dating of marine terraces. Geochimica et Cosmochimica Acta, 68(10):2313-2319.

King, P. R. (2000). New Zealand' s changing configuration in the last 100 million years : plate tectonics, basin development, and depositional setting. Technical report, Institute of Geological and Nuclear Sciences.

Laird, M. G. and Bradshaw, J. D. (2004). The break-up of a long-term relationship: The Cretaceous separation of New Zealand from Gondwana. Gondwana Research, 7(1):273-286.

Lamarche, G., Collot, J.-Y., Wood, R. a., Sosson, M., Sutherland, R., and Delteil, J. (1997). The Oligocene-Miocene Pacific-Australia plate boundary, south of New Zealand: Evolution from oceanic spreading to strike-slip faulting. Earth and Planetary Science Letters, 148(12):129-139.

Lamarche, G. and Lebrun, J. F. (2000). Transition from strike-slip faulting to oblique subduction: Active tectonics at the Puysegur Margin, South New Zealand. Tectonophysics, 316(1-2):67-89.

Lebrun, J.-F., Karner, G. D., and Collot, J.-Y. (1998). Fracture zone subduction and reactivation across the Puysegur ridge/trench system, southern New Zealand. Journal of Geophysical Research, 103(Figure 1):7293-7313. 
Lebrun, J.-F., Lamarche, G., and Collot, J.-Y. (2003). Subduction initiation at a strike-slip plate boundary: The Cenozoic Pacific-Australian plate boundary, south of New Zealand. Journal of Geophysical Research: Solid Earth, 108(B9).

L\&M Petroleum (2006). Solander Basin Marine Seismic Survey. Technical report, Ministry of Economic Development.

Malinverno, A. and Cowie, P. A. (1993). Normal faulting and the topographic roughness of mid-ocean ridge flanks. Journal of Geophysical Research: Solid Earth, 98(B10):17921-17939.

Mao, X., Gurnis, M., and May, D. A. (2017). Subduction Initiation With Vertical Lithospheric Heterogeneities and New Fault Formation. Geophysical Research Letters, 44(22):11,34911,356 .

McCave, I. N. and Tucholke, B. E. (1986). Deep current-controlled sedimentation in the western North Atlantic. In Vogt, P. R., and Tucholke, B. E., editor, The Geology of North America, volume 1000, chapter Chapter 27, pages 451-468. Geological Society of America.

McKenzie, D. (1978). Some remarks on the development of sedimentary basins. Earth and Planetary Science Letters, 40(1):25-32.

Melhuish, A., Sutherland, R., Davey, F. J., and Lamarche, G. (1999). Crustal structure and neotectonics of the Puysegur oblique subduction zone, New Zealand. Tectonophysics, 313(4):335362.

Mitchum, R. M., Vail, P. R., and Sangree, J. B. (1977). Seismic Stratigraphy and Global Changes of Sea Level, Part 6: Stratigraphic Interpretation of Seismic Reflection Patterns in Depositional Sequences. Seismic Stratigraphy - applications to hydrocarbon exploration, 165:117-134.

Mobil International Oil Company (1979). PR738 Re-processed Mobil lines (Original Survey 1972 PR587).pdf.

Mortimer, N., Gans, P. B., Foley, F. V., Turner, M. B., Daczko, N., Robertson, M., and Turnbull, I. M. (2013). Geology and Age of Solander Volcano, Fiordland, New Zealand. The Journal of Geology, 121(5):475-487. 
New Zealand Petroleum Exploration Co. Ltd. (1970). PR538 Seismic Survey Te Wae Wae Bay Southland.pdf.

Norris, R. J., Carter, R. M., and Turnbull, I. M. (1978). Cainozoic sedimentation in basins adjacent to a major continental transform boundary in southern New Zealand. Journal of the Geological Society, 135:191-205.

Norris, R. J. and Turnbull, I. M. (1993). Cenozoic Basins Adjacent to an Evolving Plate Boundary, New Zealand. In Sedimentary Basins of the World: South Pacific Sedimentary Basins, pages 251-270. Elsevier Science Publishers, Amsterdam.

Onajite, E. (2013). Understanding Sample Data. In Seismic Data Analysis Techniques in Hydrocarbon Exploration, chapter Understand, pages 105-115. Elsevier.

Ondréas, H., Scalabrin, C., Fouquet, Y., and Godfroy, A. (2018). Recent high-resolution mapping of Guaymas hydrothermal fields (Southern Trough). BSGF - Earth Sciences Bulletin, 189(1):6.

Reay, A. and Parkinson, D. (1997). Adakites from Solander Island, New Zealand. New Zealand Journal of Geology and Geophysics, 40(2):121-126.

Sangree, J. B. and Widmier, J. M. (1977). Seismic Stratigraphy and Global Changes of Sea Level, Part 9: Seismic Interpretation of Clastic Depositional Facies. AAPG Bulletin, 62(5):752-771.

Sangree, J. B. and Widmier, J. M. (1979). Interpretation of depositional facies from seismic data. Geophysics, 44(2):131-160.

Schuur, C. L., Coffin, M. F., Frohlich, C., Massell, C. G., Karner, G. D., Ramsay, D., and Caress, D. W. (1998). Sedimentary regimes at the Macquarie Ridge Complex: Interaction of Southern Ocean circulation and plate boundary bathymetry. Paleoceanography, 13(6):646-670.

Seahawk Oil International Inc. (1982). PR934 Interim interpretation report PPL 38206, Solander Basin, New Zealand.pdf.

Shaheen, E. and Hutson, R. J. (1989). Petroleum Report 1489: Stratigraphic and structural interpretation using seismic attribute processing. PPL38206, Solander Basin, South Island, New Zealand. Technical report, Ministry of Economic Development. 
Sheriff, R. E. and Geldart, L. P. (1995). Exploration Seismology. Cambridge University Press, Cambridge, U.K., 2nd edition.

Smith, R. O., Vennell, R., Bostock, H. C., and Williams, M. J. (2013). Interaction of the subtropical front with topography around southern New Zealand. Deep-Sea Research Part I: Oceanographic Research Papers, 76:13-26.

Stern, R. J. (2004). Subduction initiation: Spontaneous and induced. Earth and Planetary Science Letters, 226(3-4):275-292.

Stolt, R. H. (1978). Migration By Fourier Transform. Geophysics, 43(1):23 - 48.

Stow, D. A. V., Faugères, J.-C., Howe, J. A., Pudsey, C. J., and Viana, A. R. (2002). Bottom currents, contourites and deep-sea sediment drifts: current state-of-the-art. In Stow, D. A. V., Pudsey, C. J., Howe, J. A., Faugères, J.-C., and Viana, A. R., editors, Deep-Water Contourite Systems: Modern Drifts and Ancient Series, Seismic and Sedimentary Characteristics, volume 22, pages 7-20. The Geological Society of London, London.

Sutherland, R. (1995). The Australian-Pacific boundary and Cenozoic plate motions in the SW Pacific. Tectonics, 14(4):819-831.

Sutherland, R. (1996). Transpressional development of the Australia-Pacific boundary through southern South Island, New Zealand: Constraints from Miocene-Pliocene sediments, Waiho-1 borehole, South Westland. New Zealand Journal of Geology and Geophysics, 39(2):251-264.

Sutherland, R., Barnes, P., and Uruski, C. (2006). Miocene-recent deformation, surface elevation, and volcanic intrusion of the overriding plate during subduction initiation, offshore southern Fiordland, Puysegur margin, southwest New Zealand. New Zealand Journal of Geology and Geophysics, 49(1):131-149.

Sutherland, R., Davey, F., Beaven, J., and Beavan, J. (2000). Plate boundary deformation in South Island, New Zealand, is related to inherit lithospheric structure. Earth and Planetary Science Letters, 177(3-4):141-151. 
Sutherland, R., Gurnis, M., Kamp, P. J. J., and House, M. A. (2009). Regional exhumation history of brittle crust during subduction initiation, Fiordland, southwest New Zealand, and implications for thermochronologic sampling and analysis strategies. Geosphere, 5(5):409-425.

Sutherland, R. and Melhuish, A. (2000). Formation and evolution of the Solander Basin, southwestern South Island, New Zealand, controlled by a major fault in continental crust and upper mantle. Tectonics, 19(1):44-61.

Turnbull, I. M., Uruski, C. I., , and others. (1993). Cretaceous and Cenozoic sedimentary basins of Western Southland, South Island, New Zealand. Technical report, Institute of Geological and Nuclear Sciences, Wellington.

Uruski, C. I. and Turnbull, I. M. (1990). Stratigraphic and structural evolution of the west Southland sedimentary basins. Proceedings of the 1989 New Zealand Oil Exploration Conference, Energy and Resources Division, Ministry of Commerce, pages 225-240.

van der Pluijm, B. and Marshak, S. (2004). Earth Structure: An Introduction to Structural Geology and Tectonics. W. W. Norton \& Company, Inc., New York.

Walcott, R. (1978). Present tectonics and late Cenozoic evolution of New Zealand. Geophysical Journal of the Royal Astronomical Society, 52:137-165.

Wood, R., Lamarche, G., Herzer, R., Delteil, J., and Davy, B. (1996). Paleogene seafloor spreading in the southeast Tasman Sea. Tectonics, 15(5):966-975.

Yilmaz, O. (2001). Seismic data analysis: Processing, inversion, and interpretation of seismic data. Society of Exploration Geophysicists. Society of Exploration Geophysicists, Tulsa, OK. 